


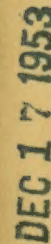

。

U)

$\frac{9}{5}$ 



\section{THE BIOLOGY OF THE SEA-SHORE}






\section{PLATE 1}

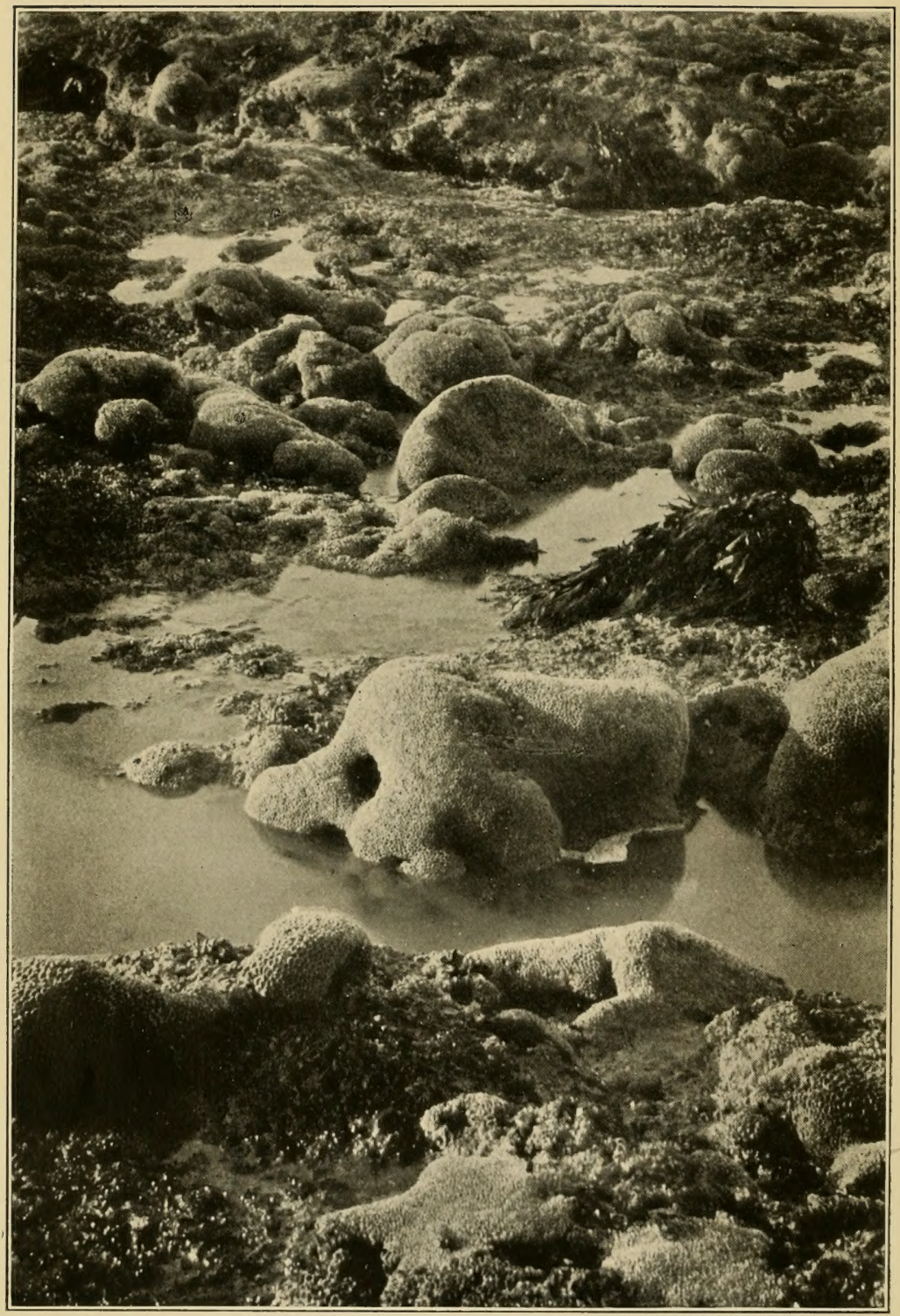

Frontispiece]

[Photo by Culliford, Aberystwyth.

Colonies of the Tube-Worm (Sabellaria alveolata) Aт Borth.

Upon the tube-masses occurs the dog-whelk (Purpura lapillus). The colonies form grottos in which a number of animals, notably Actinia equina, are able to shelter. 


\section{THE BIOLOGY OF THE SEA-SHORE}

91

$553 z$

BY

F. W. FLATTELY

LECTURER IN ZOOLOGY, UNIVERSITY OF DURHAM

AND

C. L. WALTON, M.Sc.(Wales)

UNIVERSITY COLLEGE OF NORTH WALES, BANGOR

WITH AN INTRODUCTION BY

J. ARTHUR THOMSON, M.A., LL.D.

PROFESSOR OF NATURAL HISTORY IN THE UNIVERSITY OF ABERDEEN

NEW YORK

THE MACMILLAN COMPANY

1922 


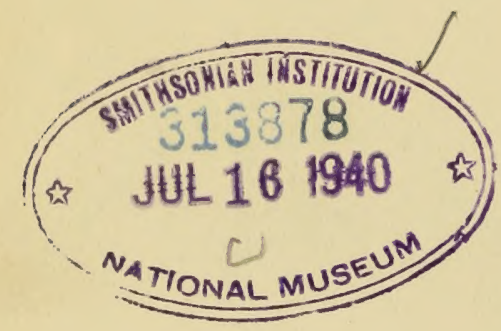

MADE AND PRINTED IN GREAT BRITAIN BY

WILLIAM CLOWES AND SONS, LIMITED, LONDON AND BECCLES 


\section{TO}

PROFESSOR H. J. FLEURE, D.Sc.

A TOKEN OF GRATITUDE FOR FRIENDSHIP INSPIRATION, AND HIGH EXAMPLE 



\section{PREFACE}

HITHERTO, the authors of works dealing with the sea-shore have confined themselves almost entirely to describing and classifying the different forms of life occurring between tidemarks. The main idea underlying the present work, on the other hand, is to treat the plants and animals inhabiting the sea-shore from the ecological standpoint: to show, that is, how they interact and, in particular, to demonstrate the influence of the environment upon their structure, functions, habits and general reactions. A knowledge of the external appearance and chief structural features of the commoner species is taken for granted, and the book is addressed more particularly to the serious student of biology. But while, on the one hand, no attempt has been made to shun technicalities, on the other, care has been exercised that they should not be multiplied unnecessarily. Consequently, there should be nothing in the mode of treatment of the work which unfits it for use by the general reader.

The value of the sea-shore as a biological training ground in general, and as a field for ecological study in particular, is generally recognised. With the exception of the shallow sea, no other area on the globe is so rich in numbers and variety of animal species. The fact that the sea-shore is one of the oldest haunts of life makes it particularly valuable for the study of evolutionary processes. Existence on the seashore implies the solution of a number of exceptionally interesting problems; in particular, the rhythmical and other alled factors influencing shore organisms are of a nature which is unparalleled elsewhere. Finally, the different 
types of sea-shore themselves afford scope for all kinds of interesting faunistic and ecological contrasts.

While the ecological aspect of the sea-shore has attracted a great number of research workers, from the point of view of teaching it would not seem to have received an equivalent amount of attention. It cannot be doubted that if a student confines himself, when on the sea-shore, purely to collecting and labelling species he is not obtaining a tithe of the benefit that his visit is capable of affording him. Consequently in planning this work, one of our chief ambitions has been to stimulate a wider interest on the part of the student by depicting for him something of the wonderfully vigorous and many-sided nature of the struggle for existence between tide-marks, and by drawing his attention to some of the innumerable problems connected with shore animals which still await investigation.

We have had no wish to treat our subject exhaustively. For the most part we have confined ourselves to those British species with which we have first-hand acquaintance. To have foregone, however, all mention of foreign and, in particular, of tropical forms, would be to have excluded phenomena of the very greatest interest to our theme. It frequently happens, for instance, that a habit or an association which is only slightly developed on our own shores has been brought to a high degree of specialisation elsewhere, especially in warmer seas. Consequently, we have not hesitated to give cases of this kind as large a measure of our attention as space allowed. For analogous reasons, while our main concern is with species occurring between tidemarks, we have not infrequently extended our survey to include forms which more properly belong to the waters beyond the Laminarian zone.

In preparing this account of the life of a marine area we have been deeply conscious of our debt to the many naturalists whose rich discoveries have been so freely at our disposal. As far as has been in our power we have responded to this obligation by the care we have given to the citation of appropriate authorities in the text. In our list of 
authorities the names of Prof. W. C. M'Intosh-the "doyen" of British faunists-and of Prof. W. A. Herdman recur with particular frequency, and we venture, in consequence, to take the opportunity of offering to these veteran workers in the domain of marine biology a special tribute of admiration and respect.

We have also great pleasure in expressing our deep gratitude to Prof. J. Arthur Thomson, who has not only placed his profound knowledge of biology unreservedly at our disposal but has helped us in every conceivable way. His kindly criticism has saved us from many blunders and his unfailing courtesy and encouragement to one of us when associated with him as his assistant are among our happiest recollections. Dr. Wemyss Fulton and Dr. H. C. Williamson, by placing the library and laboratory at Nigg at our disposal, gave us valuable assistance. The visit of one of us to the Marine Biological Station at Millport was made especially pleasant and profitable by the kindness of the Superintendent, Mr. R. Elmhirst, who, in addition, gave us much help in preparing the survey of Balloch Bay which appears in the Appendix.

With regard to illustrations, we are indebted to Messrs. Macmillan for the loan of the fine block illustrating variation in Purpura lapillus; to Prof. J. F. Gemmill and the Council of the Royal Society for the illustration of the mode of locomotion of the sea-urchin; to Mr. L. A. Borradaile and the Syndics of the Cambridge University Press for the drawing of Melia tessellata; to Prof. A. Meek and Messrs. Arnold for the drawing of a stickleback's nest; to Dr. W. Collinge and the editor of "Nature" for the diagram clealing with the food of the black-headed gull ; to Messrs. Padgett, Leigh-on-Sea, for the illustrations of the cockle industry. Prof. James Johnstone kindly lent us the photographs of pelagic forms reproduced on Plate III and of the crab larvæ on Plate XIV; and Mr. B. Storrow those of timber bored by Teredo and Xylophaga. Mr. Storrow also lent us the illustration of the starfish Solaster endeca in the act of spawning. Dr. Macgregor Skene kindly undertook 
to photograph for us the zoning of algxe reproduced on Plate VIII ; and Mr. E. L. Gill, the curator of the Hancock Museum, Newcastle-on-Tyne, rendered us a similar service in connection with a fine specimen of a sea-lily in the collection under his charge. We are especially indebted to Mr. G. P. Duffus of the Natural History Department, Marischal College, University of Aberdeen, for much assistance with the work of photography in general. The source of one or two borrowed line-drawings is acknowledged in the text. Figures $5-9,17,18,20$ and 21 were drawn by Miss Mary Mackenzie, while Nos. 14 and 15 are the work of Miss Alice Davidson.

In conclusion, we have great pleasure in thanking the publishers, Messrs. Sidgwick and Jackson, for the courtesy with which they have listened to our suggestions and the pains they have taken to give them effect. 


\section{CONTENTS}

CHAPTER

PAGF

PREFACE . . . . . . . . . vii

Contents . . . . . . . . . xi

List of Plates . . . . . . . . xii

List of Line-Dratwings . . . . . . . xiv

Introduction by Prof, J. Arthur Thomson, M.A., LL.D. xv

I. Animal. Associations and their Characteristics . I

The Study of Ecology defined, I. Animal Associations, 3. The

Terrestrial Habitat, 7. The Aerial Habitat, 8. Considerations regarding the Ecological Study of the Shore, II. Littoral Area in relation to Evolution, 15.

II. Physingraphy of ThE Sea-shore

The Sea-shore defined, 20. Sea-water $\dot{r}_{-}$21, Composition of

Sea-water, 21. Vegetation and Alkalinity of Sea-water, 24.

Light, 25. 'Temperature, 25. Effects of Ice, 26. The Tides, 27.

Circulation of British Waters, 3r. Wave Action, 32, Chief

Subdivisions of the Littoral Area, 35.

III. The Shore and its Plant and Animal Associations .

Transitional Character of Sea-shore, 40. Algal Associations, 4r.

Numbers of Shore Population, 47. Animal Associations of a Rocky Shore, 48. Zoning, 50. Sandy Shore Associations, 51. Jetsam Association, 53. Effect of Currents on Dispersal of Shore Forms, 53. Introduction of New Forms, 54. Ecological Succession, 56 .

IV. Spectal Problens of Shore Ltfe.

Problem of the Tides, 60 . Importance of Rock Pools and of Algæ, 6r. Methods of resisting Desiccation, 62. Methods of resisting Drowning employed by Air-breathers, 65. Problem of Wave-impact, 65. Problem presented by Variability of Coastal Water, 75. Effects of Varying Salinity, 79. Retrospect, 84.

V. Some Methods of AtTack and Defence among Shore ANIMALS

Intensity of Shore Struggle, 85 . Devices to secure unimpeded Growth or Movement, 86. Tactics of the Shore Struggle, 9r. Masking, 9т. Hiding, 93. Hypnosis, 93. Protective Resemblance, 94. Warning Coloration, 98. Mimicry, 100. Protective Armour, 100. Weapons, 105. Reciprocal Adaptations on the Part of Foes, IIo. Retrospect, II3.

VI. Autotomy and Regeneration in Shore Animals Autotomy and Regeneration in General, II5. In Decapod Crustacea, II8. In Echinoderms, 124. Miscellaneous cases of Autotomy, 129. Retrospect, 129. 
SEA-SHORE ${ }^{\circ} \cdot{ }^{\circ} \cdot{ }^{\circ}$ mensalism, 135. Parasitism, 139. Symbiosis, 149.

VIII. The Movements of Shore Animals

The Problem of Locomotion on the Sea-shore, 152. Clambering, 153. Gliding, 159. Swimming, 163. Burrowing, 165. Boring, 167. Jumping, I71. Locomotion on Surface Film, 172. Migrations, I73. Vertical Movements in Relation to Tides, I75. Homing, 176. Retrospect, 178 .

IX. The Nutrition and Methods of Feeding of Shore ORGANISMS . . . . . . . . The Problem in General, 178. Nutrition of Marine Plants, 180. Nutrition of Marine Animals, 183. Pütter's Theories, 185. Bacteria in the Sea, I87. The Problem in Particular, I88. Methods of Feeding in the different Groups, 190. Retrospect, 198.

X. Respiration in Shore Animals . . . . The Problem in General, 200. Accommodation of Waterbreathers to Breathing in Air, 205. Respiration in Relation to Structure and Habit, 209. Respiration in Relation to Burrowing, 211. Respiration in relation to Turbidity of Inshore Waters, 213. Retrospect, 215.

XI. The Nervous Organisation and Behaviour of Shore,

ANIMALS

Shore Animals as Subjects for Study of Behaviour, 217 . Nervous Organisation of various Shore Forms, 219. Reactions of Shore Animals to their Environment, 229. Reactions to Light, 230. Reactions to Moisture, 234. Reactions to Pressure or Contact, 235. Reactions to Gravity, 237. Rhythmic Behaviour, 239. Charncteristic Activities of Shore Forms, 24I. Tube-building in Polychrets, 24I. Occupation of Gasteropod Shells by Hermit Crabs, 243. Masking of Spider-Crabs, 244.

XII. The Reproduction and Growth of Shore animals . Risks attending Reproduction on Shore, 246. Adhesive SpawnProtective Coverings, 246. Pelagic Larvæ, 247. Spawning places, 248. Adjustment of Life Cycle, 248. Parental Care, 252. Nest-building, 255. Breeding and Growth of Common Shore Forms, 258. Retrospect, 280.

XIII. Some Economic Aspects of Shore Life

Importance of Sea-shore to Man, 282. Shore Animals utilised by Man, 282. Bait, 288. Adverse Factors, 289. Plants of Economic Value living within the Tidal Zone, 29x. Injurious Algæ, 297. Effects of Sewage, 298. Injurious Animals, 300. Sea-shore and Human Culture, 300 .

\section{APPENDICES}

I. Notes on some of the Commonest Shore Alg/e . - 303

II. SHORE INSECtS . . . . . . . 308

III. Illustration of a Method OF SURVEying a Typical PIECE of Sea-shore . . . . . . . 312 BibliograpHy . . . . . . . . . 315 INDEXES • . . . . . . . . . 325 


\section{LIST OF PLATES}

PLATE TO FACE PAGE

I. Colonies OF THE TUBE-WorM (Sabellaria aiveolata) AT BORTH . . ... . . . . Frontispiece

II. (i) TYPiCal Shore Forms: Barnacles, Dog-whelks, etc. 6

(ii) Typical Shore Forms: Sea-urchin, Starfish, etc.

III. (i) Typical Pelagic Forms: Ctenophores . . . $S$

(ii) Newly hatched Shrimps (Crangon vulgaris)

IV. Typical Deep-sea Forms : SeA-lilies (Pentacrinus decorus) IO

V. ZoNe of Futcus serratus, with COLONIEs of Sabellaria alveolata . . . . . . . . . 48 48

Vi. Arenicola Colonies on Sand-Flats of Dovey Estuary 50

VII. ZONING OF DOVEY EstuARY . . . . . . 52

VIII. Zoning of Brown Seaweeds on Shore of Cove Bay, KinCARdineshiRe . . . . . . 56

IX. Enterodiorpha POOL . . . . . . . 66

X. (i) Strands of Ascophyllum • . . . . . . 82

(ii) Laminarian Zone partly uncovered (Cove Bay, KINCARDINESHIRE)

XI. (i) Starfish Regenerating ARMS . . . . . 124

(ii) Male Starfish (Solaster endeca) Spaivning

XII. (i) TIMBer bORED BY THE SHIP-WORM (Teredonorvegica) , 170

(ii) Trmber bored by the Bivalve Xylophaga

XIII. (i) RADUla OF WHELK . . . . . , . 194

(ii) Track of Sea-urchin on Plasticene

XIV. (i) Comaion Shore Crab Parasitised by Saculina . . 270

(ii) Megalopa Larv $£$ or Shore Crab

XV. (i) The Cockle Industry at Leigh-on-Sea: Landing THE Cockles . . . . . . . . $29 \mathrm{~S}$

(ii) Cooking Cockles at Leigh-on-Sea

XVI. Shore of Balloch BaY: (i) At low Tide; (ii) AT HalfTIDE 


\section{DRAWINGS IN THE TEXT}

FIG.

rAC;E

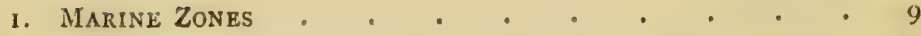

2. The Relation berween Salinity and Rainfall in Bally * NAKILL HARBOUR . . . . . . . 23

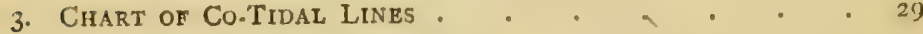

4. Variation IN Purpura lapillus . . . . . . 72

5. Shell Forms in relation to Mode of life • • 74

6. Avicularium of PolyzonN . . . . . . . 87

7. Pedicellarie of Sea-uRchin (Echimus) . . . . \$ $8 \$$

8. SpIder-crab partly MASked by SPONge on Front of

Carapace . . . . . . . 92

9. SPINE of SEA-URChIN . . . . . . . . . IOI

10. AUTOTOMY OF CRAB's LEG . . . . . . . I20

II. Crais (Melia tessellata) BEARING IN ITS Claws Two ANemones 138

12. Positions occupied By Pedal Disc of ANemone * - I6I

13. Migration of Edible Crab . . . . . $\quad$ I74

14. Periophthalmus on MUd Flat . . . . . . 207

15. BUTTERFISH (Centronotus gunnelius) PROTECTING EGGS . . 254

16. Nest of Fifteen-Spined Stickleback . . . . 256

I7. LARVF OF COMMON SHORE ANIMALS . . . . . 259

18. SPAWN OF Shore ANIMALS . . . . . . $\quad 273$

19. FOOD OF BLACK·HEADED GULL . . . . . . 290

20. Common Shore Alge . . . . . . . . 304

21. COMmon Shore Alge . . . . . . . . . 306

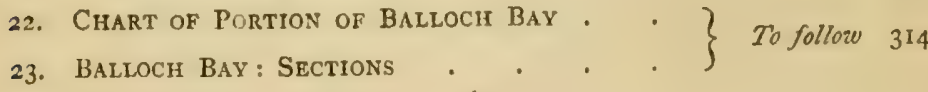




\section{INTRODUCTION}

\section{By Prof. J. ARTHUR THOMSON, M.A., LL.D.}

IT is little wonder that much has been written about the animals of the sea-shore. For it is perhaps the most interesting of all the great haunts of life. As the authors of this book make clear, the sea-shore is astonishingly varied in different places and very diverse even at one place, if its "zones" are well marked. It is likewise very changeful throughout the day and throughout the year. One might almost say that vicissitudes are the rule on the shore. It is not a place for easy-going animals unless they have special adaptations. For there are dangers in the force of the waves, in exposure at low tides, in floods of fresh water, in clouds of driven sand, and in vast accumulations of jetsam seaweed which tend to smother everything. To discover how the shore animals meet these difficulties is a fascinating study, and this book by Messrs. Flattely and Walton is the best guide we know. It is written out of a rich experience, extended by a scholarly acquaintance with the literature of the subject. There are many good books dealing with the shore, but what is distinctive about this one is the biological note. It seeks to illustrate the deeper problems and to test the principles of biology by concrete reference to the fauna and flora of the sea-shore.

Given a diversified, changeful, difficult haunt, densely peopled by a representative fauna, there must be a keen struggle for existence and a ceaseless sifting. Given a very stimulating environment, as the shore is par excellence, 
there will be opportunity to test all the variations which organisms are ever venturing. It may be, indeed, that the stimulating character of the littoral conditions has been in itself, through the ages, provocative of those new departures which form the raw materials of evolution.

In any case the result has been multitudinous adaptation. What variety of armour and of weapons, what arrangements for securing the food which tends to slip past, what diversity in breathing, how many different ways of holding on and withstanding shock! The book is a treasury for the student of fitnesses.

And besides those modes of "struggle" which secure self-preservation in the widest sense, there are those which secure the welfare of the offspring. Of "love" as of "hunger" the shore affords many a fine illustration, and here again the authors' work shows true perspective.

Whether the earliest living creatures tenanted the shore or the open sea, remains uncertain, but there can be no doubt that most of the great stocks of animals have passed through the discipline of the littoral life, and this is perhaps the crowning interest--to try to trace the organic grip that such influences as the tides have taken of the constitution of the great races-how even in man himself there are as it were reminiscences of the school of the shore.

The principles of biology can be studied in many different ways. There are anatomical, physiological, systematic, and other approaches-all with their merits. But this book opens up another way-the study of a haunt and its inhabitants, and the authors have been successful in showing that this way is one that rewards. 


\section{THE BIOLOGY OF THE SEA-SHORE}

\section{CHAPTER I}

\section{Animal Assoctations and their Characteristics}

IT is the purpose of this book to study the animals, and to some extent the plants, of a certain well-defined area-the sea-shore-in relation to their physical environment and to one another. In other words, we are to deal with the plants and animals of the sea-shore not as isolated units, but as an association. The study of animal associations forms part of a wider subject now usually known as ecology (Greek oikos, a house), a term proposed by Haeckel to cover the relations of the animal to both its organic and inorganic environment, particularly its relations, whether friendly or hostile, to those animals or plants with which it comes into contact. Another term covering more or less the same ground is "bionomics"; it is gradually passing out of use. Inasmuch as ecology is concerned strictly with the living organism and its responses to the environment, it may be said to coincide more or less completely with what we understand by biology when this term is used, as it so frequently is, to lay emphasis on the living as distinguished from the purely morphological aspect of the organism. It is in this sense that we employ the title "The Biology of the Sea-shore."

As a branch of zoological study, animal ecology, though it has only recently begun to attract attention, is undergoing rapid development, particularly at the hands of American 
naturalists. In addition to defining the limits of the study and its relation to other branches of zoology, ecologists are chiefly concerned in unravelling and reducing to order the multitudinous factors composing the environment, and in estimating their relative importance. One of the chief features of the progress of the study of ecology is the framing of a special nomenclature; but valuable as many of the new terms are, we intend to employ them as little as possible, more particularly as there is not yet complete agreement as to their equivalence.

According to Adams (I9I3) the study of ecology may be approached from three distinct points of view, which are "superficially so distinct that students of one branch may be almost unaware of the existence of the co-ordinate branches and may not realise that each is part of the larger unit." The first is that of individual ecology. In this case, investigation is focussed upon a particular animal which is studied in all its manifold relations to its environment, animate and inanimate. Not a few such studies have already been attempted; they vary, of course, greatly in degree of completeness (in many cases observations might well extend over a lifetime and be still incomplete). As an example we may quote Darwin's study of the habits of earthworms, written before the term ecology had been invented. Many of Fabre's studies come under this heading also. The tendency of the present-day ecologist, as compared with a naturalist such as Fabre, is to pay an increasing amount of attention to the physical environment and to analyse behaviour in terms of factors such as light, pressure and contact, temperature, water, gravity, etc.

A second point of view is that of aggregate ecology. Here, instead of attention being directed towards a particular individual, the study centres upon a unit group or aggregate composed of a number of animals either generically related or living as a family group. In this way, says Adams, it is possible to speak of the ecology of birds, dragon-flies, the genus Bombus, a hive of bees, or a colony of ants. To use Adams' phrase, it is " the hereditary or taxonomic unit 
which is here the hub of the microcosm." This is the study of aggregate ecology. A third branch of ecology is that which deals with the inter-relations of animals occurring together in the same habitat and regarded as a unit quite apart from any question of hereditary or taxonomic relationship among the component members. Every grouping of this kind, in spite of the complexity consequent on the innumerable reciprocal activities of the animals within it and their responses to the environment, will be found on analysis to have a constitution which is specific and which differentiates it from other groupings. The study of such a grouping is the business of associational ecology. It is largely with this aspect of ecology that the present work is to deal.

Animal Associations.-Dwelling on the earth are a vast number of plant and animal forms which vary greatly as to their relative abundance and distribution. Some have a wide range; some are restricted to more or less limited areas, others again are rare. Each of these forms has a relationship to the other forms among which it dwells and with which it is associated, hence it is that those forms which live together habitually have come to be termed an association.

Any group of forms normally occupying the same environment may be regarded as an association, and it is usual to name the association after the most obvious feature of that environment, e.g. the association of the tidal zone. The fact of a number of unrelated animals occurring together in the same habitat implies considerable equivalence of form, function, and habit. The word equivalence is used in contrast to identity, for though the problems presented by the environment may be identical, the means by which they are solved often vary markedly. The working out of these analogies and contrasts forms one of the most interesting portions of our study.

According to Shelford (1915) animals select their environments by one of three methods : (I) by the wide dispersal of the reproductive elements and selective survival, (2) by 


\section{THE BIOLOGY OF THE SEA-SHORE}

turning back on meeting with unfavourable conditions, (3) by selection after trial in connection with migration. It is because of physiological similarity that numbers of animals select the same environment. Thus agreement in behaviour and physiology among the members of an animal community is to be expected, just as there is growth and form agreement in plant communities.

What are the chief factors controlling the distribution of plant and animal life? In the first place we have the physical factors as exemplified by the three primary habitats : air, land, and water. If animals are considered in their relation to these three great environments, it will be seen that although air is essential to life, yet animals are never purely dwellers therein. A great many animals are essentially restricted to a land life, requiring air to breathe and a more or less solid substratum for their activities, while others are equally restricted to the fluid medium, either with or without a substratum. There are some that can utilise all three media to some extent, as in the case of some birds which can fly, walk, and dive. To go somewhat further, we find many animal forms restricted to particular well-defined types of physical conditions and unable to live normally, or at all, beyond their influence. We can thus distinguish animals peculiar to warm, temperate, and cold waters or climates, to wet or dry regions, to light or dark situations, to deep or shallow waters, to lowlands or mountains, to swift or stagnant waters, and so forth. With regard to aquatic communities, an interesting experimental study of the behaviour agreement among the members of communities has been made by Shelford (op.cit.). For the purpose of contrast the societies of rapids and of pools of a stream were chosen, and their reactions to various stimuli tested in the laboratory. The behaviour in relation to light, currents, etc., was found to correspond strikingly with the conditions under which the animals lived. Another fundamental factor governing the occurrence of animals is that of food. Many animals are wholly vegetarian, and hence their distribution is bound up with 
that of the host plants which, in turn, are subject to physical controls. Other animals have become carnivorous, and by virtue of this habit have escaped from the fettering control of a host plant, but must pursue or search out their prey, or perish.

A still closer relationship is that between host and parasite. While many parasites are more or less adaptable and may even exist for a time as free-living forms (facultative parasites), others again are associated entirely with a particular species of host (obligate parasites), the dependence of the parasite thus being extreme. Special devices, such as a complex life-history or enormous fertility, are then necessary to maintain the relationship unbroken. Most intimate association of all, however, is that known as symbiosis. This is a partnership for mutual benefit between an animal and a simple chlorophyll-bearing plant, or between two plants (fungus and alga). A typical shore example of such an association is that between the Planarian worm Convoluta roscoffensis and a green flagellate alga, in which the worm feeds on the reserve material manufactured by the plant, and the latter has the advantage of a plentiful supply of nitrogenous material and carbon dioxide.

A somewhat analogous association for mutual benefit is that known as Commensalism. The partnership here is not nearly so close, being simply one of habit, and though of very frequent occurrence is not essential to the forms concerned. A familiar example of this is afforded by the hermit crab Pagurus prideauxii and the sea anemone Adamsia palliata, the latter helping to conceal the crab and profiting by the food morsels it drops.

We thus see that the inter-dependence between plant and animal and among animals themselves is frequently very close. But when we add to this the influence of the environment in favouring the survival of forms specially adapted to it, it becomes evident that in any well-defined area certain forms suited to that area, or with liferelationships to one another, will be found to occur together forming communities or associations. Plant associations, 
being usually the better defined and more coherent, have generally a marked influence in determining and modifying the animal associations occurring with, and to a large extent depending on, them. Thus it is that many of the large animal communities are named after the plant association with which they occur, since although the nature of the plants depends upon physical conditions, it is the plants (or their absence) which gives the characteristic appearance to a region. We speak in consequence of the fauna of the tropical or coniferous forest, of the Savana, prairie or desert, each of which has its distinctive features. A study, however, in order to be associational need not deal with such a wide area; in fact, the smaller the area under study the greater probably the amount of ecological agreement. The possible subdivisions of any wide natural area are very numerous, and we may speak with perfect accuracy of the association of a cockle or mussel bed, of a rubbish-heap, or of a rock pool.

Any particular association contains forms which, in course of time, have become more or less inter-dependent. Many of the animals, as we have seen, depend entirely upon the plants present; others prey upon these vegetarians or upon other carnivorous forms, so that a balance is established which is only altered by some change in the environment, or by the introduction of some fresh factor or form. This balance is relative, not fixed, the centre of gravity swinging to and fro within varying limits. From time to time some local catastrophe, such, for instance, as a river shifting its course, or a volcano suddenly becoming active, will destroy the old order, and a new balance will slowly be established in its place. Man, particularly, is a disturbing agent and may himself become involved in the confusion resulting from his action. The mongoose in Jamaica, the English sparrow in America, and the rabbit in Australia are striking examples of the overturning of the local balance of nature by the sudden introduction of a completely new factor.

In considering the many different haunts of life as a whole 


\section{PLATE II}

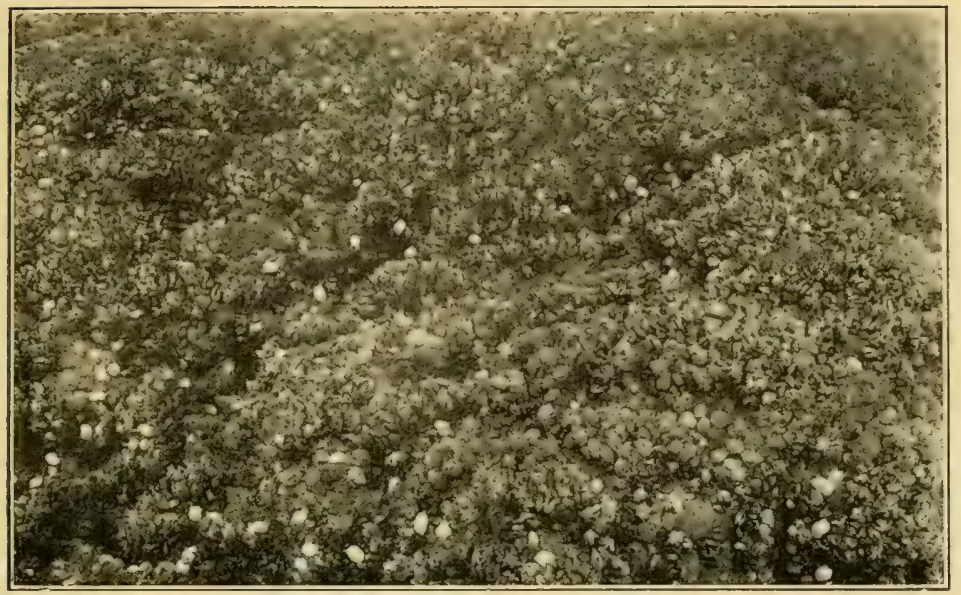

I.-Typical Shore Forms.

Association of barnacles, dog-whelks, and seed-mussels.

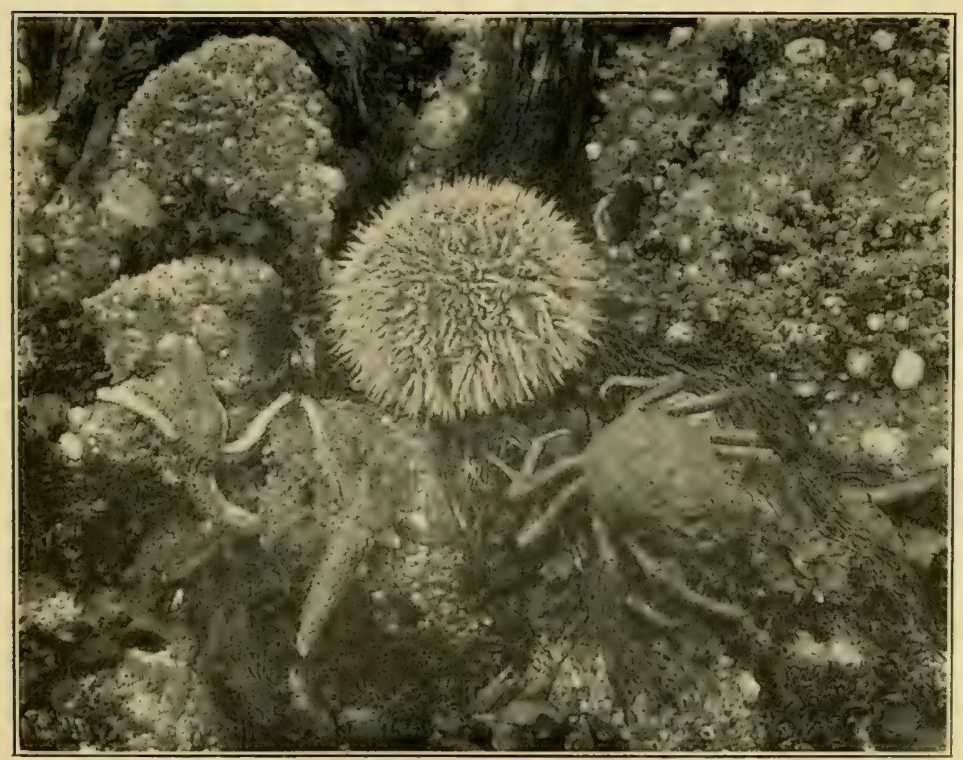

II.-Typical Shore Forms.

Including sea-urchin (Echinus esculentus), starfish (Asterias rubens), masking crab (Hyas), acorn-barnacles (Balanus), and limpets (Patella). 

we recognise three factors which have a most profound effect upon the plant and animal organism. These are : (I) the medium which surrounds the organism, either air or water. This determines the method of breathing, and with few exceptions prohibits the passage of the inhabitants from one medium to another; (2) the presence or absence of light acting either directly (e.g. effects on pigmentation, sight, etc.), or indirectly through plant life ; (3) the presence or absence of a substratum (Lull, I917).

The above factors enable us at once to distinguish at least three main types of habitat: terrestrial, aquatic, and aerial, as we have already noticed. Even these divisions are not precise: no animals are purely aerial and many, as we know, are amphibious. Let us make a cursory examination of each of these three habitats in turn.

The Terrestrial Habitat.-This may be said to extend from high-water mark to the summits of the highest mountains. Many subdivisions are possible, but we will talse only the most obvious. Though the forms which live on the surface are most familiar to us, yet a great animal populace is to be found inhabiting the upper layers of the soil in more or less complete darkness. We thus have two great sub-realms: the phanerozoic and cryptozoic (see Willey, I9II). A good illustration of a cryptozoic fauna may be found in the inhabitants of subterranean caves, which are distinguished by such features as loss of pigmentation, reduction of eyes, modification of the digestive organs, attenuation of body form, and reduction of the appendages. Owing to the absence of light, cave faunas present interesting analogies with those of the marine abysses, e.g. modification of the visual organs, simplified colours, etc. Taking our classification somewhat further, other well-marked habitats which we are able to distinguish are those of mountain, steppe, forest, prairie, etc.

The Aerial Habitat.-A suitable ecological subdivision of this habitat is not very obvious. It is the atmosphere above land surfaces which is most utilised. Relatively 
few birds venture far from land, and insects, so important a part of the aerial fauna above a land surface, with few exceptions, do not venture beyond tide-marks. Among the exceptions must be noted the group of insects known as the Halobatidæ. Further, swarms of migrating insects, such as locusts and butterflies, may be blown out to sea by gales and, with the help of the wind, may cross many miles of intervening sea. It is in this way that many insect forms have been distributed, and that foreign stragglers continue to reach our shores. The occurrence of these forms, however, above the open sea is obviously quite fortuitous. The flying-fishes, by taking a strong leap and using their pectoral fins as parachutes, are able to sustain themselves for short periods above the surface of the ocean. Historically, the aerial habitat was the last to be invaded by animals.

The Aquatic Habitat.- This we can at once divide into a fresh-water and a marine habitat, the latter containing an enormously greater number of forms. Fresh-water faunas are distinguished by their uniformity. Thus, while the population of a fresh-water lake may be very dense, the number of species is relatively small and the number of types still smaller. In considering the conditions of life in fresh water we are able to distinguish forms living in pools and in running water, and another subdivision might be made into littoral, surface, and deep-water forms. Lull (loc. cit.), however, remarks that although in a measure the deep-sea characteristics of darkness and great pressure occur in certain lakes and relict seas, yet no profound modifications of form occur comparable with those seen in the animals of the marine abysses. The reason for this, Lull thinks, is to be found in the comparatively evanescent character of lakes from the geological point of view.

Of all abodes of life the marine habitat is biologically the most important. The fauna is not only remarkable for its numbers, but still more for its extraordinary diversity. We may recognise the four following divisions: (I) Strand or Tidal Zone, (2) Shallow sea, (3) Pelagic, (4) Abyssal, 


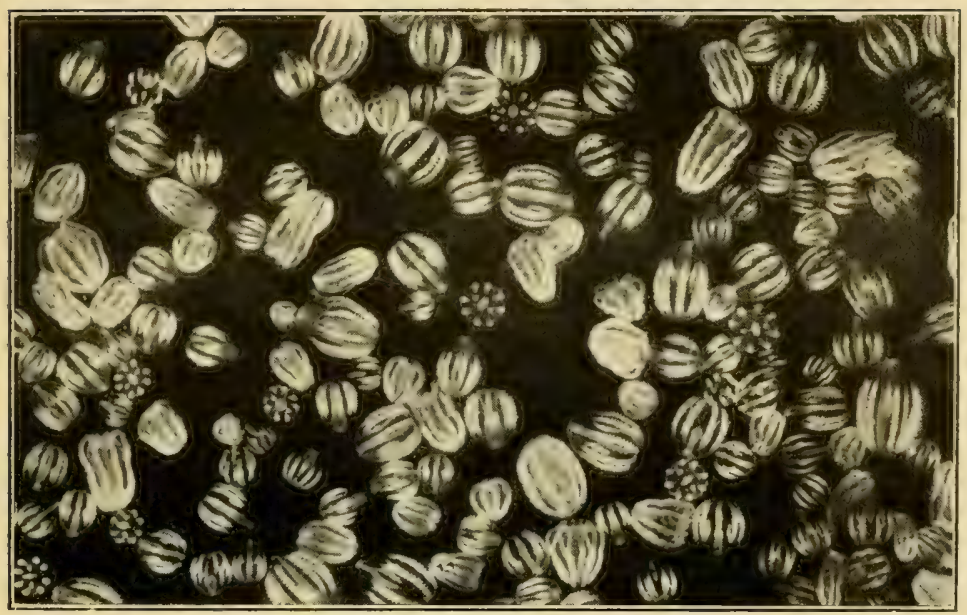

I.-Typical Pelagic Forms : Ctenophores.

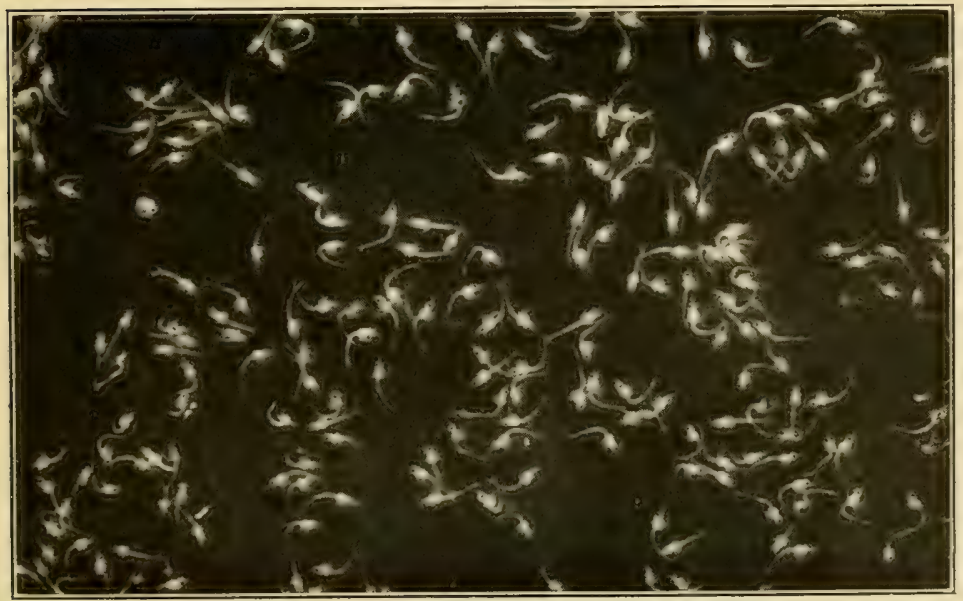

1I.-Typical Pelagic Forms: Newly Hatched Shrimps (Crangon vulgaris). 



\section{CHARACTERISTICS OF ASSOCIATIONS}

their inter-relationships being as represented in the accompanying diagram :

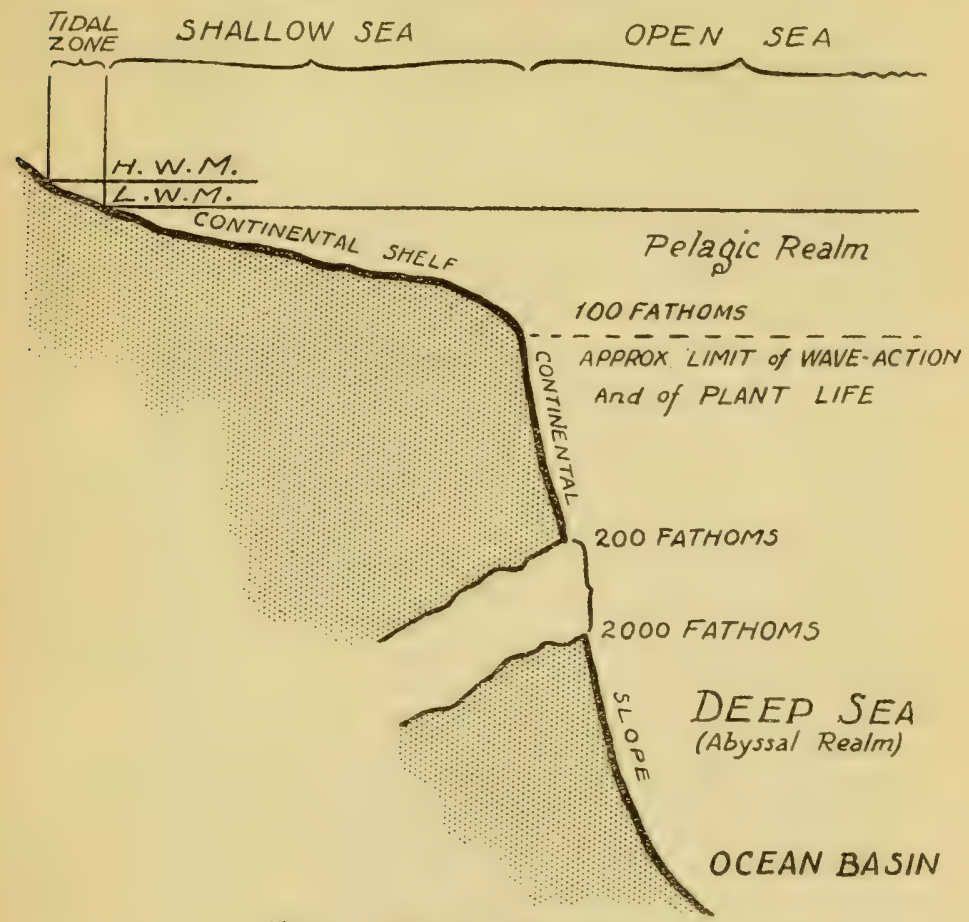

Fig. I.-Marine zones (after Lull).

Strand or Tidal Zone.-This area, to the study of which the present book is devoted, is the narrow strip of territory between the high and low water-mark of spring tides. It is remarkable for its situation at the junction of sea and land, a region of unceasing activity and of extraordinarily fluctuating conditions. Among other characters which distinguish it are the presence of a substratum, abundance of light and of aeration. Plant life (in the form of algæ) is frequently very important on the shore and presents a certain analogy with land conditions in contrast to the purely marine conditions existing beyond the littoral zone, where plant life gradually dies out as the depth of water increases. Freshwater drainage from the land frequently has considerable 
effect on the fauna and flora, the liability to incursions by birds and animals during low water, and the freeswimming and floating life of the sea coming and going at every tide, have all their influence upon the plants and animals of the sea-shore. Finally, the shore area has strong claims to be recognised as the birthplace of life and, says Thomson (1919), we may regard it as the great school wherein were learnt many of the primary lessons of life.

Shallow Sea.-This is the zone extending from the lowwater mark of spring tides to the edge of the continental shelf, the term given to the ledge usually found surrounding a continental land-mass. The extent of this life-area will thus vary considerably, but, generally speaking, the point at which the gentle slope of the continental shelf passes abruptly into the steep gradient of the continental slope may be said to be situated at a depth of about a hundred fathoms. This depth, then, which marks approximately the limit of wave action will also mark that of the so-called shallow sea.

As a haunt of life the shallow sea more or less resembles the tidal area in regard to such factors as light, the presence of a substratum with algal vegetation, wave shock, and aeration, but the influence of the tides is only slightly felt. In wealth and variety of forms it surpasses any other comparable area on the globe.

Pelagic Realm.--The extent of the pelagic realm is best conveyed by the term "open sea." More accurately, it may be said to be a seaward extension of the shallow sea, and to include the surface waters to a depth of a hundred fathoms. It thus forms a roof to the abyssal realm. Its most important features are the presence of abundant light and the absence of a substratum. The animals frequenting this area are either swimmers (Nekton), or drifting forms (Plankton) sufficiently buoyant to remain at or near the surface of the water (see Plate III). In view of the necessity for buoyancy, pelagic animals tend to be of delicate structure. They are also mostly transparent. Plant life is confined to the unicellular algæ which, however, exist in limitless 


\section{PLATE IV}

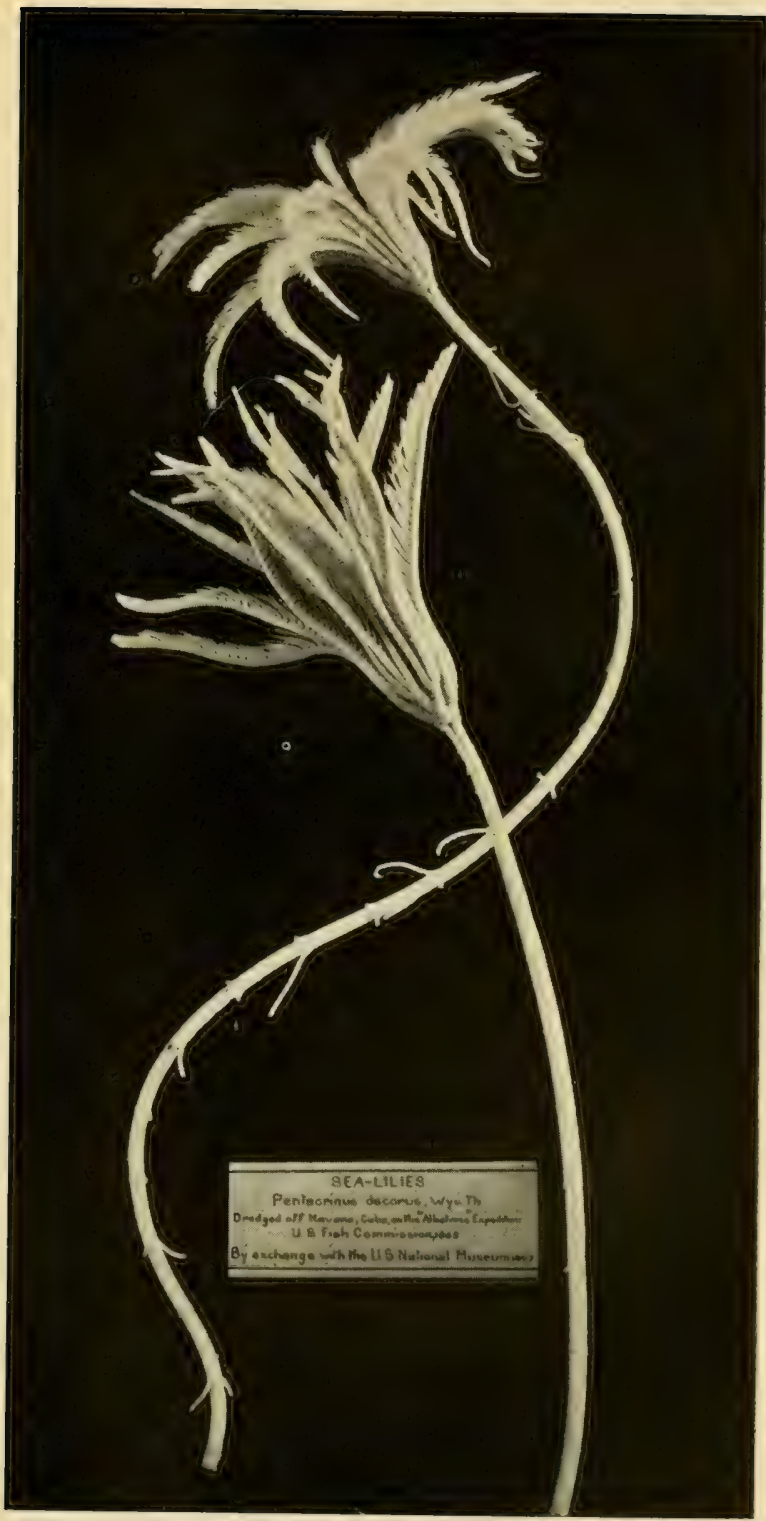

Typical Deep-sea Forus. Sea-lilies (Pentacrinus decorus). Specimens in the Hancock Museum, Newcastle-on-Tyne. 

profusion Similarly, the animal population is extraordinarily dense.

Abyssal Realm.-This is the area extending from the margin of the continental shelf to the greatest depths and bounded above by the pelagic zone. At the margin of the continental shelf the sea-floor turns abruptly downwards, and the depth of water increases very rapidly. The amount of light penetrating diminishes accordingly, and plant life with all that it implies grows less common and eventually disappears. Wave action no longer makes itself felt and the waters are motionless. It is extremely cold, almost freezing, the sun's influence not extending beyond about I 50 fathoms. Finally, the pressure of the waters is enormous, since pressure in the sea increases by about one atmosphere for every ten metres of depth (the pressure at 5000 metres being over three tons to the square inch). These four factors : darkness, quiescence, cold, and pressure, have had far-reaching effects on the fauna, particularly in the case of deep-sea fishes. The animals are frail and flabby, their colours are extremely simple, eyes are often absent, and when present they are frequently telescopic or provided with an enlarged lens like that of a bull's-eye lantern. There is a tendency to develop feelers or long filaments with a tactile sense, obviously only of use in still waters. Nearly all abyssal fishes are phosphorescent.

SOME CONSIDERATIONS REGARDING THE ECOLOGICAL

STUDY OF THE SHORE

While a detailed discussion of the associations of the shore is deferred till Chapter III, we may take this opportunity of considering how the ecological method of study may best be applied to the case of this particular life area.

The area exposed between tide-marks can usually be split up into a number of life zones. Each of these zones or horizons is characterised by a certain assemblage of forms, some of which are either confined to that horizon or are so marked in form or predominant in numbers as to 
give a readily recognised, distinctive appearance or "facies" to that particular part of the shore. In proceeding from high to low water mark a succession of these will be crossed. If the nature of the substratum remains unaltered the differences in the composition of the fauna are chiefly determined by the period of exposure the individual forms are capable of surviving. Moreover, so regular is the tidal rhythm that some forms have come to require a certain definite period of exposure and will perish if kept continually submerged. In passing, therefore, from high to low water mark, while new forms are continually coming in, others will be found to drop out. Frequently, however, a shore is not of a uniform type, in which case a particular zone, when followed for a short distance, will be interrupted owing to the interpolation of a different physical type (sand may succeed rock, etc.), but will reappear with its characteristic plant and animal association when the same type of shore is again met with. It is impossible to draw up a classification of shores which will fit all cases, but that of Pruvot reproduced opposite is of fairly general application and will serve as a working guide, and for the further assistance of the student we have included in the Appendix a chart of a typical piece of shore of mixed physical character with a list of the common forms occurring there.

In addition to the linear zoning of shore forms, the vertical aspect also requires consideration. It is only in the case of completely flat shores that submergence proceeds uniformly, and on certain shores the height of the rocks or boulders becomes of great importance. Suppose, for instance, the vertical range of the tides to be ten feet, the summit of a rock of this height situated in the Laminarian zone will frequently carry an association in all respects identical with that occurring at high-tide mark. This will be seen in the chart referred to, where the succession of algæ clothing the sides of the rocky reef, as one passes from top to bottom in the region of low-tide mark, exactly repeats the linear arrangement found on passing from high 


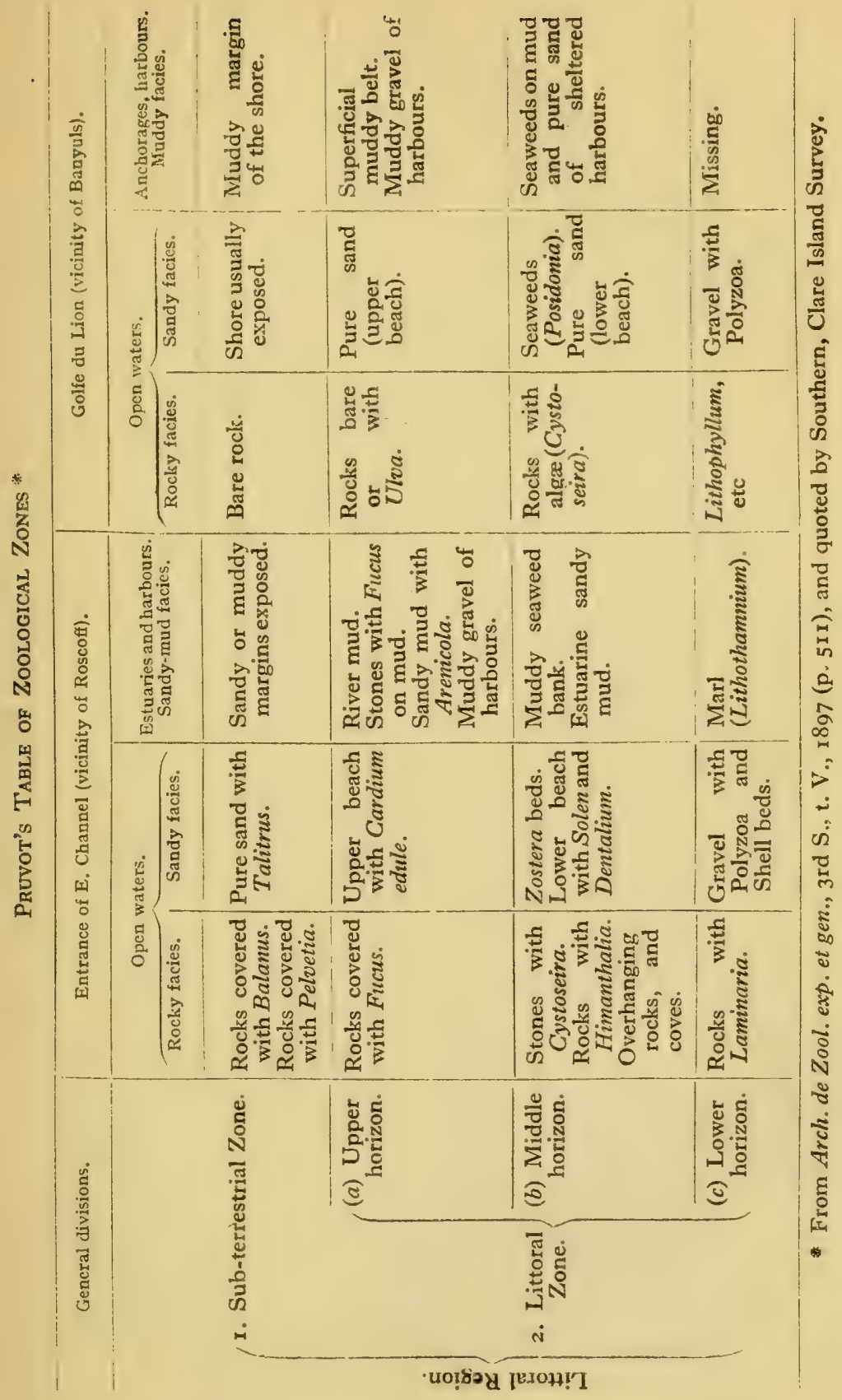


towards low tide mark. And the same is true for the animals associated with the weeds.

Not only may we study the fauna of these zones or horizons as a whole, but we may go further and study the animals dwelling together among some marked algal or other associations (such as a Fucus bed; in a rock pool ; in an area of sandy mud ; in a cockle or mussel bed, etc.). Interesting results may be obtained by contrasting the fauna living on and under stones, etc. King and Russell (1909) recognised four chief positions in dealing with the fauna of a particular bay, but the distinctions are capable of wider application. These "positions" were (I) the upper surfaces of stones (and rocks); (2) beneath stones (not embedded); (3) in the substratum; (4) on, or amongst, different kinds of weeds (noting in the last case that the base and branches of large algæ will show typical associations of forms).

Davenport (1903) grouped the fauna of another area in a manner which is also of value (but more locally than widely, as the groups are not always clearly defined), into (I) sessile, (2) crawling, (3) burrowing, and (4) swimming animals. This method of grouping is, however, physiological rather than ecological.

We may conclude these introductory remarks, intended to be suggestive and not by any means exhaustive, by summarising the chief features of an association. Within any particular association a normal relation between its members comes to exist. We shall find at the time we examine it, a certain number of genera, species, and individuals, and these are more or less constant for each association. Several members of any given genus may be present, and one or more of these species may be abundant, so much so as to be called dominant, while others are rare. One member of an association may be large and prominent, but relatively few in numbers; while another is extremely abundant, but microscopic in size. There will be a balance between vegetable feeders, predatory species, and parasites; though the predatory element may be largely external to any given association (such as fish or bird). Any 
departure from this balance will result in changes in the association. Great variation will be found in the relative representation of the various phyla in different associations, according to their type. In rocky pools Cœlenterates may be well represented owing to the presence of a suitable substratum for attachment ; on sand they may be practically (or even entirely) absent; in both, Molluscs will probably be numerous, but in the former case Gasteropods, and in the latter Lamellibranchs, will predominate. In the pool there will be Anemones and creeping Molluscs; in the sand, burrowers.

\section{THE LITTORAL AREA IN RELATION TO THE EVOLUTION OF LIFE}

The problem of the evolution of life has for long exercised the minds of scientists, and in view of the importance usually attached to the shore in this connection it may be useful to give it a small share of our attention.

Amid much doubt and disagreement one fact remains certain, namely, that life began in the water: whether in salt or fresh water has not been decided. The earliest forms of life probably were nitrifying bacteria, since they alone are capable of deriving their energy and nutrition from inorganic chemical compounds and are independent of the sun or of other forms of life. It is less the actual origin of life which concerns us, however, than the manner in which it was able to spread from its original home and has come to occupy the various habitats we have been dealing with above. Of this, various explanations have been put forward based upon the varying conceptions of the conditions prevalent at the time when the temperature of the earth had dropped to the highest limit at which we believe life to be possible. Some of these may now be quoted.

Church (1919) believes " the beginnings of Botany are in the sea," the first phase of plant life being pelagic. Church conceives of an early world entirely covered by watera world-ocean some two miles deep in which life was 
evolved and gradually increased in complexity till at length unicellular plants were produced possessing chlorophyll, and capable of elaborating their own food. At this period portions of the earth's crust were uplifted to within a comparatively short distance of the surface of the ocean, and came within the influence of the sun's rays. Profiting by the presence of light some of the pelagic forms took to a sedentary life upon the sea-floor, and from these were evolved multicellular forms of gradually increasing complexity and with more and more efficient forms of attachment. Next, at a period corresponding to the very earliest geological record, the earth's crust underwent a further movement of uplift and areas of solid land appeared above the surface of the waters. Certain sedentary aquatic plants now found themselves exposed at intervals to the air. As the uplift continued the periods of emergence became gradually longer ; some of the sea forms again were able to adjust themselves to the changing conditions, their organs of attachment becoming organs of absorption, and reproductive cells capable of aerial dispersal taking the place of those adapted for locomotion or transport in water. Such was the way in which, according to Church, plant life proceeded to its conquest of the land. It will be seen that although this writer assigns a pelagic origin to life, yet his theory emphasises the importance of littoral conditions without which the migration from sea to land would not have been possible.

Totally opposed to that of Church is the view taken by Osborn (1918), who argues that the more or less complete absence from the primal ocean of those chemical elements so essential to living matter (particularly nitrogen) must force us to abandon the idea of life having begun in the sea and to conclude instead that "the lowliest organisms originated either in moist earths or in those terrestrial waters which contained nitrogen." Nitrite and nitrate presumably arose by the union of nitrogen and oxygen in electrical discharges (as in a thunderstorm) and with related nitrogen compounds " may have been specially concentrated in pools of water to degrees particularly favourable for 
the origin of protoplasm." Further, according to Osborn, "it appears that every subsequent higher life phase-the bacterial phase, the chlorophyllic algal phase, the protozoan phase-were also primarily of fresh-water and secondarily of marine habitat. From terrestrial waters life may have gradually extended into the sea."

Of considerable interest to us are Osborn's remarks on the great antiquity of most of the marine invertebrate groups and the extraordinary persistence of type, which is such that forms " with an antiquity estimated at 25,000,000 years can be placed side by side with existing sea forms with very obvious similarities of function and structure." Again, a comparison of fossil and modern Polychæts, both swimming and burrowing forms, affords clear evidence that the Cambrian sea-shore and its tidal conditions closely resembled those of the present day.

Macfarlane ( 1918$)$ takes the view that life originated in thermal fresh-water areas, the earliest forms being probably colourless bacterial forms similar to the thermal sulphur bacteria. From these slowly originated the unicellular blue-green algæ which, by a process of gradual accommodation to cooling terrestrial conditions in fresh water, or in moist places and later in the sea, gave rise to a wealth of species that became in turn the ancestors of all green plants. Similarly, by a train of arguments we have not space to follow, a lacustrine origin is claimed for animals.

Simroth (1891), in analysing the factors and reviewing the various possibilities necessary for the first production of life, in this connection remarks that this could not have taken place in the hydrosphere without the concurrence of air, since respiration is one of the first and most essential functions of life. On an a priori view, therefore, the most favourable point for the first appearance of life would be where the two essential factors, air and water, interact most effectively. The question of an abyssal origin of life is thus, to all intents and purposes, excluded, and all that remains to be decided is at what part of the ocean's surface the exchange between air and water could take place most favourably, whether in 
the open sea or in the neighbourhood of the coast. Simroth considers the choice must inevitably fall upon the latter.

With regard to the pelagic origin of life at a time when the earth was entirely surrounded by water, as postulated by Marshall, and later, as we have seen, by Church, Simroth argues that since the earth first began to solidify at a temperature far greater than that at which it was possible for life to exist, a disproportionately longer time must have elapsed between the first formation of a terrestrial crust and the appearance of life, than from this latter period till now. There seems no reason, however, why the earth's crust should not have become folded and portions of it have projected above the water surface, long before it could have cooled to a temperature favourable to life; and consequently the theoretic possibility of a coastal or even a land origin of life cannot be excluded.

Sollas (1884) assigns a marine origin to life and brings evidence to show the probability of fresh-water faunas having arisen by modification of marine forms following the conversion of shallow continental seas into fresh-water lakes. The fact that practically all marine forms have free-swimming larvæ makes their direct transference to rivers extremely difficult, since the larvæ are at the mercy of currents. Sollas enumerates three considerable methods by which freshwater animals may be derived from marine forms as follows: (I) direct migration into rivers from the sea; (2) conversion of the original habitat into a fresh-water basin or lake; (3) acquisition of a terrestrial or marshy habitat and subsequent exchange of this for a fluviatile or lacustrine one. It is interesting to compare this with the observations of Pearse (I9I5) on the migrational highways utilised by Crustacea. In dealing with the Crustacea of the southern shores of the Caribbean Seas, and the varying habitats : sea, mangrove swamps, streams, forest, and desert, this writer shows that this group, like the Amphibia, is in process of transition from aquatic to terrestrial life. Every phase of the transition is shown: marine, fresh-water, terrestrial, arboreal. The variety of habitat is facilitated by 
the habit of egg-carrying by the female, omnivorous habits, protective cuticle and plasticity of behaviour in relation to special conditions. In their migrations they have followed three main highways : (I) through rivers to land, (2) from the ocean direct to the land, (3) from marshes and swamp habitats direct to fresh water. Respiration appears to have been of most importance in keeping the majority of Crustacea aquatic. Issel (I9I8) in contrasting life in fresh and salt water notes that while there is much in common corresponding to the similar requirements of aquatic life, yet there is a barrier between them depending on the quantity of dissolved substances. The difference is quantitative, whereas the difference between aquatic and land life is qualitative.

In conclusion, as the result of this short review, although we are unable to affirm that life originated in the littoral zone, yet we have accumulated a certain amount of evidence to that effect and have at least demonstrated the great importance of this area from the evolutional standpoint. The chief factors concerned are the transitional characters of the area; neither entirely aquatic nor entirely terrestrial, the presence of light, abundant air, and a substratum. It is these which justify the claim of the littoral area to be called the " cradle of evolution." 


\section{CHAPTER II}

\section{Physiography of the SEA-shore}

THE coast-line of all countries exhibits a succession in varying degrees and extent of cliff, headland, reef, bay, estuary, lagoon, delta, inlet, and fiord; of sand and shingle or of mud flat. These physical features, which are of fundamental importance to animal and plant life, are the outcome of complex geological and geographical factors, and result from the action of the ocean upon varying strata and deposits, generally already moulded and modified by denudationmarine, fluviatile, or glacial action-and now in process of still further modification by the salt waters acting under the rhythmical power of the tides, and by the more spasmodic forces of the wind.

We are going to deal with the life of a narrow zone, which, although primarily under the influence of the sea, is daily exposed to land influences; hence the chief peculiarities of the zone are periodicity and variability, and we have here, more than anywhere on earth, fluctuating conditions. The relative area of the sea-shore exposed during tidal absence depends on two chief factors, namely, the degree of slope and the vertical tidal range, and some idea of its extent may be gained from the statement that the total frontage of coastal foreshore in the United Kingdom is 9700 miles, and that the total area between high and low water marks is about 620,000 acres (Carey and Oliver, I918).

Before dealing further with the characters of the tidal area it becomes needful to consider a few of the vital characteristics of the sea, and the manner in which they modify and affect this zone and the life inhabiting it. 
Sea - water. - Osborn (I9I8) has summarised the opinions of a number of writers regarding the ocean and its waters. Among other points of interest he quotes the computations of T. Mellard Reade, J. Joly, Sollas, and Becker and Clarke, from which it is inferred that the age of the ocean since the earth assumed its present form is somewhat less than $100,000,000$ years. "The $63,000,000$ tons of sodium which the sea has received yearly by solution from the rocks has been continually uniting with its equivalent of chlorine to form the salt $(\mathrm{NaCl})$ of the existing seas. So with the entire present content of the sea, its sulphates as well as its chlorides of sodium and of magnesium, its potassium, its calcium as well as those rare chemical elements which occasionally enter into the life compounds, such as copper, fluorine, boron, barium-all these earth-derived elements were much rarer in the primordial seas than in those of the present time. Yet from the first the air in sea-water was much richer in oxygen than the atmosphere. As compared with primordial sea-water, which was relatively fresh and free from salts and from nitrogen, existing sea-water is an ideal chemical medium for life. As a proof of the special fitness of sea-water to life processes we have the remarkable resemblance in composition between the chemical composition of the chief body fluid of the highest animals, namely, the blood serum, and that of sea-water" (see Henderson, 1913).

Composition of Sea-water.-While it is easy to determine the total solids in sea-water, the percentage determination of the individual constituents is a matter of great difficulty. At the present time oceanographers agree in considering sea-water as a solution in which the individual constituents are always present in the same relative proportions, no matter how the degree of concentration may vary. Consequently, in any given sample, once the quantity of a single chemical constituent has been determined, e.g. chlorine, the proportion of the other substances maybe calculated. For this purpose use is made of Knudsen's tables, in which 
the quantities of the various constituents are given corresponding to the amount of chlorine determined. Another point to be considered is that in a dilute solution such as sea-water the salts will to a large extent be disassociated as ions, so that the compounds given in analyses represent arbitrary combinations. On the other hand, an analysis, such as we append below, which is that of Dittmar, implies that the solution obtained by dissolving the different saits in the proportions indicated in the proper amount of water would be similar in composition to sea-water (Lake, 1915). On an average 1000 grams of sea-water contain-

\begin{tabular}{|c|c|c|c|}
\hline Sodium chloride $(\mathrm{NaCl}) \quad \ldots$ & . & $27^{\circ} 213$ & rrams. \\
\hline Magnesium chloride $\left(\mathrm{MgCl}_{2}\right)$.. & . & 3.807 & " \\
\hline Magnesium sulphate $\left(\mathrm{MgSO}_{4}\right)$ & & $r^{6} 65^{8}$ & , \\
\hline Calcium sulphate $\left.(\mathrm{CaSO})_{4}\right) \quad \ldots$ & & $1 \cdot 260$ & و \\
\hline Potassium sulphate $\left(\mathrm{K}_{2} \mathrm{SO}_{4}\right) \ldots$ & ${ }^{\circ}$ & 0.863 & 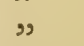 \\
\hline Calcium carbonate $\left(\mathrm{CaCO}_{3}\right) \quad \ldots$ & .. & 0.123 & " \\
\hline Magnesium bromide $\left(\mathrm{MgBr}_{2}\right)$ & . & 0.076 & " \\
\hline
\end{tabular}

The terms density and specific gravity have different meanings and should not be confused. Density is used when temperature is regarded as a variable factor, and is then usually considered as the relation betwen a given mass of sea-water at the particular temperature and the mass of an equal volume of distilled water at $4^{\circ} \mathrm{C}$. Specific gravity, on the other hand, is used when both terms of the relation are understood to be reduced to a constant temperature. The most usual method is to relate sea-water at $0^{\circ} \mathrm{C}$. to distilled water at $4^{\circ} \mathrm{C}$. It is assumed for purposes of comparison that the composition of sea-water taken from the open ocean is the same everywhere; in fact, standard sea-water. It is obvious, however, that the seamargin will generally show much variation from this mean in the vital matter of composition expressed as salinity, and that the distribution of the fauna will be correspondingly influenced thereby. Near large rivers and in estuaries the amount of fresh water will lower the density of the sea surface, often for miles, the effect varying, naturally, with the 
mass involved, and it is this surface water that comes in contact with the tidal zone during the rise and fall of the tide. The effect of such changes in salinity upon animal distribution may be important, as we shall have occasion to see later on. The average percentage of salinity for the open sea varies from $3^{\prime} 3$ to $4^{\cdot} \mathrm{I}$; the latter in the Red Sea. The Atlantic average is about 3.5 .

Density as recorded by the hydrometer shows seasonal variation largely in accordance with prevailing winds. It

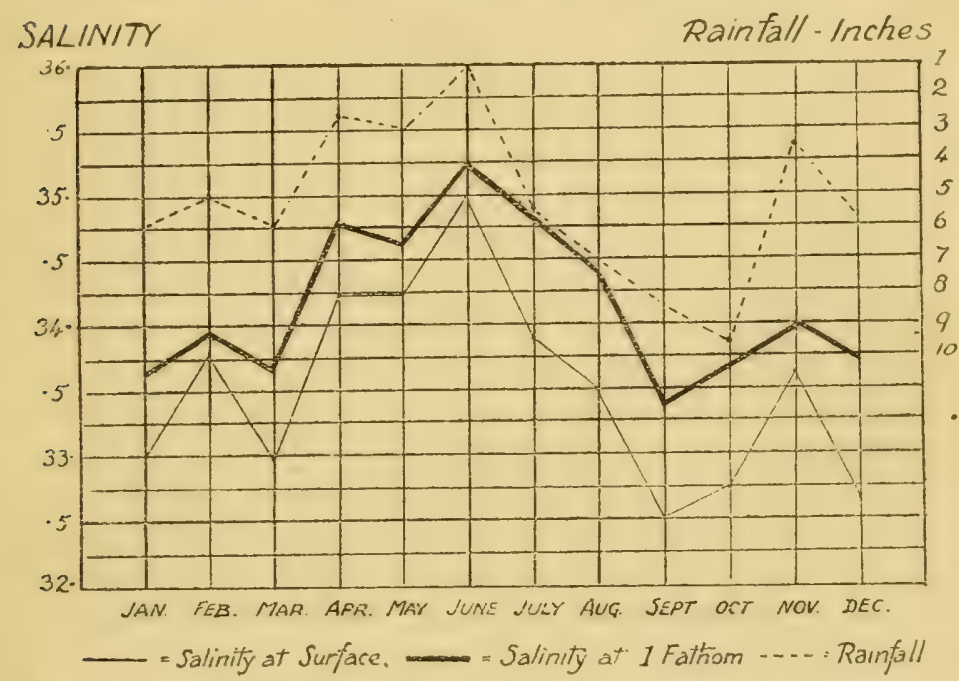

FIG. 2.-The relation between salinity and rainfall in Ballynakill Harbour (Southern, 1915).

varies also with the state of tide. In November, 1913, in the Dovey estuary in West Wales one of us found that the density varied between $\mathrm{I}^{\circ} 0265$ (temperature $\mathrm{I} \times 8 \mathrm{C}$.) with a high wind, and $\mathrm{r}^{\circ} 0048$ (temperature $9^{\circ} \mathrm{I} \mathrm{C}$.) at low water.

The relation between salinity and rainfall is well shown in the above graph (Fig. 2) compiled by Southern (I9I5) from data obtained in Ballynakill Harbour, Ireland, in which " the salinity curve responds with fidelity to that of rainfall." Discussing these results Southern points out that 
" in a shallow bay like Ballynakill Harbour, a large proportion of the water is renewed from outside at each tide. . . . Ballynakill Harbour is partially surrounded by high hills and several rivers flow into it. After heavy rain the fresh water streams down on to the surface of the bay and in calm weather forms a distinct layer of low salinity on the surface." Further, it was found that the difference between the salinity at the surface, and at a depth of one fathom varied directly as the rainfall, and inversely as the amount of wind ; the lowest surface salinities were found on calm days after rain. The density of the water of rock pools may oscillate from a little above I to about I'220. Further, the solubility of oxygen diminishes with increase of salt and still more with increase of temperature, with consequent effects on animal life. Nitrogen exchange in the sea can be modified by certain bacteria which can fix free nitrogenous compounds (nitrates, nitrites, and ammonia salts). In the warmer seas in particular bacteria are of importance, and in the region of the Great Bahama Banks chalk mud is precipitated by $B$. calcis. Such bacteria swarm in the shallow coastal waters and have the power of secreting and precipitating lime, and at the same time of converting nitrogen combinations (Drew, I9r3). Loeb also dwells upon the importance of the bicarbonates as regulators in the development of marine organisms, by keeping neutral the water in which these animals live.

Vegetation in Relation to the Alkalinity of Seawater.-The effect of vegetation in promoting alkalinity and the importance of this to the animal life is discussed by Shelford (I9I6), who discovered a surprising difference (which is constant) between the waters of the two sides of Friday Harbour, San Juan Island, Puget Sound. The water on the south side is always more acid than that on the north side, the latter being usually neutral or slightly alkaline and at times, especially at the end of a sunny day, decidedly alkaline. Water pumped from the acid side into tanks has never been satisfactory for aquarium purposes, and animals do not develop well in acid water. The oxygen 
content of the water also was higher on the north side, where vegetation is abundant, and often, in this vegetation, reached nearly twice saturation. On the south side the oxygen content rarely reached saturation. Herdman quotes Moore (1915) as to the greater alkalinity of the sea in spring than in summer, and considers that testing the water for alkalinity may be said to be merely ascertaining and measuring the results of the photosynthetic activity of the great seasonal phytoplankton rise in spring due to the daily increase of sunshine.

Light.--The effect of light on life processes is known to be profound, and the abundant illumination of the shore zone is one of the chief reasons for its suitability as a haunt of life. With increasing depth the amount of light which penetrates rapidly diminishes, the red rays being absorbed the first, then the yellow and so on, absorption occurring in the order of the spectrum. The degree of illumination varies considerably, being modified by local climate and by physiographical features; similarly the extent to which light may penetrate varies with the transparency of the water. In particular, the distribution and character of plant life are governed by light; in the sea beyond a certain depth plant life is entirely absent. Algæ living at a given depth receive light of different quality from that received at a higher or lower level. It was once thought that pigments supplementary to the chlorophyll enabled the plant to utilise light rays of a quality useless to the latter, and that consequently the powver of an alga to grow at a given depth depended on the presence of a particular pigment. While, however, it is an undoubted fact that algæ living at different levels tend to differ in colour (for instance, at a certain depth red algæ predominating sometimes almost to the exclusion of other forms), this explanation cannot now be accepted without considerable modification (Sauvageau, I920). To speak of the succession of colours in the narrow tidal zone as being explicable on this basis is inaccurate.

Temperature.-Coastal waters in the temperate regions display very considerable seasonal and even daily variations. 
In the Gulf of Kiel the mean monthly temperature varies between a maximum of $14^{\circ} \mathrm{C}$. and a minimum of $15^{\circ} \mathrm{C}$. (Semper). Great range is experienced within the tidal zone, since it is liable to exposure to frost in winter and the full glare of the sun in summer ; and the waters bathing it tend to be similarly affected, since the more shallow the water, the more readily will it be influenced by temperature variations.

The mean annual temperature of the sea-water off the western coasts of Great Britain is from $10^{\circ} \mathrm{C}$. to $13^{\circ} \mathrm{C}$. Off Labrador it varies from $2^{\circ}$ to $5^{\circ} \mathrm{C}$. In the tropics the surface temperature generally exceeds $267^{\circ} \mathrm{C}$. Sea-water freezes at $-2^{\circ} \mathrm{C}$. (see Johnstone, I908; Fowler, I9r2; Allingham, I9I7). One of us found the surface waters of the Dovey estuary to vary between $9.0^{\circ} \mathrm{C}$. and $12.2^{\circ} \mathrm{C}$. during November, 19I3. Southern (op. cit.) gives some very interesting data obtained during the Clare Island Survey. For Ballynakill Harbour the result of daily observations taken in 2 fathoms of water ( 9 a.m. readings) showed that the mean surface temperature is higher than the mean bottom temperature from May to August; lower from September to March, and equal to it in April. The figures for 1902 showed the highest record to be $19.6^{\circ} \mathrm{C}$. on June 30 ; the lowest $3.30^{\circ} \mathrm{C}$. on January 28 , and the annual range $16.3^{\circ} \mathrm{C}$. The greatest difference within twenty-four hours was $4^{\circ} \mathrm{I}^{\circ} \mathrm{C}$. on June 30 .

Effects of Ice.-Portions of the coast are at times during the winter more or less completely frozen over, and small harbours may have a thick covering of ice. Sheltered portions of the coast which are not exposed to surf or strong tidal currents may become fringed with ice. The movement of ice, along the shore and through channels, serves to scrape bare the large stones and boulders wherever they are exposed, so that they may be almost or entirely free from algæ in the spring when the ice disappears. At times, also, the common barnacle (Balanus balanoides) which covers their surfaces in summer may be removed. Rocks which are perfectly bare after the winter become thickly covered during spring and summer with algæ (Davis, r9I3). 
The Tides.-A factor which is of immense and fundamental importance in shaping the area we are studying and in influencing the life upon it is that of the tides. These may vary greatly in relative force and extent, ranging from practically nil to a rise and fall of many feet, with corresponding effects on the fauna. In Britain the biggest tides occur in the Severn estuary, the mean range of spring tides at Chepstow being 42 feet, and of neaps 21 feet. In France, at St. Malo, spring tides range $42^{\circ} 5$ feet and neap tides I 8 feet, this being the maximum for that country. The tidal range in the Dee is 26 feet at springs and I2 feet at neaps, the mean range of spring tides round the coasts of Great Britain being $16{ }^{\circ}$ feet and of neap tides 8.6 feet. (These data are taken from an article in Nature, vol. I05, June 3, I920.) The causation of the tides is too well known to need lengthy description. Briefly, since the moon attracts the side of the earth nearest to it more strongly than the centre, and since, moreover, the water surrounding the earth is attracted most strongly of all, the waters on this side yield and are heaped up beneath the moon. On the other hand, since the moon attracts the side of the earth remote from it less strongly than the centre, and since, moreover, the water on this side is attracted least strongly of all, the waters, which are less attracted than the solid earth, bulge outwards on the side arvay from the moon also. (For a more adequate yet not too technical explanation reference should be made to Lake, Physical Geography, Cambridge, I908.)

High tides are thus produced at two opposite sides of the earth at the same time. This means that water has been drawn away from other parts of the earth, and consequently at two opposite points half-way between the two high tides the sea is below its normal level and there is low tide. As the earth rotates on its axis every meridian comes opposite the moon in turn, and a rotation occupying twenty-four hours, there are normally two high tides and two low tides in that period. The lagging of the tides, or the difference of roughly fifty minutes in the time of high or low tide on successive days, is due to the fact that while the earth is rotating 
on its axis the moon is moving in the same direction round the centre of gravity of the earth and the moon, and the earth has consequently to make a little more than a complete revolution before a particular meridian is again beneath the moon.

The differences in height of tide are due to the greater or lesser degree in which the attractions of the sun and moon coincide or are in opposition. With the moon in the first or last quarter, moon and sun form a right angle with the earth's axis and, the attraction of the one tending to neutralise that of the other, neap tides result. With new and full moon, all three bodies are in the same straight line and, the effects of sun and moon coinciding, we get spring tides. The great tidal wave produced in the way described sweeps round the earth with a velocity of 480 to 660 miles per hour. The proximity of land reduces the velocity of the oceanic tidal wave, and local interference (due to local coastal configuration) causes calculations to become in many instances a matter of some uncertainty.

It is important for us to follow the course of the tidal wave in British waters. The wave reaches the British Isles from the west, and on meeting Ireland divides into two. Of these, the southern portion is again divided by the Cornish peninsula, one branch going up the Irish Sea and Bristol Channel, the other travelling up the English Channel. The northern portion (after sending a small offshoot to the Irish Sea) has travelled round the north of Scotland and down the east coast to mingle, in the southern part of the North Sea, with the Channel wave of the next tide, having taken, owing to its longer course, exactly twelve hours more to reach this particular spot than the Channel wave. Reference to the co-tidal chart will make this clear.

Where the tide can enter a sea from both ends there may be various modifications of the normal tidal rhythm. For instance, along the Hampshire coast there are four tides a day, owing to tidal waves entering the stretch of water between the Isle of Wight and the mainland from both the east and west ends. Similarly one tide may serve to neutralise 
the other. It is possible that these anomalies may have

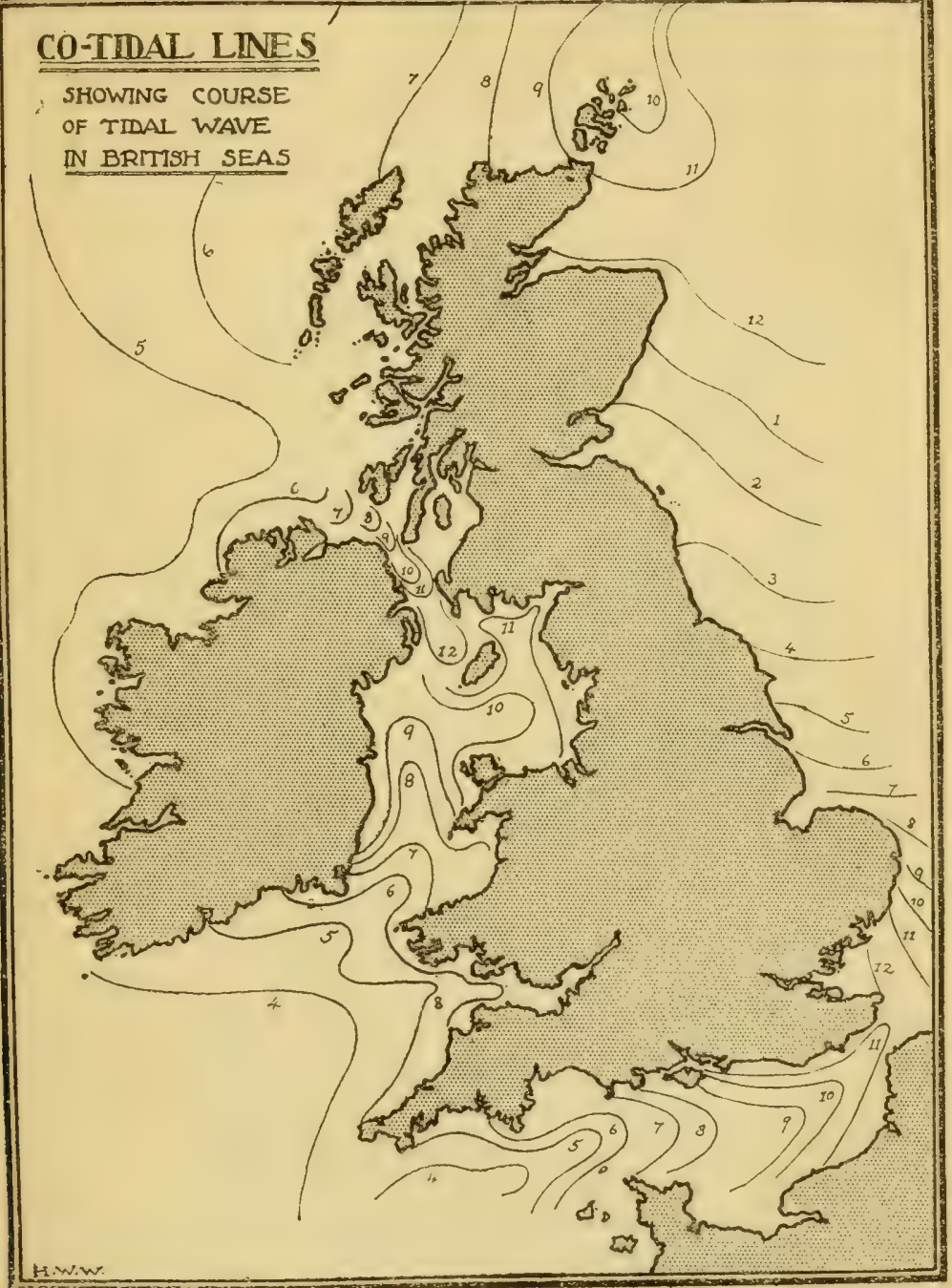

FIG. 3.

effects on the tidal fauna, although no attention appears to have been paid to them from this point of view hitherto. Wind causes great perturbation in tidal range and will 
heap up or depress it many feet, especially if of long continuance. In the North Sea the maximum effect is produced by a N.N.W. wind, and it is recorded that such a gale in I 905 caused an extra rise on the Suffolk coast of 6 feet 3 inches. Water is warmer when the wind blows toward land, and the reverse also holds good; on-shore winds pile the warmer surface waters up against the coast, and the colder bottom waters escape seaward (Johnson, op. cit.).

According to Johnson (1919) the tides may best be considered as great waves which combine some of the features of both oscillatory waves and waves of translation (see "Wave Action," p 32). There is a shoreward movement of the water particles until the time of high tide, after which a seaward movement takes place. In water 30 metres in depth a tidal rise of 3 metres should result in currents of $\mathrm{I}^{\prime} 7$ knots; with 4.5 to 6 metres it would attain over 3 knots. In the Channel between Scilly and Hastings the tidal velocity is 2 miles an hour; in the N. Wash, 4 ; off Ushant, 6 to 7 ; through Petite Passage, S.W. of Digley Gut, Nova Scotia, not less than 8. In the Severn estuary the speed is 6-12 miles (according to Sollas), and Kurmmel cites 8-10 between Orkney and Shetland, II in the dreaded "Roost" of Pentland Skerries. The transporting and croding power of such currents is enormous. A velocity of but 4 knot will drive ordinary sand along the bottom, while fine gravel will be moved at I knot; shingle about $I$ inch in diameter at 2.5 knots, and angular stones $I \frac{1}{2}$ inches in diameter at 3.5 knots. As the currents continue for many miles in the same direction, they must play a very important rôle in the transportation of shore debris. Tidal currents do not always, or even commonly, act in a direction which the lie of the shore-line would indicate as normal. Along the sides of a bay or headland whose axis is in the line of tidal advance, the currents may be parallel to the shore. Shoreline irregularities will deflect the tidal waters, giving longshore currents in all possible directions. It is also a well-known fact that a narrowing bay compresses a tidal wave into smaller space, and constrains it to rise higher. "In bays and sounds 
the swiftest tidal currents follow the deepest channels, and are therefore not as directly effective in shore processes as when they infringe upon an exposed portion of the coast . . . however ... they remove vast quantities of debris originally eroded from the land by wave action or carried to the sea by rivers, and then transported by longshore currents . . . until brought within the influence of the inflowing or outflowing tidal current. The inflowing tide sweeps the finer material far up the bay, where it is deposited in mud flats and tidal marshes . . . while the coarser sand is moved landward a much shorter distance, often forming bars along the channels. In estuaries because of the river water usually poured into a bay the ebb current predominates over the flood, and the direction of debris migration is prevailingly seaward" (Johnson, op. cit.).

Circulation of British Waters.-According to Herdman (I9I9) three masses of sea-water of different origin and character may enter or affect the British seas in varying quantity.

1. Arctic water, such as normally surrounds Iceland and E. Greenland, and may extend towards Norway, the Faroes, and Shetlands.

2. Atlantic (or Gulf Stream Drift) which impinges on the western shores of Ireland, and may flood the English Channel and extend round the Shetlands or down into the North Sea.

3. Coastal water, such as flows out of the Baltic, and, mixed with other waters, bathes the coasts of N.W. Europe generally, and to a large extent surrounds the British Isles.

The Irish Sea is regarded by Herdman as primarily an area of coastal water which is, however, liable to be periodically invaded to a greater or less extent by bodies of warmer and salter Atlantic water (reinforced possibly by a portion of a deeper outflowing Mediterranean current) carrying in oceanic plankton; and more rarely, perhaps, by Norwegian or Arctic water causing an invasion of Northern organisms.

The variations which are found in different years in the nature and amount of the plankton at the same localities no 
doubt depend to some extent upon the volume and period of such southern or northern invasions; but they may also depend upon other factors, such as the weather (temperature, sunshine, rainfall, wind, etc.), at the time and previously.

Wave Action.-This has a very decided effect upon shore life and varies according to the depth of water, exposure to prevailing winds and their relative force, shelter (visible or submerged), character of shore-line, and other factors. The following remarks are taken largely from Johnson's recent work, already referred to.

Waves are of two chief kinds: waves of oscillation and waves of translation. In waves of oscillation in deep water, each water particle moves through a circular orbit, the particle moving forward on the crest of the wave, downward on the back, backward in the trough, and upward on the wave front. When this form of wave passes into shallow water, it becomes higher and shorter, the front steepens, the crest arches forward, and, finding itself unsupported by sufficient water on the front of the wave, dashes downward in a roar, producing the phenomenon known as the "surf"; the individual breaking wave being known as a "breaker," or less frequently as a combing wave.

The initial height of waves of this type depends upon (I) the strength of the wind, (2) its duration, (3) the extent of open water over which it blows. A faint breeze sets in motion very small waves, which increase in size to a certain limit, but which would never become billows. In the trade wind belt the maximum height of a wave for a certain strength of wind is soon reached, and, although the wind may continue steadily for days at a given strength, there is no increase in the size of the waves. In very severe storms the highest waves may not occur when the wind velocity is at a maximum, but may develop as the wind begins to subside, the excessive force having blown off the wave-tops and cast them into the preceding troughs. The size of waves may increase very rapidly, and Cornish records an increase of seven feet during a squall lasting four minutes. The following are approximate wave heights: Mediterranean Sea, 
25-30 feet; North Atlantic, 43 feet (maximum); North Pacific, same; Southern Ocean, 45-50 feet. Combined waves may reach 50-65 feet. Swells seldom exceed 15-20 feet, and near the coast may be reduced to a few feet only. Entering shallow water they seem to awaken to new life, crowding closer together and increasing in height until they break, at which time they may be anywhere from a few feet up to 25 feet or more. Waves striking a vertical rock surface are reflected back without breaking, the water next the wall moving up and down through a vertical distance to twice the original height of the wave.

Regarding wave velocity, Johnson states that if a wave be 400 feet long and I 5 feet high the velocity will be about 45 feet per second in deep water. In shallow water waves move less rapidly.

In waves of translation the water particles move forward as the wave passes, but do not exhibit a compensating backward motion. While not important in the open sea, this type is extensively developed in the shallow water along all coasts, the waves of oscillation generated in deep water becoming more or less completely transformed as they approach the shore. Immediately before and after the passage the surface of the water may be quite still. The surface-water particles rise and move forward, descending again to the original level in an advanced position, the paths of the particles being semi-ellipses. The velocity depends upon the depth of the water measured from the crest of the wave.

That this question of wave movements is not merely of theoretical interest to us is evidenced by a theory of Hurst's (1893) to account for the presence of the tentaculocysts of medusæ. According to this writer the tentaculocysts function in a manner directly related to the water movements produced by waves and, by their automatic response thereto, serve to maintain the animal in the zone of optimum tranquillity.

An important factor in the work of waves is the effect produced by stones, logs, blocks of ice, and other objects 
moving with the waves. Large storm waves may break against a cliff without removing the barnacles which are attached to its face, but this merely indicates that the pressure of the liquid mass is so evenly distributed upon all sides of the strong shell, that the excess of pressure on any one side is not sufficiently great nor applied with sufficient suddenness to cause rupture. The same waves will wrench great blocks of rock from their places, and drive air and water into joint-crevices with such force as to loosen large fragments of cliff. According to Lake (I9I5), "the waves of the sea continually falling upon the shore gradually wear away the land, whether its margin is a shelving beach or a steep and rocky cliff. If the coast consists of loose material, the waves themselves may wash away the fragments, but if it is formed of firm and solid rock their action is indirect. The pebbles and boulders that they throw against a cliff serve as battering rams, and the face of the cliff is slowly broken up, especially at its base. Most rocks, moreover, are fissured, at least to some extent, and the fissures are filled with air. When a wave rises against a rock or cliff, the air in the fissure is compressed ; when the wave falls away the air expands. By this alternate compression and expansion the fissures are enlarged and masses of rock are broken off. ... If the shore slopes gently into the sea, the action of the waves is almost entirely confined to the part between tide-marks, extending only a little below the true high-water and in heavy storms a little above the true high-water level. Consequently this part of the land is worn away and the material so worn is deposited between tide marks and below low-water mark." The sea will continue to act for some time upon the cliff and the shore will gradually be widened. At length, the beach becomes so broad that the waves no longer reach the cliff; and unless the beach material is removed by some means, erosion by the sea will practically cease

Much also depends upon the stratification and jointing of the rock, as to the manner in which erosion will act. Soft rocks erode easily, while the harder they are, the 
greater the resistance offered; if the coast-line consists of rocks of different texture, the soft beds are worn into bays, etc., and the harder beds stand out as promontories. Eroded material may be removed below low-water mark, or drifted laterally by currents and piled up elsewhere, with the result that the land loses at some points, but gains at others, while shingle banks, spits, and sand banks and bars are also formed. It has been estimated that between the years 1863 and $1896,35,444$ acres were added to, and 4692 acres lost to the United Kingdom through erosion. Lake (op. cit.) also makes an interesting comparison between the coasts of the west of Scotland and that of Cardigan Bay, in West Wales. "Wales, like Scotland, is an ancient rocky highland partially submerged, but while the west of Scotland is deeply indented the shore of Cardigan Bay is comparatively smooth. In the west of Scotland the tide approaches and recedes at right angles to the general trend of the coast, and the ebbing tide helps to keep the firths and lochs free from deposits. In Wales the tidal wave runs along the coast and sweeps the loose material into the sheltered inlets. It is because nearly all the inlets are filled with deposit that the outline of Cardigan Bay is smooth." Protection, with the effect of reducing scour to relatively harmless proportions, is a most important factor. The effects of moving sand banks can be well studied in connection with the fauna of estuaries, and those of shingle on many rocky shores. A certain amount of water movement, on the other hand, is needful to provide oxygen content for life processes, while tidal sweep and local currents play a considerable part in faunal distribution.

Many attempts have been made to classify the Littoral Area-of which the tidal zone forms the upper portioneach largely influenced by the particular region investigated. Davenport divides the shore at Cold Spring Harbour Sand Spit into (I) The Submerged Zone : all that portion of the beach below mean low tide, but which may be exposed by the lowest spring tides; a region usually covered with water. (2) The Lower Beach : this lies between mean low 
tide and mean high tide, and is twice daily exposed to air and submergence. (3) The Upper Beach : only reached by extreme high tides. From the geographical standpoint this is a satisfactory division that can be applied to practically all shores, and may form the basis for other subdivisions from the biological standpoint. Johnson (op. cit.) discusses this matter in an interesting manner. "The line where land and water meet has been called the shore-line, the strandline, the coast-line, and the water-line. The terms shore, beach, strand, and coast are also loosely used with varying significance. ... Four zones extend from low water to the base of the cliff, whether large or small, which usually marks the landward limit of effective wave action. This is the zone over which the water-line, the line of contact between land and sea, migrates: and it will here be called the 'shore.' Landward is an indefinite zone, the coast. The boundary between coast and shore is the coast-line. The lowtide shore-line marks the seaward limit of the intermittently exposed line, and we have likewise the high-tide shore-line. The shore is subdivided into two minor zones : the foreshore daily traversed by the oscillating water-line, and the backshore covered by exceptional storms only." At the seaward coast edge is the wave-cut cliff, varying from an inconspicuous slope to a high escarpment. In front of this, occupying all the shore zone and part, or all, of the shore face, is the wave-cut bench, a sloping erosion plane inclined seaward; lastly, we have the more extensive, nearly horizontal plane produced by long-continued wave erosion, and commonly called the abrasion platform. At the outer margin of this there accumulates an extensive deposit of material moved across the platform and deposited in the quieter water-that is the continental terrace, which together with the abrasion platform makes the continental shelf. Areas where erosion is active are naturally not able to support a rich fauna, and are particularly unsuited to sessile forms of life. The artificial regulation of rivers and harbours may cause great alteration in local conditions. The type of local rainfall and rock (or soil) porosity will determine whether a 
river is subject to marked fluctuations, or maintains a more or less steady flow. The number, size, and proximity of large towns usually seriously affects its purity, through pollution with sewage, or the waste of manufactures. Coastal configuration, and local currents and wind direction determine largely the subsequent direction taken by the mass of river water on reaching the coasts, and even when no river is present a shore-line may be considerably affected by seepage and the action of springs.

The shore can be considered in relation to one or other of three chief physical types: (I) rock, (2) sand, (3) mud, with a number of sub-types within each type and between the different types. The rocky type varies greatly according to the kind of deposit forming the shore, and the manner in which its erosion proceeds. A vertical cliff face descending sheer into water of considerable depth ; slopes of varying degree; and reefs, may all appear in the same locality, and show either considerable uniformity or diversity of surface, as the strata or rock masses are uniform in texture or resistance, or dissimilar in structure, or show different degrees of contortion, fracture, or faulting, and hence weather irregularly, giving a series of exposed and sheltered situations which offer different types of environment for plant and animal life. A steep cliff may have at its base a mass of boulders, shingle, an erosion plane, or sand (rarely mud) and pass laterally into the sandy or muddy types, or into shingle beds. Several distinct types may occur along a line drawn straight from high to low water levels, where a successive geological series may appear. Volcanic rocks frequently present a smooth surface, unsuited for attachment, while a sandstone of fine texture will support a richer fauna than one of coarse grain. Limestone often wears into many hollows and fissures and gives ample protection. Conglomerates and drifts weather into loose detritus and are faced with, and provide material for, shingle banks. Sand, whether derived from the erosion of sandstone, or comminuted shells, etc., varies considerably in texture, weight, and other characters, and according to degree of admixture passes into mud. 
The mud, again, shows all degrees of texture and composition according to homogeneity, or admixture of vegetal or other matters. These two, sand and mud, may be in situ, or transported from some distance by current or river action, and may (together with shingle derived from glacial drift) obscure the local substratum.

Mud deposition denotes shelter, and is chiefly found in estuaries, creeks, and other inlets, while sand may occupy great stretches of open coast, though requiring shelter and the accompanying stability in order to show its maximal faunal development (within the tidal range).

Plants may play an important part in causing changes, chiefly within estuaries, as in the case of Spartina townsendii at Poole, and other places, where it rapidly advances, converting the mud flats into firmer ground and raising its level above marine influence. The Salt-wort (Salicornia) and others may have a distinct effect, while, on open shores, stony algæ, such as Lithothamnion, form considerable, hard masses. Rocks give shelter in their crevices to various animal forms, and, on the other hand, compact colonies of sedentary species, such as Balanus, Mytilus, and encrusting algæ, protect the surface of rocks from destructive marine action (Issel, 1918).

Davenport (op. cit.) describes a constant struggle taking place at the top of the Cold Spring Sand Spit, between the upbuilding tendencies of the Spartina and the scouringaway tendencies of the tide. There is a tendency to form channels at weak spots in the Spartina. These channels widen and anastomose, and thus little hummocks are formed ; but these are prevented from being washed away by an interesting association. The current that rushes through the channels carries with it an abundant supply of microscopic food such as Lamellibranchs can make use of. The food is taken advantage of by the mussels which come to line the muddy banks of the channels and form so close a wall that erosion is almost completely stopped.

The importance of the activity of rock-boring organisms in the gradual disintegration of rocks must not be overlooked, 
and their action has been well reviewed by Jehu (1918). The bivalve Pholas operates at extreme low water, each generation cutting a series of auger holes $2-4$ inches deep, the weakened intermediate portions being readily broken down. Sponges of the genus Cliona ( $C$. celata being the most important species) attack shells and calcareous rocks and riddle the surface with small holes, which intercommunicate below. As to how the boring is accomplished, the theories of foot suction, rotation of shell valves, hard particles in the foot, acid secretion, spicula action, etc., have been either not proved, or disproved ; probably, in the case of Cliona, certain special cells are protruded through the epidermis and absorb calcareous matter (as the osteoblasts of the vertebrates absorb bone).

A small Annelid worm, Leucodora, destroys chalk, etc., and also perforates sandstone, shale, and mica-schist, and at St. Andrews occurs in soft blue shale. In some French localities 250,000 to 300,000 per square metre are said to have been enumerated. Of others, the tube-worm Sabella, the Mollusc Saxicava, and the Echinoderm Strongylocentrotus may be noted. The latter occupies thousands of depressions at about low-water mark on the coasts of Clare, Cork, and Donegal Bay (Ireland); in the nummulitic limestone of Biarritz Fischer noted from 20 to 100 on the floor of troughs of rock; they also occur in the walls of pot-holes, and in sandstone, granite, lava, etc.

To sum up : diversity of rock surface and a sufficiency of shelter, which modify wave action and erosive power, are the most favourable factors influencing shores of all types, from the biological standpoint. Uniformity of physical conditions over considerable areas and distances leads, however, to the most pronounced and well-marked (if more limited) faunas. 


\section{CHAPTER III}

\section{The Shore and its Plant and Animal Associations}

IT has already been pointed out that, whereas the fauna extends to the greatest known depths, the vegetation of the sea is definitely limited to the surface and shallow waters. In contrast to the deeper waters, therefore, we find that the shore presents the same typical combination and interaction of plant and animal as is seen on land, except that life here functions in both media, air and water, by turns. The life factors are thus duplicated. In passing from entirely land to purely marine conditions, we traverse this region, which may be considered as a region of fluctuation and of evolution; a region wherein are to be found the most complex conditions of the whole globe.

We have firstly the upper limits of sea action, the zone only reached by spring tides; next, the typical shore zone lying between the high and low water marks of ordinary tides; below that, a zone only exposed during low spring tides : these make up the shore. Below it we have a region which, although still affected by some of the conditions of stress (wave action, etc.) found on the shore, nevertheless contains vegetation and enjoys abundant light; tidal phenomena are eliminated. As we proceed seaward we gradually eliminate two further factors of importance, namely, wave action and light. With the latter, plant life is also eliminated, with all that it means to animals, while the absence of wave action frees the fauna from another (generally adverse) set of factors. We thus get a simplification of the environmental factors as compared with the land fauna, and especially with that of the shore. The shore, then, is 
the specialised, upper portion of the Littoral which encircles the land margin and is usually considered to end at a depth of Ioo fathoms. The extent of the Littoral varies with the structure of the region under consideration-the British Isles, for instance, are situated on a submarine plateau which forms part of the European "Continental Shelf," and the Io0-fathom limit will be found to include a portion of the Atlantic to the west of Ireland and Scotland; the Irish Sea ; the English Channel and the North Sea. Much of the North Sea has a depth of less than 300 feet and, except in a few places, the whole is less than 600 feet.

Algal Associations.-As has already been indicated, the interaction of the numerous physical peculiarities of the tidal region has resulted in a sorting out of the shore population into series capable of inhabiting the successive horizons or zones that occur between high and low tide marks. This "zoning" is one of the first facts that strikes an intelligent observer. The algal life is affected, and through it the animal life. Where conditions vary, zones will vary. Particular strata spread out when conditions are favourable, and "pinch out" when the struggle becomes too severe (Pearse, 19r4).

Marine vegetation falls into two great subdivisions:

I. Free-floating or free-swimming plants: Plankton (haloplankton).

II. Fixed plants : Benthos (Warming, I896).

It must be noted that, in contrast to the vegetation on land, the fixed vegetation of the sea is greatly localised (Petersen and Jensen, I9II). Cotton (I9I2) distinguishes three main regions :

I. The Littoral region, extending from the level of highest marine vegetation to that of low-water mark, neap tide.

2. The Sub-littoral, which begins from the lower limit of the last named, and extends down to the limit of seaweeds (about 25 fathoms).

3. The Elittoral, which is devoid of vegetation.

He further recognises three principal formations (for the west of Ireland), (a) rocky shore formations, $(b)$ sand and 
sandy mud formations, $(c)$ salt marsh formations, and in addition $(d)$ vegetation of river mouths, $(e)$ vegetation of brackish bays.

Johnson and York (I9r5), as a result of their investigations carried out at Cold Spring Harbour (U.S.A.) between I905 and I9I3, recognised five vegetational zones or belts. I, Plankton; II, Bottom Vegetation; III, Mid-littoral belt (I'5 to $6{ }_{5}$ feet), characterised by Spartina glabra, Fucus, Ascophyllum, etc.; IV, Upper Littoral belt (8-I2 feet) vegetation varied, Salicornia, Spartina patens, Suada, Scirpus; V, Supra Littoral belt (8-I2 feet) less clearly defined; chief plants Ammophila, Solidago, Salsola, Cakile, Scirpus, Lathyrus, Aster, and others. The authors believe that " the vertical range of a littoral plant is exactly proportional to the range of the tide and give "Habit Analysis Tables" for each plant, with the following particulars: salinity of soil water; light demands; upper limit ; lower limit; average emergence per lunar day; average submergence per lunar day; ratio of submergence to emergence : $(a)$ at lower limit, $(b)$ at higher limit.

Currents disseminate seeds and spores, and break off and transport shoots of Zostera, Ulva, Fucus, etc.; or on the other hand retard extension by causing mechanical injury. Rapid movement favours some forms by increasing the interchange of material between plant and water, and possibly also by excluding competitors (Johnson and York, op. cit.).

On the open shore organic matter cannot accumulate much, nor in strong currents and tidal scour. Only in the sheltered parts of estuaries, creeks, lagoons, etc., can such deposits take place in quantities. On the open coast decaying organic matter (animal and vegetable) may be found under fixed stones, boulders, etc., and there offers a suitable habitat to certain types of animal life. Atmospheric moisture plays an important part in connection with the littoral vegetation, and the problem of desiccation during low tide is complex; latitude and the accompanying climatic conditions (wind, sunshine, etc.), together with situation and aspect, cause 
many local variations in distribution and extent. Each of Cotton's five formations enumerated above consists of a number of associations, and these may be grouped in a manner which varies considerably in different localities.

It should also be pointed out that many species appear periodically, some being but short lived, and conspicuous only for a few weeks, while others require six or eight months to complete a life cycle. Owing to these seasonal phases the varying zones may present very different appearances and offer different degrees of protection and food supply to their animal inhabitants during the course of the year, and thereby profoundly affect their life-histories and distribution.

The methods of attachment of algæ to the substrata are of some importance also, as the typical stout disc frequently offers shelter to considerable animal communities. Algæ with a membranous thallus may be found on the smooth faces of schists, quartzites, etc. Yendo (I9I4) found that pure cultures of Glcoopeltis can be obtained by laying quartzite as a substratum while, for Laminaria, andesitic and basaltic stones are found most useful (by the seaweed cultivators of Japan), as they are hard, yet have many minute surface cavities which afford resting-places for the spores. Soft stones-sandstones, conglomerates, claystones, tuffs, etc.-are unsuitable; only small algæ can grow on them : if large, the resistance offered to the water movements may cause the plants to come off. One or two local phenomena may be also noted, such as the extension of algæ even far above the spring-tide limit, in situations where much spray, shade, and terrestrial moisture combine to render such a condition possible, as in the Faroes. Sunlight is of course essential for algal growth, and algæ may be absent from vertical cliffs with a northern exposure (Pearse, 1913-14).

As is well known, botanists classify plant zones, associations, etc., by using the names of the dominant species in each. Since algæ are abundant on almost all rocky shores, this nomenclature can be conveniently used in describing almost all the various types encountered, though some 
difficulties occur in dealing with wide sandy and muddy areas which are largely barren of plant life, in which case the name of a dominant animal species must be used.

The first zone encountered is either the Salicornetum (typical plant Salicornia, the Salt-wort) of muddy or sandy coasts, or the Enteromorpha Association. The latter, however, varies in position with regard to the manner in which fresh water appears along the shore-line. At times it forms a bright green band near high-water mark, but by the end of summer much of it may have been killed by drought, and then appears as a band of white dead tissue (Cotton, I912). The succeeding Fucaceæ Association, typical of exposed coasts, is of especial ecological value and affords a good deal of shelter for other forms. Cotton $(o p$. cit.) gives the typical sequence of species from above downwards, as follows: I. Pelvetia canaliculata. 2. Fucus spiralis (disappears under very sheltered conditions). 3. Ascophyllum nodosum (needs a moderate amount of shelter). 4. Fucus vesiculosus (cannot stand exposure). 5. F. serratus. 6. F. ceranoides (admixture of fresh water a necessity). Many epiphytic species take advantage of the size of, and shelter afforded by, these Fucoids which, when present in abundance, impart a most marked aspect to the shore, obscuring the rocks with their masses during low water, and waving in dense groves buoyed up by their bladders during the tidal period (cf. Plate VIII).

The Fucus Associations of Achil Sound showed the following widths :

A. Sloping shore, belt narrow.

I. Pelvetia, 2-3 feet.

2. F. spiralis, $5^{-6}$ feet.

3. $F$. vesiculosus, to feet.

4. Ascophyllum, io feet.

5. $F$. vesiculosus, to feet.

6. F. serratus, io feet.
$B$. Flat shore, belt wide.

I. Pelvetia, 5 yards.

2. F. spiralis, Io yards.

3. $F$. vesiculosus, 40 yards.

4. Ascophyllum and $F$. vesiculosus, 30 yards.

5. F. vesiculosus, 50 yards.

6. F.vesiculosus and $F$. serratus, 50 yards. 
Baker (1909-1910) states that the species of Fucaceæ inhabiting the upper portion of the tidal zone can resist desiccation both during germination and vegetative growth, and that those seaweeds that best resist this danger are of slow growth. On the other hand, those that grow rapidly are the least tolerant of desiccation, which factor would be sufficient to cause their exclusion from the higher zones.

Observations have recently been made regarding the density of these algal groves at Port Erin, Isle of Man, the weed being all cut away from a square foot of surface. In one case, at half tide, where Fucus commenced, 35 stalks of $F$. serratus were counted, in another instance 352 stalks of $F$. vesiculosus were found, arising from $\mathrm{I}_{2}$ " roots." On the upper edge of the Laminarian Zone 6 to 8 stalks of Fucus occurred and mingled with an equal amount of Laminaria ; 2 feet lower down the place of Fucus was entirely taken by Laminaria, at times 36 stalks to the square foot (Mayne, 19r8).

An interesting example of the interaction of plants and animals is furnished by a case of an excessive growth of Ulva investigated by Cotton (IgII) in Belfast Lough. Mussels can cover ground on which the common green alga Ulva latissima cannot find anchorage until preceded by mussels, which then form a suitable foundation. Absence of rough water is also important as otherwise the alga becomes torn. The Sea-lettuce has been proved to be able to thrive in either pure sea-water or polluted brackish water, to which latter it has probably become adapted. In polluted brackish water Ulva absorbs quantities of ammonia, and its tissues are found to contain a much larger proportion of nitrogen than those grown in pure sea-water. The results of this excessive nourishment are seen in an increased rate of growth; the fronds are of a different texture and darker colour, while there is also a tendency for spore formation to remain in abeyance, the growth being rank rather than healthy. The investigator considered that the Ulva, which was a decided nuisance in the locality, would not be suppressed until the mussels were exterminated. 


\section{THE BIOLOGY OF THE SEA-SHORE}

The vegetation of rock pools differs according to their situation within tidal range, geological nature, size, depth, configuration, temperature, illumination, and drainage. Their species are perennial and more or less constant. In upper pools encrusting forms are conspicuous (Cotton, I9I2). Pools may become too warm for certain species, while others are found in these situations beyond their normal limits, as in the case of some tropical species. Skinner (1903) found that the higher the elevation of the pool, the fewer the species, though the greater may be the number of the individuals; the more gradual the slope, and the rougher and more irregular the sides, the more abundant, however, becomes the plant life.

The Corallines and others are protected by a deposit of carbonate of lime. The Lithothamnion Associations which occur in Arctic, Temperate, and Tropic regions are often known as " Coral Banks," and play an important part in the formation of coral reefs.

The tidal zone in the tropics is, as a rule, poor in vegetation, and often absolutely barren down to I metre below low-water mark, except where the surf constantly breaks. This is due to the killing of spores and seedlings by intense heat; calcareous species such as Lithothamnion, however, may exist in enormous number. In other cases, in summer, the tidal algæ may become so dry as to break to powder between the fingers, and yet on the return of tide are able to resume their normal functions (Yendo, op. cit.). On the other hand, many algæ can survive temperatures below $3^{\circ} \mathrm{C}$, , but may succumb to the attrition of floating ice.

Mention must also be made of Maritime Lichens. Lichens occur on three forms of substratum. (I) Rocks (saxicolous) ; (2) bark of trees, or wood (corticolous); and (3) soil (terricolous). The shore forms naturally belong chiefly to group (I). They have been studied in several localities. Knowles (1913) described five belts for the Howth coast : (a) a wide belt characterised by Ramalina and extending landward from just above high water, $(b)$ the orange belt, due to species of Physcia and Placodium, (c) Lichina vegetation 
semi-marine, (d) the Verrucaria maura belt, normally occupying the shore between high neap and high spring tides, and $(e)$ a belt of marine Verrucarix, marine encrusting species submerged by the tide each day.

Finally, at the seaward margin of the shore is found the great Association of the Tangle weeds, Laminaria, only uncovered by spring tides, and accompanied by a rich fauna (see Plate X).

In addition to the horizontal zoning above described, there exists on the shore a distinct vertical stratification, affecting both the plants and animals. We find species of plants and animals forming associations of yarying heights above and below the general surface level (just as in a wood there are species on and under shrubs and trees, each showing sub-types), while epiphytic species may be found on all. Similarly, the animals inhabiting the sea-shore show both horizontal and vertical zoning. Different assemblages of animals accompany the different algal zones and associations, while there are distinct animal associations and communities of mud and sand attached to rocks or boulders, or boring into rocks ; living among algæ ; free-swimming, or floating ; all with their distinct and typical features. Some examples will be given shortly.

Numbers of Shore Population.-As to the actual number of species found within tide-marks, it is exceedingly difficult to give any accurate data, most enumerations of local faunas extending much deeper than low-water mark. Some of the faunas are extremely rich in species : Whitelegge (1889) enumerated 2136 species for Sydney Harbour; the Irish Sea yielded over 1680 species of Invertebrates; Trieste, I268 (Dr. Graafe), and Woods Hole the same (Sumner, 1913), while I2I3 were recorded for the Firth of Forth (Evans, 1909), etc.

Undoubtedly by far the largest number of the species inhabiting the tidal region occur between the limits of lowwater neaps and low-water springs. The species able to endure exposure to air every twelve hours are comparatively few in number (although there are a small minority that 
require periodic exposure) and every few inches below the limit of low neap tide adds numbers of species to the list, provided that physical conditions remain suitable (Farran, I9I4). As far as actual numbers are concerned the floating population (Plankton) very easily take first place. Although only temporary inhabitants of the shore they must play a very important part as food for the sedentary and sessile members of the shore communities during their periods of activity, when covered by the tide. Herdman (I9I9) states that during March or April some millions of Diatoms may usually be obtained by hauling a small silk tow net for about five minutes through about half a mile of the surface water of the Irish Sea; similarly during July-August tens of thousands (up to 214,000 ) Copepods may be thus obtained. Estuarine faunas show a marked paucity of species, as compared with rocky shores, although the actual number of individuals present may be large.

The number of individuals of certain species occupying quite a small portion of the shore is frequently enormous. Thus a square yard of a Sabellaria colony has been estimated by Herdman (1920) to contain nearly 30,000 worms (see Plate V). The same writer has shown that one square foot of rock may carry 2940 barnacles (Balanus balanoides). The wall of a cave at the south end of the Isle of Man was covered with the small red Ascidian Styelopsis grossularia at the rate of over 50,000 to the square yard. Counts of other common shore animals were made by the same writer, and gave the following results: Patella, an average of 29 to the square foot; Purpura (two counts), 72 and IoI to the square foot. The number of beadlet anemones (Actinia equina) found in rock pools averages over 46 to the square foot. Some idea of the numbers of lug-worms (Arenicola marina) present on a sandy shore may be obtained from the view shown in Plate VI. Ashworth (see Herdman, loc. cit.) estimated the number of these worms present between tide-marks in a portion of beach about a mile in length at 3 to 4 million.

The Animal Associations of a Rocky Shore.-The animals 


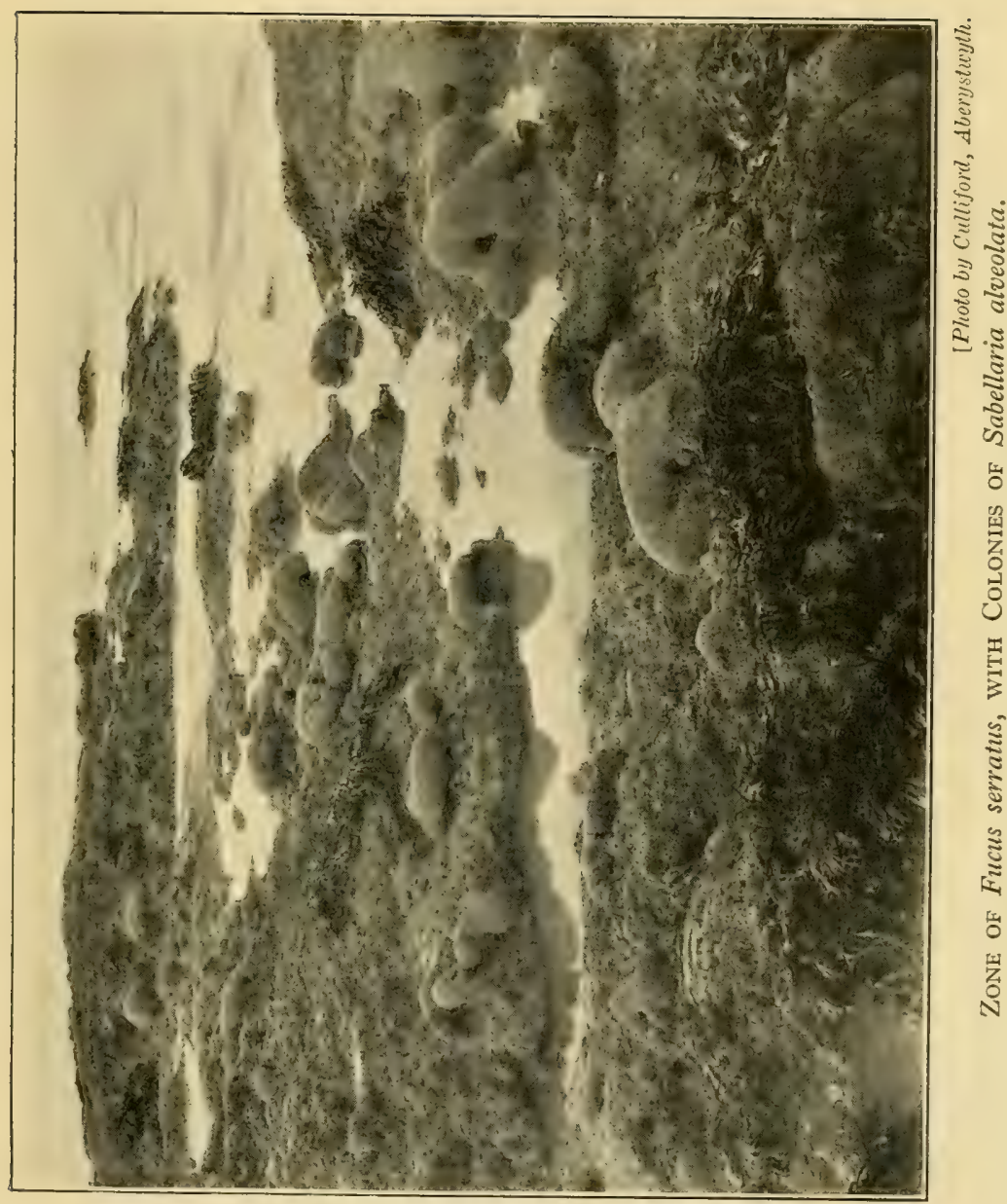

䃾 

of rocky shores can be conveniently studied in groups according to the positions occupied. Farran (19r4) arranges those of Blacksod Bay, Co. Mayo, as follows: $A$. Animals exposed to the air on stones, rock faces, or weeds ; $B$. Animals found under stones; $C$. Animals living in crevices of the rocks; $D$. Those living in Laminaria roots. Group $A$. includes such species as the barnacle (Balanus balanoides), the periwinkle (Littorina), dog-whelk (Purpura), Monodonta crassa, Gibbula umbilicata, and limpet (Patella). Low down but exposed come the sponges Halichondria panicea and Hymeniacidon caruncula. On overhanging rock faces, and not so liable to desiccation, are the "purse sponge" (Sycon compressum) and "dead men's fingers" (Alcyonium digitatum). Still lower are Spongelia fragilis, Spirorbis, the bivalves Pecten varius and Mytilus edulis, and the Tunicate Phallusia mentula. On Fucoid fronds: Helcion pellucidum, Lacuna divaricata, L. parva, L. pallidula, and again Spirorbis.

$B$. Under stones, on sand, and near high-water mark are the Amphipods Orchestia, Gammarus, Talitrus, and the Isopod Ligia, with beetles, mites, and springtails. Lower are Lineus ruber and other Nemerteans, the Polychæt Cirratulus cirratus and numerous Oligochæts, and the common shore crab Carcinus. Nearer low-water mark stones in muddy sand or gravel shelter sand-burrowers, with Polychæts predominant ; Sthenelais boa, Nereis cultrifera, Lanice conchilega, etc., also Tubifex benedeni and the Crustacean Nebalia bipes. These communities are small, however, compared with those near low-water mark under loose stones partly submerged, or at extreme low-water mark. The lists include 20 Porifera, 2 Celenterata, 9 Echinodermata, 5 Turbellaria, 9 Nemertea, 39 Polychæta, I3 Crustacea, and 35 Mollusca.

C. In crevices of the schist, which usually contain a thin layer of mud, are many individuals, chiefly representatives of classes of worms : Polychæta, Nemertea, and Gephyrea ( 30 species in all), with the rock-boring bivalve Saxicava, and Kellia.

D. Laminaria roots of three species digitata, saccharina, 
and bulbosa. The roots are exceptionally exposed to the air and the following, among others, inhabit them : 15 species of Turbellaria, 12 of Nemertea, 67 Polychæta, Phascolosoma, 6 Nudibranchs, and many others. Farran suggests that collecting from Laminaria roots would seem to furnish a reliable basis for the comparison of littoral faunas of different countries. As many as 66 species of worms have been obtained from half a dozen roots. The method of procedure is to tear the plants off the rocks, cut away the stems, and submerge the roots in water, in dishes. Some species soon collect around the margin, others require prolonged soaking, and a succession emerge in two or three days. At the end of three days putrefaction begins, and tube-dwellers usually emerge and fall to the bottom of the dish. Now add a few drops of formalin to hasten the process, throw away the roots, and examine the debris at the bottom of the dish.

Zoning of the Animal Forms of a Rocky Shore.Zoning is very well exhibited by the Trochidæ and Littorinidæ of the shore. Investigations in Cardigan Bay revealed the presence of nine species which (allowing for local differentiation and overlap) show the following succession, from above downward :

Littorina neritoides.

L. rudis.

Monodonta crassa.

L. obtusata.

L. littorea.

Gibbula umbilicata, G. magus.

G. cineraria.

Calliostoma zizyphinus.

The presence of L.obtusata is dependent on that of Fucoid Algæ ; C. zizyphinus is rare in that area and G. magus, local ; $L$. neritoides is constant when conditions are suitable, and requires a rocky foreshore affording crevices just above highwater mark, and not exposed to the midday sun and the resulting desiccation (Walton, I9I3). In other countries different species of periwinkle inhabit the supra-littoral zone ; 


\section{PLATE VI}

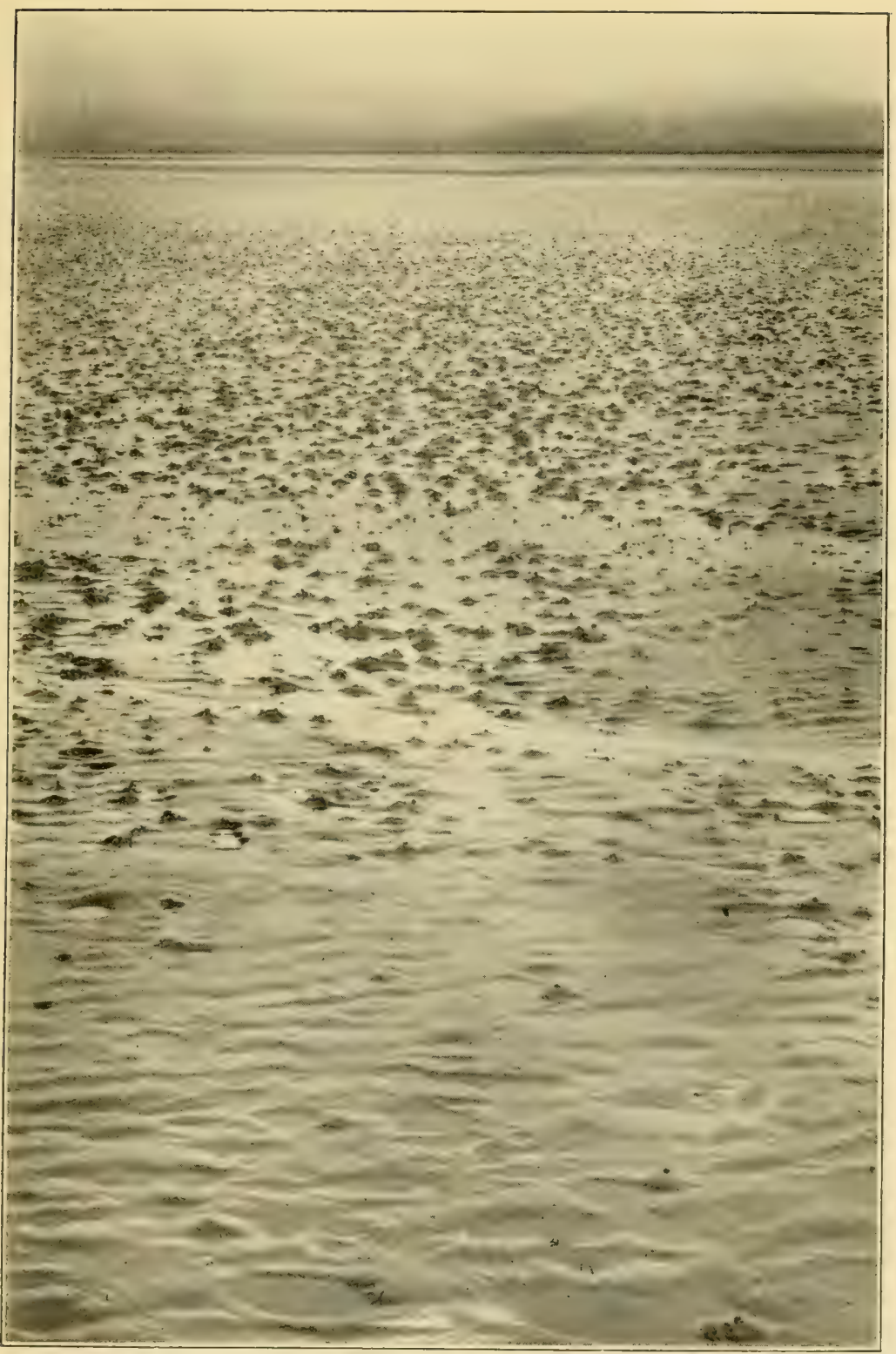

[Photo by Culliford, Aberystwyth.

Arenicola Colonies on Sand-Flats of Dovey Estuary.

Note the enormous numbers and the comparative absence of the worms on the ribbed - less stable-sand. 

L. exigua in Japan (Mitzukuri, I902). The periwinkle Tectarius in New South Wales is stated to withstand the hottest sunshine (Kesteven, 1903), while Melaraphe is described by Hedley (I9I 5) as leaving its small rock pools for dry land should conditions in them become unsuitable during neap tides.

In Cardigan Bay the Littorinidæ persist in the areas devoid of Trochidæ, the presence of which is apparently correlated with shore drainage and the type of rock or soil from which it flows; their presence or absence may depend on the lime content of the water. Thus $M$. crassa can be seen to break zone and follow seaward streamlets flowing from boulder clay. At the mouth of the River Wyre, near Llanrhystyd (and probably elsewhere), there occurs a curious lateral zoning due to the influence of fresh water in bulk. The spawning habits of the Littorinidæ are likewise adapted to their different life conditions in a most interesting manner, as will be noted elsewhere. Even the coastal and shore fishes are subject to a zonal distribution. In the Plymouth area the Gobiidæ have the following distribution. The most estuarine form is Gobius microps, the young occurring in the Sound and even outside the breakwater, while the adults are found in brackish, or frequently nearly fresh water. The black goby (G. niger) and spotted goby (G. ruthensparri) also occur in estuaries but near the surface, not at the bottom; the rock goby ( $G$. paganellus) is common under stones at the level of the lowest spring tides, while the freckled goby (G. minutus) never appears to go far from shore. On the other hand, the painted goby (G. pictus) is found in more open water, and $G$. elongatus and $G$. jeffreysii are deeper water species (Lebour, I919).

The Animal Associations of a Sandy Shore.-Recent investigations of sandy shores and cockle beds on the west coast of Great Britain have brought out not only a distinct zoning, but a very interesting stratification (Walton, I920). Broadly, these strata are :

I. Floating and swimming tidal species (Plankton).

2. Surface-dwelling species, Paludestrina stagnalis, etc. 

surface.

3. Stratum of cockle (Cardium edule), I to 2 inches below

4. Stratum of the two bivalves Macoma balthica and Tellina, 2 to 3 inches below surface.

5. Stratum of lug-worm (Arenicola marina).

No doubt further subdivisions could be enumerated if the other species of Annelida which are usually present were more carefully collected. We agree with Farran $(o p$. cit.) in considering that the variations in the fauna of sandy beaches depend largely on the purity of the sand, and the proportion of mud present. The plants Zostera, Ruppia, etc., modify sand faunas considerably, as many animals live on the blades, and many worms among the roots. The slope of a beach modifies its capacity for retaining moisture, and is thus of importance. In fine clean sand Farran found the anemone Cylista undata (on C. edule), 4 Nemertea, 3 Echinoderms, I7 Molluscs: Tellina, wedge shell (Donax), Tapes, cockle (Cardium), etc.), and 3 species of Crustacea, 24 of Polychæta, and the Sand Eel, Ammodytes ( $c f$. Plate VII).

Most of the sand-dwelling species of Mollusca are burrowers, and being subjected to considerable pressure from shifting of the surrounding loose material, have in many cases developed stout, more or less globular shells, such as Isocardia, Cardium, Venus, and others. In proportion, however, as the bivalves seek shelter from the strains of the shifting sands, either in quieter waters, or by burrowing deeper, so the shell in response tends to become less heavy and solid, and to assume a flatter shape, permitting a more rapid passage down into the silt (see Fig. 5, p. 74). This is seen in Tellina, Scrobicularia, and others. This deeper burrowing is accompanied by a lengthening of the siphons to ensure proper respiration, and this in turn results in the prolongation of the posterior portion of the test, to house them, until in the deepest burrowers such as the "Gaper" (Mya) and "razor fish" (Solen), the closed shell is abandoned, and the valves function solely as fenders against lateral pressure from the surrounding silt (Woodward, I907). 

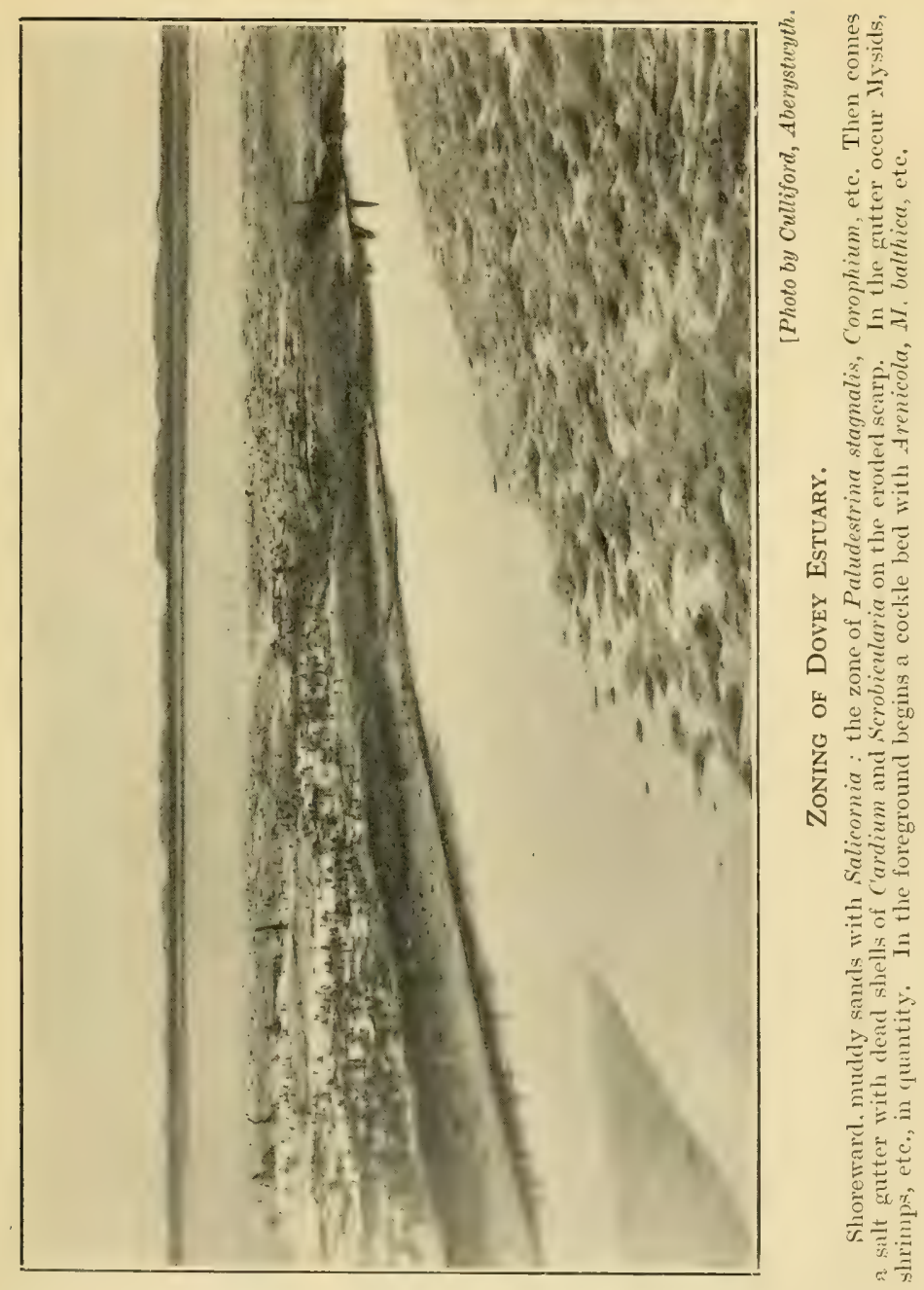

量 

Jetsam Association.-A distinct and interesting animal association which must not escape our notice is that occurring among the jetsam deposited by the waters at high-tide mark. The most important form is undoubtedly the sand-hopper Talitrus locusta, which performs useful work as a scavenger by devouring plant remains. Other forms with the same food are Staphylinid beetles and Enchytræid worms. Feeding on decaying animal remains are the flesh-flies (Sarcophagus) and carrion beetles (Necrophorus). Associated with these again is a predaceous fauna consisting of spiders, tiger-beetles, etc. (Davenport, I903), and finally birds (crows, jackdaws) can generally be seen picking over the heaps and taking their choice of the foregoing.

\section{THE STRUGGLE FOR EXISTENCE AMONG SHORE ANIMALS}

A few remarks may not be out of place here regarding the struggle for existence among the inhabitants of the shore.

This struggle falls into two categories: (I) against physical conditions which have already been discussed, and will be treated further in the next chapter; and (2). the interaction and competition of species with species, and individual with individual.

Effect of Currents on Dispersal of Shore Forms.In this connection there arises a factor that has not yet been discussed, viz. that of currents as agents in the dispersal of shore forms, both plant and animal. Many of these are, in their early stages, either free-swimming or floating, and are then carried to and fro, and hither and thither, by the tides, and are thus temporarily members of the Plankton. They are thus, for a time, removed from some of the typical dangers of the tidal zone (though exposed to some others). Many of these forms return to settle near their point of origin, while many others are, naturally, carried far by tidal currents, and when ready to assume the sessile, crawling, or burrowing stages of later life, may have arrived in a region either more or less favourable than that from which they were transported. Thus dispersal commences. Those 


\section{THE BIOLOGY OF THE SEA-SHORE}

carried into unfavourable environments will succumb, while those that are more fortunate in this respect are still faced with the problem of obtaining a foothold, since in favourable localities almost every possible spot may be already preempted. These factors may prevent the appearance of certain species in many localities, but should even small changes occur in a locality unfavourable to some form or forms, immigrants may at once appear. Given a foothold, a further struggle ensues, namely, that for maintenance of life in competition with the local species; while yet a final stage exists, in which reproduction and the fixation of the young must again be accomplished before the species can persist as a regular member of the community. Occasionally a new-comer may be better fitted for the struggle than some local species, and will then more or less rapidly increase its numbers and range until checked by encountering limiting factors once more.

Introduction of New Forms.-The following are instances illustrating the above :

Among the algæ, Colpomenia sinuata appeared suddenly on the coasts of Brittany and Cornwall, and in the course of a few years became completely naturalised over a large area on both sides of the English Channel (Cotton, op. cit.). Hedley (op. cit.) records that in Sydney Harbour this species is likewise active, and says that " occasionally the Zosteretum is invaded by the Bubble-weed C. simuata (see Stead, 1912). This pest spreads over the flats, smothering other vegetation and attaching itself to the oysters, whelks, or cockles. When the gas forms in the expanding balloon it lifts the shell and floats it away, so that oyster plantations are sometimes seriously denuded by its agency." The same writer notes that certain species periodically colonise within the area (Sydney), being brought by the Notonectian flood from the tropics ; Bonellia, for instance, then gains a footing, but perishes when the flood swings offshore; Strombus luhuanus, common and conspicuous on coral reefs, was abundant on some rocks, but disappeared from May, 1865 , to April, 1896 , when it reappeared. 
The periwinkle, $L$. littorea, appeared for the first time on the coast of Canada at Bathurst, New Brunswick, in I 85 , and spread thence by stages southwards. It was recorded from the Nova Scotian coast in 1868, then from Maine, and so onward as far as New Haven and Newport (Rhode Island) by I88o. It is believed to have been transported in the first instance in ballast. Further south than New Haven the animal has encountered its temperature limit, namely, water of $26^{\circ} \mathrm{C}$., a temperature fatal to its floating masses of ova. Its southern limit on the coasts of the Old World is the Gulf of Gascony (Pelseneer, 1914). The struggle for foothold is well exhibited by the common Cirriped Balamus balanoides, which colonises even the most wave-swept rocks and boulders. During the recent observations in the Port Erin district, already mentioned (Mayne, I9I8), this species was found to be most abundant on rocks between three-quarters and full-tide levels, growing thickly on the big boulders and flat-topped rocks : in all cases on the metamorphic "Manx Slates." On the limestone shore at Port St. Mary patches of smail ones were found, but sparsely scattered between comparatively large areas of the alga Enteromorpha, and the two never seemed to inhabit the same piece of rock. In this connection Orton (19I5) records a case at Plymouth in which specimens of Patella (the common limpet) had eaten out paths in the green algæ (chiefly young Enteromorpha) on cement piles between tide-marks. These paths radiated from the "scar" of the limpet, and showed fine lines made by the teeth of the radula : Balanus spat settled along these cleared spaces.

Miss Mayne carried out some enumerations of Balanus, using a wooden frame one foot square, which was laid upon the rock, and all within counted by hundreds, and ticked off with a blue pencil to avoid errors. In one case 2940 occurred within a square foot, varying in size from $\frac{1}{16}$ inch to $\frac{3}{8}$ inch across the base; while of another lot (in another place) 1138 were counted within a square foot, the average size being $\frac{3}{8}$ inch. Petersen and Jensen (IgII) 


\section{THE BIOLOGY OF THE SEA-SHORE}

observe that Blennies seek clean objects on which to fasten their eggs, and any fresh and hence uncoated object will usually be so covered within twenty-four hours.

Ecological Succession.-An opportunity to observe the colonisation of a new area by shore forms was provided by the opening of the Kiel Canal, which connects the Kiel Bight with the Lower Elbe and is some 62 miles long, in the summer of 1895 . Up till the time of opening and for a short period afterwards the canal contained only fresh water, and consequently supported a fresh-water fauna and flora. The ousting of fresh-water forms from the canal, and their gradual replacement by marine species, has been described by Brandt (1897). Owing to seasonal changes in the amount of water entering the canal and to the periodical opening and shutting of the lock gates, the salinity of the canal water is subject to considerable variation. This is a feature of importance.

The first phase of the colonisation of the canal with marine organisms consisted in the penetration of plankton and the free-swimming larvæ of colentera, worms, crustaceans, and molluscs; the second phase in the development of such forms, which derived their nourishment from the plankton (no other form of food being present). Up to the autumn of the year in which the canal was opened only planktonic organisms and plankton-feeders were present (e.g. Mysis vulgaris, Mytilus edulis, Balamus improvisus), together with such forms as live on the remains of dead organisms (e.g. Gammarus locusta). In the winter of the same year and in the following spring came the third phase, signalled by the entry of animals which prey upon plankton-feeders : starfish, larger crustacea, fish, etc. Contemporaneously, other rivals to the plankton-feeders put in an appearance in the shape of species with a similar mode of feeding, so that the mussels, for instance, decreased considerably in numbers. Following almost immediately upon this phase came the fourth : the appearance of plants (algr) along the banks. As soon as the algæ were present in good numbers other animals which 


\section{PLATE VIII}

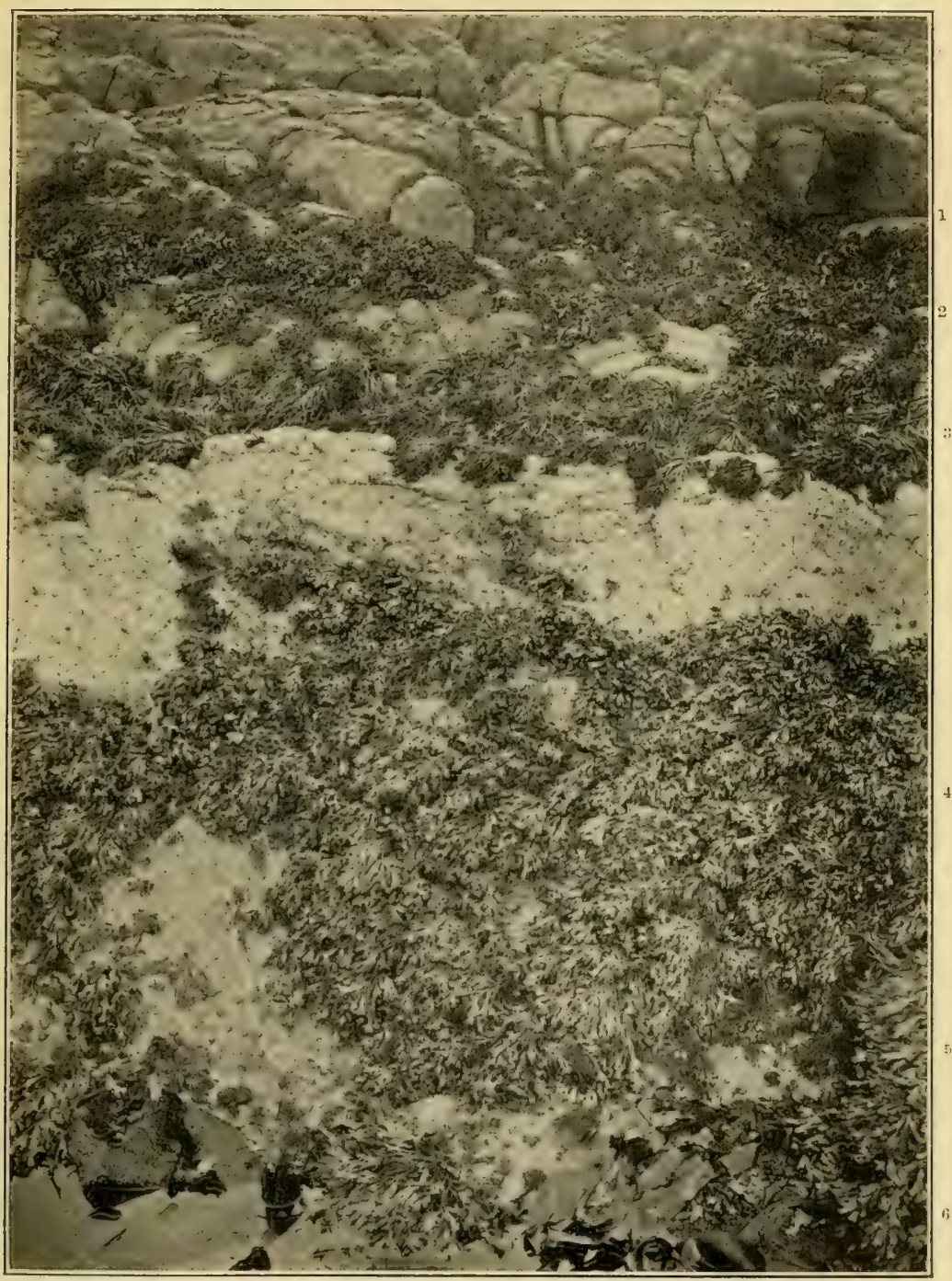

Zoning of Brown Seaweeds on Shore of Cove Bay, Kincardineshire.

1. Pelvetia canaliculata. 2. Fucus platycarpus. 3. Ascophyllum nodosum with Polysiphonia fastigiata. 4. Fucus vesiculosus. 5. Fucus serratus. 6. Laminaria digitata and $L$. saccharina. 

find concealment and nourishment among them were able to colonise the canal. So far, however, no Fucus or Zostera was present in the canal, and no Palcemon or Nerophis. The sea-urchin occurred, however, and in the absence of Zostera fed on Enteromorpha. Species of Idothea, Rissoa, and Littorina were present in small numbers. A few mud-dwellers had put in an appearance in addition to several worms. The brittle-star Ophioglypha entered the canal some eighteen months after the opening. Many mud-worms, mud-frequenting Nematodes, and forms such as Scrobicularia, Mya truncata, Acera bullata, Molgula, etc., were still absent in the autumn of 1896 and could not appear in any numbers until a more copious deposit of mud had been formed by the decomposition of the algæ growing on the banks. At that stage a slight mud deposit had already accumulated from the remains of dead planktonic organisms.

Sorby (Igor), in the course of ten to twelve years' collecting along the coasts of Essex and parts of Suffolk, has noticed that while certain forms appear to be more or less constant, many others show very considerable changes both in their distribution and frequency of occurrence. Various factors are no doubt concerned, such as extremes of temperature (particularly cold), cyclical weather changes influencing salinity; human agency operating through the discharge of sewage in estuaries, the dilution or contamination of estuarine water resulting from the drainage of fields, the taking of fish, shrimping, and the various operations of oyster culture, etc. Sorby claims to know of a case in which the largely increased amount of fresh water entering an estuary at a time of heavy rains killed off thousands of pounds worth of oysters.

A mussel bed illustrates vividly the competition within a species, i.e. between its individual members. These are frequently so numerous as to occur growing upon one another until they are several layers deep and actually smothering and poisoning one another by the accumulation of waste products and the silt, etc., that settles among their masses. The manner in which the various members of the shore 
associations and communities prey upon one another will be treated in a later chapter, and it only remains here to stress the fact that, in addition to the struggle that is maintained among themselves, they are subject not only to the predatory visits of creatures belonging to the deeper waters during high tide, but also to incursions by land forms during the periods of low water.

A good instance is given by Stafford (I901), who states regarding Mya arenaria that, although buried, and hence escaping the open direct struggle to which the mussels are subject, they are nevertheless preyed upon by a considerable number of animals. They may be washed out by storms and cast on shore or left to die in the sun, or ravaged by gulls, cormorants, crows, etc. In places along the New England coast, pigs systematically visit, root up and eat the clams. In Greenland they are sought after by walrus, Arctic fox, and birds. Their siphons are often found in the stomachs of fish such as flounder and sculpin, which also eat the young, while cod will eat them if they get the chance. Starfish are one of their greatest dangers, and the whelk hores holes in the shell. Crabs are likewise enemies. Man is a great enemy, leaving many exposed, to die or fall a prey to other creatures. M'Intosh (1896) found that the ova of the Lumpsucker, Cyclopterus lumpus, were eaten by rooks and other birds, while at the same time (April) cod were found to be distended with the same food. The same authority records that another common bird, the sparrow, has been noticed to be destructive to the young flounders in the harbour. "At ebb-tide in May this bird watches by the side of the tiny pools in the mud and seizes on a young flounder whose prominent glistening eyes (minute though they be) are sufficient to betray it, though its almost transparent body is immersed in the mud. It then lays it on one side, and watches for another, and so on until it has a fair mouthful to carry to its young " (M'Intosh, I888).

Of the destructive action of sea-gulls, one instance must suffice. Scott (I9I5) writes that on visiting the Bardsea cockle beds in Morecambe Bay, his attention was drawn to 
a flock of gulls which were feeding on the sands. Their excreta proved to consist of well-defined heaps of white, pale pink, and dark shells. The white proved to consist of barnacles, the pink of "henpens" (Macoma), and the dark heaps of mussels comminuted. All the heaps were practically pure, showing that the birds had confined themselves to one type of food at a time. Finally, a monkey, the Crab-Eating Macaque (Macacus cynomolgus), derives its name from its habit of feeding on crabs from the brackish waters of the lagoons and swamps of the Malayan coast. 


\section{CHAPTER IV}

\section{Special Problems of Shore Life}

WHILE every well-marked type of environment has special features of its own, which tend to give its fauna a characteristic "facies," nowhere are such features so varied or so far-reaching in their effects as on the sea-shore. Not all the important factors affecting littoral animals are entirely peculiar to the sea-shore. During periods of storm, for instance, the margins of large fresh-water lakes and the animals living there may be pounded with a violence equal to that of marine waves; moreover, the waters of the same lakes are subject to fluctuations of level known as " seiches," which though very slight may possibly have results on the fauna comparable to those caused by ocean tides. These two phenomena, however, wave-impact and the fluctuation of the water level, are so much more important as they occur on the sea-shore, that the problems they present can legitimately be regarded as "special" to the shore area. Since factors of this type, together with others of a kind unparalleled elsewhere, give the shore fauna its characteristic impress, it becomes necessary to examine them thoroughly as regards both their nature and effects. From the point of view of the organism, each of the features we are about to discuss affords a particular problem the solution of which is imperative if the animal is to survive. As one might expect, the same problem is met in various ways.

THE PROBLEM OF THE TIDES

An outstanding feature of the tidal zone is that, while its upper limit marks the permanent boundary between two 
entirely different habitats, the area between this and the lowest limit of spring tides is one in which marine and terrestrial influences predominate alternately. In other words, the tidal area is a sort of "Tom Tiddler's ground" where land and marine animals may play alternately, provided they can find some means of passing the intervening periods. This is not difficult for the roving higher forms like mammals, birds, and fishes, but the lower forms which, as it happens, form the bulk of the shore population, are mostly incapable of rapid displacements and require special adaptations of structure, function, and behaviour if they are to resist the set of conditions which is inimical to their particular case.

The problem for animals breathing atmospheric oxygen is the reverse of that which confronts typically marine organisms breathing the oxygen dissolved in water. And since the overwhelming majority of shore animals are of this latter class, the problem for us to consider is how animals breathing dissolved oxygen can endure protracted periods of drought. We shall not, however, omit to discuss the not infrequent cases of the reverse type, particularly as these afford fine examples of evolutionary progress.

Importance of Rock Pools and of Algæ.-To some extent, the problem of the tides, so far as the typically marine forms are concerned, is solved by the permanent occupation of pools ; this is particularly the case on a rocky shore. Moreover, even on retreat of the tide, a considerable amount of moisture is retained by sand, stones, and especially algæ, the function of the latter being equivalent to the soil mulch adopted by agriculturists in regions of low rainfall. Needless to say the greatest advantage is taken of this feature of the environment. One has only to turn over a mass of wet Fucus, at low tide, to disclose countless numbers of Gammarus hiding in the damp weed, and the removal of a flat stone will give a similar result. While sedentary animals have been constrained to respond to the tide-factor by suitable modifications of structure, the effect on actively moving forms has been rather to influence behaviour. The 
pressing need of the non-sessile animal is to keep in touch with moisture, and this it may achieve by burrowing, by hiding under stones, in crevices, under seaweed, etc.

Methods of resisting Desiccation.-Among sessile animals, as we have hinted above, there occur numerous devices for the retention of moisture. A good example of these is afforded by the acorn barnacles, the commonest animals of the sea-shore, in which the limy cup surrounding the animal is covered by four plates forming an accurately fitting valvular roof. A bubble of air is sometimes imprisoned by the tips of the valves at low-tide and serves for breathing. It is the more complete closing of these valves and the consequent rupture of the air-bubble when barnacles are disturbed which gives rise to the characteristic clicking sound familiar to every one who has walked on barnacle-covered rocks.

Though a barnacle can only expand and obtain food when covered with water, it is able to live so far above ordinary high-water mark as to remain dry for days at a time, amounting, according to Vaillant (quoted by Herdman, I892), on an average, to $\frac{18}{20}$ ths or $\frac{19}{20}$ ths of its life. The same worker has determined by experiment that a barnacle can live out of water for at least forty-four days. This capacity to remain for long periods in a condition of suspended activity is a marked feature of sedentary shore animals, and the devices which make it possible are clearly of an adaptive nature. One may notice, in passing, that these periods of suspended activity correspond biologically to the periods of æstivation or hibernation among land animals, the only difference of importance being that the periods of activity or quiescence on the shore are of very much shorter duration and succeed one another at much shorter intervals.

The opercula of Gasteropod molluscs, horny skin products formed from groups of cells situated on the upper surface of the foot, serve a similar purpose to the valves of barnacles. In many Polychæt worms (e.g. Serpulidæ) one (sometimes more) of the gill filaments is enlarged terminally to act as a stopper, which closes the mouth of the tube 
when the animal withdraws into it. In some cases this operculum is grooved on one side and serves as a brood pouch in which the eggs undergo development.

The capacity of shore animals for resisting desiccation varies considerably, this capacity being in direct relationship to the position occupied by the animal on the shore.

The Littorinidæ have progressed a considerable distance on the road to a land life. Thus, L. neritoides lives in shaded crevices just above high-tide mark. Its salt-water requirements are satisfied by dashings of spray and the moisture consequent on its close proximity to the sea. Tropical species of Littorina seem still more capable of dispensing with moisture. Cooke (1895) has seen in various parts of Jamaica, L. muricata living at the top of low cliffs among grass and herbage, and at Panama he has taken three large species of Littorina ( $L$. varia, L. fasciata, L. pulchra) on trees at and above high-water mark.

The following table of Colgan's (1910) gives the maximum period of survival of littoral mollusca on $(a)$ exposure to dry air, $(b)$ immersion in fresh water, and $(c)$ immersion in water of treble the salinity of sea-water.

\begin{tabular}{|c|c|c|c|c|c|}
\hline & & $\begin{array}{l}\text { On exp } \\
\text { to dry }\end{array}$ & $\begin{array}{l}\text { posure } \\
\text { y air. }\end{array}$ & $\begin{array}{l}\text { On immer- } \\
\text { sion in fresh } \\
\text { water. }\end{array}$ & $\begin{array}{l}\text { On immersion } \\
\text { in water of } \\
\text { treblc salinity. }\end{array}$ \\
\hline Littorina neritoides & . & 42 & days & I I days & 6 days \\
\hline L. rudis $\quad$. $\quad$. & . & 31 &, & 7, & $7 "$ \\
\hline L. littorea : . & . & 23 & $"$, & 7 & 6, \\
\hline Hydrobia ulvae & . & & $"$, & 18 & $9 \frac{1}{4}, "$ \\
\hline Purpura lapillus .. & . & $91_{2}^{1}$ & $"$ & 4 & 3 \\
\hline Lasaa rubra (a bivalve) & . & 9 & ", & $"$ & 0 \\
\hline Trochus umbilicatus & . & 7 & $"$, & $"$ & $"$ \\
\hline Littorina obtusata.. & . & 6 & $"$, & $"$ & ", \\
\hline
\end{tabular}

As might be expected, capacity for resisting desiccation is accompanied by greater tolerance of fresh water, but Lascea rubra and Paludestrina stagnalis (Hydrobia ulva) form exceptions which are not easy of explanation.

In spite of the undoubted capacity of these littoral molluscs for resisting drought and the importance of the 
opercula and similar devices in this connection, it is by no means certain, as Colgan remarks, that the opercula act by perfect exclusion of the fresh water. For how are we to explain the fact that individuals of littoral species which have remained closed for considerable periods when exposed to dry air or immersed in fresh or abnormally salt water, return to activity almost immediately when placed in normal sea-water? Is the operculum permeable only to water containing a definite concentration of salts ? This seems unlikely. To us, the most feasible explanation seems to be that the mollusc first makes trial by allowing the operculum to relax by a minute fraction. If the result is favourable, the animal relaxes still further. The subject, however, merits further investigation.

The habit of tube-building among Polychæts may, or may not, have its primary origin in the necessity for avoiding enemies and possibly also wave-shock, but in the case of littoral Polychæts it is certainly of value in preventing desiccation also. Actively moving Polychæts such as the Nereidæ have no difficulty in keeping in touch with their proper requirements; moreover, they are able to burrow. The habit of burrowing is one of the commonest methods of avoiding both desiccation and enemies. It has the additional advantage that it does not necessarily imply cessation of activity.

The fisherman's lug-worm, Arenicola marina, inhabits a $\mathrm{U}$-shaped burrow of which one end is marked by a casting and the other by a funnel-shaped hole or depression through which the head is probably protruded when the burrow is covered by the rise of the tide (Ashworth, 1904). Low tide for these burrowing animals is not the time of complete stagnation that it is for the sedentary forms. Feeding still goes on to a certain extent, but during spring tides and in the summer months there is probably considerable accumulation of decaying organic matter which, swelled by the excretions of the animals themselves, gives rise to progressively unfavourable conditions which would result in the death of the worms by auto-intoxication if it were not for the return 
of the tide (Bohn, I90I). A pretty way of solving this difficulty is seen in Cirratulus. In this worm one of the anterior segments bears two thick clusters of long, very vascular filaments. In the natural habitat all that is seen of the worm is this cluster of delicate rosy processes gently waving in the water of a pool. When Cirratulus burrows, these filaments, which are exceedingly elastic, are left protruding in the waters of a pool and serve to aerate the blood while the worm is finding its food in the decaying mud below. In this way, safe from drought, enemies, and asphyxiation, Cirratulus is able to live undisturbed (Flattely, I916).

Methods of resisting Drowning employed by Shore Forms breathing Atmospheric Oxygen.-So far, the problems we have been discussing are those confronting the essentially marine animals which form the mass of the shore population. There is, however, another small group of animals which, though the near relatives of typically terrestrial forms and quite incapable of breathing dissolved oxygen, form an undoubted part of the shore fauna. This group is composed of forms, mostly insects and arachnids, which are making a tentative return to the habitat which their distant ancestors may, perhaps, be said to have deserted. The difficulty offered to these forms by the tides is the exact opposite of the one confronting the marine types. It is low tide which is the period of activity for these forms, the problem for them being how to subsist during the periods of high water. We may mention here the fact that the littoral mite Gamasus (Halolcelaps) glabriusculus has been shown by King (I I I 3 ) to be capable of enduring complete immersion for at least forty-eight hours. During this time the mite is quite inactive, but resists asphyxia by the aid of the air imprisoned in its breathing tubes. Marine insects are usually liberally covered with hairs which serve to imprison bubbles of air.

\section{THE PROBLEM OF WAVE-IMPACT}

As the tide rises and falls successive areas of the shore are pounded by the breaking waves, often with tremendous 
force. In these circumstances no animal could possibly survive which had not some efficient means either of eluding or withstanding the impact. And so it is not surprising to find that wave-shock has had a profound influence on shore animals, particularly as regards their form and habit. Indeed, granted the littoral origin of life, it seems not too much to consider the sedentary habit as due essentially to this factor.

To a lesser extent the problem of wave-impact occurs on the margins of fresh-water ponds and lakes. The special adjustments of fresh-water organisms to withstanding the wash of moving waters have been studied by Wesenberg Lund (1908), and by Needham and Lloyd (I916). They show an interesting parallelism to those occurring among shore animals.

In considering the question of wave-impact in relation to shore animals it will be useful to follow Hunt (1885), and to distinguish between :

(a) Animals living on rock or other firm foundation;

(b) Animals living in sand or other unstable deposit; and to deal with them separately.

\section{(a) Animals living on Rock or Other Firm Foundation}

Forms inhabiting areas of this type have often the advantage of natural cover in the shape of sea-weed, the part played by the latter in absorbing wave-shock being of some importance. This is particularly true of Ascophyllum nodosum, the long (often several yards) strands of which have an undoubted effect in smoothing out the waves (see Plate X). Apart from this the following are some of the chief ways in which the problem is met by this class of animal.

I. Occupation of a Sheltered Position.-It is a characteristic of shore animals that they find shelter in nooks and crannies, under stones and seaweed and are rarely found in exposed situations. On a bad coast, like that of Cardigan Bay, if the strike of the rocks is fairly parallel with the coast, the dip of the rocks becomes an important factor as regards the fauna. Where the dip of the rocks is low, the 


\section{PLATE IX}

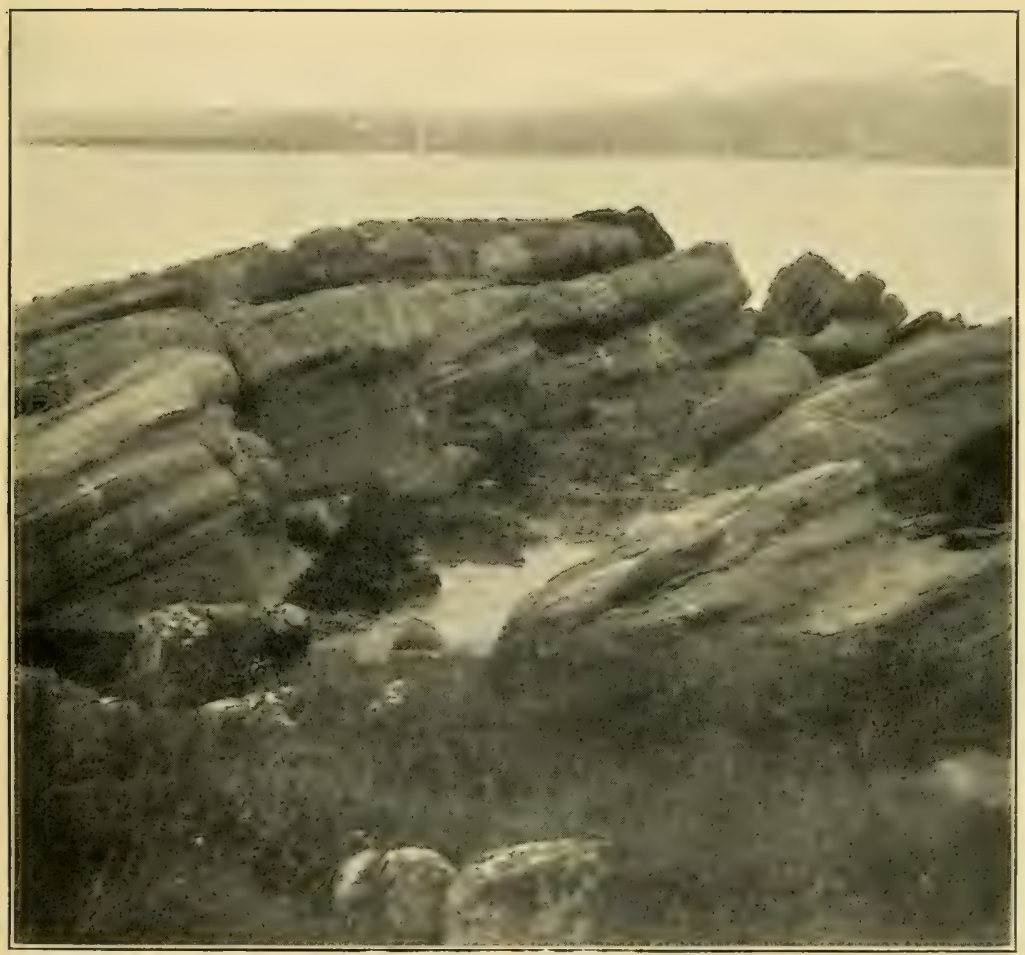

Enteromorpha PoOL.

Pool above high-water mark at Millport, Cumbrae, fed by sea-spray and by rain. It contains an interesting transitional fauna, which at the time it was examined in. cluded Littorina rudis, Carcinus monas, Jara marina, Gammarus locusta. Procerodes ulva, brackish-water Copepods of the genera Eurytemora, Diaptomus and Harpacticus, the Ostracod Cythere, and the common stickleback (var. trachypterus). 

whole surface is exposed to wave action and the rocks are barren, but where the dip is high and seaward there may be a good fauna on the more sheltered landward slope. By the adoption of a home in the sheltered niches on the landivard side of these rocks the risk of dislodgment is greatly reduced. Such situations are largely chosen for the act of spawning, as will be seen in a later chapter. Interesting are the ways in which the labours of certain forms are instrumental in providing shelter for others. For instance, the tunnels bored by Saxicava rugosa in limestone rocks are occupied by the Polychæt Eulalia viridis which is very numerous where such shelter occurs. Again, the activity of the common tube-worm Sabellaria alveolata results in the formation of elaborate grottos which afford protection to a whole association of shore forms (see Plate V).

2. Special Powers of Adhesion.--Another marked characteristic of shore animals is the capacity to adhere closely to the substratum. Some, e.g. sponges, zoophytes, Tunicates, remain permanently fixed, and once detached are incapable of regaining foothold and like uprooted plants are doomed to perish. Others, e.g. anemones, though normally fixed, are capable of securing fresh hold if chance so allows, and, in certain cases, are even capable of a limited amount of locomotion.

Others again, viz. Gasteropods, during their progress cling tightly to the rocks or weeds by means of the broad foot.

The regions of attachment of sedentary animals are liberally supplied with mucus glands, but, according to Davis and Fleure (1903), it is doubtful whether the secretion of adhesive material is always of first-rate importance. In the anemones adhesion is secured by the exceedingly close apposition of the pedal disc to the substratum, the tissue following every rugosity of the underlying surface. The limpets probably adhere in the same way, but according to the writers just mentioned the method of adhesion is not known with certainty. They say that "limpets will hold on very tenaciously to a surface smaller than the foot, so 
it seems improbable that the latter acts like a sucker as has been suggested. Another view is that the animal is fixed to the rock by means of a glutinous substance secreted by its foot, but, from examination of specimens allowed to fix themselves to plate glass, it seems that this view also is unfounded. The most plausible explanation is that it is a case of two very closely apposed surfaces, the foot being, so to speak, rolled out on the rock." This is not the case with the barnacle, however, whose powers of adhesion are due to the presence of definite cement glands which have been described at length by Darwin $(185 I-4)$. The glands with their ducts adhere to the basal membranes or shelly plate and the secretion is shed all around the basis. The cement issues either in a cellular condition, or, more commonly, as a fine network which forms, at a short distance from the orifices of the ducts, a fine sheet or layer which has the capacity of occupying and filling up all inequalities in the supporting surface. Darwin has seen it, when spread over an encrusting Flustra, present an exact model of every cell. In Coronula, a barnacle which is found on the whale, the cement has the faculty of penetrating into and almost blending with the epidermis of the Cetacean. The area of attachment of sedentary shore animals seems to have a similar capacity for fusing with the substratum, so that many animals cannot be removed without damage. Probably some chemical reaction takes place between the living tissue and the substratum (of a similar nature to the dissolving capacity of the roots of rock plants) so that the rock becomes so intimately associated with the tissue as, for all practical purposes, to become one with it. This is the case with the Tunicates; some species, e.g. the genus Pleurociona, lie flat and are attached to large shells or other objects along the greater part of the left side of the body. In some cases, the test is prolonged, especially at the posterior end, to form extensive expansions and stolon-like processes (Herdman, I889).

Littoral Turbellarians are not only by their shape particularly well adapted to withstanding wave-shock, but 
they are provided, in addition, with special means of attachment. In Convoluta paradoxa the " tail " or pointed hinder end of the body is provided with sticky adhesive papillæ which enable it to remain firmly attached to its favourite weed (Ceramium sps.). These papillæ are elevations of the epidermis. Gamble (1893) has roughly estimated their power of adhesion by the use of a powerful syringe. 'Repeated action of an in-going or out-going stream does not affect the Convoluta. It merely sways slightly in the direction of the current without in the least loosening its hold on the substratum. This device, according to the same writer, is general among littoral Turbellaria; some forms indeed (e.g. Planaria dioica) are provided with adhesive papillæ over their entire surface.

A similar method of adhesion has been observed in the Nudibranch Ancula cristata. This is a very slimy species. Herdman and Clubb (I892) state that "in the natural state the mucus is chiefly on the foot and especially at the posterior end, each individual having a slimy string attached to the end of the tail by which it is anchored. This no doubt accounts for the manner in which the animal is able to live on exposed rocks in the wash of the tide. We have several times watched specimens of Ancula in a few inches of water where there was a strong tide running past the rocks and the waves were dashing on them and noticed that they were swayed backwards and forwards in the water but were securely anchored by their tails."

In a number of common shore fish, e.g. species of Liparis, Gobius, Cyclopterus, the pelvic fins have become partially or completely modified as suckers. Speaking of the function of the suckers in young individuals of Cyclopterus, M'Intosh (I896) says these fishes "adhere to the blades of the tangles and other seaweeds and in the mazes of these find that safety from the ready application of their suckers which would be denied them in the open sea."

Aflalo (1904) makes a similar statement in regard to species of goby: "the ventral fins of these gobies show the transition to the disc of the 'suckers' and many of these fish 
cling in like fashion to the rocks, and thus resist the force of the waves. This method of adhesion must be a great convenience to these shallow - water dwellers in rough weather, when the swirl of the surf would otherwise dash them ashore, or, at any rate, transport them far from their eggs. Other fishes, not provided with these suctorial fins or discs, have to burrow in the sand." According to experiments by Cunningham (Aflalo, op. cit.), the fish by pumping water with its fins between its body and the object of attachment sets up differences in the pressure and direction of the water which are sufficient to keep it in position.

3. Form of Body adapted to minimising Friction.-There is no fact more evident on the shore than that the animals which compose its fauna are essentially flattened forms. Everywhere the need for reducing friction is apparent. We have encrusting sponges, like Halichondria and Oscarella, leaf-like Turbellarians, leaf-like or encrusting Polyzoa like Flustra and Membranipora, encrusting compound Tunicates, as Botryllus. Among plants, the encrusting stony Lithothamnion, Melobesia, and others have successfully solved the problem presented by the surf. The numerous molluscs are all squat forms, their shells devoid of spines and mostly inornate. Shore Crustacea show the same influence, the flattening being either lateral as in Amphipods like Gammarus, or dorso-ventral as in Isopods like Ligia and in the crabs, especially Porcellana platycheles.

The "stream-line" form, however, is less common than one would expect at first glance. This is probably because shore forms are mostly sluggish in habit, and more particularly because the impact of the water is not acting, as in a river, in one definite direction. Moreover, the majority of shore animals are clinging to and moving upon solid surfaces so that they have to meet the water on one side only. If, as Needham and Lloyd (op.cit.) remark, we take the typical fish form and divide it in the median vertical plane and then apply the flat side to the supporting surface, flattening it out a little at the edges, the form obtained is that of a limpet. This shape is very common on the shore and is directly 
traceable to the environment. Eliot (1910), in discussing the close resemblance between Nudibranchs of very different types, says "the general conditions of marine life probably make it natural that a mass of soft flesh adhering by its base, not moving much and not attempting to swim, should assume this form."

Interesting variations in form have been noticed among molluscs, which bear a direct relation to the degree of exposure (see Fig. 4). Individuals of Purpura lapillus, the common dog whelk, " occurring in very exposed situations, e.g. Land's End, outer rocks of Scilly Islands, coasts of North Devon and Yorkshire, are stunted, with a short spire and relatively large mouth, the latter being developed in order to increase the power of adherence to the rock and consequently of resistance to wave force. On the other hand, shells occurring in sheltered situations, estuaries, narrow straits, etc., are comparatively of great size with a well-developed, sometimes produced spire and a mouth small in proportion to the area of shell surface" (Cooke, 1895).

Davis and Fleure (1903) claim that the shells of limpets on exposed flat surfaces are typically low and broad, and that shells on sheltered surfaces are typically high and narrow. This conclusion, however, is only partly confirmed by the observations of Russell (1907).

\section{(b) Animals living on Sand or Other Unstable Deposit}

The habitat being unstable no powers of attachment will serve the animal, its safety depending practically entirely upon the celerity with which it can penetrate the sand.

According to Osler, quoted by Hunt (I884), " animals which from their small size or the little depth at which they reside are particularly liable to be exposed, will generally burrow readily, but the large species will scarcely attempt to bury themselves except in the very young state." It is not difficult to see that while some Lamellibranchs are admirably adapted by their shape to penetrate the sand, 


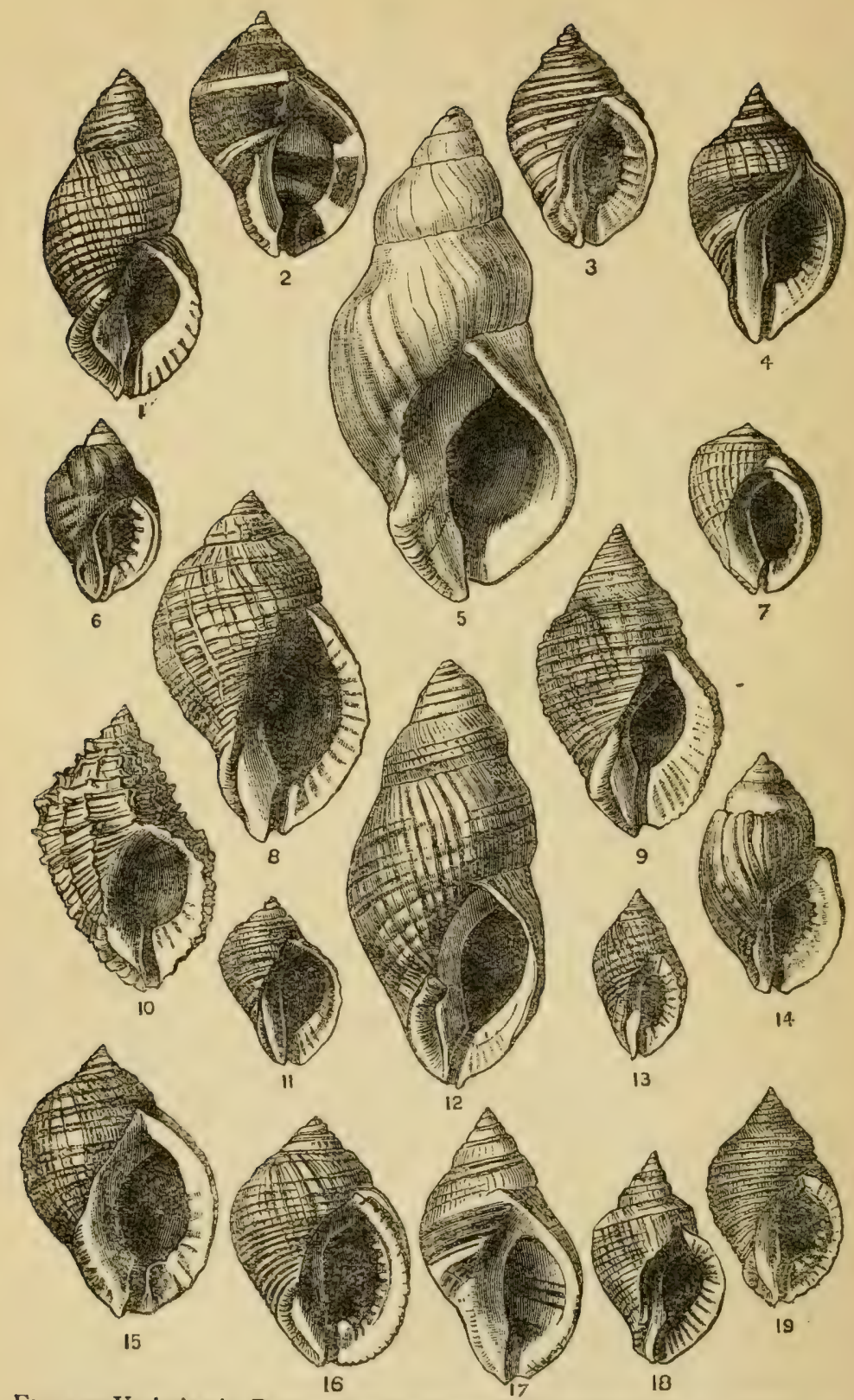

FIG 4.-Variation in Purpura lapillus (from The Cambridge Natural History). 
others are as evidently ill-adapted. One has only to compare the compressed and hatchet-like form of Psammobia tellinella with that of the comparatively globular Cardium. In a form like the latter, however, the ridges and other outgrowths, when present, serve to give the shell firm anchorage. In particular the long spines of Cardium aculeatum are of service in increasing its holding powers in the fine sand. The excrescences on the shell of $C$. tuberculatum are of similar value while $G$. echinatum owes its safety to its powers of burrowing and to its spines which, recurved in the direction of its tubes, offer the minimum of resistance to progress, but the maximum of resistance to dislodgment. The long wing-like processes of Aporrhais pes-pelicani are, according to Hunt (loc.cit.), " self-acting pieces of mechanism that will in the majority of cases ensure the mollusc being ultimately left in its normal posture should it encounter wave-currents sufficiently strong to upset it." An individual of this species when lying on its back will rock freely backwards and forwards along a line regarded as joining the end of the middle wing-like process and one of the ridges on the body of the shell, so that a very moderate alternate current will cause the shell to resume its normal position.

The snails Natica catena, Buccinum undatum, Nassa reticulata, Bulla hydates, Philine aperta have no special means of withstanding wave currents on the surface of the sea-floor, but there is no need of them as they all burrow freely.

The method by which starfishes deal with wave currents is interesting. The common Asterias lies rigid on the bottom with extended arms, its flattened form offering the minimum of resistance to the current. Added to this it has the power of sinking vertically into the sand. The swimming crab (Portunus) can also escape beneath the surface, but in this case the sand is shovelled away actively by the swimming feet.

The habits of the sand-eel (Ammodytes) are well known to fishermen, to whom it affords valuable bait. Frequenting sandy shores between tide-marks, it escapes wave action by burrowing rapidly beneath the surface. 

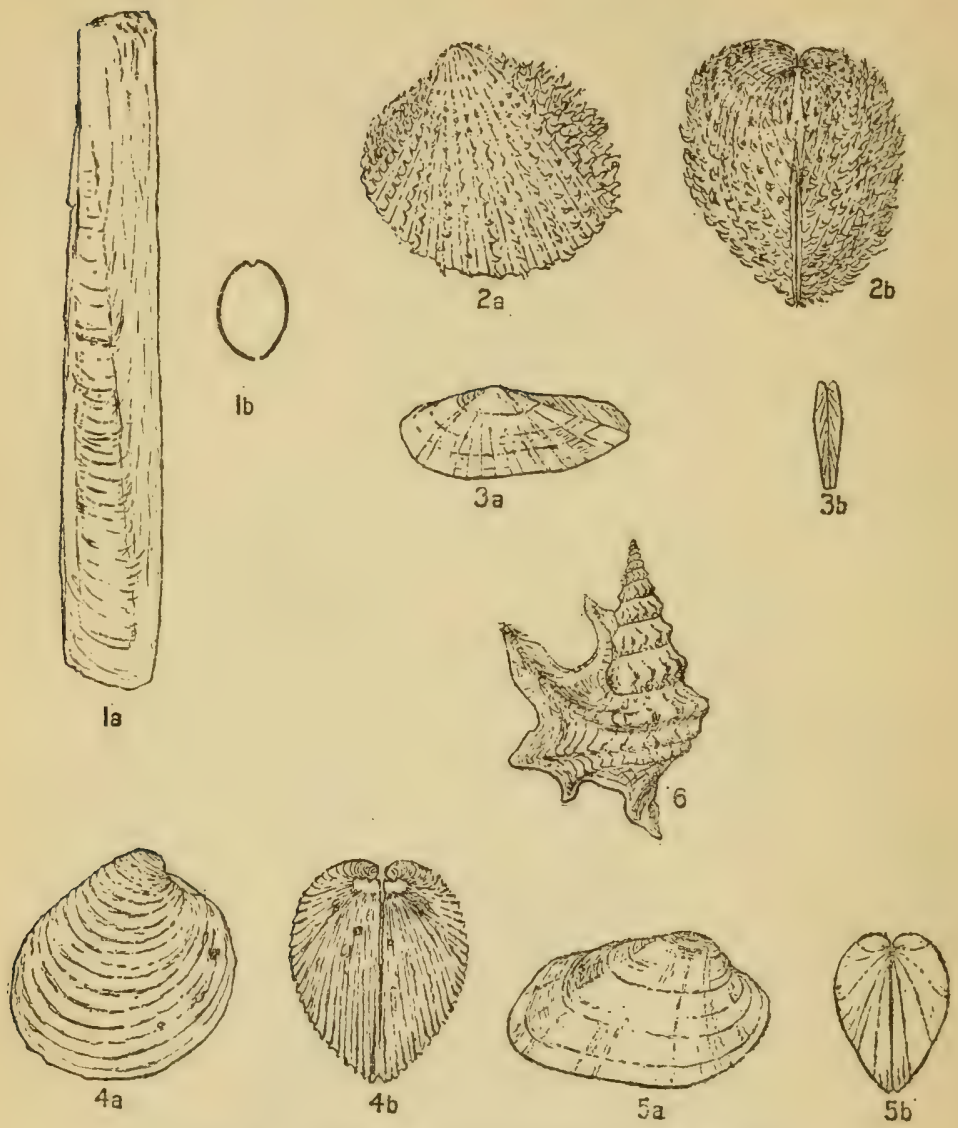

FIG. 5.-Shell forms in relation to mode of life.

1a. Razor-shell (Solen siliqua). Valves elongated, oval in cross-section, with sharp edges. Burrows deeply and rapidly.-1b. The same in cross-section.

2a. Spiny-cockle (Cardium acule. atum). Almost globular. A shallow burrower, the recurved spines mooring the animal firmly to the sand.-2b. The same in profile.

3a. Psammobia tellinella. Valves wedge-shaped, much compressed, giving a shape well adapted to deep burrow. ing. $-3 \mathrm{~b}$. Profile.

4a. Venus verrucosa. Habits similar to those of Cardium aculeatum, the ridges serving the same purpose as the spines of the latter, - $4 \mathrm{~b}$. Profile.

5a. Tapes pullastra. Shape of shell intermediate between that of $2 \mathrm{a}$ and $3 \mathrm{a}$. Burrows to a medium depth. - $5 \mathrm{~b}$. Profile.

6. Aporrhais pes-pelicani. Lives on surface of bottom. The wing-like procosses are thought to serve as a counterpoise, enabling a slight current to return the animal to its normal position when overturned. 
THE PROBLEM PRESENTED BY THE VARIABILITY IN TEMPERATURE AND SALINITY OF COASTAL WATER

It is well known that, at a comparatively small depth in the sea, life proceeds in surroundings of exceptional stability ; as one approaches the shore, however, the range of variation becomes more marked till, between tide-marks the water, owing to its shallow depth, and the influence of sun, air, and fresh water from the land, is subject to wide changes both in temperature and salinity.

The Effects of Varying Temperature.-According to Möbius (quoted by Semper, 188I), the coastal waters of North European countries display considerable seasonal and even daily variations in temperature. These variations may be observed not only in surface water, but not infrequently at considerable depths. In the Gulf of Kiel, for instance, the mean monthly temperature varies, at a depth of I6 fathoms, between a maximum of $64^{\circ} 4^{\circ} \mathrm{F}$. and a minimum of $34^{\circ} 7^{\circ} \mathrm{F}$. Hedley ( 1915$)$ gives the highest known water temperature in Sydney Harbour as $75^{\circ} 5^{\circ}$ F. (July, I887), and the lowest as $50^{\circ} \mathrm{F}$. At Woods Hole, on the eastern coast of the U.S.A., the range is from below freezing point to $70^{\circ} \mathrm{F}$. ; San Francisco Bay ranges from $69^{\circ} \mathrm{F}$. to $42^{\circ} \mathrm{F}$.

Local climate accounts for much variation in the amount of heat and cold affecting the tidal region; the particular aspect and type of substratum are also of importance. The higher and more landward portions are naturally most affected. Rock surfaces become greatly heated unless heavily overgrown with algæ; rock pools, if deep and shaded, will be comparatively unaffected, while shallow pools near the upper tidal limits evaporate rapidly. Boulders, etc., will provide shelter not afforded by sand. Wind plays an important part in aiding desiccation, and the salinity of the water is of some consequence.

In tropical seas the variation at the surface, even between winter and summer heat, is relatively very slight-at the Philippines, for instance, not more than $2^{\circ} \mathrm{C}$. In northern seas, so small a variation only occurs at a great depth. It 
is to this apparently, says Semper (loc. cit.), " that we must refer the fact that many genera of sea-creatures which are known as boreal forms live in the north at great depths while in tropical seas they live very near the surface."

Correlated with the normally small range of temperature variation in tropical seas is the fact that tropical marine animals are much more susceptible to wide variations of temperature when they occur than are forms inhabiting the temperate or arctic zones. With the latter a considerable range of temperature above or below the normal produces relatively little difference in activity, whereas in the case of tropical forms even a few degrees of cold or heat causes a marked depression in movement.

Generally speaking, tropical marine animals live within $5^{\circ} \mathrm{C}$. of their temperature of maximum activity and within $10^{\circ} \mathrm{C}$. or $15^{\circ} \mathrm{C}$. of their upper death temperature. In order, moreover, that a marine animal may live throughout the year in the shallow or surface waters of the tropics it must be capable of surviving at $29^{\circ} \mathrm{C}$. For instance, at Tortugas, Florida, when after several hot, calm days the temperature of the shallow water over Bird Key Reef rose to $33^{\circ}-38^{\circ} \mathrm{C}$., it was observed that large numbers of Diadema, Octopus, Fissurella, and other molluscs and small fish were killed over extensive areas. Corals also were injured even when not exposed to the air. Experiments conducted at the Murray Islands (Australian Great Barrier Reef) show that those corals which die at temperatures below $365^{\circ} \mathrm{C}$. are killed by being buried eleven hours under the mud, but those which resist $37^{\circ}$ and above are proportionately less sensitive to the smothering effects of mud and may survive burial for thirty to forty hours. This suggests that high temperature produces death by causing asphyxiation, the oxygen of the sea-water being insufficient to sustain the increased metabolic activity of the animal (Mayer, I9I4).

Certain forms (e.g. Cœlenterates and Sponges) have been shown to enter on a quiescent phase during the heat of the day in the tropics and to become active again later. Thus Annandale (1907) finds that for some hours in the middle 
of the day the currents of the fresh-water sponge Spongilla cease, and the oscular collars are somewhat contracted. This is a response to unfavourable conditions analogous to the retraction of an anemone at low tide.

Mayer (loc. cit.) observes that it is easy to see why certain forms are confined to the tropics as they lose all power of movement at from $10^{\circ}$ to $12^{\circ} \mathrm{C}$; indeed, he thinks it probable that no single factor is a more effective barrier to the extensive geographical range of marine animals than is that of temperature. The temperature factor is, of course, not always decisive, since, as Mayer points out, the tropical Limulus polyphemus from Florida survives being frozen into the ice and from near its northern limit (off Massachusetts) continues to move until heated to at least $40^{\circ} \mathrm{C}$. Yet it is not world-wide, only ranging from Maine to Yucatan. Interesting also is the fact, noted by the same writer, that when a boreal animal becomes acclimatised to the tropics its upper death temperature is raised, and, conversely, it becomes unable to withstand a degree of cold in which its northern relatives may thrive. Its optimum temperature is, however, raised even more conspicuously than its death points, and thus its factor of safety against abnormally high temperatures is reduced. Analogous observations have been made at Naples, where Vernon (I899) found that the mean death temperature of various invertebrates ranged from $34^{\circ}$ to $42.3^{\circ} \mathrm{C}$., and that it was higher for the same species by $0^{\circ} 6^{\circ}$ to $r^{\circ} 3^{\circ}$ in July-August than in March-April, this greater tolerance being associated with a rise in surface temperature of about $10^{\circ} \mathrm{C}$.

Marine animals of the temperate and arctic zones seem relatively more tolerant of excessive cold than do tropical forms of abnormally high temperatures. Thus, Cyanea arctica, for instance, continues to pulsate even when half its bell is frozen into the ice, and after being embedded solidly for several hours it revives at once, apparently uninjured, when the ice has melted.

The above facts are mentioned not for their bearing on the distribution of marine animals, a subject with which 
we are not concerned here, but for the way in which they illustrate the problem of varying temperature, a problem which is evidently presented in its acutest form in the shallow waters of the tidal zone.

The effect of extremes of temperature has been to give rise to many interesting adaptations to seasonal changes. These, as might be expected, are mostly concerned with reproduction and are fully discussed under that heading. Extremes of heat and cold tend to produce a similar result ; for instance, in the Mediterranean, the shallow and stagnant waters of harbours, and the like, which are subject to intense putrefaction and excessive heating in summer, are populated by species which mostly reproduce in winter and spring (Lo Bianco, r91 I). Such conditions are probably rare around the coasts of Britain, where cold is a more important factor. Prolonged frosts have been shown to have a material effect on mussel beds, particularly those higher up the shore, which are uncovered for many hours a day. Similarly an intense frost may kill large numbers of cockles. In the winter of $1904-5$, when the whole of the Lancashire coast-line was covered with ice-floes for a considerable time, many hundreds of tons of dead cockles were washed up by the first gale after the frost had disappeared (Scott, I909). Unfortunately there are very few data dealing with the effects of temperature on the occurrence of shore animals, at least round British coasts, and a detailed study of a particular piece of shore at all seasons should be very instructive.

Where the cold is so intense as to cause the water to freeze, the effect on the shore fauna and flora is particularly deleterious. At Woods Hole, where sheltered portions of the coast are at times during the winter more or less completely frozen over, the movements of ice along the shore and through channels, whether due to the rise and fall of the tide, to storms, or to tidal currents, serve to scrape bare the large stones and boulders so that they are frequently almost or entirely bare of algæ when the ice disappears in the spring. The same is sometimes true of the common barnacle ( $B$. balanoides) which covers these surfaces in 
summer (Davis, 19r3). For a similar reason, so Dr. Bruce informs us, Arctic and Antarctic shores are entirely devoid of invertebrate animals.

To some extent, as we shall see in a subsequent chapter, the extremes of temperature are avoided by means of seasonal migrations when the fish of rock pools : blennies, gunnels, gobies, and Crustaceans such as the edible crab (Cancer pagurus) and lobster (Homarus vulgaris) retire to deeper water.

Gosse (see Bate and Westwood, I863) found shorehoppers (Talitrus locusta) burrowing some inches deep in decomposing beds of algæ, so hot that he could hardly bear his hand among them. This occurs in summer when the creatures are in need of moisture. On the other hand, such beds of rotting algæ afford warm shelter for these animals during periods of frost and snow.

The Effects of Varying Salinity.-Littoral waters are continually receiving large quantities of fresh water from the adjacent land by streams and rivers. The influence of fresh water is most felt at certain seasons, and is most marked in the neighbourhood of large estuaries, though there are no figures to show how far this influence extends; probably not to a great distance. On the other hand, there is rarely a patch of rocky foreshore which does not receive its quota of fresh water, a fact which is demonstrated by the invariable presence of the green Enteromorpha. As we know that fresh water is poisonous to the majority of marine animals, it remains to be seen how shore forms are able to resist a degree of dilution of the salt content of the water which is often extreme. The question, which is an exceedingly difficult one, depends on the degree of permeability of living membranes by solutions of varying composition and density.

Several authors have established on different animals (Dreser and Winter on mammals, Bottazzi on marine invertebrates) that the glandular secretions have an osmotic pressure equal to that of the blood of the same animals. The experiments of Bottazzi (see Florentin, 1899) show, moreover, 
that among marine invertebrates the osmotic pressure of the internal fluid and that of the external water are in equilibrium: there is thus isotony or equimolecularity between these two liquids, no matter what the protein content of the blood. Frédericq (1889) finds that the blood of the shore crab (Carcinus monas) has a salt content which varies with the degree of salinity of the water in which the animal is living. For instance, in the blood of crabs from Roscoff (sea-water) he found 3.07 per cent. of salts, whereas in that of crabs from the estuary of the Escaut (brackish water) he found only $\mathrm{I}^{\circ} 4^{8}$ per cent. Similarly the blood of a crab of the genus Maia at Naples living in very salt water gave 3.37 per cent. of soluble salts, whilst at Roscoff the blood of the same animal only contained 3.045 per cent. of salts. By gradually altering the salt content of the medium Frédericq has been able to reduce the salt content of the blood of Roscoff crabs from $30^{\circ} 45 \mathrm{gr}$. per litre to $5^{.} 6 \mathrm{gr}$. of soluble salts per litre. Again, the invertebrates of the Baltic, which is of very low salinity, have only a small percentage of salts in their internal fluids. A similar agreement in the concentration of internal and external fluids is found also among cartilaginous fishes in general. No such agreement, however, is found in bony fishes, where, in consequence, the osmosis must be of a selective kind. The broad features of the phenomenon are, however, the same in all cases : a marine animal placed in fresh water absorbs water and swells, whereas with a fresh-water species placed in the sea the opposite takes place. Frequently the osmotic currents and consequent change in volume affect the tissues to such an extent as to cause death. Where the body is protected by a thick cuticle and diffusion through the skin is impossible, the exchange of salts probably takes place through the thin membrane of the gills, which thus acts as a dialyser. Terrestrial insects, like beetles, with thick cuticle and no gills are able to resist the action of salt water almost indefinitely.

Without our going into unnecessary detail, the numerous experiments on this subject enable us to say that where the change is effected gradually the powers of adjustment of 
shore animals to variations in the medium are relatively enormous. The Polyzoan Membranipora membranacea, for instance, has been found living in brackish water up to one-tenth of the normal salinity. The colony growing in this situation showed variations in the number and arrangement of the cell spines and the number of tentacles; these, however, seemed to be related rather to the movement of the water than to the salinity (Loppens, I 906). On the other hand, animals from near or below low-tide mark, even when the change is accomplished exceedingly slowly, show far less power of accommodation. Beudant, for instance, who experimented as long ago as 1816 (see Frédericq, loc. cit.), by gradually diluting the sea-water in which common shore and off-shore forms were living, showed that forms such as Balanus striatus, Patella vulgata, Purpura lapillus, Cardium edule, Ostrcea edulis, and Mytilus edulis, were able to survive in water that was completely fresh, whereas Haliotis tuberculata, Buccinum undatum, Tellina incarnata, Pecten varius, etc., all succumbed before the experiment was completed (see Plate IX).

While typical rock-shore forms like Balanus, Patella, Purpura, etc., and estuarine forms like Cardium, Ostrcaa, and Mytilus, are able to tolerate water which is completely fresh, there is undoubtedly a mean optimum salinity for each of these species, and it is only when exposed to this that the animal is capable of reaching its full development. What this optimum salinity is seems never to have been determined for the majority of shore forms, but for species of economic importance it has been ascertained empirically to within fairly narrow limits. In many estuaries, for instance, where the bed of the main channel is stony, mussels may be distributed from the lowest outlet to a point a couple of miles upstream, as in the river Dovey, which enters Cardigan Bay. Only those mussels, however, which are situated some distance up from the mouth of the estuary are capable of growing to marketable size. The shells of bivalves which have grown in unfavourable conditions of salinity are typically stunted and often deformed. In cases of this kind 
salinity may quite well be more important than temperature. On the other hand, the close dependence of off-shore forms on a definite degree of salinity is well shown by an unusual extension, in 1917, in the distribution of the Shipworm (Teredo diegensis) in San Francisco Bay (Barrows, I9I7). A salinity of at least ten parts per rooo seems to be required for the existence of this pest, at temperatures ranging from $6^{\circ} \mathrm{C}$. to $19^{\circ} \mathrm{C}$. An increase in salinity of as little as three or four parts per 1000 above the minimum causes the worms to increase considerably in numbers and stimulates their activity. On the other hand, during a season of heavy rainfall, when much fresh water enters the bay, they may be killed off entirely, though reinfection may occur during the next summer and autumn, and in dry seasons the shipworms increase so as to become a very serious pest.

Phenomena of an essentially similar nature to those which cause the variation in salinity and temperature of coastal waters in general, are regularly affecting, in a similar manner, the conditions of life in shore pools deserted by the tide. The smaller the volume of water in the pool, the more intense are the effects. Under the influence of a strong sun the density of the water increases rapidly, as does also the temperature. Rainfall, obviously, has the reverse effect. According to Issel (I9I8) the salinity of rock pools may vary from a little above 2 or 3 grams per litre of dissolved salts to over 300 grams of salts per litre. The same writer has made some interesting observations on the behaviour of the flagellate Protozoan Carteria subcordiformis, and that of the Copepod Harpacticus fulvus in shore pools under evaporation. The former is sometimes present in such numbers as to colour the surface of the pools green. By the time the water in these pools has become strongly saline, about $I^{\circ} 125$, these animals have come to rest and show no sign of life. They have entered upon a period of latent life and may survive in this condition for 2 or 3 weeks, recovering on the salinity of the water being reduced again to normal. Herdman (1892) has made similar observations 


\section{PLATE $\mathrm{X}$}

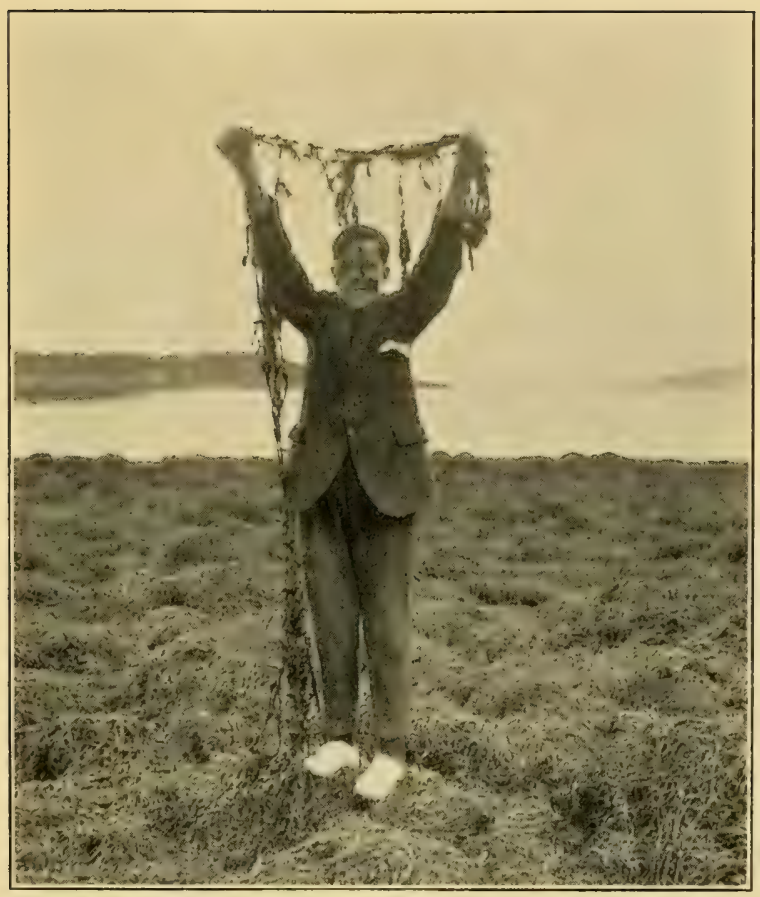

I.--Strands of Ascophyllum.

Their great length plays an important part in absorbing wave-shock.

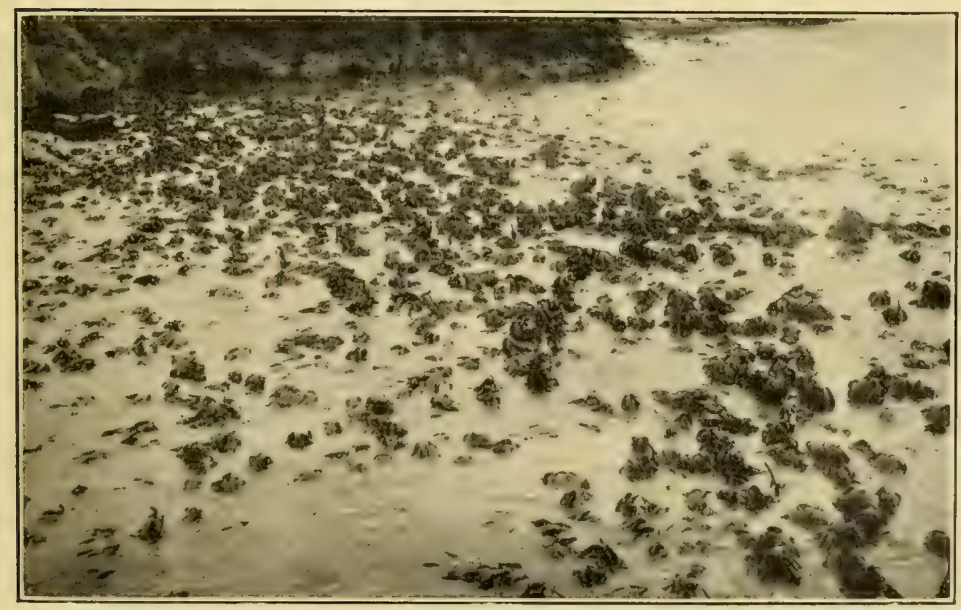

II.-Laminarian Zone partly uncovered (Cove Bay, Kincardineshire). The richest portion of the shore : only uneovered at spring tides. 

on the effects of salinity in relation to Copepoda. He has found that the green weed Enteromorpha intestinalis, which covers the pools above high-water mark, harbours enormous quantities of Copepoda belonging to the genus Harpacticus. The condition of some of the pools suggested that these animals would probably be able to stand considerable variations in the salinity of the water, as in wet weather they are flooded with rain while in dry summers the pools become almost or completely dried up.

Herdman took sample tubes containing Enteromorpha and Harpacticus and added fresh water until there were 19 parts of fresh water to $\mathrm{I}$ part of original sea-water. The Enteromorpha appeared healthy and the Copepods had increased greatly in numbers and were very active. The young ones hatched in the nearly fresh water were all colourless, but the adults had not lost their original bright red tint.

A second sample tube containing Enteromorpha and Harpacticus, and sea-water from the pool, was emptied into a shallow glass and allowed to evaporate slowly. The Copepods did not increase in numbers, but they did not die until the dish was almost dry and the salt had crystallised out round the edges. After evaporation had been going on for a few days the Copepods had retreated into the interior of the Enteromorpha filaments. Possibly under natural conditions they escape death in this way when pools have dried up.

Similar powers of resistance are possessed by Entomostraca from salt marshes, where the density of the water is even more variable than in rock pools. We have, for example, the classic experiments of Schmankewitsch on the Phyllopod Artemia salina. According to Feronniere, Artemia salina resists a density as great as $1 \cdot 16$ in the salt marshes of Lorraine, and according to Artom (quoted by Issel, op . cit.) up to 123 in those of Cagliari. Calman, even, has found in a variety of grey salt consumed in this country, mixed with the salt crystals, numerous eggs of Artemia, which in water of suitable salinityare capable of developing in normal fashion. 


\section{THE BIOLOGY OF THE SEA-SHORE}

Retrospect.-We have now discussed the different problems confronting shore animals and given brief illustrations of the way in which they are met. Some of these problems are of such importance as to have had a profound effect on both structure and behaviour.

In particular, the feature of the shore as a region of intense dynamic action - the biological importance of the wave, in fact--is reflected in the numerous devices to secure adhesion and especially in the small size and squat shape of the animals inhabiting there. Where shells are present (as in numerous shore Gasteropods) these are typically stout, flattened, with reduced spires, coarsely sculptured and severely inornate. The limpet shape is the most typical.

The other great feature of the shore, viz. as a region of extraordinarily fluctuating conditions, is reflected in the possession by shore animals of a greatly increased adaptability and a marked capacity for weathcring sudden changes ; in short, a greater tenacity of life. On the other hand, it is safe to say that in the majority of cases, a place has been obtained on the shore only at the cost of surrendering considerable periods of potential activity. 


\section{CHAPTER V}

Some Methods of Attack and Defence among Shore ANIMALS

IN the foregoing chapter we have discussed the methods by which shore animals cope with some of the chief problems offered by their environment. We have now to deal with another aspect of the struggle for existence on the sea-shore, namely the conflict between the animals themselves. It is safe to say that in no other area are the weapons and stratagems of offensive and defensive warfare so varied in character as on the sea-shore. This is the logical outcome of the many advantages presented by this particular habitat: light, aeration, abundance of plant-food, the presence of a substratum, etc. Moreover, the same comparative isolation of shore areas due to the shallow waters (and the consequent importance of even low physical barriers) which has favoured the evolution of new forms has also stimulated the production of new methods of sustaining the conflict.

The methods of attack and defence with which we are to deal are essentially those employed in the struggle for food among animals of different kinds, e.g. carnivores and herbivores. There is, however, a type of struggle which, having a somewhat different biological significance from that of attack and defence as generally understood, demands separate consideration. This is the tendency, an outcome of crowded shore conditions, for many animals to lodge on the bodies of others. We are not dealing here with cases of parasitism nor of commensalism (properly so called), but more especially with those of sessile forms : hydroids, polyzoa, barnacles, etc., settling on the bodies of other 
species in exactly the same way as they would on an inorganic substratum of rock. This may be a serious matter for the species providing the foothold, its movements being impeded or its growth stifled. It is advisable to give separate consideration to this factor in the struggle for existence, as its biological significance is of a different nature from that of attack and defence as generally understood.

Devices to secure Unimpeded Growth or Movement.(a) In Plants.-The broad fronds of algæ such as Laminaria offer particular advantages to encrusting animals, and to adhesive forms of spawn, but in the majority of cases it is probable that the functions of the plant are very little incommoded thereby. Occasionally galls arc formed, but not necessarily by encrusting forms. For instance, the empty air-vesicles of Ascophyllum nodosum are often invaded by the larva of Mytilus edulis. Tobler (r909) has shown that in such cases the growth of the larval shell causes the plant tissue to split. The breaking away of parts of the frond necessitates a strengthening of the mechanical tissues, and this is provided for by a development of the medullary hyphæ.

(b) In Animals.-The tendency of shore forms to assume an encrusting habit has alrcady been noticed (Chapter IV), when it was shown to be of value in resisting wave-shock. It is not difficult to see that in the crowded conditions of shore life, any form offering a suitable surface is likely to be encrusted or settled upon either by the same or by a distinct species. Other factors than chance, however, are concerned since, according to Harmer (1896), many species of Polyzoa "show a decided or even exclusive preference for particular situations ; as, for instance, species of Triticella which are only found on certain Crustacea." Many encrusting forms prefer the inside of dead shells of Pecten, Cyprina, etc., to any other habitat; Terebripora excavates tubular cavities in the substance of the shells of Molluscs ; Hypophorella inhabits passages which it forms in the walls of the tubes of the Polychrts Lanice and Chrotopterus. One of the Cheilostomata, Lepralia foliacea, forms masses which may 


\section{METHODS OF ATTACK AND DEFENCE 87}

reach a circumference of several feet, simulating a small coral-reef. Its contorted plates are a perfect museum of Polyzoa, "so numerous are the species which delight to find shelter in the quiet interstices of the colony. The exquisite little colonies of Crisia eburnea are commonly found on red seaweeds, or on the branches of the Hydroid Sertularia."

In the case of Hydroids the form attacked has no special means of warding off the epizoic form, but each endeavours to outgrow the other. Warren (I909) has twice found the Hydroid Lafœea dispolians sp. n., growing up inside the hydranth of Sertularia bidens, and supplanting the original polyps by its own. Both cases illustrated

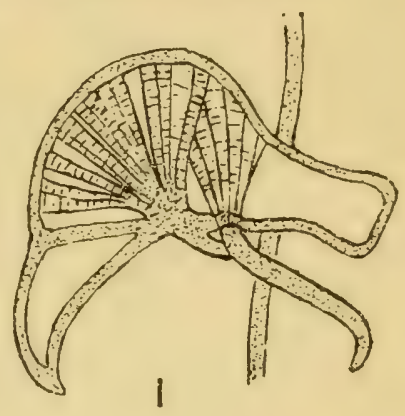
in a striking manner the struggle of the host to squeeze out the parasite and shut it off from its depredations. The term parasite employed by Warren is perhaps too strong; what he is describing is simply a severe case of animals of similar habit competing for foothold.

The avicularia and vibracula of certain genera of Polyzoa, in addition to their food-catching functions, are probably of ser- FIG. 6.-Avicularium of Polyvice in picking off intruders zoan. (1) Open; (2) closed. such as the larvæ of encrusting forms, and removing foreign particles which might tend to obstruct the functions of the colony. An avicularium is a modified Polyzoan cell or zoœcium with, in typical cases, a strong resemblance to a bird's head, each avicularium being provided with two long snapping jaws worked by powerful muscles (see Fig. 6). A vibraculum represents a further modification of a zoœcium, 
being exceedingly long and forming a whip-like process which sweeps through the water.

Structures with a similar function to those of avicularia are characteristic of many Echinoderms. These are the

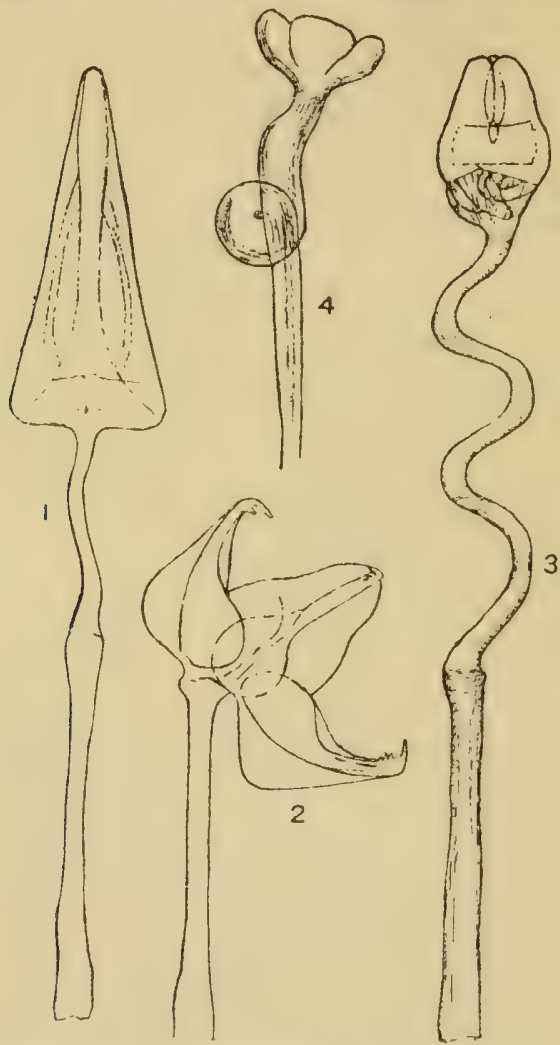

Fig. 7.- Pedicellarix of sea-urchin (Echinus). (I) Tridactyle (after Chadwick); (2) Gemmiform (after Chadwick); (3) Ophicephalous (after Chadwick); (4) Trifoliate (after Uexküll).

pedicellariæ (see Fig. 7), which may be regarded as modified spines. They occur scattered over the surface of the starfish and sea-urchin, but reach their greatest development in the latter group. In Echinus esculentus there are four varieties of pedicellarix: " tridactyle," "gemmiform," " trifoliate," 
and "ophicephalous," the functions and reactions of which have been studied by von Uexküll (1899). Each pedicellaria includes a clawed portion or head with an independent nervous centre controlling the opening and closing of the claws or blades. The "head" is supported on a long stalk, also innervated, and rigid or flexible as the case may be. Two only of the four types concern us here : the tridactyle and the trifoliate pedicellariæ. These have been shown by von Uexküll to be concerned with the removal of foreign material from the "test." The tridactyle form is large and conspicuous with three pointed blades each with a double row of teeth along its edge, borne on a slender stalk. The blades, which close very accurately, are worked by distinct sets of adductor and abductor muscles. A very slight mechanical stimulus is sufficient to throw the pedicellaria into action and to cause them to grasp and destroy foreign organisms such as the minute swimming larvæ of various sessile parasitic animals which would otherwise settle on the delicate exposed ectoderm of the sea-urchin. In consequence Uexküll calls them "snap-pedicellariæ." The trifoliate pedicellariæ are of much smaller size. Their function is similar but their method of action affords an interesting contrast. Any prolonged general irritation of the skin, such as bright light or a rain of particles of grit or mud, will bring them into action, and they have the peculiarity that the blades do not close simultaneously, so that an object may be held by two blades and smashed by the third. Their function may be studied by causing a shower of ground chalk to fall on the animal, when the particles are seized and broken down to an excessively fine powder which the cilia covering the skin speedily remove. In view of their function of removing foreign particles Uexküll has given them the name of " cleaning pedicellariæ."

It is evident that Echinoderms, particularly sea-urchins, with their sluggish habits and broad, firm surface, are particularly liable to being settled upon by encrusting organisms. To this serious menace the high degree of specialisation of the cleansing organs is evidently to be ascribed. In this 
connection it is interesting to notice that in forms like brittle stars which have no delicate ectoderm to protect and which practise autotomy in addition, pedicellarix are either completely absent or at most rudimentary.

The higher Crustacea are also, through the nature of their covering, very liable to become encrusted with sedentary forms, especially barnacles. In the University Museum, Aberdeen, is a crab of comparatively small size with its carapace literally loaded with a heterogeneous collection of Lamellibranchs (Ostrcea, Anomia), Gasteropods, barnacles, tubeworms, polyzoa and hydrozoa of various kinds, etc. This assemblage of forms, far exceeding the actual crab in bulk, has evidently grown through each new-comer affording a fresh area of foothold. The crab serves as nucleus for an ever-growing colony. In view of such facts the act of moulting assumes a double significance, for not only does the shedding of the cuticle permit the animal to grow, but it is of immense advantage in liberating it from an embarrassing collection of sedentary forms.

Herdman (1907) remarks on the term "granny crab" employed by Port Erin fishermen to denote a crab of any size above four inches which is of worn and dilapidated appearance. The shell of these "granny crabs" is pitted and stained with black and the great claws are corroded and often broken. The surface is frequently overgrown with barnacles and other foreign bodies. Such crabs are caught in considerable numbers during July and August and are promptly killed by the men, who are under the impression that they are diseased. When eaten, the flesh is said to have a strong, bitter taste, and powerful purgative effect. Herdman states, however, that there is in all probability nothing abnormal about these crabs. They are merely individuals which are nearing the time when in every second year the crab will cast its shell. The practice of destroying them is consequently unwarranted.

The shells of molluscs, particularly those of sessile bivalves, are likewise subject to encrustation. The menace here is not so much from unrelated species as from young 


\section{METHODS OF ATTACK AND DEFENCE 9I}

forms of the same species. For instance, mussel beds are much subject to overcrowding, the older forms becoming gradually suffocated beneath an ever-growing mass of younger individuals.

The mollusc Crepidula normally attaches itself to other shells, either of the same or of unrelated species, and as many as five individuals may occur one on top of the other in a manner that has been likened to a sky-scraper.

It would be unwise to conclude from the preceding account that epizoic forms invariably constitute a menace to their host, but it is difficult to determine at what point the association ceases to be harmless. Undoubtedly, encrusting forms are often of considerable benefit in helping to hide the underlying species or to render it less conspicuous. Not only so, but cases occur in which active encouragement is given to epizoic forms. In short, there are three possibilities : an epizoic association may be trivial, indifferent and may remain so, or it may be seized upon and utilised or may sink into a drawback.

\section{TACTICS OF THE SHORE STRUGGLE}

Masking.--The long-legged spider-crabs (e.g. Inachus, Hyas) have evolved the habit of planting out upon their hairy carapaces all kinds of seaweeds, hydroids and the like, the result of which is to render them almost invisible in their normal environment. Specimens with their bodies covered with algæ, when placed in a tank among sponges have even been observed to pick the former from their bodies and to plant fragments of sponge in their place (see Fig. 8).

In some forms (especially Galatheidea and Dromiacea) the last two pairs of thoracic limbs are reduced in size and are carried. pointing dorsalwards. By means of these upturned appendages (chelate in the Dromiacea) the crabs are able to hold shells and similar objects (in tropical forms, even mangrove leaves) upon their backs.

It is scarcely necessary to point out that masking and 


\section{THE BIOLOGY OF THE SEA-SHORE}

other similar phenomena are often just as important for offensive as for defensive purposes, enabling the animal to

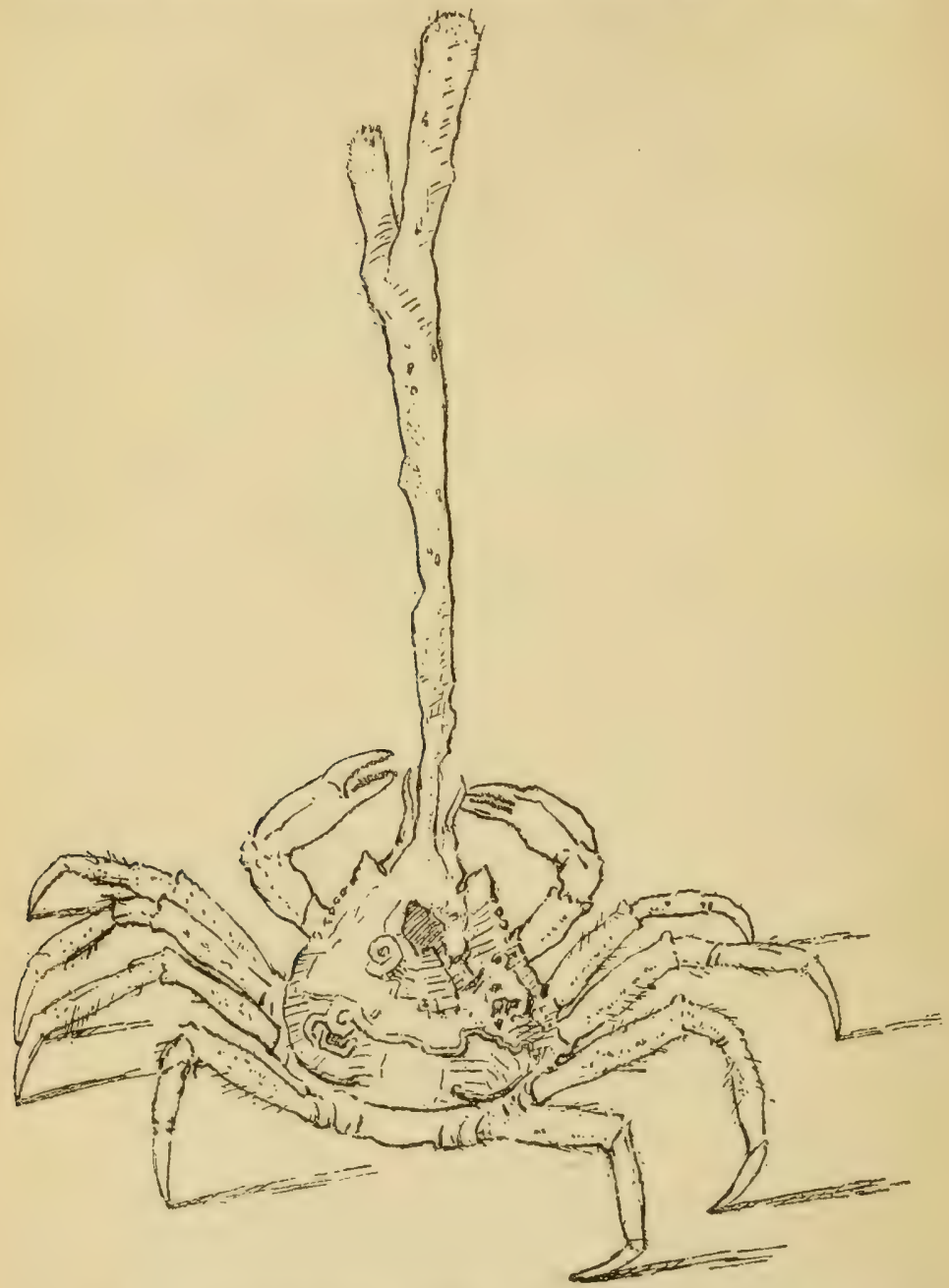

Fig. 8.-Spider-crab partly masked by sponge on front of carapace.

stalk its prey or to lie in wait for it unseen. For instance, the habit possessed by Tealia crassicornis of covering its warty body with particles of shell and gravel found in shore 
pools is of value in concealing the anemone from its prey rather than from enemies.

In spite of its chance nature, the menace to certain forms from being settled upon by other animals is so serious as to have led, as we have seen, to the elaboration in certain cases of special cleansing organs. In other cases it would appear as if this chance factor had been brought under control, and, from being a menace, had been turned to the positive advantage of the animal.

Leaving the subject of encrustation, we now turn to a consideration of the stratagems and weapons employed in the direct conflict between hunter and hunted.

Hiding.-It is a commonplace feature of the struggle for existence among animals that the weak find safety in hiding. As Frédericq (I889) puts it, "l'animal chassé se cache," and there are manifold ways in which the weaker forms elude pursuit : by hiding under stones and seaweed, by burrowing, by taking refuge in shells (hermit-crabs), and so on. The habit of burrowing is very common on the shore and indeed in marine forms generally. On the shore, it is doubly valuable as securing immunity both from enemies and wave-shock. All phases of the habit are exemplified: from the swimming crab, which merely shovels sand over its body by means of the last pair of paddle-like thoracic limbs, through the numerous Annelids, such as the lugworm, to the highly specialised species such as the shipworm (Teredo), and the Piddock (Pholas), which excavate wood and rock respectively. A discussion of commensalism, which perhaps represents an elaboration of the hiding habit, is reserved for a later chapter. Another obvious means of securing safety is by rapid flight or by its antithesis "death feigning."

"Death-Feigning" or Hypnosis.-Certain animals when disturbed show a sudden complete cessation of activity akin to death. A similar state can also be induced experimentally in a number of forms. As Thomson puts it, " in the state of animal hypnosis, seen for instance when a snake 'becomes a stick,' there is a sleep-like inability to move 
or to 'right' the body when placed in an abnormal pose. There is a striking change in the tone of the muscles and a great decrease in sensitiveness to touch and to pain."

Among shore animals this phenomenon may readily be observed in Carcinus monas, Cancer pagurus, and other Crustacea. On being seized in the hand the two species just mentioned become perfectly rigid. There is a characteristic difference in the manner of disposing the appendages (thoracic). In Carcinus these are extended almost at right angles to the body, the last joints alone being somewhat bent, whereas in Cancer they are folded neatly over the under-surface of the thorax as if to protect it.

Frédericq (op. cit.) mentions Neritina sps., which creep over the surface of submerged stones and when touched quit their hold and fall to the bottom of the water. This is analogous to the habits of certain terrestrial insects. When a stone under which Porcellana platycheles is hiding is upturned the crab will often "sham dead," and owing to its frequent resemblance to its surroundings will then be quite inconspicuous.

One should guard against too readily assuming that this habit of death-feigning is primarily or necessarily of an adaptive nature. Issel (I9I8) remarks that a state of hypnosis due to loss of muscular tone is not necessarily induced by the sight of another animal or by brusque contact with it. Slight variations in the external medium are sufficient : an inequality in the substratum, a difference of temperature or of illumination; indeed, slight stimuli are more effective than strong ones. Recent experiments on Phasmids (stickinsects) tend to show that in these animals "shamming dead" is of the nature of a rhythmic phenomenon, i.e. it occurs at definite intervals, and is not a direct response to any external stimulus. Possibly the adaptation is secondary. According to Bohn (I9II) the phenomena of death-feigning are akin to those of "differential sensitivity" exhibited by unicellular animals or tubicolous worms.

Protective Resemblance.--Many shore animals, particularly those which are without skeletal protection, and are 


\section{METHODS OF ATTACK AND DEFENCE 95}

able neither to fight nor to run away, are rendered inconspicuous by their close resemblance to their surroundings. Such resemblance is usually regarded as having been fostered by natural selection, and is therefore termed "protective." It should be borne in mind, however, that in many cases the term " protective" (like the term " adaptive ") is applied merely a priori, and has no strict scientific value unless the protective function has been demonstrated experimentally. It frequently happens that an observer is tempted to draw rash conclusions from the chance occurrence of an animal of a particular colour upon a seaweed of the same hue and will allow cases of contrast to pass unheeded. For instance, the Polychæt worm Eulalia viridis, when it occurs on a green weed such as Ulva is quite inconspicuous, but being an active species it occurs just as frequently on red and brown seaweeds.

We shall content ourselves with selecting for comment a few of the many cases where a shore animal shows distinct resemblance to its environment.

Generally speaking, cases of protective resemblance are most frequent among Crustacea and Mollusca. The commonest shore Coelenterates, viz. anemones (particularly Actinia equina), show a marked diversity of coloration which is apparently quite incapable of explanation in terms of the environment. Mortensen (1914-16), in his interesting paper on protective adaptations and habits in marine animals, states that worms, Echinoderms and Tunicates are all poor in adaptive phenomena, whereas among Crustacea there occur some of the finest cases of protective resemblance known. The habit of masking in this group has already been discussed. Over and over again, when examining dredge material on his Pacific expedition, Mortensen took for pebbles what were really crabs. Crabs of the genus Parthenope (Lambrus) are wonderfully protected, some by long claws resembling pieces of old coral branches while the body looks like an ordinary pebble, others by the carapace being expanded into flat crests covering the legs completely, the animal from above looking like an old bivalve shell. On 
the shores of Hawaii, near Hilo, and on those of Tobago Island in the Gulf of Panama, was found a shrimp of the genus Hymenocera, not merely resembling red algæ in colour, but actually simulating their broad flat iridescent "leaves " though, curiously enough, the animal was not living among the algæ.

On British coasts a common example of protective resemblance is afforded by the Porcelain crab (Porcellana platycheles). Herdman (I892) notes that, on Puffin Island, where it frequents the under surfaces of irregular fragments of carboniferous limestone, the animal with its flat body tends to take up its position in slight depressions on the rock where the dirty greyish brown colour of its carapace corresponds exactly with the muddy surface of the decaying limestone. Moreover, to heighten the resemblance, the tiny hairs with which the limbs and carapace are fringed entangle mud and dirt, and so help to grade the body off into the surrounding stone.

Numerous cases of close resemblance to surroundings have been recorded in British Nudibranch molluscs. Often the resemblance is heightened by the form and coloration of the "cerata." These are outgrowths of the body wall, and a characteristic feature of Nudibranchs. According to Herdman and Clubb (1892) they are of two distinct kinds : they may contain diverticula of the liver, and be directly concerned in digestion, e.g. Aeolis and Doto; or they may be simply lobes of the skin with no connection with the liver, and no special functions to perform, e.g. Tritonia, Ancula, Dendronotus. The form Tritonia plebeia (fairly abundant at Puffin and Hilbre Islands) is found creeping on colonies of Alcyonium digitatum, and in no other situation. The polyps of a colony differ markedly in colour, size, and degree of expansion, and the Tritonia is found to differ accordingly. In large measure the resemblance is due to the "cerata," which are placed just the right distance apart, and are just the right size and colour to resemble the crown and tentacles on the half-expanded polyp. The brown Runcina hancocki is said to crawl over brown mud and seaweeds, but to "avoid" 
green weeds. On the other hand, green specimens of Hermea dendritica are said to "avoid" red weeds, and to "choose" the colour which matches their own. The commonest species of Dorid in the Mersey, Lamellidoris bilamellata, is richly coloured with yellow-brown and though a striking object when placed in a white dish or in clear water is quite inconspicuous on the dark purple-brown rocks spotted with patches of adhering mud, sand, small algæ, and zoophytes. Again, Rostanga coccinea and Doris flammea live on red sponges (the former on Microciona altrasanguinea) to which their colour is closely assimilated; forunna johnstoni frequently occurs on stones associated with Halichondria panicea which it resembles so closely in outline, colour, character of surface and projecting plumes as to be hardly distinguishable; Calna glaucoides eludes observation among the fish-eggs which it eats, and many forms bearing prominences or branched processes such as FEgires, Doto, or Dendronotus have been noticed to correspond exactly in colour with the Bryozoa or algæ which form their usual habitat. Finally, Hermea bifida occurs on red seaweeds of the genus Griffithsia. Though the shapes of plant and animal do not correspond, yet in the water the outline of the latter becomes blurred, and the only conspicuous features are the red hepatic canals in the body, and their red diverticula in the cerata. These are the exact counterpart of the fine branches of the seaweed in form and colour, the latter, indeed, being transferred from the plant to the animal which sucks its juices.

Examples of protective resemblance in shelled Gasteropods are less frequent, and a reason does not seem far to seek. Walton (1913) remarks, however, that the distribution of Littorina obtusata is coincident with that of Fuci, and that the shells of the former often bear a striking resemblance in both form and colour to the vesicles and conceptacles of the algæ on which they live, so much so that he has himself mistaken the vesicles of the algæ for the shell of the mollusc. "The conceptacles are of shades varying from white to bright yellow, and indeed the whole of the parts of the 
plant exposed to sunlight are frequently much lighter in hue than the more sheltered portions, which are usually dark brown or olive." He has found that the darker varieties of $L$. obtusata are seldom found upon the surface of the algal masses, and that the greatest resemblance is between light brown and yellow shelled varieties and the vesicles of $F$. vesiculosus, and between the colour of the frond and the ordinary brown and olive shells. But yellow shells may be found at times on the dark stems, and are then very conspicuous. Many shells which, when seen dry, appear out of harmony, are not so in reality when wet.

In considering the resemblance which so frequently occurs between associated forms, the possibility of this being of a convergent rather than a protective nature must be borne in mind. Thus, says Eliot (1910), whatever the causes which give a certain sponge a particular appearance they must also affect the Dorid which lives on the sponge, at least so far as they are external and concerned with water, temperature, and general surroundings. Hence also the resemblance between certain Holothuroids (Psolus spp.), Turbellarians (especially Polyclads with tentacles), and molluscs such as the Elysiidæ.

Warning Coloration.--In sharp contrast to the cases we have just been discussing are those in which the coloration of a particular animal has the effect of rendering it extremely conspicuous. Frequently this vivid coloration is associated with unpalatability or with qualities which render the animal dangerous to eat. For instance, each of the intense blue patches which form a ring beneath the tentacles in Actinia equina is associated with a battery of nematocysts. It is therefore concluded that the vivid coloration associated with the unpleasant taste would, after a few unfortunate experiences on the part of an enemy, leave an impress on the nervous system of the latter sufficient to deter it from making fresh attacks. The colours would thus come to have effectively a warning significance. Poulton (I890) quotes an interesting case investigated by Garstang, viz. that of a Terebellid worm, Polycirrus aurantiacus. Unlike 
the rest of the Terebellids this worm has no tube, but creeps about actively. It is bright red in colour, and has a number of tentacles which on stimulation become brilliantly phosphorescent, and are coiled round the body in protective fashion. When offered to certain fish in the aquarium these worms were, after one or two trials, rejected by them. Upon the tentacles being removed, however, the body was attacked and eaten with relish. Evidently, then, some distasteful property is associated with the tentacles, and it is their bright colour which enables the fish to recognise and avoid them.

Occasionally, it is interesting to note, the cause of the unpalatability is also the cause of the conspicuousness, e.g. uric acid.

Crossland (IgII) concludes from the almost universal occurrence of colour in the family of Chromodorids, and from their habit of crawling about in the open, that the bright colours have some protective value. Distastefulness has been proved experimentally by trying to feed Chromodorids to fishes. The fishes would not eat them though they would swallow pieces of Margaritifera and Balistes which had been soaked in formalin. Some would dash up to a Chromodoris and then turn away after touching it. Others went so far as to take the Chromodorids into their mouth, but at once dropped them undamaged.

On the flats of the coral reef at Little St. Cruz Island (Philippines) Mortensen (op. cit.) remarks the presence of shoals of a small fish, Plotosus anguillaris, which has a long, pointed and barbed erect spine in each pectoral fin and a similar one in the dorsal fin, all provided with poison glands. The fishes, which are black with two longitudinal white stripes on the sides of the back, swim in a close mass making a large ball which seems to roll along over the corals, and is exceedingly conspicuous. These balls can easily be caught in a hand net. A fish when touched stuck to the fingers and caused considerable and lasting pain. Singly, this fish would not be conspicuous, hence the importance of the gregarious habits. 
Mimicry.-The term " mimicry" is applied to those cases in which forms themselves quite innocuous bear a marked resemblance to other forms in the same habitat which have some particularly efficient means of protection, and, consequently acquiring a false reputation, are able to live undisturbed. Cases of so-called " mimicry " are frequently recorded from the shore which should really be placed under the heading of convergent resemblance or under that of protective coloration. Only a very few examples of the phenomenon " mimicry" (in the strict sense of the term) have been recorded from the shore. Mortensen (op. cit.) mentions the little crab Zebrida adamsii from the Pacific which devours the spines, tube feet and pedicellariæ of the sea-urchins Salmacis bicolor and Toxopneustes pileolus, generally following one area from the top downwards. The crab is conspicuously coloured, with brown and white longitudinal stripes, and has curious projections on the legs and body resembling the close short spines of Toxopneustes, the colour of which (brown and white) corresponds to that of the crab. The close resemblance of crab and sea-urchin probably renders the former immune from the attacks of fish, and may therefore be a genuine case of mimicry.

Protective Armour.-Many shore animals have become specialised for defence. Apart from other considerations, the necessity, in many cases, for retaining a firm hold on the substratum in order to resist dislodgment by waveshock makes for sluggish progression, and would render the existence of such forms very precarious if it were not for the presence of some special form of protection. We may distinguish three chief means of defence.

I. Skeletal Structures forming an Integral Part of the Animal.-The armour in this case consists of limy or flinty spicules which are embedded in the tissues. Under this heading may also be included the hard external skeleton of Crustacea and the shells of molluses which, though completely external to the animal, yet form an integral part of its structure. In addition to their protective function such structures obviously serve to support the body, and to give 
attachment to the different organs. It is thus impossible to disassociate the skeletal function in the strict sense from that of defence.

The life of sponges depending upon the maintenance of a continuous flow of water through the pores and out at the osculum, the occurrence of a very efficient system of protection, in the form of myriads of sharp spicules, occasions no surprise. Around vital parts such as the oscula the spicules are frequently arranged in such a way as to leave no doubt as to their protective function.

The name Echinoderm (Spinyskinned) speaks for itself. The limy plates which are such a feature of this group, sometimes forming a very complete shell or " test," are not external, but are covered in starfish and sea-urchins by a thin layer of epidermis, often to a large extent ciliated. In the sea-urchins the protection they afford is greatly increased by numbers of long spines articulated to them. The base of a seaurchin spine is hollowed out into a cup which fits over a corresponding boss or elevation on the test. A

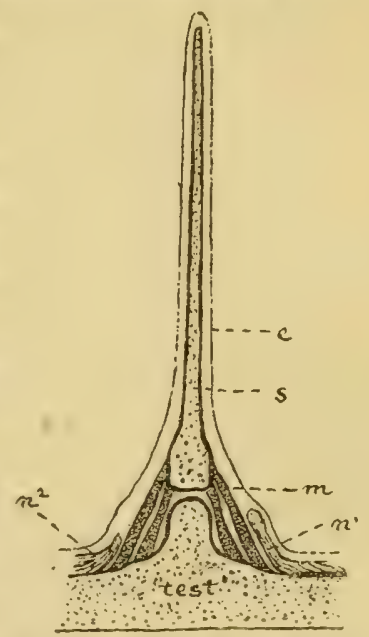

FIG. 9.--Spine of sea-urchin. $e$, epidermis ; $s$, calcareous spine; $m$, muscles ; $n^{1}, n^{2}$, nerve branches.

muscular sheath holds the spine in position and by the contraction of particular fibres can cause it to point in any direction. The mode of articulation is analogous to that of a ball-and-socket joint. Covering the sheath is a layer of skin containing numerous nerve fibres (see Fig. 9).

The chætæ of Polychæt worms are mainly used for locomotion, but it is probable that they have considerable protective significance as well. No attempt has ever been made to explain the enormous variety of form which occurs among Polychæt bristles : many of them with their curious processes and serrations resembling nothing more closely 
than "spillikins." The larger of these, and particularly the stout forms known as acicula, are probably of some use as weapons either of offence or defence; but in any case the occurrence of so many bristles must render the owner very unpalatable as food. In Polynoids the bristles are supplemented by flexible, overlapping scales which protect the back. In Aphrodite aculeata, bristles and elytra form a dense felting which must not only provide valuable protection, but by collecting mud, etc., also serves to merge the animal into its surroundings.

2. Construction of Tubes.-This is a characteristically Annelid habit, though occasionally forms which construct tubular dwellings are met with in other groups also. The forms of Annelid tubes have been discussed in an interesting manner by $\mathrm{M}^{\prime}$ Intosh (I894). In its simplest phase, e.g. in many Oligochæts, the tube is simply a thin envelope of hardened mucus, and is little more than a lining to a temporary burrow. As a development of this we have the more permanent tubes of forms such as Myxicola which are soft and gelatinous, or the Eunicidæ which are parchment-like or even leathery. In Hyalinoecia the material secreted, consisting of a phosphoric salt containing magnesia, and an organic substance called "onuphin," is so firm that the tube is able to stand freely in the mud and the animal has no need of further protection. In many worms the body secretion is of a calcareous nature and forms on consolidation a hard shelly tube. The commonest of these are Serpula, Pomatoceros, and Spirorbis. Probably the most numerous forms of all are those in which the secretion is used for the purpose of cementing together particles of mud, sand, gravel, shell, etc. Some of the tubes so formed provide examples of animal workmanship so accurate and beautiful as to challenge comparison with the combs of bees and wasps and even with the nests of the most skilful birds. The tube of Sabella consists of the very finest particles of mud; Terebella conchilega makes use of shell-fragments, grains of sand, spines of heart urchins, etc., no special regularity marking their arrangement. The tube of Nicomachia is also 


\section{METHODS OF ATTACK AND DEFENCE 103}

quite irregular; Sabellaria, which occurs in immense colonies, makes use only of sand-grains ; Pectinaria builds a very neat tube, in shape like a slightly curved horn, which it carries about with it. The grains are nearly all of the same size and only one layer in thickness. It is among the Amphictenidæ that the most finished tube-builders are found; for instance, the tube of Lagis koreni, abundant on the west sands of St. Andrews, is smaller in shape than that of Pectinaria, but, to quote M'Intosh, " in placing the grains together in the tube there is no haphazard, but angle fits angle, as in a skilfully built wall, and no excess of cement hides slovenly masonry. The tube is perfectly round, and tapers from the narrow lower end to the wider upper end, and its symmetry and workmanship are faultless. The tubes harmonise closely with their surroundings, the wall being formed of similar proportions of pale sand-grains of yellow, brown, and black, probably because in such a selection the average colours are fairly represented."

In Amphictene auricoma the grains of sand are still finer than in Lagis, and where, amongst deep sea mud, the worm is able to employ the spicules of flinty sponges the workmanship is entirely perfect.

This habit of tube-building which, originating in the secretion of a simple sheath of mucus to form a lining for the burrow, has become so wonderfully elaborated, is of double importance in the tidal area, for it affords not only ample protection from enemies, but from desiccation as well, the mouths of many of the tubes being closed by opercula which prevent evaporation at low water.

3. Borrowed Forms of Armour.-It is a wonderful commentary on the keenness of the struggle for existence that discarded forms of armour, such as empty molluscan shells, should have been utilised as houses by forms totally unrelated to the original owner. This is what occurs in the group of the Paguridea, which comprises the Hermit crabs. The habit of lying concealed within a Gasteropod shell is so deep-rooted as to have had profound effects on both the structure and behaviour of the hermit crab. The abdomen, 
for instance, has lost its hard covering, and has become spirally wound in accordance with the shape of the shell, the abdomen thus being equivalent in function to the columella muscle which previously attached the mollusc. The swimmerets are very much reduced, except the sixth pair, particularly the appendage of the left side, which has the form of a hook, and is coiled round the columella. The attachment of the crab to its shell is so secure that it cannot be removed without damage. Some of the hermit crabs (and other species of Crustacea as well) make a similar use of plant structures. For instance, the deep water form Pylodieles miersii found in the Indian Ocean inhabits hollow pieces of bamboo. Since these are quite straight the animal is perfectly symmetrical. The tropical Robber-crab (Birgus latro), the adult of which is practically entirely terrestrial, frequenting the coasts of coral islands in the Indian and Pacific Oceans, and living on coconuts, differs from the true hermit crabs, to which it is closely related, in not making use of a portable shelter, perhaps, as Calman (I9II) suggests, owing to the difficulty of obtaining one of suitable size. The terga of the abdomen have become re-developed and the body is strictly symmetrical. Notwithstanding this, a vestige of the old habit remains, the crabs thrusting their abdomens under logs or into holes among the roots of trees.

Issel (I9I8) describes a habit similar to that of the hermit crabs in the Isopod Zenobiana prismatica occurring on the Ligurian Coast. This form, which is a relative of Idothea, lives in tubes formed of plant debris, either fragments or roots of Posidonia, or in straws and similar structures. Of the seven pairs of thoracic limbs the fourth is rudimentary. They are folded over the back, and at the extremity of the limb are two patches covered with tubercles which aid the Crustacean in sticking to its house. The habits, it is interesting to note, show points in common with those of tubicolous Annelids. For instance, the creatures are acutely sensitive to changes in degree of illumination, the least shadow causing them to withdraw into the tube. Apparently Zenobiana excavates its tube by eating out the pith of the plant tissue. 
Weapons.-Under this heading we shall consider the various structures which have for their object the disablement of foes, but only so far as they are distinct from structures, such as jaws, teeth, etc., which are concerned with feeding in the strict sense, i.e. with the preparation of food for the work of digestion.

Weapons acting partly mechanically, partly by means of Poison.-Frequently, the mechanical action of a weapon is designed merely to inflict a small wound into which a supply of poison may then be poured, and also in a certain measure to hold the animal while it is being paralysed. The commonest weapons of this type are the nematocysts of Colentera, the structure of which is familiar to every zoological student. Briefly stated, a nematocyst is an oval bag filled with fluid and produced at one end into a long whip-like process usually provided with barbs. In the unexploded state the long process is tucked into the cavity of the dilated portion in a neat spiral. The nematocyst is contained in a special pear-shaped cell, or cnidoblast, from the free margin of which there projects a short sensory process or cnidocil. When this process is stimulated the cell contracts and the fluid within being incompressible the thread is jerked out of the capsule with great force. The free end of the nematocyst, while lying in the "ready" position, is bathed in a poisonous fluid. Some of this adheres to the lash when ejected, and enters the wound, or according to another view, makes its way down the interior of the lash and escapes by a tiny aperture at its end (Cuénot).

The arrangement of the nematocysts varies according to the species, but they invariably occur in masses or "batteries." These are particularly numerous on the tentacles, and, in anemones, upon the mesenteries, in which position they serve to administer the "coup de grace" to any organism which still gives signs of activity. Further, in many anemones the mesenteric filaments bear long thread-like processes termed "acontia," which are also armed with numerous nematocysts, and can be protruded 
from the mouth or through tiny pores (" cinclides ") in the wall of the column.

Structures of a similar nature to the nematocysts of Cœlentera occur in several Turbellarian and Nemertine worms, but it is doubtful whether they are homologous with the Cœlenterate forms. The undoubted occurrence of nematocysts in the cerata of Nudibranch (Æolidæ) molluscs has given rise to a great deal of controversy, but the researches of Strethill Wright, Grosvenor, and Cuénot have definitively proved that these are derived from the anemones on which the molluscs feed. The nematocysts pass through the stomach and hepatic diverticula without being digested. Eliot ( $o p$. cit.) summarises the evidence which has led to this conclusion as follows :-

I. Several kinds of nematocysts may occur in one Eolid, and individuals of the same species may have different kinds of nematocysts.

2. It has been shown experimentally that the cnidosacs always contain nematocysts similar to those of the Coelentera on which the Eolid has been feeding, and that the nematocysts found in the hepatic diverticula and fæces are similar.

3. The nematocysts of an Æolid can be changed by changing its food, and those Eolids which feed on animals devoid of nematocysts have none themselves.

The use of the nematocysts by the Æolid seems to be purely fortuitous ; there is no evidence that they are discharged against advancing enemies. On being attacked the animal contracts its body, at the same time erecting and sometimes lengthening its cerata so that the assailant can hardly help touching them. When the cerata are squeezed or bitten the stinging nematocysts are liberated; the assailant probably withdraws and the Eolid escapes with the loss of a few cerata, a fact which seems to cause it little inconvenience. Apparently those Æolids which have no nematocysts, e.g. Calma and Fiona, have specially abundant mucus or offensive glands.

In connection with this partly mechanical, partly 
poisonous type of weapon, Martin (I9I4) proposes the following classification:--

I. Autocnidæ: true nematocysts confined to the Cœlentera.

2. Cleptocnidæ: Cœlenterate nematocysts which have been ingested with the food (Æolids, Turbellaria, etc.).

3. Pseudocnidæ: often confused with true nematocysts, but not homologous. This group includes the nematocysts of certain Nemertines from which a spiral thread can be discharged and those of Turbellaria in which no trace of a thread has been discovered.

4. Polar capsules : strictly analogous as regards development, structure, and mechanism to true nematocysts, but confined to the Sporozoa.

In Echinoderms (e.g. the sea-urchin) the place of nematocysts is taken by the gemmiform pedicellarix. These, the largest of the pedicellariæ, are about $10 \mathrm{~mm}$. long. The " head " is composed of 3 valves or jaws each provided with a poison gland which opens at the base of the tooth forming the apex of the valve. Further, there is present at the base of each jaw on its inner side a sense organ in the shape of a small papilla formed of sensory cells, each of which is provided with a stiff process or hair.

When the sea-urchin is attacked by its inveterate enemy the starfish, the chemical substance exuded by the latter causes the gemmiform pedicellariæ to gape. Upon the enemy coming in contact with the sensory papilla the blades close violently, inflicting a wound which causes the poisonous juices of the starfish to exude. The effect of this is a renewed stimulus, which causes the poison glands to discharge their contents into the wound.

Prouho (1890) has watched a combat in an aquarium between the starfish Asterias glacialis and the sea-urchin Strongylocentrotus lividus. As soon as the latter feels the contact of the tube feet of the starfish it directs its spines away from the part attacked. This discloses the pedicellariæ, which are seen to be stretching towards the starfish with their javs agape. No sooner does one of the tube feet 


\section{8}

\section{THE BIOLOGY OF THE SEA-SHORE}

of the starfish touch the head of a pedicellaria than it is immediately bitten, the pedicellaria remaining in the wound. The effect of such bites is to cause the starfish to withdraw. The first " round " invariably ends in favour of the sea-urchin. If the starfish renews the fight the sea-urchin will eventually succumb owing to the loss of its weapons.

A point of great interest is the fact, emphasised by Prouho, that in such a conflict as the above, the movement of the spines away from the threatened area, is such as to leave the pedicellaria a clear field of action, and is the exact opposite of the convergent movement of the spines produced when the surface of the test is stimulated by an instrument such as a needle.

Weapons acting purely mechanically.-We meet with no examples of these below the Echinoderms. In this group (Echinoids) a last form of pedicellariæ still remains unconsidered, namely, the ophicephalous pedicellariæ. These occur over the whole surface of the test, but are most numerous in the region of the mouth, and are specialised for taking a firm grip. Their function is to assist in holding small animals such as Crustacea till the tube feet can reach them and convey them to the mouth. Strictly speaking, therefore, the ophicephalous pedicellariæ are concerned with nutrition. Just as it is difficult to draw a sharp line between weapons of attack and defence, so it is impossible to dissociate weapons in the strict sense from jaws, teeth, and similar organs which, though chiefly concerned with mastication, may be turned to other uses if occasion requires it. For instance, the pharynx of Nereid worms bears on its muscular inner walls, in addition to numerous small spines, a pair of powerful chitinous jaws. When the pharynx is protruded the jaws become completely terminal, and are used for seizing prey. If one of these forms is picked up in the hand the jaws are at once brought into action, and form powerful weapons of defence. The jaws thus serve the triple purpose of mastication (when the pharynx is retracted), attack, and defence. 
The best example of weapons with a purely mechanical action is furnished by the chelæ of many of the higher Crustacea (crabs and lobsters). The appearance and mode of operation of these are too well known to need description. An interesting fact, however, in the lobster, is the almost invariable differentiation of the chelipeds into a large crushing pincer and a smaller cutting one. The latter kind is more slender in form with numerous accurately fitting teeth along the edges of the blades, while the crushing claw is heavier in appearance, and the teeth are large, blunt, and irregular. The lobster has been seen to hold its prey with the cutting forceps, and at the same time to administer a formidable blow with the larger claw. Indeed, it has been the experience of one of the writers to be treated in this way. Lobsters may be right-handed or left-handed, the large crushing claw occurring on either side. Occasionally specimens occur with the cutting forceps on both chelipeds, and very rarely with crushing claws on both sides.

The strength of Crustacean chelæ is often enormous. Plateau (quoted by Frédericq, op. cit.) has shown experimentally that the left chela of Carcinus mœnas is capable of supporting a weight of nearly two kilograms, which is equivalent to nearly thirty times the weight of the body, while the right chela is still more powerful. Compare this with the average grip of a man's right hand, which, as tested by the dynamometer, is only capable of exerting a pull of $50 \mathrm{kgs}$., or a little more than two-thirds of his own weight.

It is not out of place here to speak of the strength of the adductor muscles of the molluscan shell, as it is largely on this that the safety of these otherwise defenceless animals depends. In estimating the power of contraction of the muscles of various common bivalves Plateau takes not a unit weight of muscle, but a unit sectional area of one square centimetre, as in this way complications due to the number and the length of fibres are avoided. 


\section{Power of Contraction of Adductor Muscles of Common Bivalves (after Plateau)}

Venus verrucosa

Pectunculus glycimeris

Mytilus edulis

Ostrcea hyppopus

Ostrcea edulis

Cardium edule

Anodonta cygnea (fresh-water)

Per sq. c.m.-sectional area

For purposes of comparison the power of contraction of the muscles of a man's calf, calculated on the same basis, may be put at 9000-10,000 grams, that of frog muscle at 3000 grams.

Reciprocal Adaptations on the Part of Foes.-Where a particular form has some inveterate enemy it seems that the struggle between them has favoured reciprocal adaptations of attack and defence, which result in the establishment of a sort of equilibrium in which the two foes are about equally matched. A German worker, Bauer (I9I3), has made some interesting observations, though many of his conclusions are of a distinctly speculative kind. Bauer has observed Nassa reticulata escaping from pursuit on the part of the starfish Astropecten bispinosus by a series of curious leaps, the snail employing the foot as a lever in the same way as the cockle. The movement is such a convulsive one that it is difficult to follow but appears to be a kind of somersault. The interesting feature, however, is that the escaping reflex is only exhibited when the snail comes into direct contact with the skin of the starfish, nor is the snail's body everywhere equally sensitive to the stimulus. It is only when the tentacular-like extensions of the hind end of the body are touched that the reflex occurs. The writer was unable to induce the reflex either mechanically or chemically but only through the medium of a starfish, consequently one is forced to conclude that this is a case of a very specialised kind in relation to a natural enemy. 
Bauer has noticed an absolutely similar case in an animal belonging to quite a different group, i.e. Pecten jacobaus. The remarkable swimming motions of this bivalve are only induced by the chemical stimulus of the secretion of the skin of the starfish. A similar phenomenon with regard to this secretion has been noted above (p. 107) when we were dealing with the function of Echinoid pedicellariæ.

While watching a starfish attempting to overpower an individual of Murex brandaris Bauer came to the conclusion that the strongly developed spines on this Gasteropod are of the nature of a protective adaptation, the starfish being prevented by the spines from enveloping the shell with its stomach. Bauer believes the strange forms of other molluses such as Murex trunculus, Typhis tetrapterus, Trochon carinatus may be due to a similar cause. Again, the young of Australium rugosum have a strong resemblance to a cog-wheel, and so in spite of their small size are still protected from the attacks of the starfish. In the adult animals the spines become less and less well developed, so that their protective value is doubtful. On the other hand, the surface of the shell becomes covered with numerous conchoidal scales, the shell coming to resemble closely a rasp or file.

Bauer also develops an interesting theory with regard to the relations between Gasteropods and hermit crabs as suggested by a conflict in an aquarium between a hermit crab and a snail (Murex brandaris). The hermit crab had fastened on to the Murex and, while holding fast to the spines, endeavoured to introduce its pincers into the shell opening. When, after repeated attempts, the crab had at length succeeded in jamming its pincer a little way between the edge of the shell and the glass of the aquarium, the snail raised itself a little and as the crab, taking advantage of the opportunity, advanced, the snail quickly jumped back against the side of the vessel. This movement was repeated at short intervals, when the crab, either through the shaking or the pressure on its chela, temporarily desisted from its efforts. Shortly afterwards the battle began anew. The crab had again got its pincer under the shell and the 
snail, unable to remove it, altered its tactics. The shell, remaining pressed to the glass, turned quickly round through a considerable angle, so that the anterior portion of the outer shell edge came to lie on top of the wedged pincer. By slowly moving its shell backwards and forwards the snail sawed at the limb until the crab withdrew, released its hold and fell to the ground.

A similar result was obtained, though not quite so satisfactorily, with a piece of wood. In searching for an explanation of the snail's conduct, Bauer remarked that the edge of the shell where it pressed on the pincer was beset by a row of sharp teeth which, used in the manner above described, would act as a powerful saw.

In the light of this phenomenon the relations between hermit crabs and snails seemed to Bauer to be less harmless than has been hitherto imagined, and he set himself to examine them afresh.

If Gasteropod shells inhabited by hermit crabs are examined many are found to be damaged and the fractures have a characteristic appearance. The last turn of the spiral is broken off exactly as if by small tweezers or bone forceps. Other shells are undamaged, and these belong to particular species. Those of Nassa mutabilis, for instance, often show the typical fracture, while those of $N$. lacepedei are always undamaged. Bauer attributes these fractures to hermit crabs, and considers the reason for the immunity of certain forms is to be found in the thickened edge of their shells, on which even the strongest hermit crab is unable to get a grip.

Some shells show periodic thickenings or ribs. For instance, Scalaria communis is distinguished by particularly thick ribs of a strengthening nature. Bauer here comments on the curious fact that he has never been able to find, either in museums or elsewhere, a shell in which the last rib was not exactly at the shell edge. This was the case in spite of the fact that shells, apart from the museum specimens, were collected at all seasons. The portions between the ribs must therefore be formed extraordinarily 
rapidly, the time during which they are under construction being probably one of danger to the animal. According to Bauer, similar phenomena, which possibly have their biological explanation in the relations between foes, are: (I) the reinforcement of the whole of the last turn in the shells of Conus and Cyprcea; (2) the strong calcareous operculum (sometimes with spinous processes) of numerous unrelated forms; and (3) the frequency of the disk-like shape in unrelated groups, which is a protection not only against wave-shock, as in Patella, but against marauders as well.

The observations of Bauer are of considerable interest, and we have accordingly dealt with them at some length, but it would be unwise to regard the various shell modifications which he discusses as being due exclusively to the conflict between foes, though this is no doubt an important factor. Some writers have seen in Gasteropod spines an adaptation to life in the sand, e.g. Hunt (1885); others, again, regard them as the expression of some internal factor such as growth or age (Beecher, I901). It is for the ecologist to unravel these various factors, to determine the manner in which they interact, and to estimate their relative share in the production of a particular form.

Retrospect.-Competition on the shore is extraordinarily keen, and the methods of attack and defence are correspondingly varied. The dense crowding of this area and of its continuation, the shallow sea, gives a clue to the occurrence of special organs such as the pedicellariæ of Echinoderms and the avicularia of Polyzoa which serve to keep the body free of encrusting organisms. This encrustment of certain species by other sedentary forms may be of trivial importance or it may be such as to cause considerable inconvenience. On the other hand, it may be brought under control and turned to advantage Apart from distinct organs of offence and defence we are justified in speaking of " tactics " such as hiding, masking, protective coloration, warning coloration, mimicry, etc., 


\section{II4 THE BIOLOGY OF THE SEA-SHORE}

which may assist an animal to escape its pursuers, or may less frequently be aggressive in character, enabling a carnivorous form to stalk its prey unseen.

Some form of protective armour (spicules, plates, spines) is of particularly frequent occurrence on the shore, since the necessity for retaining a firm hold on the substratum makes for sluggish movement and renders many shore forms very liable to attack. Shells and tubes have the double advantage of protecting shore animals both from enemies and from desiccation at low tide. Offensive weapons may act purely mechanically as, for example, the chelæ of crabs and lobsters, or both mechanically and chemically, as the nematocysts of Cœlentera.

Very interesting is the suggestion that certain features of structure and behaviour have their explanation in the reciprocal relation of attack and defence between inveterate enemies. 


\section{CHAPTER VI}

\section{Autotomy and Regeneration in Shore Animals}

A GREAT many animals are well known to have the faculty of growing anew, or regenerating, portions of the body which have been lost as the result of an accident or of the attacks of other animals. Extreme cases are those in which an entirely new individual may be reconstructed from a relatively small portion of the body that has been left, or where, the body having been divided into two or more portions, as many new individuals are regenerated as there were segments resulting from the division. To give an example: worms, of all kinds, have very considerable powers of regeneration. One of the earliest experimenters, Bonnet, cut a fresh-water worm into as many as fourteen pieces and found that each piece produced a new worm, the anterior end in each case growing a new head and the posterior end a new tail. However much our ideas may vary as to the significance of regeneration, we seem safe in supposing that so marked a capacity for regrowth is correlated with the lowly and undifferentiated organisation of these forms. Broadly speaking, the higher we proceed up the animal scale the less the amount of regeneration that is encountered, until, in the highest vertebrates, such power does not extend beyond the healing of comparatively simple wounds. This rule is, however, by no means without exceptions, some of the most striking cases of regeneration occurring among vertebrates. Newts of the genus Triton, for instance, can regrow both their legs and tail : in a famous experiment Spallanzani caused one of these animals to regrow its legs six times. 


\section{II6 THE BIOLOGY OF THE SEA-SHORE}

A widely held view is that which considers the power of regeneration to have arisen in connection with liability to injury. The more liable an animal is to be damaged the greater would be its regenerative faculty. This view has had particular support from Weismann, and also finds expression in what is known as Lessona's Law, which states that regeneration is most highly developed in those animals and parts of animals which are most exposed to injury. To us, who are dealing with the ecology of the sea-shore, there is perhaps a special temptation to adopt such a view, whence we could proceed with easy conscience to emphasise the special features of the shore struggle which we might regard as having fostered this power of regeneration, as it occurs in a number of shore animals. Unfortunately for such a purpose we feel too strongly the objections which have been urged by Morgan (I9OI) in his work on Regeneration. We may best summarise these objections by using Morgan's own words. "Our discussion," he says, "has led to the conclusion that the phenomena of regeneration are not processes that have been built up by the accumulation of small advances in a useful direction; that they cannot be accounted for by the survival of those forms in which the changes take place better than their fellows, for it is often not a question of life and death whether or not the process takes place, or even a question of leaving more descendants. On the contrary, it seems highly probable that the regeneration process is one of the fundamental attributes of living things, and that we can find no explanation of it as the outcome of the selective agency of the environment. The phenomena of regeneration belong to the general category of growth phenomena and as such are characteristic of organisms."

It is because we feel the force of Morgan's view that regeneration pure and simple is a more or less fundamental property of living matter, and is in consequence by no means a specific attribute of shore animals, that we have decided to leave out of account the numerous experiments on regeneration which have been performed with animals such 
as hydroids, anemones, flat-worms, ascidians, and so on, and to confine our attention to this phenomenon only so far as it occurs associated with the process known as autotomy. The latter process is generally of very much more restricted occurrence than regeneration and is yet of relatively frequent occurrence on the sea-shore, an association of facts which affords us considerable justification for regarding the two processes together as of the nature of a response to environment.

Autotomy is the term applied to the reflex act of throwing off a limb or surrendering a portion of the body in relation to some external stimulus. Probably the most familiar case of autotomy is provided by the lizard, which, when seized by the tail, at once breaks it off at a level corresponding to that of the seventh caudal vertebra, or below, the act being rendered easy of accomplishment by the presence of a special weakened area in the middle of the vertebral " centra." Another interesting example of a similar kind is recorded by Semper and concerns snails of the genus Helicarion which frequent trees in the Philippines. When grasped roughly by the "tail" (posterior end of the "foot") the snails escape in the same way as does the lizard, by leaving this part of the body behind. The most readily accepted explanation of these and similar cases is that they are protective adaptations. The tail of the lizard, for instance, on account of its conspicuousness, is thought to be particularly liable to attack, and since the autotomy provides a valuable means of escape, the process would have been fostered by natural selection. Autotomy does not necessarily always require a breaking plane, but when one is present we think we are right in saying that it is regarded as a refinement of the process: affording the most favourable conditions for subsequent regeneration or, it may be, reducing hæmorrhage.

This view of autotomy as a process which has been fostered by natural secretion has also been criticised by Morgan, who finds the same difficulty in picturing its evolution on these lines as he does that of regeneration. Morgan's 
criticism need not, however, greatly disturb us in this case, since it is directed chiefly against the Darwinian theory of the manner in which adaptations arise, and he does not, as in the case of regeneration, deny the influence of the environment. Certainly, in some cases, a relation between autotomy and the problems of the environment does appear to exist, and Morgan himself can find no other explanation of autotomy than " as an adaptive response of the organism to its conditions of life." We may now, however, leave general considerations on one side and turn to an examination of the numerous cases of autotomy encountered on the shore.

Autotomy and Regeneration in Decapod Crustacea.The faculty of shedding a limb is found in a number of crustaceans, but varies considerably in the degree of its elaboration. Basing our account on recent work by Paul (I9I 5), we may begin, as he does, by considering the prawn (Leander squilla), which exhibits autotomy in its least specialised form.

When seized roughly by a leg the prawn extends the basal segment and, jerking itself backwards by a violent flap of its tail, causes the leg to fall off at the joint between the second and third segments. This is the normal form of autotomy, and in prawns taken from the sea with a leg missing the break has always taken place at this precise point. A curious modification of behaviour is seen, however, when a limb is severed quickly with sharp scissors. The backward jump still takes place, but the limb is not autotomised and the animal, on quieting down, flexes it in towards the mouth and begins pulling at it with its jaws (autophagy). Later, the limb resumes its normal position except that for a brief period the next sound joint is sharply flexed, a process which is thought to limit hæmorrhage.

In the lobster the process of autotomy is developed a step further. The rupture of the walking leg takes place, as in the prawn, at the region of the joint between the second and third segments, but a new element has now made its appearance, since the break, instead of involving only a 


\section{AUTOTOMY AND REGENERATION}

tough membrane, is partly through brittle calcareous matter as well. In the case of the great claws there is a breaking joint at the base similar to that in the crab's leg, which we are to study presently. Autotomy takes place only when the limb is roughly held or crushed; a clean cut with sharp scissors across the limb does not result in the remainder of the limb being thrown off, but produces attempts at autophagy as in the prawn. The fact that the walking leg of the lobster requires to be held to produce autotomy suggests to Paul that autotomy is mainly of advantage as a means of escape.

It is, however, in the Brachyura, or true crabs, that the autotomy reaches its highest development. In the walking limbs and chelæ of all Brachyura there is a definite breaking plane situated in the middle of the second segment from the base (basi-ischium), and marked externally by a ring-like groove. On comparing the legs of the crab with those of the lobster, it will be seen that the groove in the crab's leg corresponds to the joint between the second and third segments in the other form. When the leg of a crab is injured it is invariably thrown off at the breaking plane. The mechanism by which the autotomy is effected has recently been reinvestigated by Paul (op. cit.), who, using improved methods, reaches a somewhat different conclusion from that formulated by Frédericq, whose researches in this field have long been familiar. Paul's explanation is as follows. The segment in which the breaking plane occurs is connected by muscles to the basal limb segment and to the body wall, a short extensor and a short flexor moving it on the basal segment, and a long extensor and long flexor joining it to the body. The tendons of the extensor muscles are inserted on a ring-like thickening of cuticle which surrounds the basal part of the second limb segment. In the ventral part of this ring is a slanting joint formed of material which is not calcified like the remainder (see righthand of Fig. Io). The action of short and long extensors being in nearly opposite directions their simultaneous contraction tends to pull the jointed parts of the ring 


\section{0}

\section{THE BIOLOGY OF THE SEA-SHORE}

asunder, the result being to cause great weakening of the limb at the breaking furrow. If the limb is now flexed its distal portion will be brought into contact with the carapace, or possibly with some external point of resistance, when the slight lateral force will be sufficient to cause the already weakened limb to snap. In Portunus no lateral resistance is required, the antagonistic action of short and long extensors being sufficient of itself to cause splitting at the breaking plane.
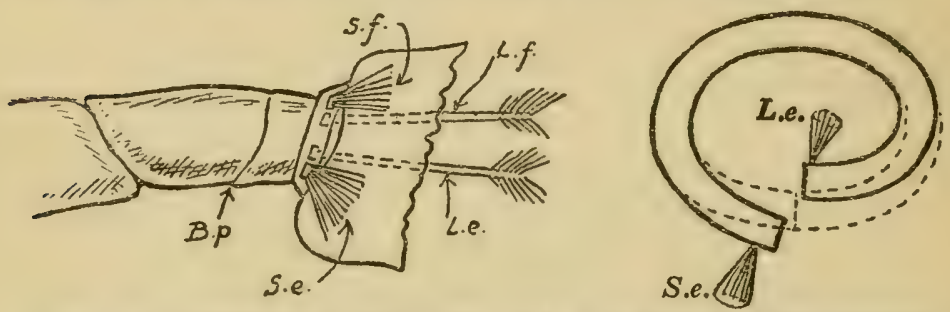

Fig. 10.-Autotomy of crab's leg. S.e., L.e., short and long extensor muscles; $S . f ., L . f .$, short and long flexors; $B . p .$, breaking plane (after Paul).

In a typical crab autotomy is a purely unisegmental reflex action, that is to say, it has its centre in a restricted area of the nerve cord, and can take place when the nerve cord is severed both above and below this area. It is only in the spider crabs that imperfectly successful autotomy may be completed by plucking with the forceps, and that higher nerve centres consequently come into action.

One of the most remarkable circumstances associated with the phenomenon of autotomy is the occurrence of a membrane or diaphragm the function of which seems almost certainly to be that of preventing hæmorrhage. The diaphragm takes the form of two flaps which stretch across the limb cavity from either side and appear to be formed from modified epidermal cells at the breaking furrow. It is pierced by a pair of foramina which allow for the passage of artery and nerve. Immediately after autotomy the crab extends the stump so that the diaphragm faces upwards. "The artery retracts and its torn end dilates, forming a little aneurism filled with plasma and lined with blood cells. The nerve also retracts, and the funnel-like flaps of the 
diaphragm are forced over it owing to the great increase in pressure on the outer side of the membrane. Meeting together, the flaps at once stop bleeding " (Paul, op. cit.).

The question will possibly occur to the reader as to whether the blood of these Crustacea possesses special clotting powers which would aid in the prevention of hæmorrhage after autotomy. Tait (rgr 3 ), however, who has made experiments in this direction, has not been able to establish a relation between the degree of blood coagulation and the process of autotomy.

Other remarkable facts have been elucidated by Paul as to the manner in which a new limb is regenerated. Regeneration of the limb begins immediately after autotomy by the growth of epidermal cells over the stump, and eventually a papilla is formed which is really a limb in miniature. The new limb remains in this condition until immediately following a moult, when it is apparently at once expanded to several times its previous size. This laying down of the limb in miniature and its expansion only when it is almost ready for use is in remarkable contrast to the gradual process of regeneration seen in other groups, and, according to Paul, must be interpreted as a beautiful adaptation to the needs of the animal, since the latter would only be hampered by the presence of a gradually regenerating limb. Similarly, the form of the papilla would also be adaptive. In the lobster which, in natural circumstances, spends all its time under water, the miniature limb is straight, is covered by only a thin layer of uncalcified chitin, and requires the presence of water for its support. In the shore crab, however, which spends a large part of its time out of water, the papilla is compactly rolled (it may be folded on itself three times) within a tough envelope, and is quite firm in the air as well as in water. The hermit crab is said to be intermediate between these two other forms both as to its habits and as to the shape of its papilla.

It is evident from the foregoing account that Paul is in no doubt as to the adaptive nature, in Decapods, both of the process of autotomy and of that of regeneration. He gives 


\section{I22 THE BIOLOGY OF THE SEA-SHORE}

the following figures relative to the loss of limbs in shore crabs taken from their natural habitat :-

Shore Crabs collected at Cullercoats, Northumberland, January, I9I5, FROM ROCKY SHORE

\begin{tabular}{|c|c|c|c|c|c|}
\hline Number. & \multicolumn{2}{|c|}{$\begin{array}{l}\text { Breadth of carapace } \\
\text { in } \mathrm{cm} \text {. }\end{array}$} & $\begin{array}{l}\text { Number } \\
\text { with legs } \\
\text { missing. }\end{array}$ & $\%$ & $\begin{array}{l}\text { Average } \\
\text { loss of legs } \\
\text { per crab. }\end{array}$ \\
\hline 37 & Over $5 \frac{7}{2} \ldots$ & .. & I8 & $48 \cdot 6$ & 2 \\
\hline 29 & $\Rightarrow 4 \ldots$ & . & 7 & $24^{\circ} I$ & I'2 \\
\hline 40 & Under 4 .. & $\cdots$ & 9 & 225 & $I^{\prime} I$ \\
\hline
\end{tabular}

Shore Crabs collected from Rocky Shore at Keppel, Milllport, MARCH, I9I3

\begin{tabular}{c|c|c|c}
\hline \multirow{2}{*}{ Number. } & Carapace in cm. & $\begin{array}{c}\text { Number } \\
\text { with legs } \\
\text { missing. }\end{array}$ & $\%$ \\
\cline { 3 - 4 } 22 & $4 \frac{1}{3}-3 \frac{1}{2}$ & 11 & 50 \\
26 & $3 \frac{1}{2}$ & 6 & 23 \\
14 & $2 \frac{1}{2}-2$ & 4 & 28 \\
13 & $2-1 \frac{1}{2}$ & 0 & 0 \\
\hline
\end{tabular}

From these tables it is seen that of crabs three years old and upwards collected from rocky shores, 50 per cent. are found to have lost a limb. On the other hand, among crabs collected from sandy beaches at the same time of year, the percentage is said to be very considerably lower. Paul concludes, in consequence, that the chief factor in producing autotomy is crushing by the movement of stones, and this would be most pronounced after winter storms. Fighting is not the cause, since as many as fifty crabs of various sizes live peaceably in one tank, and only one autotomised limb may be found in weeks. The purpose of self-amputation, as has already been mentioned, would be the prevention of hæmorrhage rather than escape, since it allow's the valvular mechanism at the breaking plane to close. In lobsters and prawns, on the other hand, the object of autotomy is thought to be escape.

Against Paul's adaptive and purposive interpretation of 
autotomy and regeneration there tells the fact, which he himself does not undertake to explain, that hermit crabs, which in natural conditions are very rarely found to have lost a limb, possess the power of autotomy and regeneration in a marked degree. Again, in those forms with a breaking plane regeneration may take place not only from the breaking plane, but from other parts of the limb as well. It is possible that these two objections may be fairly met by supposing hermit crabs to have inherited capacities of autotomy and regeneration though they do not need them particularly, and did not themselves evolve them. Nevertheless, even supposing this explanation to be correct, other difficulties remain, such, for instance, as that of accounting for the manner in which-if we call autotomy and regeneration "adaptive" - these phenomena have been brought to perfection. The argument based on the accumulation of small variations in a particular direction is, in the case of processes of this kind, by no means convincing.

The forms which we have been considering are, of course, not the only Crustacean species which exhibit autotomy. Most shore collectors have had personal experience of the autotomy of hermit lobsters (Galatheidæ), and of porcelain crabs. Similarly, crabs of the tropical genus Grapsus, when seized by a limb, leave the limb in the hand of the collector, and make off so readily as almost to force him to conclude that the animal has a very precise appreciation of the danger which threatens it! Incidentally we may notice that Piéron (1907), who has studied autotomy in Grapsus and in other groups, distinguishes between "evasive" autotomy, which seems to him to be "voluntary" in the same sense as an endeavour to escape is voluntary, and reflex autotomy, which is much more general. The muscular contractions which cause autotomy in Grapsus are of the same order as the normal locomotor contractions. Voluntary or evasive autotomy is particularly well developed in Grapsus, but it also occurs elsewhere, as in hermit crabs. Reflex autotomy, according to Piéron, is not universally distributed, even among the Brachyura. 
Autotomy and Regeneration in Echinoderms.-The faculty of self-amputation is, perhaps, still more widely distributed among Echinoderms than in the group we have just been discussing, but it is not accompanied by the same elaborate provision that is seen in the shore crab, for example.

If the arm of the starfish Asterias is held in such a way as to cause injury to the radial nerve, the animal will sometimes throw off the limb close to the base. The arm is then gradually regenerated. Here, again, the tendency is to regard the autotomy as adaptive. It is probable that the sacrifice of an arm will sometimes enable the starfish to escape, but whether it is legitimate to take this as furnishing an explanation of the act is somewhat doubtful. The relative frequency with which starfishes are found to have autotomised limbs in natural circumstances certainly seems to indicate that the autotomy is definitely of value to the animal. Thus, King (1898) found that out of a total of 1914 specimens of Asterias vulgaris there were 206, or nearly II per cent., which had grown new arms, and with one exception all of these arose close to the disc-evidence that the arms had been autotomised and not merely torn off by enemies.

Not only is the place of an autotomised arm always taken by a new one, but a single arm, provided it has a portion of the disc still attached to it, will regenerate a new starfish. Several workers have even found that in certain species of starfish, including Linckia multifora and Asterina tenuispina, a single arm, without any part of the disc attached to it whatsoever, may produce a new animal. The so-called " comet-forms," one of which is illustrated on Plate XI, are forms which show a new set of arms regenerating from a single arm in this way. In Asterias vulgaris, however, about half of the disc requires to be left if the arm is to regenerate ; but in exceptional cases one-fifth is apparently enough (King, op. cit.). It has further been found by King that the rate of regeneration is more rapid when the arm is autotomised, in the normal manner, close to the disc, than when removed at a lower level. At first view this appears to be 


\section{PLATE XI}

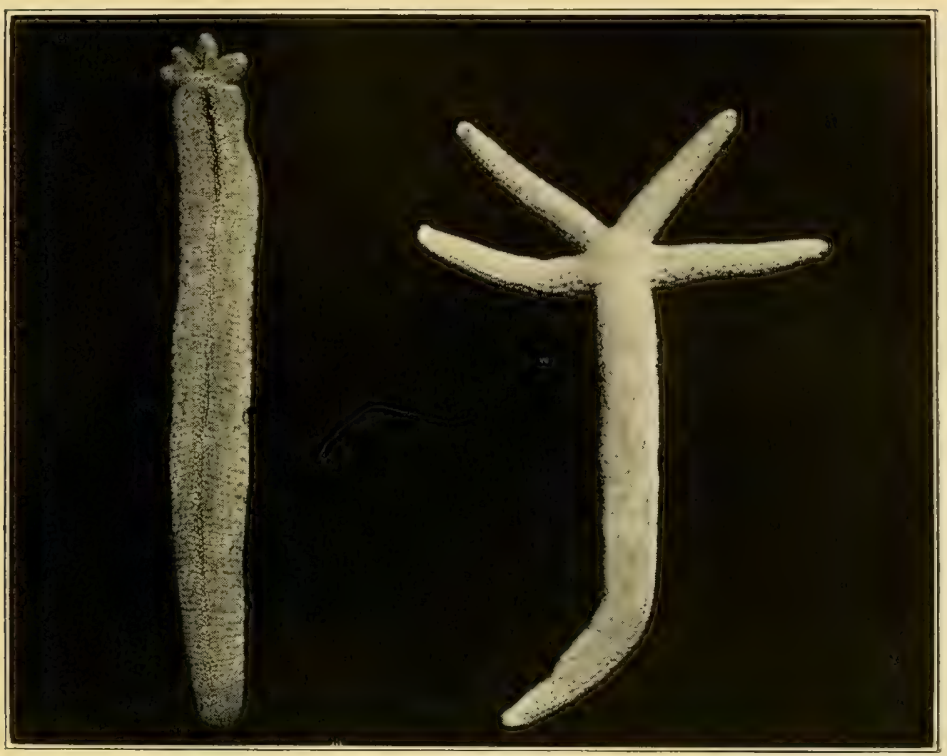

I.-Starfish regenerating Arms.

To left, a single arm regenerating a new disc and four other arms (comet-form). To right, a later stage showing disparity in size between original arm and four re. generated arms.

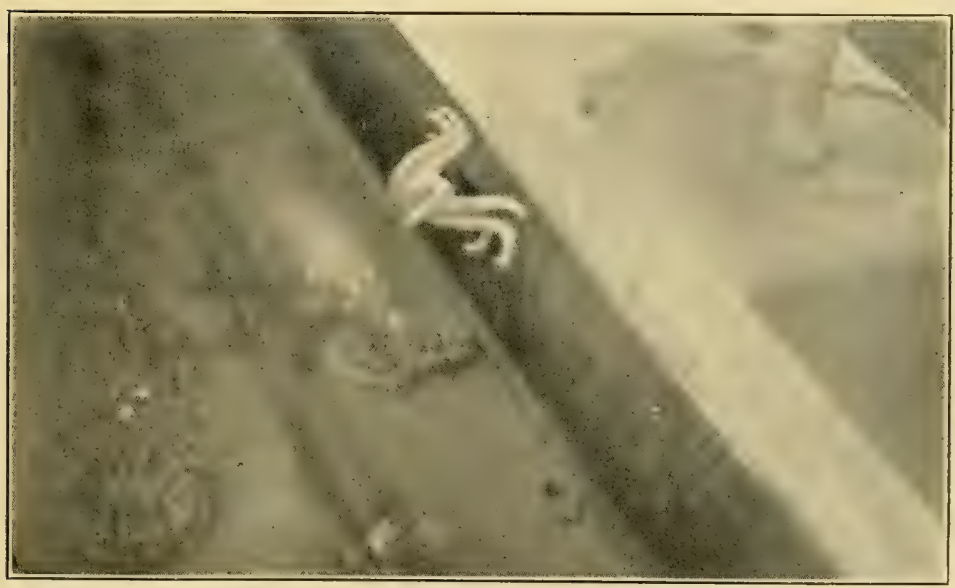

II.-Male Starfish (Solaster endeca) Spawning. 

a strong argument in favour of the adaptive nature of the autotomy. Against such an interpretation, however, Morgan places the fact recorded by King that "although the arm regenerates faster at the base, yet a new arm is not any sooner produced in this way, since there is more to be produced, and the new arm from the base may never catch up to one growing less rapidly from a more distal cut-surface, but having a nearer goal to reach."

The name " brittle-star " accurately describes the marked tendency, well known to shore collectors, which members of this group have towards autotomy. When removed from a rock pool to the palm of the hand a brittle-star will frequently autotomise its arms, piece by piece, until practically nothing but the disc remains. Preyer (quoted by Ludwig, I 901 ) finds that autotomy occurs, as a result of various kinds of slight stimuli, particularly readily in the six-rayed or sevenrayed Ophioactis virens, and also in Ophioderma, Ophiomyxa, and Ophioglypha. Either the arm is shed in one piece-at a level above the point of application of the stimulus-or it at once breaks up further into several pieces, the latter being the more usual method when the autotomy takes place out of water.

Regeneration is said to take place at any region, and the same observations as in starfishes have been made on the rate of regrowth of the arm at different levels ; in other words, the closer to the disc the arm is severed the more rapidly it regenerates. This has been noted by Stockard (1908) for Ophiocoma riisei and for another, undetermined, species of Ophiuroid. Another writer, Morgulis (Ig09), has some interesting observations on the effect, upon regeneration, of injury to the radial nerve prior to amputation of the arm. He finds that if, in Ophiocoma pumila, the radial nerve is injured in advance only a small stump is regenerated. Similarly, if the nerve is destroyed close to the disc so little new tissue is formed that it is difficult to recognise it at all. When the radial nerve is left intact a long new part is regenerated. In cases where the brittle-star throws off the arm at the place of injury to the nerve, there is absolutely no 
regeneration from the cut surface so produced, while other arms in the same specimen with the radial nerve intact regenerate normally.

The discussion of autotomy and regeneration in starfishes and brittle-stars affords a fitting opportunity to draw attention to another important aspect of these phenomena. This is the value of self-division as a means of propagation. Among single-celled animals multiplication by division is a perfectly normal phenomenon, and among the lower manycelled animals it is also by no means uncommon. Anemones, for instance, are capable of dividing lengthwise, and each of the halves gives rise to a complete individual which continues life on its own.

One of the most remarkable of these cases of propagation by self-division is found in Syllid worms. In this family of marine worms, as we shall see in Chapter XII, the hinder, genital portion of the body becomes separated off from the anterior non-sexual portion. The sexual portion then regenerates a new head, and the asexual portion a new tail, which will; in due course, again become sexual and split off once more. In the genus Autolytus the process of separation is anticipated, as it were, by regeneration, and as many as sixteen complete worms may be found as connected links in a long chain.

It is hardly possible to disregard these facts when attempting to find an explanation of self-division in the more special sense. Indeed, Morgan considers that the process of autotomy differs from the process of self-division as a means of propagation only in the fact that in autotomy proper the part thrown off does not produce another animal. Clark (1913), again, in commenting on autotomy in the starfish Linckia, states that this process affords an asexual method of reproduction which is of prime importance. Considerations of this kind serve to point to the possibility of autotomy, in the strict sense, being rather of the nature of a modification, for a special purpose, of the more fundamental habit of self-division as a means of multiplication. This is a suggestion which is perhaps worth noting. 
Structural considerations obviously preclude the possibility of autotomy playing any important part in the life of the sea-urchin. The spines, however, are continually being shed in the aquarium, and new ones regenerated in their place. Similarly, sea-urchins which have been captured by the trawl are also found to grow new suits of spines. New pedicellariæ are also constantly being regenerated to replace those lost in combat and in other ways. Prouho (I887) found that if a fully-grown spine of Dorocidaris papillata is broken off near the base the remainder is autotomised and a new spine regenerated in its stead.

Sea-cucumbers are remarkable for showing a very thorough-going form of autotomy which, since it involves the internal organs, is known as self-evisceration. When a sea-cucumber is strongly irritated by any of a large range of stimuli, the body contracts so violently as to compress the fluid within the body cavity and cause the gut to tear, and to be thrust out of the cloacal opening along with other viscera. Among the first of the viscera to be extruded are the Cuvierian organs or modified lower branches of the respiratory trees. These are extraordinarily elastic and sticky, and form a tough mass of white threads which look like cotton ; hence the popular name of " cotton-spinners " given to this group. In some species of Holothurian the tearing of the gut is aided by a modification of the musculature of the gut wall just behind the gullet. This extraordinary habit of self-evisceration has been the subject of a considerable amount of speculation. Attempts have been made, in particular, to find a purpose for the extrusion of the Cuvierian organs and of their curious property of swelling up in water. A widely-held view is that they serve for protection, animals such as crabs and fish becoming entangled in their meshes. Certainly, as Ludwig remarks, they cannot be used for attack, since evisceration has never yet been seen to be produced spontaneously, but only as the result of some perfectly definite external stimulus.

The drastic nature of self-evisceration in this group is balanced by the remarkable capacity these animals have of 
regeneration. Normally, the left respiratory tree, the upper part of the gullet and the genital organs are retained in the body cavity, but on occasion the whole of the viscera may be thrown off. Semper (quoted by Ludwig, I889-92) records that a specimen of Holothuria scabra, which had thrown off its gut close behind the ring-canal and the left respiratory tree and genital organs along with it, had regenerated everything except the genital organs in nine days. The power of regeneration has also been found to extend to the calcareous ring and to the tentacles.

Stimuli of a more or less similar nature to those which cause self-evisceration in many Holothurians give rise in the Synaptids to a process of self-division. Contraction of the circular muscles of the body wall causes the body to constrict at one or more places, and to fall into pieces. Some species are said to be so sensitive as to break up at the least approach to rough handling, and are, in consequence, very difficult to collect and keep. Here, as in several other instances we have noticed, the nature of the phenomenon has not been satisfactorily explained. Quatrefages (1842), one of the earliest observers, tended to regard it as a normal mode of reproduction capable of occurring spontaneously. On the other hand, it is generally agreed with regard to this process in Synaptids that it is only the head portions which regenerate new individuals. Semon (1887) has noticed that the autotomy, if we may so call it, occurs at the point where the body is gripped by the collector, the head end then burrowing quickly into the sand. He consequently regards it as a means of escape from enemies, the animal saving its life by the sacrifice of a portion of its body. Ludwig (op. cit.) tends to the opinion that self-division in Synaptids is more or less of a pathological response to unaccustomed conditions. This view draws support from the fact that in Quatrefages' experiments the self-division occurred more frequently as the period of confinement in the aquarium grew longer. Ludwig further points out that the restriction of this habit to the family of the Synaptids need cause no wonder, since they alone among Holothurians possess a 
genuinely uninterrupted circular musculature in the body wall.

Miscellaneous Cases of Autotomy.-It remains to notice one or two cases of autotomy which, though of minor importance, are not infrequently brought to the notice of shore collectors. For instance, every shore naturalist will have noticed the readiness with which Polynoid worms autotomise segments, and, more especially, throw off their scales (elytra) when captured or kept in captivity. We have heard of no special provision by which this is achieved, but the observations of Michel (I9II) on Halosydna gelatinosa and Lagisca extenuata prove that the casting of the scales is genuinely autotomic, and not the result of mere fragility, since they cease almost entirely to be shed when the animal is beheaded. Further, after a number of elytra have been shed the autotomy becomes more difficult, but after a period of rest is continued as readily as before. An elytron takes no more than five days to regenerate, and a remarkable feature is the precision of the process. Not only is the number typical of the species always reproduced, but the original arrangement, in twos in certain segments, and in threes in others, is also preserved.

Another minor case of autotomy occurs in Æolid molluscs. Eliot (1910) remarks on his occasionally finding an Antiopella with tiny regenerating cerata instead of the normal large ones which have been lost, the animal presenting a totally different appearance in consequence. Other British species which commonly autotomise their cerata are Tergipes despectus, Galvina exigua, and Doto. In Proctonotus the cerata are glandular, easily detached, and have a special apparatus at the top which enables them to fasten to extraneous objects. When seized by an enemy they are said to adhere to it and disturb it with their secretion, while the slug itself crawls away. The tropical Discodoris fragilis and others are said to be capable of casting off the whole of the mantle margin, and yet to remain in apparent good health.

Retrospect.-While our survey of autotomy and regenera- 
tion on the sea-shore has disclosed a number of interesting facts it has not enabled us to reach any one explanation which will apply to every case of these phenomena. There is a general tendency to regard autotomy as of value as a means of escape from enemies, or, at any rate, as an adaptive response to particular features of the environment. Among the facts which lend colour to this view are the restricted occurrence of autotomy in general and its relatively frequent occurrence on the sea-shore, where the struggle for existence is admitted to be particularly severe. Thus, the remarkable structure at the breaking plane in the crab's leg, whereby bleeding is reduced to a minimum, is regarded by Paul as having arisen in connection with the tendency of shore crabs to have their limbs crushed by stones. The reality of the danger is thought to be proved by the number of crabs which are found to have lost a leg in natural conditions, the proportion on rocky shores after winter storms being as high as fifty per cent. The autotomy of the legs and chelæ of the lobster, on the other hand, is interpreted as providing a means of escape from enemies, but the evidence for this view is of a more slender nature than that adduced in the case of the common shore crab. So far as the autotomy of starfishes and the self-evisceration of Holothurians are concerned the adaptive nature of these processes is, apart from one or two observations, almost entirely a matter of conjecture.

Some cases of what we call " autotomy " may be nothing more than the normal asexual methods of reproduction, and others may be responses of a pathological nature to unaccustomed stimuli. Our own conclusion is that it is perhaps not impossible that the tendency of lower multicellular animals to reproduce by fission may have formed the raw material upon which, under the stimulus of the shore struggle, natural selection may have worked in order to produce the more specialised forms of autotomy as seen, let us say, in the shore crab. The tendency towards fission, in turn, may be referred back to considerations of a mechanical kind such as weak lines occasioned by axial growth increase ( $c f$. D'Arcy 


\section{AUTOTOMY AND REGENERATION I3I}

Thompson, 1917, p. 151). As regards regeneration, if we take this to be a specialised form of fundamental regrowing and rejuvenescing processes, we may admit the possibility of it, too, having become adaptive in certain cases in much the same way as we have suggested for autotomy. 


\section{CHAPTER VII}

\section{Parasitism, Commensalism, and Symbiosis on the SEA-SHORE}

We have seen, in the early part of this book, that, under the influence of environmental factors, plants and animals become sorted out into numerous more or less distinct groupings or communities, the members of any one community being, generally speaking, related to one another in virtue of the similar nature of the problems set them by their surroundings. In not a few cases, however, the relationships between certain members of a community are of a more intimate kind than is normal. These cases fall, for the most part, under three headings : (I) commensalism ; (2) parasitism; and (3) symbiosis; but they cannot all be defined with equal exactitude, nor is the significance of any one of these associations to the forms concerned in it always of the same importance.

Such associations are undoubtedly a result of the stimulus of competition, and the frequency of their occurrence on the sea-shore is eloquent testimony to the intensity of the struggle for existence in this area. They are the expression of a general tendency of evolutionary processes, acting in conjunction with or superposed upon the struggle for existence, to link lives together. The same peculiar conditions which have led to the growth of a numerous, varied, and resourceful population on the sea-shore have at the same time been the spur to the formation of the peculiar types of association we are about to discuss. The conditions we have in mind are, more especially, the narrow width of the tidal zone, the usually broken nature of its surfaces, the 
extension of the area in the vertical as well as in the horizontal sense-all of which mean that a small area may provide foothold for a great variety of creatures-and, finally, the influence of wave-shock in causing frequent displacements on the part of the animal inhabitants. All these features seem to make it probable that the needs and the opportunities of forming close relationships are more pressing and numerous on the shore than elsewhere.

Stages in the Development of Intimate Associations (Commensalism, Parasitism, and Symbiosis) among Shore Animals.-There are many cases on the shore to illustrate how an intimate association between two forms of different kinds may have arisen. For instance, in shallow coastal waters algal spores settle upon every available surface, and it is quite usual to find various small algæ growing upon many shore animals; on the shells of the sluggish limpet, for example, or sometimes on the slowly moving periwinkles and similar forms, while trailing tufts of Enteromorpha frequently mark the position of cockles in the sand. Slowmoving Crustacea like Inachus, which live among algæ and hydroids, generally carry a share of these organisms on their backs, and other Crustacea frequently carry small growing plants. These plants are usually without significance, although some of them may be fortuitously of advantage in concealing the individual to which they are attached. In certain cases (spider-crabs, etc.) they may have been placed on the carapace by the Crustacean. Whether it is legitimate to say that this is done on purpose is a matter of opinion (cf. p. 245). It is usual to find the small shore urchin Echinus miliaris with a number of various algal fronds attached to its spines. A Pleurococcus-like alga has been described (Mortensen and Rosenvinge, I910) as attacking brittle-stars. In this case the colonies of algæ appear first on the back of the animal beneath the epidermis. Subsequently they may destroy the connective tissue, lay bare the food canal and cause death.

A very interesting and instructive case is that of Odostomia rissoides, which both illustrates a stage in the development 


\section{I34 THE BIOLOGY OF THE SEA-SHORE}

of the parasitic habit and affords an instance of hyperpara sitism(the parasitisation of a parasite). This little Gasteropod is found exclusively among the old and resistant byssus threads of adult mussels which live affixed in cracks of the rocks in the east and south of La Tour de Croy, at Wimereux, etc. They are held firmly to their support by a slender mucous thread secreted by a foot gland, and may be so found during low-tide. This species of Odostomia has no radula but is furnished with a long sucking tube. Experiment has shown that whenever the snail was placed in a basin together with a fresh mussel it would first remain in the byssus, and then climb upon the shell of the bivalve, about the posterior or ventral edge ; on arriving there the animal would extend its tube and introduce it in a curved manner between the valves. Endeavours to infect Tapes, Tellina, and Mactra gave negative results. The Odostomia reaches 4 to $5 \mathrm{~mm}$. in size. It is itself parasitised by a Copepod (Monstrilla helgolandica), which occupies the anterior region of the body. In parenthesis, it may be noted that $O$. rissoides, living as it does with the mussels above the limit of low tide, achieves its complete embryonic development within the egg capsule and does not possess a free pelagic stage, in the form of a veliger larva, like its relatives (Pelseneer, I9I4).

We have already commented on the number of different organisms to be found on the surface of some of the larger Crustacea (see p. 90). As a further example of the heterogeneous collection of forms to be found associated with a single species we may take the case mentioned by Pearse (1913), where a single crab (Carcinus borealis) bore on the dorsal surface of the carapace the tube-worm Spirorbis and the alga Hildenbrandtia; on the right side anterior to the legs, a specimen of the limpet Crepidula plana and its eggs ; on the legs, the tube-worm Spirorbis and a small Crepidula, and under the abdomen three mussels (Mytilus).

The common hermit crab Eupagurus bernhardus, the younger forms (seldom the adults) of which are so abundant between tide-marks, makes use of shells of forms such as Littorina, Trochus, and Purpura which themselves live 
within tidal limits, and of other forms such as Buccinum, Turritella, and Natica, which are found beyond low-tide mark. With the crab is found the Polychrt Nereilepas fucata, a commensal which lives in the top whorl of the shell and probably changes shells with the crab. Upon the shell may occur either of the anemones Sagartia parasitica and Adamsia palliata (the latter species more rarely), colonies of the hydroid Hydractinia echinata, and the sponge Suberites domuncula. Both inside and outside occur the bivalve mollusc Anomia and the tubeworm Pomatoceros; the Amphipod Podocerophis excavata almost invariably infests the dirt at the bottom of the shell, and with it is not infrequently the small crab Porcellana longicornis. True parasites are an Isopod of the genus Bopyrus, which inhabits the branchial chamber and the degenerate Cirripede Peltogaster paguri (Jackson, I9I3).

Conmensalism.- Strictly speaking, this is an external partnership between two forms of different kinds for mutual benefit. Many cases, however, exist which may be allowed to come under this heading where the advantages resulting from the association are by no means equally divided, and may, in fact, be entirely on one side. From such a state of affairs the step to parasitism is not a long one. Similarly, the step to commensalism from a relationship which is at first merely that of neighbours, is equally short.

Issel (I9I8) describes specimens of the fish Serranus as standing sentinel outside the holes or crevices inhabited by Octopus. This is probably a very loose association, the fish feeding upon the remains of the Crustacea devoured by the mollusc. Frequently, one form will take advantage of the shelter afforded by the body of another form, and the two are then usually described as being commensals although the benefits are all on one side. Colonial forms such as sponges and corals offer safe hiding places, and are much utilised by other animals. A common example of this incomplete commensalism is that of the bivalve Modiolaria and the sea-squirt Ascidia mentula, the mollusc colonising the whole of the "test." Occasionally an association of this 
kind becomes more intimate, and has important consequences. For instance, there are certain small crabs of the genus Hapalocarcinus, which become profoundly modified in form owing to the fact that they pass the greater portion of their life confined in small cavities in coral colonies. At an early stage the crab settles between two coral branchlets, and so affects their growth that they broaden, and later coalesce to form a so-called gall, which is about the size of a large nut. Each of these appears to be occupied by a solitary female crab. The male is free-living (cf. Pinnotheres, p. I45) and visits the female while the galls are still open. The crab does not feed on the coral, but probably lives on small organisms drawn in with the water current (Potts, r9r4). Reference has already been made to gall formation in the common seaweed Ascophyllum nodosum, due to young forms of Mytilus edulis occupying the air vesicles. The growing valves cause the tissues to split. The plant is stimulated to respond, and abnormal form results.

The classical example of commensalism is provided by the hermit crab of British coasts Eupagurus prideauxii, and the sea-anemone Adamsia palliata. The anemone serves to conceal the crab, and may find its reward for doing so in the scraps of food let drop by the Crustacean. No doubt, also, the presence of the anemone is an aid to the crab in attack and defence. Another species of hermit crab, Eupagurus pubescens, almost invariably has the shell in which it is living entirely concealed by the sponge Suberites domuncula. On rare occasions (in three cases out of several thousand, according to Elmhirst) another species, E. bernhardus, is found with the same sponge. As we have already noticed, the top whorl of the shell of the last-named species is tenanted by the worm Nereilepas fucata. This worm, in fact, was probably the first tenant of the empty shell and tolerates the subsequent advent of the crab because of the food which the latter procures (Hornell, I892).

Experimental analysis of the commensalism of anemones and hermit crabs tends to show that this association, in certain cases at least, is not a chance one. Brunelli (I9ro), 
for instance, states that the contact of the hermit crab Pagurus arrosor with the anemone Adansia rondeletii stimulates the latter in perfectly definite ways. Similarly, the occurrence of the anemone Antholoba reticulata upon the back of a crab (not a hermit crab) is due to the fact that the anemone directs its efforts towards the attainment of that position. If the anemone is dislodged it attaches itself to the sea-bottom, spreads its tentacles and waits. In four or five days it frees itself and turns upside down. As soon as the base of the animal comes in contact with the leg of a crab it lays hold and folds itself about the limb. From this position the anemone gradually climbs up on to the back of the crab, and there establishes itself. On the part of an animal without nerve ganglia this is an interesting piece of deliberate behaviour.

Among the most curious cases of commensalism are those illustrated by certain species of crab which carry about anemones in their claws. The crab Melia tessellata carries either a Sagartia or a Bunodeopsis in each claw (Fig. I I). These two anemones are interchangeable, and the crabs may reject a small polyp of the one kind to take up a larger specimen of the other. The anemones are dislodged by the insertion of the crab's first walking leg between the animal and the substratum. The crab then travels with the Actinians expanded and directed forwards, sometimes waving them from side to side. When irritated it will move the claws towards the source of trouble, thereby placing the anemone in what may be regarded as the most favourable defensive or aggressive attitude. Food secured by the anemones is abstracted by the crab, which uses for this purpose the first pair of walking legs. The chelipeds have no other function (whether for aggression, defence, or grasping) than that of carrying the Actinians, and this habit seems to have become essential to the crab though not to the anemone. The crab secures most of its food from the anemone, and also protection through its stinging-cells. It is considered to be an advantage to the anemone to be carried about, and so brought into contact with prey, despite the disadvantage of 


\section{${ }_{3} 8$ THE BIOLOGY OF THE SEA-SHORE}

having much of its catch abstracted by the crab (Duerden, I905).

Although we have purposely refrained hitherto from introducing the Protozoa we cannot leave the subject of commensalism without a reference to the many forms of single-celled animals (Infusoria) which occur in or on the bodies of a number of shore forms, and, since there is no evidence of their producing injurious effects, are usually spoken of as being commensal with the animals they inhabit.
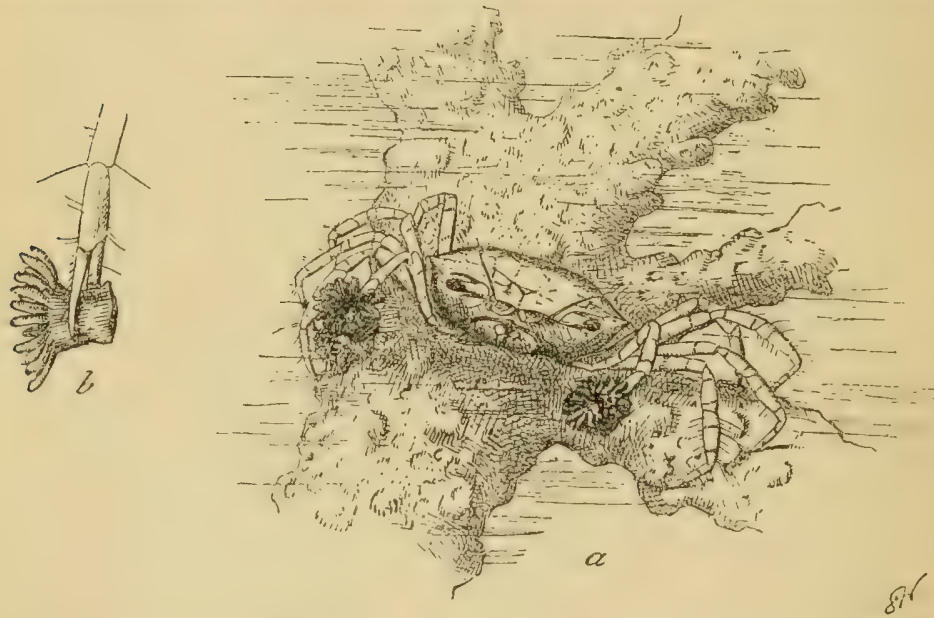

Fig. I I. - $a$, Crab (Melia tessellata) bearing in its claws two anemones; $b$, claw much enlarged. (From The Fauna and Geography of the Maldive and Laccadive Archipelagoes, after Borradaile.)

They are particularly numerous, for instance, in the gut of Polychæt worms, and on the gills of molluscs. Issel (I918) mentions various species of Protozoa commensal with Iittorina. According to this writer, the commonest forms are of oval shape, flattened and very active. They move about over the surface of the gill lamellæ. The individuals of a less common species are usually united in small groups, and are fixed to the gills of the host by the base of their cylindrical body; their free extremity is spherical and surrounded by a ring of cilia. Issel names this second species Scyphidia littorince. 
The commonest forms belong to the genus Ancistrum, and are characteristic dwellers among the gills, occurring in many other Gasteropod molluscs also. The cilia are long and powerful, the mouth opens posteriorly on one of the narrow sides of the body. One of the surfaces is concave, and is provided with a denser plume of cilia which work in a determinate direction, exactly like those of Rotifers. These cilia work in opposition to those of the gills, otherwise, of course, the Infusorian would be swept away. Issel states distinctly that Ancistrum is not parasitic, but probably functions as a sweeper of the gills, ingesting excremental products or loose cells. They might possibly become harmful if they were too numerous.

Parasitism. - The late Prof. Max Braun (I906) defined parasites as "living organisms which, for the purpose of obtaining food, take up their abode, temporarily or permanently, on or within other living organisms," but to us this definition seems hardly adequate. We might extend it somewhat as follows: "Parasites are organisms which take up their abode, temporarily or permanently, upon or within other organisms in order to feed upon them or to share their food, and which are more or less specialised for that purpose." The term parasitism, however, must always be somewhat elastic in view of the varying forms this habit takes. There are few animals that do not harbour some unbidden guest, yet numerous as parasites are on land they are still more numerous and varied under aquatic (particularly marine) conditions.

Parasites are without doubt descended from freeliving ancestors, and are generally considered to have been evolved, by degrees, from forms that in the universal search for food have been attracted to other forms by reason of surplus food, body products, shelter, etc., and have thence become more and more closely associated with such forms until, finally, they have come to depend wholly upon the food which they obtain at the expense of these hosts, frequently to the victims' serious detriment. We have, then, a long series of stages ranging from cases where parasitism. 


\section{0 THE BIOLOGY OF THE SEA-SHORE}

has become an integral and unalterable habit, through other forms where the inter-relationship is less close or stable, to cases in which doubts may be entertained as to whether the plant or animal in question is or is not a parasite.

In particular, some confusion of thought would appear to have arisen through the tendency to regard as parasites creatures such as Ichneumon-fly grubs or Myxine, the Hag-fish, which are really predatory animals eating from within instead of from without. There is a sense, of course, in which all predatory animals are parasitic, but the main point of difference here between a predatory and a truly parasitic animal is that the former encompasses the death of its victims, whilst the latter seeks merely to be tolerated.

We may distinguish parasites as being temporary (or occasional) when they use a host for a part of their lifehistory or at feeding times only; permanent (or stationary) when the host is never left by the adult parasite ; facultative in the case of animals resorting to parasitism only as a second-string; and incidental when they occur on unusual hosts. Those which confine themselves to the exterior of the host's body are known as ectoparasites, while those which dwell within the host's body receive the term endoparasites. We may summarise the most essential of these features as follows :-

Parasites : i.e. forms living in or on other organisms and obtaining food from them without rendering benefit in return, and yet without necessarily killing their hosts.
Ectoparasites : confining themselves to the exterior of the host's body.

$$
\begin{gathered}
\text { Endoparasites : dwelling } \\
\text { within the host's body. }
\end{gathered}\left\{\begin{array}{c}
\text { Feeding on di- } \\
\text { gested food of } \\
\text { gut. } \\
\text { Feeding on living } \\
\text { tissue. }
\end{array}\right.
$$

There is great diversity in the form, habit, and life-history of parasites. In some instances we have species with sedentary parasitic females and free-living males (or now and again the reverse may occur), while in others both sexes may be parasitic. An asexual reproductive phase may alternate with the normal sexual manner of reproduction, and so on. Nowhere are the many different possibilities better illustrated than among Nematodes. There is in fact 
among Nematodes "scarcely a stage that may not be parasitic ; the eggs, the larvæ, the adults are all in some cases free, in others parasitic, and in many cases first the one and then the other " (Shipley, r896. See also Borradaile, I918).

Parasitism exerts a marked effect on nearly all the animals which practise it, whether they are ectoparasites or endoparasites. There is frequently a loss of activity, of appendages, and of sense organs on the part of the parasite; the form of the parasite is more or less modified and adapted to that of the host, or to suit that part of the host where it lodges. Organs such as hooks, spines, suckers, and claspers are developed to facilitate the adhesion of the adult, or to assist the entry of the larval parasite into the host's body. So profound is the modification in some instances that the place of the parasite in classification can only be determined by reference to its development. Hermaphroditism and great fertility are characters very generally exhibited by endoparasites. The effect on the host is sometimes severe and may cause death. Malnutrition and growth abnormalities frequently result from the presence of a parasite, and in extreme cases the host's sex-organs may be rendered sterile. Some parasites, however, do not cause recognisable disturbance in their host or do so only when present in unusual numbers. Others, such as tapeworms, have been shown to produce substances which act as toxins upon their host and have effects analogous to those produced by pathogenic bacteria. Generally speaking, a balance is maintained between host and parasite which tends to limit the amount of injury, since the death of the host would, in many cases, entail the death of the parasite also. The number of parasites affecting a particular host varies very considerably ; one individual may at times harbour thousands while in other cases only a few are normally present. Attention has been drawn to the fact that many endoparasites derive their sustenance from the tissue fluids of their host or from the liquid nutriment in the latter's gut. Such forms, though they may be associated with land animals, are aquatic rather than terrestrial in their mode of life. 


\section{I42 THE BIOLOGY OF THE SEA-SHORE}

All parts of the host are liable to infection, but parasites are most general in the alimentary canal; they are frequent also in the swim-bladders of fishes, the lungs, liver, body cavity, and serous spaces, bladder, sex organs, heart, bloodvessels, eye or brain of various animals, or encysted in the skin, connective tissues, muscles, or nervous system. (See Ward, 19r8.) In fact, no organ of their Invertebrate or Vertebrate hosts is immune. Parasites are, however, most common in Vertebrates and Insects, Crustacea and worms being less frequently infected; while the chief groups supplying parasitic species are the Protozoa, Platyhelminthes (Flukes and Tapeworms), Nematoda (Round-worms and Thread-worms), and Arthropoda (Insects, Mites, Ticks, etc.); but nearly all the other invertebrate groups show parasitic forms also. With regard to the origin of the complex forms of parasitism with alternation of hosts, it has been suggested among other theories that the present intermediate host is possibly the original one, and at one time harboured both larval and adult stages. In time, as evolution proceeded and other and higher animal forms were produced, later stages of the parasites would have sought out other hosts from among these higher animals. If this is correct we are able to understand how it is that a particular parasite has its larval stage in an Invertebrate animal, and its adult stage in a Vertebrate form, as so often happens (Fantham, Stephens, and Theobald, I9r6).

The commonest shore parasites belong to one or another of two groups, viz. the " worms " and the Crustacea. Among the latter, the form which most frequently comes under the notice of the observer is Sacculina. This well-known parasite of the common shore crab (Carcinus monnas) degenerates into a sac-like mass of gonads which is external and a rootsystem which penetrates every part of the body of the crab and draws nourishment therefrom. The adult parasite bears no resemblance whatever to a Crustacean, and it is only the fact of its passing through a nauplius and a cypris stage in the course of its development that enables us to class it, along with the common rock-barnacle, as a Cirripede. The 


\section{PARASITISM, ETC., ON THE SEA-SHORE I 43}

portion of the parasite which protrudes consists mainly of the reproductive organs surrounded by a "mantle," which has a small opening surrounded by a sphincter muscle (see Plate XIV). The visceral mass is fixed to the host by a short stalk which penetrates the abdomen and gives off a number of branching roots that serve to absorb nourishment from the crab's tissues.

With regard to the development, the larva escapes from the mantle-opening as a nauplius. Subsequently it passes through a cypris stage, and then eventually attaches itself by one of the antennules to the base of a seta situated on any readily accessible portion of the crab's body. After undergoing a series of profound changes the larva penetrates the soft cuticle at the base of the seta by means of a specially developed boring organ, and gets into the blood stream. By this means it is carried to the under side of the intestine, where it becomes attached. The fact that the crab carries its abdomen closely apposed to the under side of the thorax makes it practically impossible for the larva to enter at or near the point where the adult is seen to emerge, and the larva can only reach this position in the manner described. (See Delage, I884, and Smith, I906.)

Both Sacculina and Peltogaster (a form very similar to Sacculina, which attacks hermit crabs) exert an important influence on their hosts. In particular, the effect of the parasite upon a male crab is to convert it towards the female condition. Externally, the resemblance of a parasitised male crab to a female is practically complete. The copulatory styles, which are the only abdominal appendages of the male, give way to the normal swimmerets of the female. Internally, the effect is to cause the testes to degenerate and to destroy their functions. Not least remarkable is the fact that, if by some means the parasite should drop off its victim, the cells of the testes still remaining give rise not to sperms, but to ova. Smith (I9I3) considers the effects upon the male crab are due to the roots of the parasite affecting the crab's metabolism in the same way as does the developing ovary, viz. by their taking up fat and stimulating the ovary 


\section{I44 THE BIOLOGY OF THE SEA-SHORE}

to make more. Generally speaking, the effects of this parasitic castration of the crab accord with those observed in the case of the castration of domestic animals by man, though it should be noticed that the results in the second case are due to the absence of a hormone. The effects of Sacculina upon the female crab are less far-reaching, and are merely those of speeding up the appearance of the adult female characters and of partly destroying the ovary. (Smith, op. cit., and Potts, r906.)

A remarkable example of a parasitic "chain" was provided by Perez's (1903) discovery of a hyper-parasite upon a Sacculina which was parasitising a pea-crab (Pinnotheres), the latter dwelling in a bivalve (Spondylus).

Another crustacean, the pea-crab (Pinnotheres pisum), inhabits the shells of various living bivalves, particularly the mussel. This association has long been known, and is even depicted in Egyptian hieroglyphics, where it has been interpreted as signifying the dependence of man upon his friends. Recent researches, however, would seem to show that the relation between crab and mussel is not that of partnership, but rather that of parasite and host.

Field (I9I3) found that the stomach contents of the peacrab were composed of diatoms and other materials utilisable by the mussels as food, and Wright (1917) found that Pinnotheres never (or at most, very rarely) occurred within poorly nourished mussels, although it was frequent in those from the fishing grounds, where the shell-fish were fat and were making rapid growth. He concludes that the association is a profitable one from the point of view of the crab. In certain cases where the female had attained a relatively large size it would seem to have exerted considerable pressure upon the mantle-lobes and upon the shell beneath, causing, in some cases, the nacreous layer to be dissolved away.

In a recent communication to Nature (1920), Orton throws further light upon the habits of the pea-crab. In order to observe what takes place within the mussel a window was cut in one of its shells. The large pea-crabs were usually 
found to sit on the middle of the bivalve with a pair of the bivalve's gills on each side of them, and in such a position as to bring the edge of a gill-leaflet up against the abdomen, the smaller crabs being found in any position, but most often upon the gill. The position taken up by the crab enables it to feed without trouble by scraping its claws over the gill and transferring to its mouth the mucous strings of food which are in process of being wafted along to feed the mussel. In view of the way in which the crab robs the mussel of its food and of the manner in which it is adapted for that purpose we are justified in regarding it as a parasite, although its effects upon the host are not of a serious nature.

Orton's researches, which at the time of writing are not yet complete, bring out several facts of interest in connection with the life-history. Thus the females appear to be dimorphic, since they are male-like when still very small and only assume the adult female characters after insemination, which occurs at a very early stage. The male apparently visits the female after the latter has taken up its abode in the mussel, since male crabs have been found trapped between the shell-valves on their way in. The extremely tough carapace of the pea-crab is regarded as adaptive since it prevents the animal being crushed to death when caught in the way described.

Turning to the smaller members of the Crustacea (Entomostraca) we find the parasitic Copepoda passing the greater part of their lives as parasites upon fish and other animals. They often occur in great numbers upon any particular host and may assume strange forms, many losing almost all resemblance to their free-living relatives. Thus, they may be worm-like in appearance and show other profound structural modifications. Some bore into the tissues of their host, while others fix themselves to the gills or elsewhere. All these parasitic Copepods arefree-swimming in their early stages. In some, the male, though highly organised, is very small and lives what is practically a parasitic life on the body of the female. (See Marsh, C. D., in Ward and Whipple, op. cit.) 


\section{I46 THE BIOLOGY OF THE SEA-SHORE}

Not a few of these parasitic Copepods are found associated with shore animals. Herdman (1892) has noticed the occurrence of a minute species, Lichomolgus agilis, in a number of cockles, and considers it to be a commensal. Eliot (1910) reports the occurrence of members of the same genus as common external parasites of Nudibranch molluscs. They occur on a number of species, their coloration varying with that of the host. Copepods are also the most common internal parasites of both Eolids and Dorids. Though they are rightly called internal parasites their egg-sacs may project outside the body of the host. The female of another Copepod (Trochicola enterica) described by Dollfus (I9I4) is found in the rectum of the common shore molluscs Trochus zizyphinus and Gibbula cineraria. This parasite is elongated and worm-like in form, bright red in colour, and almost fills the rectum, reaching a length of $8 \mathrm{~mm}$. Only one individual occurs in each host.

Well-known fish parasites of this group are Caligus, Lepeophtheirus, and others. The species $L$. pectoralis is most frequent upon Pleuronectes flesus, the flounder, and the males and immature forms of both sexes are to be found all over the skin on each side of the fish. Mature egg-bearing females, however, are usually situated under the pectoral, pelvic, ventral and dorsal fins, and as many as twenty to thirty may often occur under each pectoral fin. They are affixed by means of their powerful second maxillipeds, assisted by the antennæ. These creatures can move rapidly over the skin of the fish if irritated (except mature females which only cling tighter), and they can also swim freely. (Scott, I90r.)

The remaining shore parasites which we have to consider belong to the worm group, and to the flat-worms in particular. The flat-worms are at once the most highly specialised and the most ubiquitous parasites in the animal kingdom. They illustrate all the most characteristic features of parasitism including great fertility and complicated life-histories. Very frequently the life of the parasite is linked up with two quite distinct animals, one a vertebrate and the other an invertebrate, the adult parasite occurring in the former. 
A possible explanation of this alternation of hosts was put forward earlier in this chapter, viz. that the present intermediate host may be the original one and that, as evolution proceeded, later stages of the parasite came into association with other and higher forms. If this is correct, then it is not difficult to see that the chances of such a thing happening are greatest at the point where two or more distinct faunas meet and interact. In other words, the conditions for parasitic linkages of this kind are nowhere more favourable than on the sea-shore.

Thus it is, no doubt, that great numbers of parasitic flat-worms, particularly "flukes," have their intermediate stages in shore-dwelling molluscs. The life-history of the common Distomum hepaticum, the cause of the sheep disease known as "liver-rot," which is familiar to every zoological student, may be taken as closely resembling the life-histories of those Trematodes which are connected with the shore. It should be noted, however, that while sporocysts and cercariæ have been recorded from numerous shore animals, the complete life-history has in many cases not been worked out.

The common periwinkle Littorina littorea harbours Cercaria linearis in the kidneys and mantle-cavity and Echinostomum secundun and C. lophocerca in the digestive gland, while the whelk (Buccimum undatum) has three species affecting this latter organ (Lebour, 1912-16).

The cockle has Bucephalus haimeamus throughout the body, Gymnophallus margarite under the umbo, a third species in the visceral mass and a fourth in the foot. The first-mentioned form, which is a larval stage of the adult fluke Gasterostomum gracilescens of the " angler," may entirely spoil the cockle for edible purposes. Small adult Trematodes are also to be found in cockles and two species are known to occur in the mussel. The tissues of the edible and shore crabs are often crowded with the cysts of the fluke Spelotrema excellens. The digestive glands of infected molluscs look unhealthy, and are of a grey or sickly yellow, or of a peculiarly unnatural orange colour. For the most part the 


\section{I48 THE BIOLOGY OF THE SEA-SHORE}

injury is due to the presence of sporocysts and rediæ, encysted cercariæ seeming to do little or no harm to the host even when present in great numbers. The adult flukes are mostly to be found in various fishes and sea-birds, which feed upon the molluscs containing the intermediate stages above mentioned (Lebour, op. cit.). Jameson and Nicol (I9I3) state that no fewer than sixteen distinct species of Trematodes are known from the Scoter Duck (EEdemia nigra).

More than academic interest attaches to the life-histories of these flukes, since the cercariæ are often responsible for the formation of pearls. Jameson pointed out in 1902 that the agent in forming pearls in the common edible mussel (Mytilus edulis) is the larval stage of a Trematode, possibly Leucithodendrium somaterice (Gymnophallus øedemia), which lives in the Scoter Duck. The cercaria reaches the space between the mantle and the shell and causes a portion of the epithelium of the mantle to become separated off as a circular sac. The cells forming the sac then secrete an organic substance known as conchiolin and also calcareous salts, which are deposited in concentric layers around the remains of the parasite. The precise method of pearl formation in different molluscs is still a matter of discussion. It is quite certain, however, that true pearls are by no means always due to the presence of parasites, but may originate from the inclusion of foreign bodies such as sandgrains or from some internal cause. A good account of the various theories of pearl formation will be found in Dakin (I9I3), who summarises the most important investigations up to that date.

In view of the great number of Trematodes whose existences are dependent on those of shore animals the comparative rareness of larval tapeworms in shore invertebrates is a matter for surprise. Many fishes, of course, harbour tapeworms ; the skates and rays, for instance, are particularly subject to the attentions of Cestodes, but the intermediate stages are usually in other fish. Cysticercoids have been obtained from various molluscs, e.g. Solen vagina 
and Pleurobranchus and from the cephalopod Sepiola atlantica, but these cannot be called common. The same remark is true of the intermediate stage of a Tetrarhynchus found in Nudibranchs.

Nematodes or thread-worms occur in numbers on the sea-shore. They may be free in the substratum or parasitic, both on shore weeds and animals. A small thread-worm is responsible for the small growth irregularities or galls frequently seen on Ascophyllum. All fishes, shore forms included, are likely to be parasitised by Nematodes, which occur either in the gut cavity or in the wall of the gut or in the body cavity. For the most part shore Nematodes are of small size and unlikely to attract the interest of the ordinary observer. A very large form, however, Icthyonema grayi sometimes occurs within the test of the edible seaurchin Echimus esculentus, almost filling the cavity.

Symbiosis.-This term is applied, in the strict sense, to the close physiological association of two distinct organisms for mutual benefit. So intimate, indeed, is the symbiotic relationship that one or both of the partners may be incapable of living alone. The most familiar case of symbiosis is that of the lichens which occur so frequently on trees, on rocks above high-tide mark, and elsewhere. As is well known, every lichen is the outcome of a partnership between a fungus and an alga, the latter supplying the chlorophyll and the fungus forming, as it were, the matrix weaving the separate algal cells together into a single, complex entity.

Another illustration is provided by the mycorrhizæ of trees, an intimate association between the tissues of plantroots (particularly those growing in humus), and the mycelium of a fungus. The fungus decomposes organic substances present in the soil and hands them on in assimilable form to its partner, profiting, in return, by the protection and safety from drought which the higher plant affords. The reason why certain plants, such as heaths, are difficult to transplant is that the partnership, owing to the disturbance of the soil, has been temporarily destroyed. 
Similar relationships are not infrequent between plant and animal. The plants are minute unicellular green or brown cells known as Zoochlorellae and Zooxanthella, and they dwell within the tissues of some of the lower invertebrates, such as sponges, hydroids, sea-anemones and flatworms. The most striking partnership of this kind is that between particular kinds of minute algæ and the small flat-worms Convoluta roscoffensis and $C$. paradoxa. The appearance and occurrence of $G$. roscoffensis have been described elsewhere (p. 239). The species C. paradoxa is the less abundant of the two and occurs on seaweeds which are epiphytic on larger weeds such as Ascophyllum and Himanthalia.

Both species of worm contain plant cells, which are green in the case of $G$. roscoffensis and yellow in that of $C$. paradoxa. The green cells are judged to belong to the Chlamydomonadex, and have been provisionally assigned to the genus Carteria. They occur in large numbers just below the surface of the body of the animal. It is sometimes stated that the worm is dependent for its food on the products of photo-synthesis on the part of the alga; but this appears to be not altogether correct, since Convoluta has not lost its power of independent nutrition. Apparently, one function of the plant cells, at a particular period, at least, is to serve as an excretory system to the worm, by receiving (it is thought) nitrogenous decomposition products from its amœboid cells. These wandering amœboid cells act as a digestive system to the worm by ingesting and circulating food particles. The worm contains no green cells when born, but these obtain entry from the sea-water later on. When once they have entered the tissues of the worm the plant cells become modified and lose their nucleus so that they are thereafter incapable of leading a free existence. At first, as we have already stated, they serve as an excretory system to the worm, but later on, apparently, the worm turns on its ally and assimilates it into its own tissues. The relationship between plant and worm thus varies with age. It is remarkable that while Convoluta feeds 
PARASITISM, ETC., ON THE SEA-SHORE $I_{5}$ I ravenously for the early part of its life on diatoms, algal spores and organic debris, when approaching maturity it ceases to feed altogether and nourishes itself entirely on the symbionts in its tissues (Keeble and Gamble, r904-7). 


\section{CHAPTER VIII}

\section{The Movements of Shore Animals}

THE animals of the shore may be divided into two great physiological groups: the sessile and the freely moving. Between the permanently sessile forms such as sponges, and the essentially roving forms such as Crustacea there is every grade of activity. Sessile forms are relatively very numerous on the shore; indeed, so widespread is this sedentary habit among invertebrates generally that as Willey (I9II) suggests "something peculiarly primordial" would seem to lie at the back of it. This is an interesting point, but we shall reserve further discussion of it until we come to deal with behaviour in the wide sense. The advantages of the sedentary habit have already been seen. We may note, however, that there is no such thing as a sedentary terrestrial animal; to animals such a habit is only possible in the water, and in moving water at that, the latter serving to transport the food. Physiologically the only sedentary animals which are not aquatic, viz. the endo-parasites, are really equivalent to aquatic animals in this respect, since they are bathed on all sides in a nutrient medium. Without exception, the larvæ of sedentary animals are free-swimming, as otherwise it would obviously not be possible to secure distribution.

The methods of achieving displacement on the shore are very varied. Owing to the fact that water is relatively very much denser than air a correspondingly lesser amount of structural adaptation is necessary for an animal in the former medium to raise itself from the ground. Consequently, there are not a few bottom-living forms on the shore which are 
capable of swimming as well as crawling or burrowing. Moreover, the varied nature of the bottom and the topographical position of the shore at the junction of land, air, and water mean that among animals living on or frequenting the littoral practically every conceivable means of locomotion can be studied.

The bodies of freely-moving animals and the hulls of moving ships, etc., provide a convenient means of transport for sedentary forms, and it is fully utilised by them. Whether or not a particular larva of one of these sedentary animals will settle upon a moving or upon a stationary object would seem to be, however, almost certainly a matter of pure chance. And yet there must be more in it than this, for how have barnacles, for instance, acquired the resistance to changes of salinity, temperature, etc., which enables them to cling to a ship during the whole of a long voyage ?

As some of the most characteristic types of displacement we may enumerate the following: clambering, gliding, swinmming, burrowing, jumping, gliding on or hanging from the surface film. Before entering upon a detailed discussion of movement under these headings it will be profitable to notice Gamble's (1908) interesting treatment of this subject, in which he asks us to imagine a man in a boat provided with oars and a boathook. The methods of progression possible to this man are four, and they are analogous to four important methods of movement among animals. They are : by punting with one of the oars against the bottom, comparable with the way in which many animals use their legs or similar appendages; by hauling against obstacles on the banks just as burrowing animals (worms, Crustacea, and insects) use hooks and claws to cling to the sides of their burrows; by sculling over the stern exactly as a fish uses its tail ; and, finally, by rowing with a pair of oars, which is not unlike the way in which insects and birds use their wings, though, in the latter case, in order for the analogy to be accurate we must picture the man as rowing with his face towards the bows.

Clambering.-Probably the animals showing some form 


\section{I54 THE BIOLOGY OF THE SEA-SHORE}

of scansorial adaptation are the most numerous; the uneven nature of the substratum is largely responsible for this. Many others again spend their time climbing among seaweeds where they find their food or to which they cling, at least, in order to resist dislodgment by water movements. Biologically, such forms correspond to the terrestrial wall and rock climbers or to arboreal forms. Adaptations to climbing over rocks and weeds are well seen among the group of Decapod Crustacea sometimes referred to as the Reptantia, which includes the lobsters, hermit crabs and their allies and the true crabs. In contrast to the swimming forms or Natantia (shrimps and prawns) the Reptant Crustacea tend to have their bodies dorsally flattened; moreover, the thoracic limbs are much more strongly developed. The lobsters are more or less intermediate forms; those which show the greatest degree of adaptation to the clambering habit are the crabs. In the crabs the body is, of course, very much broadened, and with this broadening, first obvious in the hermit lobster Galathea, as Newbigin (I9OI) points out, the insertion of the legs moves outwards "so that the body becomes more definitely adapted to the creeping habit." Moreover, in typical clambering forms like the crabs, of the five pairs of thoracic legs only the first pair is chelate, the remaining four pairs being devoted exclusively to supporting the body. But it is chiefly in the long straddling legs with their incurved claws that the crab shows itself adapted to clambering and to taking a grip of flat stones; it is not too much to say that there is something resembling an ectoparasite about the appearance of a crab. Stebbing (I893) quotes the following description by Miss J. M. Arms of the method of locomotion of the common American species of crab Cancer irroratus: "The legs of one side are used to push with and those of the other to pull with, when the crab is in motion. Those of the same side do not, however, all move together, but alternately, so that there is no halting in their gait; some of the legs are always in the act of taking new steps and by shoving and pulling in unison a continuous motion is kept up." 
This crawling by means of jointed appendages can be readily imitated in the following way. "Cross the two wrists side by side, placing the fingers down on a level table; bind the wrists by an elastic band, hold them well up from the table, so as to show the fingers. Then let one set crawl while the other pushes, so as to keep up a continuous motion sidewise without assistance from the arms. The terminal sections of the legs show wear only on the points where these are inserted in the ground." In tropical crabs of the genus Grapsus the art of moving over a broken surface has apparently reached a high degree of development. Speaking of the forms G. grapsus and G. strigosus, Alcock (1902) says that they are exceedingly difficult to catch, running very fast and dodging and doubling like a hare - " their bodies are so thin and flat that they can cling to any surface, however steep ; they keep such constant watch that one can never surprise them, and even when you think you have succeeded in cutting off their every chance of escape, they hurl themselves headlong into the sea and disappear."

Amphipods, like Gammarus, which climb over weeds have their bodies laterally flattened, and when clambering over a weed with fine branches the plant is grasped between the appendages, the lateral extensions of the body-covering (pleura) aiding the animal in keeping its balance. Both Amphipods and Isopods have the last joint or claw of the legs incurved and the limbs show the same general adaptation to clinging as do those of crabs. In Ligia the shape (flattened dorso-ventrally) of the body is adapted to climbing over rock and stones rather than over weeds.

The Pycnogonids are found climbing over seaweeds and zoophytes, a habit to which they are admirably adapted by their long slender appendages each of which ends in a sharp recurved claw. The movements, however, are slow and deliberate, "manifestly not adapted to capture or to kill a living prey" (D'Arcy Thompson, 1909)

It is not surprising that the Arthropods should furnish such a large number of ectoparasitic forms when the nature of their appendages fits them so well for clinging. It is 


\section{I56 THE BIOLOGY OF THE SEA-SHORE}

interesting to consider how far shore conditions have opened the way to ectoparasitic habits. For instance, Pycnogonum, a rather stouter form than most, is frequently found clinging in close contact with some large anemone such as Tealia, "whose living juices it very probably imbibes" (D'Arcy Thompson, loc. cit.). It is rarely, as we shall see, that a particular animal is restricted to a sole mode of locomotion; thus in addition to hanging on to seaweeds and hydroids some Pycnogonids are able to perform gentle swimming movements.

Without a doubt, the most highly specialised form of locomotion on the shore is that characteristic of Echinoderms, e.g. Asterias rubens. It is one peculiarly adapted both to a rocky substratum and to progress between tide-marks where, in addition to climbing up vertical surfaces or beneath overhanging ledges, the animal is obliged to keep a firm grip to avoid dislodgment by wave action. The organs of locomotion are, of course, the tube feet, and the power capable of being exerted by these is so great that, when an attempt is made to remove a starfish, they will break rather than release hold. The customary explanation of the locomotion of the starfish is very much as follows : the tube feet, distended with fluid, are swung forward in the direction of movement and placed upon the substratum. By muscular contraction in the lower part of the tube feet the water is forced back into the ampullæ and a vacuum is thus created between the under surface of the foot and the surface of attachment. By means of the hold so obtained the starfish pulls itself a short distance forward. Contraction of the ampullæ then forces the water into the lower part of the foot, destroys the vacuum, and the hold is released. The tube feet are now swung forward again and the cycle of movements repeated. With this view, namely that the starfish is supposed to haul itself along as one might do by attaching ropes and then shortening them, Jennings (1907) is in disagreement. Locomotion has been shown by this writer to proceed normally when the animal is placed either on a greased surface, the attachment of the suckers being thereby impeded, or on 
loose sand, when the exertion of even a small pull would at once bring away the sand-grains to which the sucker is attached. Jennings' explanation is that the action of the tube feet is essentially similar to that of the leg of a higher animal. In walking, each tube foot is extended forward, in the direction in which the animal is moving, the angle the tube feet make with the ray depending on the position of the ray relative to the direction of movement. The tip of the foot is then placed against the surface, the sucker helping to give it firm attachment, and the whole tube foot is given an impulse to swing back. Since the tip is against a solid body and does not slip, this backward impulse results in moving the body forward. The tube foot thus acts as a partly rigid lever for pushing the body forward, and not as a rope for hauling. Apparently, according to Jennings, the adhesive action of the tube feet only becomes of primary importance when the starfish is climbing a steep surface or hanging in an inverted position.

Forms such as Astropecten which live and burrow in sand have no suckers, and are unable to climb vertical surfaces ; in view of the nature of the habitat this is, however, not necessary. They move by means of the arms, which are used as shovels (Delage, 1903).

Gemmill (1912) has shown that locomotion in sea-urchins may be achieved by means of the lantern (aided by the spines), the animal raising itself on the tips of its teeth, which, pressing hard against the supporting surface, result in the accomplishment of a forward step or, rather, lurch After each step the lantern is retracted and swings forward so as to bring the teeth into position for initiating a new step. By allowing the sea-urchin to travel over a surface spread with a thin layer of plasticine Gemmill has obtained interesting records of the mechanism of locomotion (see Plate XIII). The lantern is employed mainly when the animal is out of water, but it is sometimes of use during partial or complete submergence in travelling up a slope or in mounting rapidly a vertical (rough) surface. In particular, according to Gemmill, the employment of the lantern during partial 


\section{I5 8 THE BIOLOGY OF THE SEA-SHORE}

submergence may be of the greatest service to urchins in the lower region of the shore by allowing them to escape into deeper water when the outflowing tide threatens to leave them in an unfavourable position. Similarly, in view of the many occasions in the normal habitat when the tube feet are unable to get a hold (sand, mud, rocks, etc., covered by growths of fine algæ, etc., or powdered with sand or mud), the action of the lantern will lend valuable aid to that of the spines.

The employment of byssus threads by the mussel is interesting because it illustrates a method of progress by hauling on ropes, and then shortening them, which, prior to Jennings' interpretation, was believed to be that of the starfish. Williamson (1907), who has made a number of interesting observations on the movements of the common mussel (Mytilus edulis), quotes Lang as stating that the mussel is able to climb up a perpendicular wall by lifting itself by the foot and then making fast a thread, the length and character of the latter varying with the degree of extension of the foot. Suspended from the position thus secured the animal may obtain further points of hold for new threads, and from this situation may then climb a further stage. The method described by Williamson by which mussels endeavoured to keep in the water by slackening the byssus will be noticed later in this chapter. We may notice here, however, the way in which a mussel may break its attachment when not bound by other mussels. A solid object is found to which the tip of the foot may adhere; the foot is then shortened, and a strain is thrown on the byssus which results in snapping some at least of the threads upon which the strain bears. Even though some of the threads remain the mussel is free to change its position to a certain extent, and when the byssus is too strongly attached to break, the mussel may get free by tearing it out by the roots. Moreover, without any aid from the foot the byssus threads may be tautened and relaxed by the action of the byssus muscles. (Williamson, loc. cit.)

A feature of considerable biological interest in connection 
with shore fishes is the tendency shown by certain species of blenny to leave the water for short periods to clamber over the rocks in order to bask in the sun. For this purpose the pectoral and pelvic fins are employed, in both of which the fin-rays are firm and fleshy. In point of fact the ventral fin on each side is reduced to a couple of stout processes resembling fingers.

Any adaptation of particular interest noticed in a shore form in temperate regions invariably occurs in more intense fashion among equivalent species in the tropics. Thus Alcock (op. cit.) has observed the behaviour of Gobies of the genera Periophthalmus and Boleophthalmus which frequent the mangrove swamps and muddy shores of the IndoPacific. During the daytime these fish may be seen basking in the sun, or hunting for food, "raising themselves on their fleshy pectoral fins, as a man, whose legs are paralysed, might use his arms. When pursued, they take great springs, using their tails and ventral fins for the purpose; and if they cannot escape into the sea, they will dive down a crab's burrow, or dash into a bunch of mangrove roots." Like the British "shanny," these tropical gobies are exceedingly wary when out of the water, having, as Alcock remarks, " eyes like swivels" (see Fig. 14, p. 207).

Gliding.-Many shore forms progress by a smooth continuous form of movement in which the lower surface or special organ of locomotion remains in close contact with the substratum, e.g. anemones, Turbellarian worms, Gasteropod molluscs. This form of locomotion is best described as gliding. It is employed in the first place by anemones, several species of which are capable of not inconsiderable displacements. According to McClendron (r906), who has carried out observations on Metridium marginatum, the method of progression is similar to the ordinary creeping of a snail ; a succession of waves travels from behind forward, but in the anemone the waves are larger and not so rapid or regular. The undulations of the foot progress in the direction of locomotion. The functionally posterior foot lets go at several points and slips forward and this contraction 
is carried forward; on reaching the centre of the foot the contracted portion rises forming a wave that deepens as it approaches the "anterior" end. On reaching the " anterior" edge the wave is retarded by the firmer attachment of the edge, which releases locally, breaking the wave into segments. A wave requires about a minute to traverse the foot, and before it has disappeared another commences. The same writer has also observed that anemones thrown into an aquarium ejected acontia which caught hold of any solid near them and contracted until some portion of the foot touched the object and caught hold. In a later paper McClendron (1908) has described a species of Cradactis from the Tortugas which is able to crawl on its tentacles, something after the manner of the fresh-water Hydra. The tentacles employed are outside the ordinary ones, and are branched structures resembling fronds of seaweed. They are not used for conveying food to the mouth, but catch hold of the substratum, from which, by considerable writhing, the animal loosens the base and walks inverted on its tentacles to a new place where it rights itself and settles down.

Many anemones, while they remain for long periods in the same spot, are capable of becoming distinctly active, at least in the aquarium, and then cover considerable distances. It is likely, however, that owing to the smooth bottom and sides of the usual aquarium tank the distances covered are greater than they would be on the shore-but this is merely a matter of conjecture. Dr. Williamson, of the Scottish Fishery Board, has observed the movements of a large Metridium dianthus in captivity, and has kindly supplied us with tracings of the successive positions occupied by the pedal disc. From these data the accompanying diagram has been compiled. An interesting point in connection with the movements of this specimen is that the periods of activity would seem to be regularly punctuated with periods during which the animal, though apparently unsettled, moves but little. Or to look at the matter in another way, the larger movements seem to be prefaced by a series of purely local movements. 


\section{THE MOVEMENTS OF SHORE ANIMALS 16 r}

Turbellarian worms, e.g. the common Leptoplana tremellaris, are remarkable for their flat shape, which enables them to maintain the whole of the under surface of the body in the closest contact with the substratum. Locomotion is effected by the cilia of the ventral surface aided probably by the longitudinal muscle layers of this surface

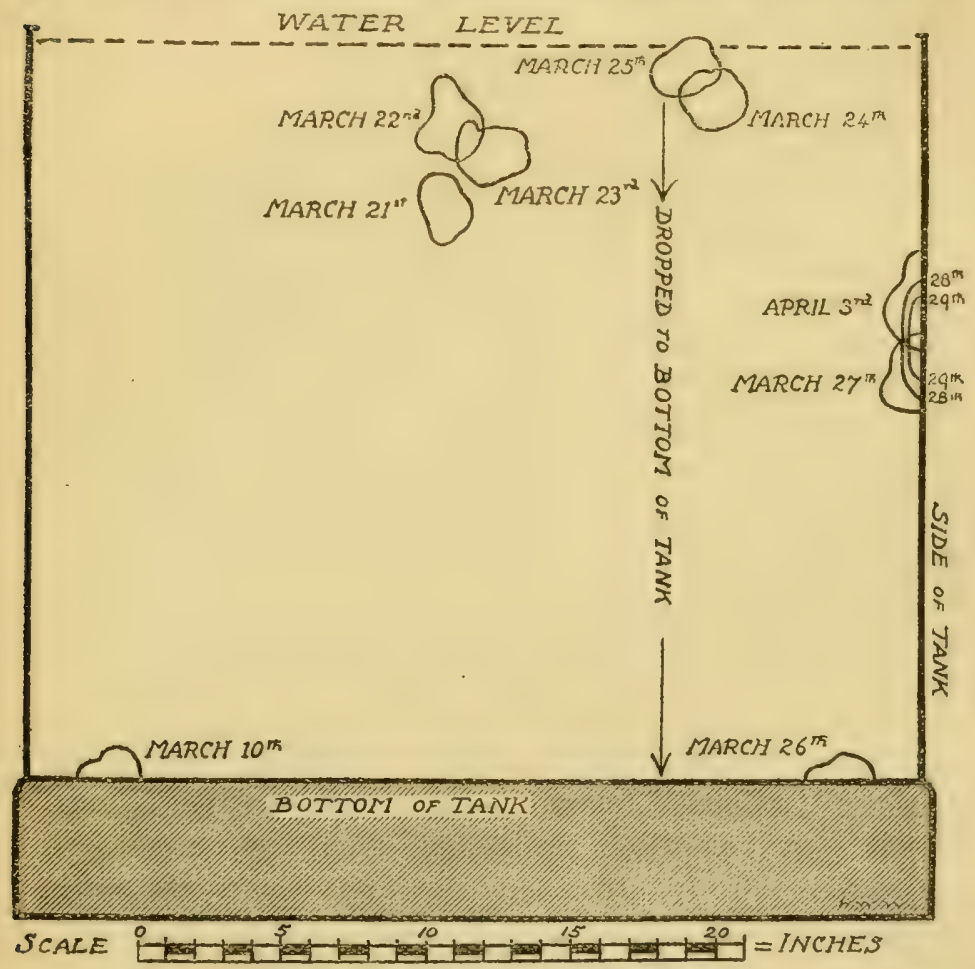

FIG. 12.-Successive positions occupied by pedal disc of a large anemone (Metridium dianthus) on the glass of an aquarium tank during a period of three and a half weeks.

(Gamble, 1896), and results in a remarkably even flowing motion which is very beautiful to watch. The term "pellicule animée " or "living film " often applied to these forms is exceedingly apt. Turbellarians also utilise the surface film of water, and are able to swim very gracefully. Both of these methods of locomotion are dealt with under other 
headings. Like snails, Turbellarian worms lay their own track in the shape of a glandular secretion which bathes the body and enables the cilia to work equally well on different substrata. The common Planarian Dendrocolum lactea, whose usual method of progress is like that of Leptoplana, is said to perform, if alarmed, a series of rapid "looping" movements by affixing a sucker, situated on the under surface of the head, to the substratum and pulling up the posterior end close behind this (Gamble, loc. cit.).

A considerable amount of research has been directed towards the mechanism of locomotion in Gasteropods, which are essentially gliding forms. The organ of locomotion is, of course, the muscular "foot" which, morphologically, is a thickening of a portion of the ventral surface of the body wall, and whose under surface in the univalve molluscs is a flat sole. Modifications of structure occur in relation to the nature of the normal habitat, and in many forms there is a certain differentiation into regions called propodium, mesopodium, and metapodium respectively. The anterior portion or propodium is most strongly developed in genera which crawl about in wet sand, e.g. Natica, Sigaretus, Oliva, Harpa, Scaphander, where " it seems to serve as a sort of fender or snow-plough, to push the sand away on both sides of the path the animal is traversing " (Cooke, I895). According to Woodward (I9I3), the expansion of the foot in the Naticidæ is assisted by the presence of aquiferous spaces, which are completely separated from the circulatory apparatus. On the other hand, in forms such as Buccinum undatum the lower margins of the foot are greatly extended, which allows the animal to crawl on the surface of the sand without sinking in (Woodward, loc. cit.).

The mechanism of locomotion may be studied by allowing the mollusc to creep over a piece of plate glass. When a snail is observed in this way the optical effect, according to Woodward, "suggests a rapidly flowing stream proceeding from the tail to the head, and this is due to the successive raising, moving forward and replanting down of succeeding portions of the under surface of the foot, and is 
comparable to the mode of progression of a caterpillar, save that only the creeping surface and not the whole body participates in the action. The lateral margins frequently do not share in this motion, but have a gentle, lateral, undulating movement of their own." The foregoing description is by no means applicable to the gliding movements of all Gasteropods. In Littorina, for instance, the foot is divided into two halves by a median groove, and the animal moves by lifting and advancing the alternate halves, the mode of locomotion being comparable, according to Woodward, with that of a man with his ankles tied together. Robert (I908), in discussing locomotion in Haliotis, Helix, Chiton, Littorina, and other Gasteropods, maintains that two modes of muscular undulation in the foot-from in front backwards and vice vers $\hat{a}-$ may cause progression, but the waves are not always equally distinct, and the matter does not seem to admit of short formulation. Vlès (1907) divides the different types of wave-motion to be seen on the foot of creeping molluscs into two groups: (I) direct, i.e. forwards in the direction of progress; and (2) retrograde, i.e. from front to back. The group of " direct" forms is further subdivided as follows :

(a) monotaxic: one or more waves visible traversing whole width of foot, e.g. Helix, Limax, Arion (terrestrial) ;

(b) ditaxic : two systems of waves, each occupying half the foot, with the median line unaffected, e.g. Haliotis, Trochus; these are rapidly moving forms ;

(c) tetraxic : four systems of waves, two sets of lateral alternating waves; seen in small species of Littorina. The group of "retrograde" forms contains the following types :

(a) monotaxic, e.g. Chiton; and

(b) ditaxic, e.g. Littorina littorea and L. rudis.

Swimming.-In addition to creeping or gliding over the substratum (stereotropic) numerous shore forms, leaving fishes on one side, possess in more or less developed fashion the power of swimming (pleotropic). It is, in fact, a feature 


\section{I64 THE BIOLOGY OF THE SEA-SHORE}

of shore animals that they are by no means tied to a particular mode of locomotion. For instance, the Planarian worm already mentioned, Leptoplana tremellaris, when alarmed or in search of prey, may exchange the gliding habit for that of swimming, which it performs somewhat in the manner of a skate except that the undulations are more rapid. According to Gamble (loc. cit.), in swimming " the expanded fore parts of the body act as lobes which are flapped rapidly up over the body and then down beneath it, undulations running rapidly down them from before backwards." Again, as pointed out by Eliot (1910), some Nudibranch molluscs which are provided with lateral winglike expansions or with flat tails have some powers of swimming, e.g. Elysia, and even clumsy-looking Dorids when dropped into a few feet of water may find their way to the bottom with movements like those of a flat fish.

We owe to Eisig (1906) a very thorough-going analysis of the methods of locomotion in Annelids. The predominant method of locomotion is described by this writer as " podial-undulatory," and consists of a horizontal undulating movement of the body in conjunction with the movements of the parapodia. In this form of locomotion, successive parapodia on the same side of the animal are working in opposition. When the undulations consist of numerous small waves of low intensity, each individual wave embracing only a small number of segments, the resultant progress is described as a swimming gait (" Schwimmgang," or " Marche natatrice " of Bohn). With an increase in the amplitude and intensity of the waves the animal rises from the bottom and begins to swim (e.g. Nereis). In typically swimming forms (e.g. Nephthys) the undulatory element predominates. Cases of purely undulatory locomotion occur in forms such as Nemerteans but not in Annelids, although undulatory movements (albeit in the vertical plane) are performed by tubicolous Polychæts in connection with respiration within the tube.

7. Crustaceans of the genus Portunus have the last two joints of the last pair of thoracic appendages considerably 
expanded and flattened, and are known as swimming crabs. Stebbing (I893) quotes Gosse as having observed species of this crab in the Caribbean Sea and among the gulf-weed in the tropical Atlantic, shooting through the water almost like a fish, "with the feet on the side that happens to be the front all tucked close up and those on the opposite side stretched away behind, so as to hold no water, as a seaman would say, and thus offer no impediment to the way." The swimming powers of British species of the genus are not nearly so well developed and the paddle-like last pair of thoracic limbs are used as much for shovelling sand as for swimming.

A peculiar form of swimming may be observed in the common scallop Pecten opercularis, and to a lesser degree in $P$. maximus. The mechanism of this curious jerky motion has been described by Vlès (1906) and by Dakin (1909). Briefly stated, the movement is due to the sudden expulsion of water (brought about by the vigorous clapping of the shell-valves) in a narrow jet at each side of the dorsal edge of the shell, the pallial folds acting as a valve and preventing the escape of the water elsewhere. The opening of the shells is normally in the direction of movement, the hinge behind. As in many other forms, however, a sudden danger or stimulus gives rise to what may be called a special flightreaction, the animal reversing its normal procedure, and darting away with its hinge-line foremost. Dakin (loc. cit.) suggests the following structural modifications as being in close relationship with the swimming habit : the equilateral character of the shell, the evolution of a muscular mantlefold or velum, the large single adductor muscle with its adaptations for rapid contraction, and also the large internal cartilage for opening the shell.

Burrowing.-The number of burrowing forms occurring on the shore is very large, and, as one might expect, the majority are Annelids. The advantages of this habit on the shore are, as we have seen, protection both from enemies and from drought. In addition, the sand or mud of most shores contains a large amount of organic debris, decaying 


\section{I66 THE BIOLOGY OF THE SEA-SHORE}

weed, algal spores, etc., which provides rich nutriment for those forms which are able to extract it. Since the object of burrowing is predominantly concealment, Eisig has applied the term "cryptoid" to this form of locomotion. He further recognises three or four subdivisions according as to whether the chief agent in burrowing is the proboscis (e.g. Glycera) or the paropodia (e.g. Aphrodite, Psammolyce, etc.), or whether the initial movement is one of swimming (e.g. Nephthys, Sthenelais) or a screw-like (helicoidal) motion (e.g. Lumbriconereis).

Another group in which the burrowing habit is exceedingly well developed is that of the Crustacea. In some forms the burrowing is only very superficial and temporary (prawns and shrimps); others, particularly tropical amphibious forms, excavate galleries in mud and sandbanks which are practically permanent. Between these two extremes are numerous forms which excavate temporary burrows that are destroyed at each new tide, e.g. the common sand-hopper. Many interesting accounts have been given of the habits of the burrowing Crustacea of American shores, but it is only possible to accord them the briefest mention here. The method of burrowing of the American "fiddler" crab (Gelasimus pugilator) has been observed by Verrill and Smith (quoted by Stebbing, I893). The holes made by this species are mostly from half an inch to an inch in diameter and a foot or more in depth, the upper part nearly perpendicular, becoming horizontal below, with a chamber at the end. The moist sand is removed in small pellets, the crab transporting each pellet to a distance of four or five feet from the hole before depositing it and running quickly back for a new load. Another writer, Smallwood (r9o3), has made a number of interesting observations on the habits of the American "beach-flea" (Talorchestia longicornis). The burrows, from 4 to $20 \mathrm{cms}$. deep, of this species may occur over an area extending from a short distance below ordinary high-tide mark to a little above the spring-tide line, and are temporary. The animal rests in a small chamber at the lower end, always in damp sand, and the hole is usually 


\section{THE MOVEMENTS OF SHORE ANIMALS I67}

closed by sand from the bottom or by falling sand as the animal enters. In addition to burrowing, the "beach-flea" can also run and hop but swims with difficulty. The corresponding British species is the common Talitrus orchestia. Another burrowing Amphipod, which is of very common occurrence on sand and mud-flats between tide limits in this country, is Corophium longicorne.

Among Crustacea the burrowing habit has led, in many cases, to numerous adaptations of structure in relation to digging, and particularly in connection with the difficulties of maintaining a respiratory current beneath the sand, e.g. Corystes and Galathea (see under Respiration, p. 213).

The great majority of bivalve molluscs are burrowing forms. The form of the shell is obviously of great importance in relation to this habit. Forms with compressed, wedge-shaped valves usually burrow rapidly and deeply and have elongated siphons. Globular forms like the cockle burrow less rapidly and to a shallower depth, their shape rendering them less liable to be dislodged by wave action. Probably the most actively burrowing form of all is the razor-shell (Solen). The habits of an American species of razor-shell, i.e. Ensis directus, which is abundant all along the east coast of the United States, have been studied by Drew (1907). In burrowing, the foot is worked into the mud, the end swelled to a knob, and by its sudden withdrawal the shell is drawn to the position previously occupied by the anchored end of the foot. At the same time a strong jet of water is expelled from the anterior end of the shell so that the mud is softened as the shell descends. Similar observations have been made on the native species Solen ensis by Elmhirst (1910), who likens the fleshy expansion of the foot to a mushroom anchor, and remarks on its suitability for giving a firm grip of the sand.

Boring.-As a specialised form of burrowing we have the excavation of channels in wood and rock, a mode of progression entailing perhaps more extreme modifications of form than any other on the shore. From the economic standpoint the damage done by wood-boring organisms 
between tide-marks to wooden piers and similar structures is enormous, while the rock-boring forms play a considerable part in aiding coast erosion. We shall consider these boring forms under two headings, (a) rock-boring forms, $(b)$ woodboring forms.

(a) Rock-boring Forms.-The most important of these are the two bivalves: the Piddock (Pholas dactylus) and the form known as Saxicava rugosa. Considerable difference of opinion has existed in the past as to whether the boring was the result of chemical or of mechanical action or of a combination of the two. According to Calman (I919), there can be no doubt that the boring of Pholas " is effected mainly, if not exclusively, by the rasping action of the shell, which is provided with rows of spines or teeth towards the front edge." The appearance of the teeth varies according to the nature of the material in which the animal is normally operating, being sharp and slender in specimens from chalk or peat and blunt and rounded in those from harder rocks. The variety of substances in which Pholas has been observed to bore is said to preclude chemical action (Calman, loc. cit.). According to the same writer, the boring movements "consist chiefly in a twisting or rocking movement of the whole shell on the fulcrum formed by the sucker-like foot, the muscles from which are attached to the inner blades of the valves." The method employed by Saxicava in boring calcareous rocks is less apparent. Calman considers that, in spite of the fact that so far no acid secretion has been demonstrated nor the presence of any special gland, it is certain that the process of boring is at least partly chemical, since this mollusc occurs in limestone rocks so hard and compact that mechanical action seems out of the question for so fragile a shell. Polychæt worms of the genus Polydora are found burrowing in calcareous rocks and shells on British shores and sometimes in shales and sandstone as well. Calman considers that although there may be some abrasion of the rock by the bristles, chemical action must be regarded as indispensable.

Oyster shells pitted by the boring sponge Cliona celata 
are frequently picked up on the sea-shore. Here the action of the sponge seems almost certainly a solvent one, but attention has been drawn to the fact that contractile tissue is particularly abundant in the Clionidæ and that the needlelike spicules would have considerable penetrative power.

(b) Wood-boring Forms.-From the evolutional standpoint the habit of wood-boring in marine animals is of comparatively recent acquisition, standing, as it does, in close relation to the work of man. Since, apart from ships, the majority of structures utilised by these forms occur between tide-marks, they form in consequence a particularly interesting section of our study.

Here, again, the form of most importance is a bivalve mollusc, the so-called Ship-worm (Teredo). Salinity appears to be of considerable importance in the distribution of this form, the requirements varying according to the species. For instance, reference has been made elsewhere to an unusual extension of the Ship-worm, Teredo diegensis, in San Francisco Bay, owing to seasons of drought affecting the amount of fresh water entering the Bay; $T$. navalis also appears to be intolerant of brackish water and the great outbreaks of this species in Holland in $1730-32,1770,1827$, and $1858-59$ are ascribed to reduced rainfall leading to unusually high salinity in the Zuyder Zee and coastal waters (Calman, op. cit.). According to the same writer, however, certain tropical species are said to live in perfectly fresh water. Generally speaking, "ship-worms may attack timber at least as high as midway between tide-marks" (see Plate XII). We base our description of the mechanism of boring on that of Calman.

Boring is performed by the two very much reduced valves situated at the apex of the long worm-like body. The front edge of these shells is deeply notched, and parallel with the edges of this notch the outer surface of the shell is engraved with a series of fine ridges and grooves, the former of which, under the microscope, are seen to be rows of fine, sharp-pointed teeth, resembling those of a rasp or file. As the shell grows, new rows of teeth are continually 


\section{I70 THE BIOLOGY OF THE SEA-SHORE}

being added along the edges of the notch. The attachment and consequently the movement of the valves is very different from that of the ordinary Lamellibranch shells. The hinge ligament is either absent or vestigial and the hinge itself is represented by a prominent knob on each valve which works against its fellow. At the ventral edge of each shell is another knob which forms a second point of contact between the valves. Next, the two adductor muscles, instead of contracting simultaneously, do so alternately, drawing together now the front and now the hinder edges of the valves. In this way a see-saw like movement of the valves is produced about the pivot formed by the dorsal and ventral knobs, which causes the tiny teeth to rasp against the wood. In addition, it is probable that the action of other muscles, attached to a narrow curved process projecting from a point close to the dorsal knob, gives rise to a twisting movement of the whole shell which aids progress. Purchase is obtained by the adhesion of the sucker-like foot which projects between the notches in the valves.

A related form, Xylophaga, is recorded by Thompson as destroying, in company with other forms, the submerged woodwork in the harbour of Ardrossan on the Firth of Clyde (see Plate XII).

Certain Isopod and Amphipod Crustaceans are also found excavating galleries in wood, the process here being simply one of gnawing. Of these the most important on British coasts is the " Gribble," Limnoria lignorum, an Isopod, which may occur near high-tide mark but is said to be most abundant between low-water and half-tide mark. The burrows formed by this species are about $\frac{1}{20}$ th of an inch wide and of uniform diameter throughout. They run obliquely through the wood and, in consequence, though from $I \frac{1}{2}$ to 2 inches long, the average depth is usually not more than about half an inch (Calman, op. cit.).

Associated with Limnoria there frequently occurs the Amphipod Chelura terebrans. Owing to the somewhat larger size of this species the burrows made by it are a little wider than those of Limnoria, reaching $\frac{1}{10}$ th of an inch in 


\section{PLATE XII}

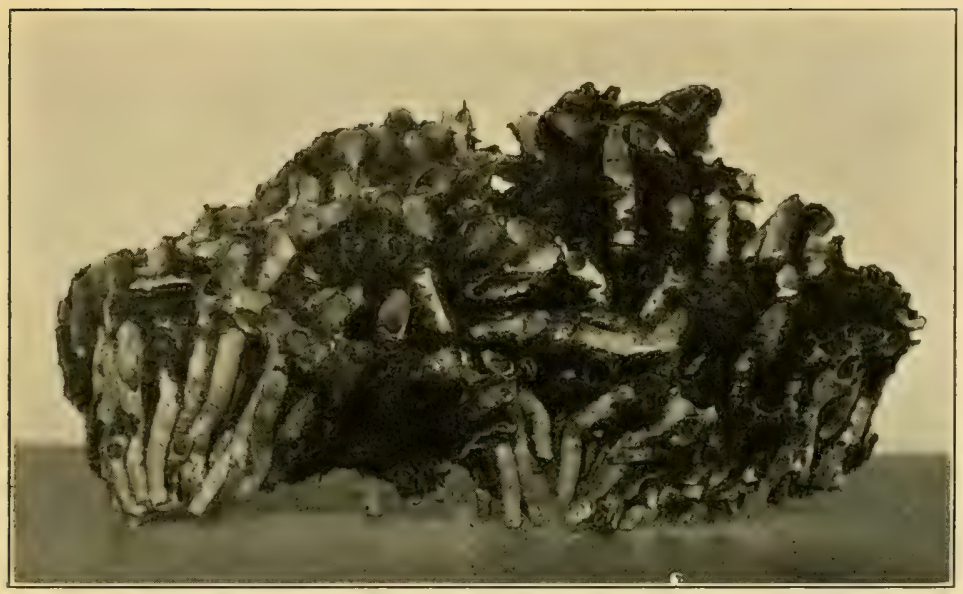

I.-Timber Bored By THE Ship-Worm (Teredo norvegica).

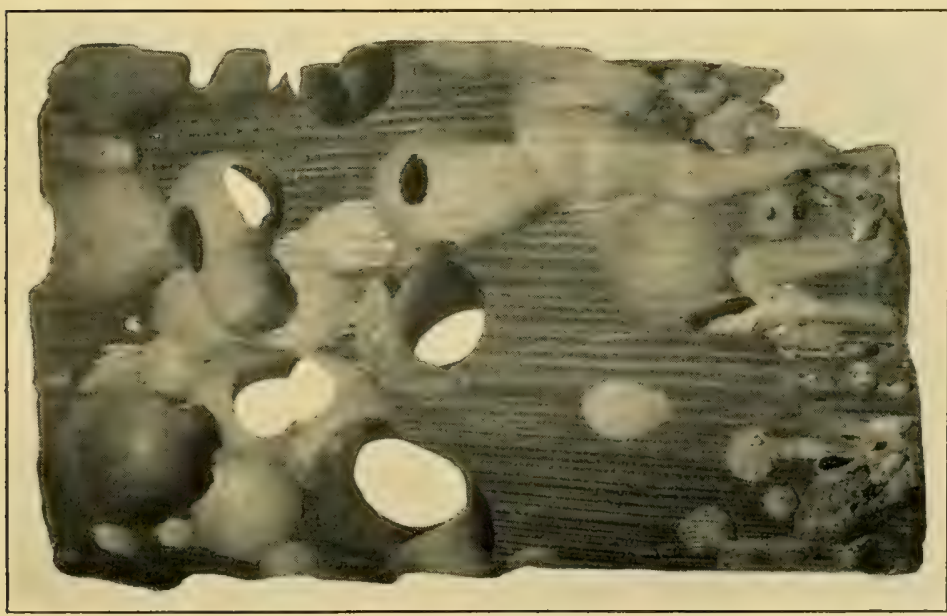

I1.-T'imber Bored by the Bivalve Xylophaga.

A form related to the ship-worm. 

diameter. Further data with regard to these boring forms can be obtained in the valuable paper by Calman so frequently referred to above.

Jumping.-Progress by means of leaps is best seen in the sub-aquatic (and terrestrial) forms or forms such as certain Amphipods (e.g. Talitrus, Orchestia, etc.) and the shorefrequenting Collembola. The former include the common "beach-fleas" or "sand-hoppers" in which the driving power for the spring is obtained by flexing the posterior portion of the abdomen and driving it swiftly backwards, the necessary purchase on the substratum being obtained by means of the last three pairs of thoracic limbs. In this way the animal can jump to a distance of several feet.

In the Collembola a special jumping organ is usually present in the shape of a long style or spring, consisting of an elongated basal portion and two small appendages, situated on the under side of the abdomen close to the posterior end. This appendage is carried flexed beneath the abdomen where in some genera it is retained in position by means of a "catch" projecting from the under surface of the third abdominal segment. The spring is considered to be elastic, so that when the catch is removed the spring sweeps backward with considerable force, and striking the ground jerks the animal forward.

In dealing with the Collembola (Poduridæ) of Cold Spring Beach, Davenport (1903) shows that the variety of movements in these forms is considerable. The Podurids of the beach live between tide-marks, burrow in the sand at high tide and rise to the surface when the tide is out. They run up surfaces in the face of the wind and leap when they reach the top, being blown back to the starting point. In addition to the normal movements of running and springing, Davenport distinguishes such special locomotor movements as whirling, descent and ascent in sand, running up stones, and leaping into the air. A similar variety marks the movements of most shore forms, and is no doubt accounted for by the varied nature of the habitat. In the majority of cases a particular shore animal, though predominantly a 


\section{I72 THE BIOLOGY OF THE SEA-SHORE}

swimming, a burrowing, or a jumping form, as the case may be, is not by any means restricted to a sole method of locomotion.

In addition to ploughing its way through the sand, the cockle makes use of its powerful foot to execute a kind of jump. This method of progress is brought about by bending the foot under the shell and suddenly straightening it, when the animal makes a clumsy kind of leap and rolls over and over. A similar form of progress is seen in the tropical Stromb shells and their relatives the Scorpion shells, Rostellaria, etc. (Woodward, 1913).

Locomotion involving Use of the Surface Film.-Shore animals with their marked resourcefulness have not neglected to make use of the elastic properties of the "surface film." Locomotion, with inverted body, on the under side of the surface film is particularly prevalent among Gasteropods (e.g. Rissoa, and many Nudibranchs), and is made possible by the flattened foot with its mucous secretion, the usually large amount of surface in relation to mass, and light weight. As previously mentioned, it also occurs in Planarian worms such as Leptoplana.

According to Colgan (1909), "Nudibranchs can float with the ventral surface uppermost and in confinement many of them show a great love of this position. . . A As far as is known, they are obliged to make their first excursion to the surface with the aid of a piece of seaweed or other material support and possess no power of levitation of their own. On reaching the surface they secrete from the foot a layer of mucus and remain in an inverted position with the dorsal region downwards and the foot and mucus-layer upwards. By bringing the margins of the foot together they can drop from this position at will and frequently remain suspended some inches below the surface by a thread of mucus connected with the superficial layer." The same writer says that reascent of the thread is probably made in the way described by Taylor for the arboreal form Limax arborum (I894-19I4), that is to say, "by bringing the extremities of the body together and transferring the point of 
attachment of the suspensory ligament from the tail to the head." The following littoral forms have been observed by Colgan to have this habit of suspending themselves by means of slime threads: Runcina hancocki, Limapontia nigra, Doto coronata, Eolis farrani, Eolis drummondi, Skenea planorbis, Rissoa striata, $R$. parva, R. cingillus, Modiolaria discors.

Having now dealt with the actual mechanism of locomotion in a number of typical cases, we may turn to a consideration of the movements of shore animals in the wide sense. As examples of such movements we have the migrations of varying extent and distinctness in relation to seasonal changes, and in connection with reproduction. To these we may also add the vertical movements of many forms in relation to the tides. Finally, there remains for consideration the question as to what extent, if any, there is developed in shore animals a topographical or "homing " sense.

The Migrations of Shore Animals.-Owing to the slowness of locomotion in most shore species, such migrations are not likely to be of great extent, and as, so far, hardly any one appears to have observed the distribution of the members of a particular shore association over an extended period, the data relating to such movements are very scanty. Sorby (I90I), however, has published some interesting observations on the changes which have taken place, over an extended period, in the distribution of the fauna of the Essex coast (see Chap. III). He remarks on the extraordinarily local distribution of some animals, and thinks the exact whereabouts of a particular form may shift from year to year owing to a partial migration. Closer observation, however, is required to determine whether these local changes are due to migration or to the disappearance of the original forms as a result of adverse circumstances and the reinfiltration of a new generation in a more suitable spot. A considerable amount of knowledge, however, has been obtained regarding the seasonal movements of such forms as crabs, prawns, and lobsters, because in addition to their 


\section{THE BIOLOGY OF THE SEA-SHORE}

economic importance the fact that they are very active forms leads them further afield and renders their migrations more likely to be remarked.

Scientific investigation has now confirmed the fact, long known to fishermen, that the adult crab undertakes definite migrations of considerable extent. In September both hard and soft crabs begin to move outward from the tidal area to deeper water, travelling to a depth which varies with the locality, but is generally between twenty and thirty

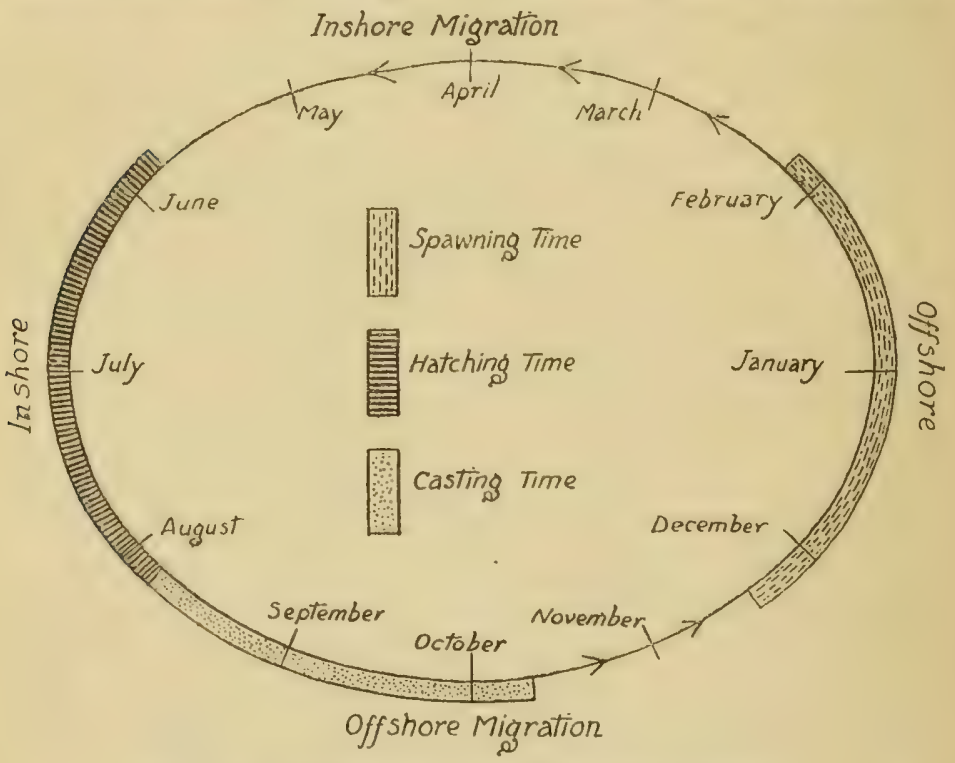

Fig. 13.-Migration of edible crab (after Pearson).

fathoms. The crabs remain in the offshore waters from December to February, and it is here that the females spawn (Pearson, 1908). The return migration begins in February and by May the majority of the crabs are probably close to the shore again. In the warm inshore waters the larvæ are hatched, and in the following autumn the cycle recommences. The above diagram, which we reproduce from Pearson, summarises the main facts of the cycle.

Williamson (1900) considers the reasons for the migration to lie in (I) the influence of temperature, and (2) the necessity 
for food. The shallow inshore waters are, of course, warmest in the summer months, and it is here that the eggs hatch and the larvæ develop. On the other hand, in winter the deeper layers of the offshore waters are distinctly warmer than the shallow waters inshore, and it is possible that it is on this account that they are sought in winter for the act of spawning. This cannot, however, be the complete explanation for, as Williamson points out, by the time the outward migration begins the inshore waters are still the warmest. Neither Williamson nor Pearson seems to have considered whether a possible explanation might not be the need for seeking more tranquil waters when the autumn storms come on.

Similar movements are undertaken by lobsters and prawns, and in the same way the fish of rock pools frequent deeper water in winter.

Of great interest are the breeding migrations of Crustacea which are in course of becoming terrestrial. Crabs of the genus Geocarcinus, as stated in Chap. XII, live in sheltered situations several miles from the sea, and make their way in spring in herds to the sea-shore in order to breed.

Eliot (I9IO) remarks that both adult and young Nudibranchs appear and disappear suddenly in considerable numbers, particularly before spawning and after hatching. Notwithstanding that Alder and Hancock were induced to disbelieve in these migrations, Eliot considers there is a good deal of evidence for their occurrence. The method by which the migration is effected is not known, but as creeping is an extremely slow process, it is suggested that the animals make use of currents, in which they suspend themselves by means of slime threads.

Vertical Movements of Burrowing Forms in Relation to the Tides.-A consideration of the rhythmical movements of shore animals in relation to the tides is deferred till Chap. XI. It is not out of place here, however, to call attention to the vertical movements which are regularly performed by burrowing worms and molluscs, as the tide ebbs and flows.

When the water has left the sand, worms and bivalves 


\section{I76 THE BIOLOGY OF THE SEA-SHORE}

withdraw to the very lowest points of their burrows. Tubicolous Polychæts are similarly retracted within their tubes. The only evidence of the life below is afforded by wormcasts or by small holes and depressions in the sand. Very different is the appearance of the same stretch of shore when covered with water. The burrowing worms are now swimming or moving about freely. Tube-dwelling forms have climbed up inside their tubes and protruded a crown of tentacles which are waving in the water. A similar vertical ascent has been made by bivalves, the siphons of which now project above the surface of the sand.

Williamson (1907) has noticed that when the water was let out of a box to the sides of which a number of small mussels were attached, the animals slackened their byssi in order to keep themselves in the water. When, however, having reached the end of their tether, the water was still receding, they hauled themselves up tight against the wall of the box again. This power of adjustment, though slight, might just make the difference between annihilation and safety, and seems to be adaptive.

Homing. - The fact that the limpet, with the edge of its shell, forms an impression or " scar" on a rock on which it has been living (if this is not too hard) long ago drew attention to the movements of this animal. The outline of the scar exactly corresponds to that of the shell-margin (by the mechanical action of which it is formed), so that if a limpet moves it must not only return to the identical spot or " home," but must orient itself exactly as before. It has now been definitively established that when once a limpet has taken up a fixed position on a rock, it only leaves it to make journeys for food and always returns to the same spot, though there seems to be a certain amount of difference of opinion as to when the movements are effected.

According to Ainsworth Davis (1895), the "homing " instinct of the limpet is well developed, and in this writer's belief the "locality sense" is independent of smell, sight, and touch, at least as far as the head tentacles are concerned. The greatest distance from which a limpet has been known 
to return to its "home" is 3 feet. Davis and Fleure (1903), in discussing the formation of the scar, state their belief that it results from the mechanical action of the foot surface, and of the bevelled edge of the shell. During life the animal constantly leaves and returns to its home, and consequently the foot, in spite of its softness, is responsible for an appreciable amount of wear, especially as fixation is usually preceded by a certain amount of " shuffling or twisting round on the scar." The deeper margin of the scar clearly indicates shell action.

According to Russell (1907) "the seat of the limpet's marvellous sense of direction is quite unknown, and the accuracy with which it returns to a definite spot is very astonishing." From careful experiments with marked limpets this writer concludes: "(I) that every limpet of I $5 \mathrm{~mm}$. and upwards occupies, for long periods at a time, a definitely fixed position, to which it returns after any wanderings that it may make for food; (2) that limpets under $15 \mathrm{~mm}$. if not yet settled in a definite position, at least never wander far away, and so generally keep to the same stone; (3) that limpets wander chiefly when covered by the tide." Results of a similar character have been obtained by other writers for other species of Gasteropod. Piéron (1909), for instance, considers there is evidence of " homing" in Calyptrea, but it is less precise than in Patella. Willcox (1905) speaks of the "homing" of Siphonaria alternata and Fissurella barbadensis, limpets which occur on the calcareous rocks between tide-marks at Bermuda. The former did not "home" if removed more than six inches, but generally returned if moved a couple of inches away, doing best in quiet shallow tide pools. If headed away from the scar Siphonaria turns of its own accord. One specimen formed a new home and made a green spot in three days. The range for Fissurella is about two inches, but otherwise its behaviour is very much like that of Siphonaria. The animals appear to recognise their own scars.

Before having recourse to explanations involving higher mental activities it is well to consider the part played by 


\section{I78 THE BIOLOGY OF THE SEA-SHORE}

the environment. Thus, Bohn (I909) finds that "homing" is not always certain. The movements of the animal seem to be influenced by gravity. There are lines of least resistance on the rock which are followed very much as one might follow them in a forest. It is not necessary to invoke a muscular or visual memory.

Retrospect.-One of the most obvious features of the shore fauna is the frequency of the sedentary habit, almost certainly related to wave action. Among freely moving types the methods of locomotion are, however, extremely varied, this, in turn, being due to the varied nature of the substratum. Owing to the relatively much greater density of water as compared with air the degree of structural adaptation required for an aquatic animal to lift itself from the ground is much less than is required in the case, say, of a bird.

The chief methods of locomotion may be described as follows : clambering, gliding, swimming, jumping, hanging from the surface film. Locomotion in the starfish is of particular interest since it represents a highly specialised method of progress in relation to broken rock-surfaces. Burrowing is extremely common, and enables a shore animal to elude enemies and to escape desiccation at low tide. Every stage of the burrowing habit may be observed, from temporary refuge beneath a shallow layer of sand, as in shrimps and prawns, to the boring of wood and rock involving a very high degree of specialisation.

Migrations are usually of small extent and have been insufficiently observed. There is evidence of a "homing sense" in the common limpet and its relatives. 


\section{CHAPTER IX}

\section{The Nutrition and Methods of Feeding of Shore ORGANISMS}

\section{THE NUTRITION OF MARINE ORGANISMS IN GENERAL}

IN approaching the problems presented by the nutrition of marine organisms it is natural that we should call to mind what we know about the corresponding problems on land. We are aware, for example, that all terrestrial animals, whether directly herbivorous or not, depend for their nourishment upon plants which, in turn, elaborate their food from the carbon dioxide of the atmosphere and from certain simple inorganic compounds (the "ultimate foodstuffs ") present in solution in the soil, utilising in this process the energy obtained from the sunlight. For a constant supply of the most essential of these materials in the requisite form plants, again, are dependent upon certain micro-organisms : bacteria, moulds, and yeasts, by whose agency the elements composing the bodies of dead plants and animals do not pass out of circulation, but are again made available for life.

So far as our present knowledge extends it would seem that the food-cycle in the sea is of substantially the same character as that we have outlined above. Nevertheless, marine metabolism exhibits not a few special features of its own, and theories are not lacking (see those of Pütter below) which, if proved correct, would very materially disturb any preconceptions that our knowledge of land conditions may have led us to form.

It is usual to divide the food-stuffs present in the sea 
into (I) those which are contained in the tissues of living animals and plants; and (2) mineral salts, organic acids, and other relatively simple compounds which occur in solution in the sea-water. The first class of food is utilised by animals and the second class by plants. This is a statement which, though essentially accurate, requires a certain amount of qualification. We must make allowance for saprophytic and even saprozoic modes of nutrition. Saprophytes are, of course, plants which derive their food not from the simple substances just mentioned, but by fermenting organic materials, such as sugars, occurring in the soil or in the bodies of other plants. Familiar terrestrial saprophytes are the moulds, yeasts, and fungi. These occur in the sea as well, but not so abundantly as on land (Johnstone, Igo8). The term saprozoic is applied to a similar method of nutrition when practised by animals; as in the case of certain protozoa or-an example of a different nature- of forms such as Convoluta which apparently utilise the products manufactured by the activity of plant cells living symbiotically in their tissues (see p. I50). These exceptions, however, do not really weaken the distinction which it is customary to make between plants as the producers and animals as the consumers. Quite different would be the case if the theory put forward by Pütter were proved to be sound, viz. that marine animals obtain much of their food in the form of organic compounds in solution in the water. Further attention will be given to this important question later on.

The Nutrition of Marine Plants.-Plants in the sea belong to one or other of two great classes : they may be either fixed or floating. The fixed plants are confined to a relatively narrow belt fringing a land mass, whereas the floating plants are universally distributed and, consequently, in the economy of the sea in general, of far greater importance than the seaweeds proper. In the case of the tidal area the importance of the two classes of plants is approximately equal.

All marine plants, however, whether fixed or floating, obtain their nourishment in precisely the same way, viz. by 


\section{NUTRITION AND METHODS OF FEEDING I8r}

absorbing over their whole surface the mineral salts, organic acids, etc., from the water with which they are bathed. The so-called "roots" of the fixed seaweeds are merely hold-fasts, and apart from this function have nothing in common with the roots of land-plants.

The foodstuffs utilised by marine plants are substantially the same as those which subserve the nutrition of plant-life on land. Following Johnstone (op. cit.), we may enumerate them as follows :-

( $\mathrm{I})$ Nitrogen compounds, in the form of nitrates, nitrites, ammonia, and possibly amines. The amount of these is exceedingly small and their precise estimation a matter of great difficulty.

(2) Carbonic acid, present in the atmosphere as $\mathrm{CO}_{2}$ and in simple solution in the sea-water or in solution as bicarbonates of calcium and other bases. Carbon dioxide results from animal respiration, and is an end-product of the decomposition of organic matter whether brought about by putrefactive or fermentative organisms. Plants, on the other hand, utilise the $\mathrm{CO}_{2}$ for the elaboration of starch. The amount of $\mathrm{CO}_{2}$ in solution or, in other words, the degree of alkalinity or acidity of the sea-water, varies with the relative activities of vegetable and animal organisms and serves, in fact, as an index to these activities. As illustrating this reciprocal activity of plant and animal with regard to $\mathrm{CO}_{2}$, we may mention the fact brought out by Benjamin Moore (I9I3-I4), namely that " almost all the $\mathrm{CO}_{2}$ provided by a lobster can be reconverted into $\mathrm{O}$ by the vegetation which forms upon its own carapace." If marine animals are to remain in health, the water must have a slightly acid reaction; too great a variation in the direction of alkalinity or acidity is likely to prove fatal. calcium.

(3) Phosphoric acid, in the form of soluble phosphates of

(4) Silica, which may exist in solution in the sea, either as colloidal silicic acid or as particles of clay (aluminium silicate) in suspension. In spite of the relatively minute quantities in which it occurs, silica is of great importance in 
the sea, since it composes the skeletons of large numbers of both marine plants and animals such as diatoms, Radiolarians, Sponges, and others. Diatoms, in particular, contain a very large proportion of silica and, in fact, the frequent presence of this largely indigestible substance would seem to have had important consequences, witness the various means which are found for dealing with it. In calling silica largely indigestible, we are not unaware of the part this substance plays in animal metabolism. We know, for instance, that it is generally distributed, albeit in minute quantities, throughout human tissues and is also of regular occurrence in the urine. The fact nevertheless remains that silica occurs in marine diatoms in far greater quantities than can ever be utilised by animals. Moreover, it seems almost certain that marine animals obtain their supplies of silica in the same way as do the plants, viz. by absorption direct from solution in the sea-water. So small is the proportion of silicic acid or silicate present in the sea that there is considerable difficulty in conceiving of the manner in which organisms, such as diatoms, are able to extract sufficient for the manufacture of their skeletons, a task which would seem to require the expenditure of an almost impossible amount of energy. This difficulty, Johnstone suggests, has its origin in the natural tendency to regard the metabolic processes of the lower invertebrates, of which we know little, as more or less resembling those of mammals about which we know so much more. An organism such as a diatom or protist absorbs food over the whole of its surface and not through an alimentary canal. Further, the smaller the organism the greater the proportion of surfacearea to volume, and consequently the larger the amount of dissolved substances it is able to absorb.

(5) Calcium occurs in solution chiefly as calcium bicarbonate and also as calcium sulphate. Lime plays an even more considerable part than silica in the sea, since it is required for bone-formation in fishes and for the formation of shells, tubes, and skeletons in a very great many invertebrates. Unlike silica, however, lime is present in the sea 


\section{NUTRITION AND METHODS OF FEEDING I 83}

in considerable amount. Other mineral salts utilised by marine plants, such as the chlorides, sulphates, etc., of sodium, potassium, magnesium, and iron, are present in ample proportions.

(6) Oxygen is necessary for the respiration of both plants and animals. It is dissolved from the air and is given off as a result of the photo-synthesis of plants. Oxygen occurs in solution in varying quantities up to saturation, the latter point being rarely reached except, perhaps, in the tidal area, which is the most highly oxygenated area in the whole sea.

Since all of these substances: nitrogen compounds, carbon dioxide, phosphoric acids, silica, and various mineral salts, are essential to the life of plants, it follows that the absence of any one of them will be sufficient to put an end to growth entirely. Similarly, if one of the essential constituents is present in minimal quantity growth will also be minimal. Thus, " the growth of a plant is dependent upon the amount of the foodstuff which is presented to it in minimal quantity." This is Liebig's Law of the Minimum, the application of which is of fundamental importance in the sea, since on it, though indirectly, the quantity of animal life also depends.

Nutrition of Marine Animals.-None of the substances which we have enumerated, however, are capable of serving as food for marine animals. These, like land animals, can utilise (if we are not to credit the theories of Pütter) only substances such as proteins, carbohydrates, and fats, which have been built up within the bodies of other organisms. Both in the sea and on land, therefore, the plants are the indispensable links between the ultimate foodstuffs and the living animal.

The immediate diet of a marine animal may consist solely of flesh or of plants, or it may be composed of a mixture of both. In actual fact the number of omnivorous marine animals probably greatly exceeds that of terrestrial animals with the same feeding habits. The most characteristic way in which marine animals obtain their food is by straining 


\section{I84 THE BIOLOGY OF THE SEA-SHORE}

off quantities of the myriad diatoms, protophyta, protozoa, and tiny multicellular animals in which the upper waters of the sea abound, a method which obviously precludes the possibility of any discrimination between the plant and animal constituents. Since the waters are in constant motion there is no strict necessity to pursue such food, but an animal may obtain a sufficient supply, even while remaining fixed, by causing a current to flow into its mouth or body with the aid of cilia. This method of "current-feeding" is employed by a great number of marine invertebrates from sponges to sea-squirts. It can, of course, only be practised in water, there is no equivalent for it on land.

The food which is at the disposal of marine animals is on the whole of a more indigestible nature than that with which land animals have to deal. The floating plantsdiatoms-which form a large proportion of the plankton have skeletons of silica, and the same substance occurs in a number of marine animals also. Chitin, which forms the exo-skeleton of Arthropods, is a substance second to none in toughness. Lime is of particularly frequent occurrence, either in the form of spicules (sponges, alcyonarian corals, etc.), or of an external covering (shells and tubes). These substances, not being internal like the vertebrate skeleton, require to be first got rid of if many marine animals are to get a meal-one of the advantages, or disadvantages, according to the point of view, of an exo-skeleton! In consequence we are able to study among marine animals many interesting arrangements for the preliminary treatment and mastication of food, such as the vomerine and pharyngeal teeth of fishes, the tentacles and horny beaks of cuttle-fishes, the radulæ of cuttle-fishes and Gasteropods, the pincers and gastric mill of the higher crustaceans, the chitinous jaws of Nereid worms, the protrusible stomach of starfishes, the teeth and "lantern" of the sea-urchin, and so on.

It is interesting to notice that the amount of food required by marine animals for actual "maintenance" is very low. Most of the food consumed is utilised for growth and for reproductive purposes, only a small fraction being used 


\section{NUTRITION AND METHODS OF FEEDING 185}

for metabolic needs arising from other activities than these two. The small amount of muscular metabolism in marine creatures as compared, say, with terrestrial vertebrates, is thought to have two causes: firstly, there is little or nothing required for maintenance of temperature; and, secondly, marine animals are balanced or counterpoised in water so that locomotion entails relatively very little exertion (Moore, Edie and Whitley, I9I4).

Pütter's Theories on the Nutrition of Marine Organisms. -We have emphasised the strong contrast between the typical modes of nutrition of plants and animals and have stated that, apart from one or two minor considerations, marine animals feed solely upon the bodies of other animals or plants. A German worker, however, Pütter ( $1907-8)$, has developed a theory which is in strong contradiction to this traditional view. The arguments which Pütter employs are so cogent and have aroused such interest that, even though his theory may not have been generally accepted, we must give them a certain amount of consideration. Before doing so, we must in fairness point out that an Italian worker, Carazzi ( 1896$)$, had already, several years before the first publication of Pütter's views, come to the conclusion that oysters absorb nutritive material in solution from the water and feed only in a secondary way on plankton organisms. While, therefore, it is customary to speak of "Pütter's theory," the credit for first suggesting the occurrence of a saprozoic mode of nutrition among marine invertebrate animals would seem to belong to Carazzi (1920).

The theories of Pütter have their basis in the difficulty of demonstrating satisfactorily the food of many of the larger invertebrates. Johnstone (op. cit.) refers to the trouble he has experienced in convincing a class of "sceptical fishermen " of the presence of food in the alimentary canal of the cockle, and remarks on the absence of food in the gut of mature plaice during the period of the maturation of the gonads. Others have encountered a similar difficulty when investigating the food of such animals as Pycnogonids, Gephyreans, and other forms. The reason for this difficulty, 


\section{I86 THE BIOLOGY OF THE SEA-SHORE}

according to Pütter, is simply that these animals are not dependent for their food upon the ingestion of planktonic organisms, since the quantity of these is much too small to be able to satisfy the requirements of the population of larger marine animals. To give a concrete example, Pütter estimated that the sponge Suberites domuncula, on the basis of its carbon requirements, would need to capture every hour the whole of the plankton contained in 242 litres of sea-water, that is to say, in an amount of water equivalent to about 4000 times its own bulk. But such a feat is manifestly impossible, since the amount of water actually passing through the osculum of the sponge would not exceed 300 c.c. The question then arises as to the way in which these animals do nourish themselves and as to what other sources of food are at their disposal. According to Pütter, another source of food is present in the numerous organic carbon and nitrogen compounds occurring in solution in the sea-water, and the animals nourish themselves by absorbing these through their whole surface. These substances are formed as the result of plant-metabolism and are given up to the sea-water, possibly after undergoing considerable changes by the agency of the numerous bacteria adhering to the algæ. Organs such as the gills of molluscs, the branchial sacs of Ascidians, the cirri of Polychæts, which are of such frequent occurrence, would not merely be of use for respiration, but would serve the purpose of absorbing dissolved foodstuffs as well. Similarly, the primary function of an alimentary canal, which is present in all but the very lowest invertebrates, is not the one which we usually attribute to it, but rather that of providing an increased amount of surface through which the absorption of liquid material may proceed. The process of taking in and digesting solid food, to which we are so accustomed in higher animals, has only been secondarily acquired by the gut.

The method of feeding of a number of marine animals would thus on Pütter's view be essentially saprozoic, and should his theories prove correct, our sharp distinction between the feeding methods of marine plants and animals 
is no longer valid. As already hinted, however, Pütter's views are not generally accepted by authorities in this country. The opinion of Benjamin Moore and others (I9I2) is that neither the dissolved organic matter nor the average amount of suspended plankton is sufficient to account for the nutrition of the larger of the marine forms. The large animals either distribute themselves along pathways, and in situations, where the supply of food is above the average, or follow up actively richer growths of minute organisms. Or, again, they may capture animals of greater size than those of the minute plankton, which animals, in turn, feed upon microscopic plankton, or upon vegetation occurring along the sea-shore or upon the sea-bottom.

Bacteria in the Sea.--When plants and animals die the substances which compose their bodies do not pass out of circulation, but by a series of changes (putrefaction, fermentation, etc.) are split up into their ultimate constituents and again made available for life. This work is effected by the agency of certain micro-organisms : bacteria, yeasts, and moulds, the importance of which in the economy of nature is fundamental. We are on familiar enough ground here, but it is important to remember that, until quite recently, our knowledge of these organisms in the sea was very scanty. Thus, even in 1908, all that could be said of fermentative bacteria in the sea was that they " doubtless exist . . . though we have little knowledge of their distribution " (Johnstone, $o p$. cit.). Fischer, in 1894 , was the first to carry out a really extensive investigation of marine bacteria. Keutner and Keding first signalled the occurrence of nitrogen-fixing bacteria (Clostridium and Azotobacter) in the sea in 1895-6 and the discovery of marine denitrifying bacteria was made almost simultaneously by both Baur and Gran in 1898 . Thanks to these and similar researches, it is now definitely known that there occur in the sea putrefactive and fermentative organisms of the same nature as those previously known elsewhere. In addition, there are also present in the sea: nitrogen-fixing bacteria capable of utilising atmospheric nitrogen for the formation of proteids; denitrifying bacteria 
which are able to liberate nitrogen from its oxygen compounds : in other words, to reverse the action of the nitrogenfixing bacteria; and nitrifying bacteria, through whose agency the nitrogen of the ammonia resulting from putrefactive decomposition is "mineralised," i.e. oxidised and combined with a base to form a nitric salt, and so rendered available for marine plants.

\section{THE NUTRITION OF SHORE ORGANISMS IN PARTICULAR}

From the point of view of food-production the shallow waters of the littoral are the most important in the whole sea. As a result of drainage from the adjoining land the quantity of ultimate food constituents, particularly the essential nitrogen compounds, is relatively much greater than in the open sea. This, of course, means an increased amount of plant-life (both fixed and floating), which leads in turn to a greater wealth of animal forms. One of the fundamental reasons for the greater density of life in shallow marine waters lies undoubtedly in the constant supply of raw food materials washed down from the land. Shore organisms get "first call" on this supply; what is not utilised by them is gradually dispersed by wind and tide and serves to nourish life in the more open waters.

The quantity of plankton in coastal waters has been said to be thirty times as great as that in the open sea. These waters, in fact, are the nursery where the development of plankton, especially plant plankton, begins and whence it spreads out gradually into the open sea (Allen, I9I7). Over and above this, they supply a quantity of fixed vegetation, in the shape of the larger seaweeds, the development of which is made possible by the presence of a substratum and of adequate illumination. In the actual tidal zone the advantages of this double food-supply are partly discounted by the fact that feeding, except in permanent pools, is necessarily intermittent. Perhaps the most eloquent comment on this is the haste with which operations are resumed when the water returns: barnacles and mussels beginning 
to feed within a minute after they are covered by the tide.

Contrary to what one would expect, the fixed algæ are directly utilised as food only to a relatively small extent. It is true that a certain number of shore creatures (several molluscs, sea-urchin) browse upon seaweeds-witness, for instance, the feeding tracks of the small limpet Helcion pellucidum on the stems and fronds of Laminaria-but a great proportion of the fixed plants of the sea-shore are allowed to live out their lives with only a comparatively trivial amount of interference from animals. When estimating the importance of the fixed plants of the littoral as a source of food, allowance must be made, however, for the quantities of organic debris they provide for the use of numerous creatures such as worms (Arenicola, Cirratulus, and numerous Oligochæts) and Crustacea (e.g. Corophium and other Amphipods) which burrow in the sandy mud of the sea-floor. Devoid of any means of attacking the living weed, these creatures will make good use of it after its reduction to detritus. Looking at the matter from another standpoint, we may say that these detritus feeders perform a valuable service as scavengers by preventing the over-accumulation of decaying matter in the sea-floor and by aiding the work of bacteria.

The larger algæ are also useful in intercepting floating organisms. These, on coming into contact with the weed, remain adherent to the gummy surface of the fronds and are then readily scraped off by animals such as periwinkles.

If the seaweeds are not consumed directly to any great extent, the plankton, on the other hand, is exploited in the intensest possible way. The floor of the sea-shore has been likened to an immense sieve through which the microscopic contents of the water disappear. Barnacles sweep it clean the carpet of bivalves siphons food from the turbid waters, periwinkles search every square inch of the rock and scrape it clean, colenterates and polyzoa spread their tentacles and take toll of passers-by (see Pearse, I913).

We now turn to a more systematic study of the feeding 
habits of shore animals, selecting one or two of the most characteristic and best studied examples from each of the chief phyla.

Some Irethods of Feeding of Shore Animals.-The majority of sea anemones expand their tentacles to seize and paralyse any swimming or creeping organisms that may wander within their grasp, and are not sufficiently strong to escape. Small Crustacea are undoubtedly one of their chief sources of food, and it is probable that many are deceived by the alga-like appearance of some anemones and alight upon their tentacles only to be conveyed to the mouth. The captured animal is passed on from the outer to the inner tentacles and finally placed within the mouth, which gapes ready to receive it. At times the outer tentacles of some species may sweep the ground, or one or more may become elongated. Many Gasteropods are so protected by shell or by slime coat that they can push their way through the clutching tentacles; in other cases a prolonged struggle may ensue before the prey is either finally ingested or succeeds in breaking away. Anemones are themselves attacked by sea-slugs (Acolidiella papillosa and others), which rasp pieces out of the body wall (Fleure and Walton, 1907).

Among Echinoderms, starfish are well known to feed on mussels, oysters, and other bivalves. Several different explanations have been suggested of the manner in which the prey is overpowered and induced to open, such as the influence of a chemical secretion, waiting for the adductor muscles of the bivalve to relax, and so on. There seems no doubt, however, that the exercise of force by the tube-feet is the real cause of the victim's undoing. In order to overpower a bivalve the starfish needs to rise into a mound with the arms pressing closely together and tips closely investing the victim, which is manœurred into a vertical position between them. The position adopted resembles very closely that used when spawning, which is illustrated in Plate XI. Half the tube-feet are then attached to one valve and half to the other, and a pull in opposite directions 
is exerted which, though not immediately effective, will, if maintained for a period of some minutes, cause the shell to gape. Immediately this occurs, the starfish is able to insert the protrusible margins of its stomach into the shell cavity and to dissolve out the contents. The efficacy of the method depends, of course, upon the fact that keeping the shell-valves closed implies an active or contracted state of the animal's muscles which cannot be prolonged indefinitely. Experimentally, it has been demonstrated that the tubefeet of a starfish will maintain a pull on the shell equivalent to $\mathrm{r} 35^{\circ}$ grams ; this strength, when applied for a period of about fifteen minutes, is amply sufficient to open a Venus (Schiemenz, 1895-7, and cf. p. IIO). Starfishes are not entirely dependent upon bivalves for their living, but consume in addition a quantity of "lesser fry" wafted to them by the ciliary currents set up by the cells of the epidermis.

Sea-urchins may browse on seaweeds or even eat rockbarnacles (Roaf, I9I0). When a sea-urchin is feeding, the pedicellariæ, spines, and tube-feet all participate in conveying food to the mouth. In sand-dwelling species such as Echinocardium and Spatangus the buccal tube-feet are said to be extended and to broaden out terminally in order to seize particles and pass them first to the spines of the lower lip and thence, with the assistance of the upper lip spines, to the mouth. There is no shovelling of sand into the mouth while the animal is ploughing through it (Hornyold, I909). Sea-cucumbers feed by plunging their tentacles, which are sticky, into the sand, and transferring the adherent particles to the mouth.

Nemerteans, or ribbon-worms, are usually stated to be entirely carnivorous. In addition to capturing living animals of small size with the aid of their proboscis, they probably do a good deal of scavenging and will almost certainly consume a quantity of decaying vegetable matter as well. The form Lineus marinus has been observed, in the aquarium, to attack and devour the tube-worms Sabella pavonina and Serpula (Curator's Rept. Port Erin, r906). 


\section{I92 THE BIOLOGY OF THE SEA-SHORE}

Among segmented worms, the large and enormously abundant lug-worm (Arenicola marina) of mud-flats and cockle-beds burrows to a depth of two feet, swallowing sand as it goes. Their number at Holy Island has been estimated at over 82,000 per acre, and the amount of earth brought to the surface in their castings every year, at I9II tons per acre (Davison, I89I). Probably the greater part of the contained organic matter is removed from this amount of sand in its passage through the gut of the worms and the sand is further purified by the action of water in the burrows. The worms thus play an important part in the removal of substances which, if allowed to accumulate and putrefy, would become noxious to life.

The feeding habits of another common Polychæt may be selected for description in view of the interesting contrast they provide to those of the lug-worm. This worm, Cirratulus tentaculatus (Flattely, I916), occurs buried in sandy mud beneath stones in shore pools and elsewhere, its presence being indicated by a group of delicate rosy filaments which usually display a certain amount of movement. Unlike the lug-worm, Cirratulus does not live by passing sand through the gut for the sake of the contained organic matter, but selects the nutritive food particles, algal spores, diatoms and general organic debris, outside the body. The selection is effected by a pair of muscular flaps, covered with sensory epithelium, which project downwards from the dorsal surface of the peristomium and curtain off the entrance to the gut proper from an external vestibule. Feeding would seem to take place by a kind of suction; the sensitive edges of the flaps admit only the smallest food particles and these are then wafted backwards by the cilia of the gut epithelium.

Tube-worms are dependent for their food upon what is conveyed to them by currents set up by the cilia on the gillfilaments (Sabella, Pectinaria, Sabellaria, Serpula, etc.). Nereids, on the other hand, have a protrusible pharynx studded with chitinous teeth and provided with a pair of powerful terminal " jaws." They are extremely aggressive. 
The method of feeding of higher Crustacea, as illustrated by crabs, lobsters, and allied forms, scarcely needs description. It is interesting above all for the long sequence of acts it involves. Before the food enters the mouth it is manipulated by no fewer than seven different pairs of appendages, ranging from the long, grasping chelæ to the stout crushing mandibles, a procedure which seems to imply a higher degree of nervous control and co-ordination than is required for any other method of feeding on the shore. The process of mastication begun by the mandibles is continued by the "gastric mill," a complicated kind of gizzard, the presence of which, as we have already noticed, is testimony to the tough nature of a marine diet. In the general food-economy of the sea-shore the higher Crustacea are chiefly important through their actively scavenging habits. They are typically cryptozoic forms, lurking under stones and in crevices by day, and coming out to feed when it is dark. In seeking food the majority of Crustacea seem to be guided more by their power of scent than of vision, prawns, shrimps, and the crab Stenorhynchus, which have been deprived of their eyes, having been observed to find pieces of food quite as readily as when uninjured. The perception of smell is in most cases obtained through the antennules, though shrimps with no antennules will hunt if a piece of worm is placed in their near neighbourhood (Bateson, r889).

The habits of concealment and the occurrence of protective armour do not prevent crustaceans from falling frequent victims to fish and cephalopod molluscs (squid, octopus). The octopus is one of their worst foes and its presence in large numbers has been known to have serious effects on the lobster-fishery in the English Channel (Calman, I9II). In addition to the employment of beak and suckers, the octopus is said to paralyse its victims (crabs and lobsters), by injecting beneath their carapace a poisonous substance secreted from the salivary glands.

The methods of feeding practised by molluscs are particularly varied and interesting. Perhaps the most highly 


\section{I94 THE BIOLOGY OF THE SEA-SHORE}

specialised of them is that practised by Gasteropods, in which the organ known as a "radula" is employed, aided by the horny margins of the mouth. The radula is a long ribbonlike structure, beset with transverse rows of chitinous teeth, which works over the surface of a muscular pad lying in the floor of the mouth (see Plate XIII). By means of muscles the radula may be drawn backwards and forwards over the odontophore as over a pulley and so made to rasp the surface of any food substance with which it may be brought into contact. New material is being continually added to the posterior end of the radula to take the place of that lost by wear and tear. The same apparatus, which is nearly always present, serves both for plant and flesh eating Gasteropods. It displays, however, very considerable specific individuality as regards the size and arrangement of the teeth and other points, which are evidently correlated with differences in the quality of the food. These adaptive modifications are well illustrated by the sea-slugs. The Doridæ, which subsist chiefly on sponges, Bryozoa and compound Ascidians, have no jaws, but a broad radula, and the whole apparatus is clearly suited to eating a stationary object which does not need to be captured and offers no projections to be bitten off, but does require to be shredded before being digested. Other forms have jaws with edges that cut like shears; Tritonia feeds upon the spiculate Alcyonium by cutting out portions with its horny jaws and triturating them with the radula, which is broad. In many forms feeding is accomplished by rasping the surface of seaweeds and sucking up their juice, the function of the radula not being strictly masticatory. An exceptional mode of feeding is practised by Melibe which has no radula at all and only feeble jaws. In compensation, the mouth is surrounded by a large funnel with cirri which is swept over the surface of stones to capture small crustaceans. The margins of the funnel then contract and force the contents down the œsophagus into the stomach where the hard exo-skeletons are broken up by a ring of stomachplates (Eliot, I9ro). 

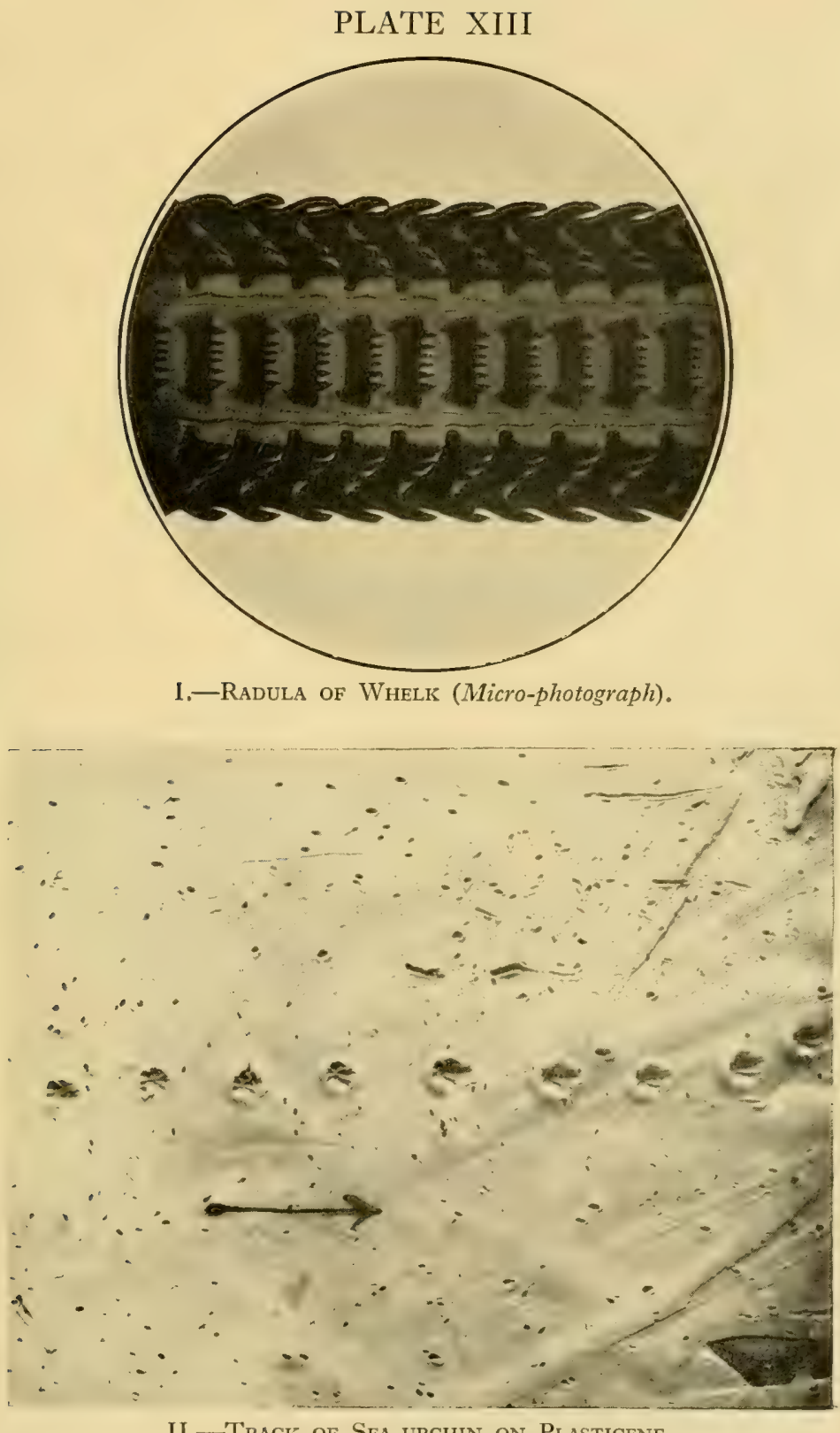

II.-Track of Sea-urchin on Plasticene.

The pushing action of the teeth is indicated by the slope of the tooth-marks, particularly in the later steps. (After Gemmill.) 

The whelk (Buccinum), dog-whelk (Purpura), and forms such as Nassa and Natica are carnivorous, feeding either on decaying animal matter or on living " shell-fish," by sucking out their soft bodies through a hole bored in the shell. The dog-whelk undoubtedly feeds on rock-barnacles with which it is invariably associated although, so far as we are aware, the manner of its feeding has not been investigated. The neat perforations often found in empty bivalve shells are caused by carnivorous Gasteropods and are usually ascribed to the action of the radula. There is, however, not a little difficulty in understanding how the radula, which is essentially saw-like in its action and incapable of being rotated, could begin its task, or how the rough teeth could produce such a smooth margin to the perforation. According to Schiemenz (189I), the rough holes which Natica produces in mussel shells are not drilled by the radula, the function of which is in this case merely of secondary importance. The hole is the work of a "Saug-platte" (suction disc), or glandular organ, situated on the under side of the proboscis, which secretes an acid substance $\left(\mathrm{H}_{2} \mathrm{SO}_{4}\right)$, capable of dissolving the shell. If a shell is examined before the work of perforation is complete a small boss is often observed in the centre of a circular depression. Not only does the concavity correspond in size with the "Saug-platte" (better called a boring gland), but in the centre of the latter there is a concavity corresponding exactly to the boss or convexity left in the shell. After the boring process has been continued for some time, the floor of the depression breaks through. The perforation is more or less kidney-shaped and has rough edges, which are evidence that the radula has now been brought into play. The work of boring is finished with the aid of the radula, the inner aperture of the completed perforation being narrower than the outer and having a slightly less even edge.

In bivalve molluscs we find typically developed the use of ciliary currents. This method of feeding is accompanied by an inactive life, the animal being frequently buried in sand or mud as a means of escape from enemies and 
from the effects of wave action. Communication with the surface is maintained by means of siphons containing inhalent and exhalent passages, through which the cilia of the gills maintain a constant current of water. Recent research has shown that the chief function of the gills is to act as a food-sieve, respiration being effected chiefly by the mantle. According to Orton (I912), evolution in Lamellibranchs has mainly followed the lines of folding and consolidating the gill-filaments in order to ensure a more perfect method of feeding.

The method of feeding of Ascidians is essentially similar to that employed by other sedentary forms. That is to say, it depends on causing a stream of water to circulate through the body. In this case the circulation is effected by the cilia on the margins of numerous perforations in the anterior part of the gut (the pharynx or branchial sac). The food particles, drawn in with the water current into the branchial sac, become enveloped in mucus secreted by a median ventral groove called the endostyle, and are transported by means of a circular groove at the anterior end of the pharynx to a median dorsal " lamina." From here they are driven backwards by ciliary action into the digestive part of the gut. Herdman (1904) has estimated the number of gill openings in an adult Ascidia mentula of medium size to be about 192,000 , and, as there is a row of cilia on each side of every slit, there are in all about 384,000 short rows of cilia lashing water through the pharynx of the animal. The process of feeding is automatic, but there is evidence that selection of food can, to some extent at least, be exercised.

Young fish, a number of which frequent tidal waters, feed in various ways. Some deliberately stalk certain selected food, others apparently eat the first thing that comes along ; some feed at all times, others only by night; some eat very little at one time, others as much as they can get. Some, like the Ballan Wrasse, are clumsy; others, like the whiting, are very quick in their movements. Young lumpsuckers are very active and unfix their suckers instantly to chase and swallow anything attractive. The rockling (Onus 
mustela) eats almost anything, and the same applies to gobies. Blennies dart after food, especially Copepods, using their long fins (Lebour, I9r9). Flat-fish, young and adult, feed inshore on cockle-beds and estuarine flats in great

Typical "Food-Chains" on the Sea-shore.

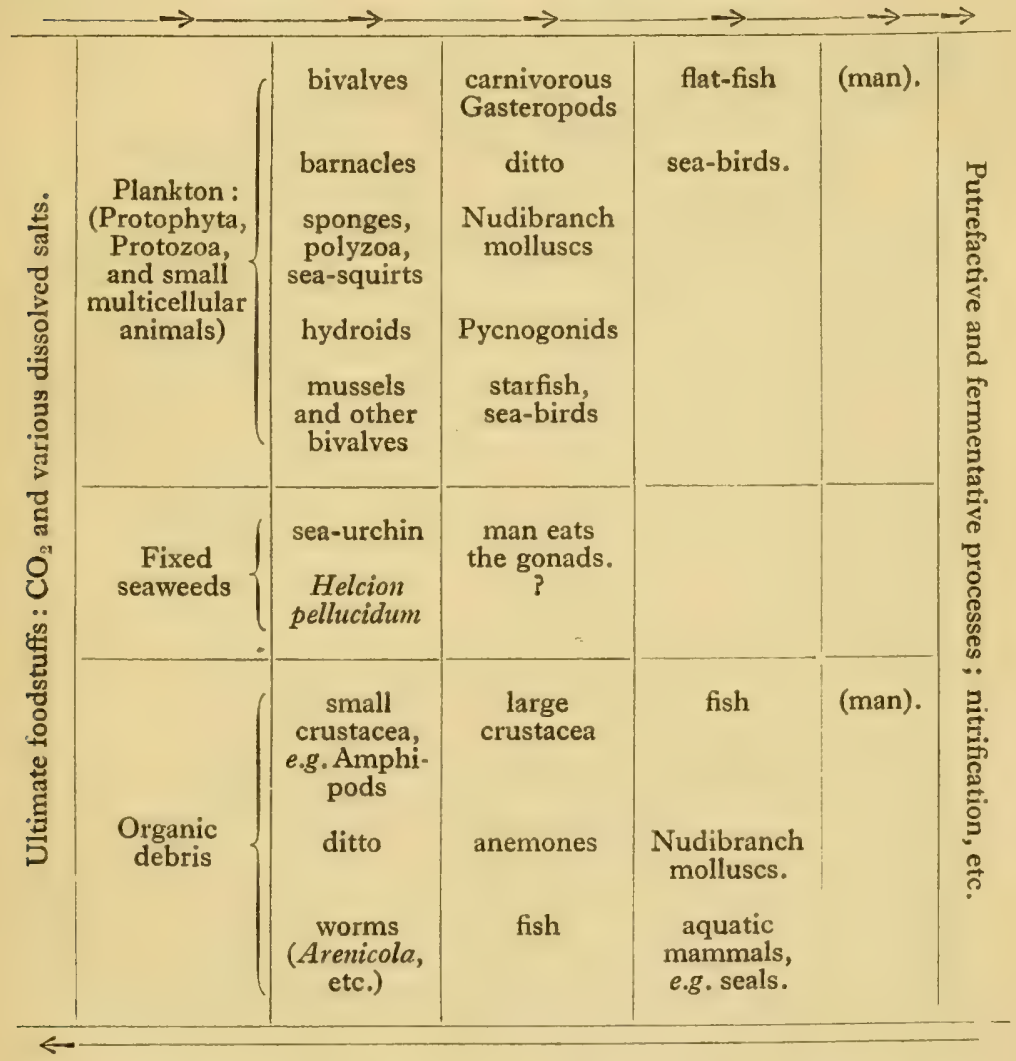

numbers during the summer months, and the food of the flounder often consists mainly of the little burrowing Crustacean Corophitum, frequently present in enormous numbers, and also of other related species and of worms. The fish follow the rising tide on to the mud flats and retire to the channels or bury themselves in the sand when it falls 
(Ashcroft, 1899, and others). The molluscs Tellina balthica and Cardium edule, generally so abundant together on the cockle-beds, are both of very great importance in furnishing food for the fry of the commercial flat-fish at a time when these first become ground-feeders and leave off eating Copepods (Herdman, 1893). The writers themselves have evidence that excessive commercial exploitation of shellfish beds in estuaries tends to spoil the fishing in those areas, the fish no longer coming in as they once did.

The food relationships of shore animals are too complex to be satisfactorily exhibited in a diagram, but an attempt is made in the table on p. 197 to indicate some of the most typical food sequences. Three main sources of proximate foodstuffs are shown: the plankton, fixed seaweeds, and general organic debris, any one of which may be the starting point of a series of upward transformations, A forming the food of $B, B$ of $C$, and so on. The foundation on which the whole structure rests is, of course, the ultimate foodstuffs : the carbon dioxide of the atmosphere and the various salts enumerated at the beginning of this chapter.

Retrospect.- Some of the most important conclusions to be drawn from this chapter may now be summarised as follows :-

The littoral waters constitute the richest food-producing area in the whole sea. This is due mainly to the constant addition, by drainage from the land, of various substances capable of serving directly as food for plants. Not only are the inshore waters a nursery for the plankton of the whole sea, but they support a bottom vegetation of large seaweeds such as cannot exist elsewhere owing to insufficient illumination. The abundance of plant-life in this area is one of the chief reasons for its characteristic wealth and variety of animal forms, though, of course, other factors are concerned as well. In the tidal zone proper, the advantages of this double supply of fixed and floating plants are partly neutralised by the periodic withdrawal of the water. Nevertheless, feeding may still go on in favoured situations. The function 


\section{NU'TRITION AND METHODS OF FEEDING 199}

of the fixed plants in the food-economy of the sea-shore is mainly indirect. They are little utilised in the living state by animals, but they are useful in intercepting floating food organisms for the benefit of creeping forms, such as Littorinas, and when reduced to detritus they provide a living for a host of creatures living in the substratum. Still another source of food income to shore-dwelling forms is the quantity of debris (jetsam) washed up on the shore, mainly after storms. Much of this, however, is permanently deposited only at the highest point reached by spring tides and is thus out of reach of strictly tidal species. It is, however, greatly utilised by amphipods, insects, and even birds. Methods of obtaining food on the shore are extraordinarily varied and interesting; they range from simple non-selective current-feeding to the highly specialised procedure employed by, say, a starfish or an octopus. 


\section{CHAPTER X}

\section{Respiration in Shore Animals}

NotwithSTANDING the fluctuating nature of the tidal portion of the sea-shore, the animals which live there are practically all truly aquatic in their mode of respiration. They require to breathe dissolved oxygen, whereas land animals, of course, use the free oxygen of the atmosphere. The proportion of oxygen in pure air is very nearly 21 per cent. by volume. On the other hand, according to the computations of Fox (1907), one litre of sea-water of average salinity (say $34^{\circ} 33$ pro mille) and temperature $10^{\circ} \mathrm{C}$. will absorb from a free dry atmosphere of normal pressure 6.44 c.c. of oxygen. It thus follows that, from the point of view of oxygen supplies, land animals have a considerable advantage over animals which live in the waters.

The oxygen content of sea-water diminishes with increasing temperature and salinity, and also with increasing depth. Owing to their shallowness, relatively low salinity, and to the effect of wave action, the littoral waters are the most highly aerated of the whole sea-one of the reasons why this area is so favourable to life.

In both terrestrial and aquatic animals the respiratory exchange is effected by bringing an adequate quantity of the blood which, in all vertebrates and in most invertebrates also, contains a pigment with a special affinity for oxygen, into the closest possible relation with the ambient medium. What we are accustomed to regard as the typical organ of water breathers is a thin-walled, usually feathery, structure, known as a gill, such as is present in fishes and the larger crustaceans. But among invertebrates the term "gill" 
has no very precise significance, and may be applied to practically any delicate extension or fold of the body surface through which an exchange of gases might reasonably be supposed to take place. Gills or respiratory outgrowths may occupy almost any position on the body. They are superficially similar in fishes and in the larger crustaceans, not only in situation, but also in appearance, and further also in the manner in which they are protected-a convergence which, as we shall see later on, has had interesting consequences in the two groups. In both Isopod and Amphipod crustaceans, many of which are amphibious, the gills, though not homologous in the two groups, are placed beneath the body and have the form of thin plates. These gill-plates seem almost equally well adapted to breathing either moist air or water, since those of Ligia, for instance, differ little from those of permanently aquatic forms. It is interesting to notice, however, that in the related terrestrial wood-louse, Porcellio scaber, the respiratory plates are traversed by fine branching tubes, which suggest the trachea of insects. In molluscs, as Semper (1899) points out, there are no less than five forms of gills, all morphologically different. We may mention those of bivalves, folded plates perforated in a complex manner and situated within the shell (see p. 196); those of most marine shelled Gasteropods and of Cephalopods which for the most part resemble the typical form, and those of naked marine molluscs (Doris, EEolis) which are extensions of the dorsal body surface. The parapodia of Polychæt worms are generally supposed to have some respiratory significance,especially the cirri, which are sometimes greatly elongated as, for example, in Cirratulus. Tubicolous Polychæts have typically a "crown" of tentacles, or "gills," which project from the open end of the tube. The term "gill" expresses the general opinion as to the function of these appendages, but they evidently serve other purposes besides that of respiration (tube-building, food-wafting). A certain amount of respiration is no doubt effected in starfishes, sea-urchins, and brittle-stars by means of the tube-feet ; starfishes have, 
in addition, scattered over their dorsal surface, delicate finger-like extensions of the body wall which contain an extension of the body cavity. Both inside and out these processes are lined by cilia, the internal cilia serving to keep in motion the cœlomic fluid and the outer ones to ensure the constant changing of the water (Delage and Hérouard, 1903).

In every group there are animals of small size which are able to obtain sufficient oxygen through their skin, over their whole surface. No special organs of respiration occur at all within the groups of sponges and coelenterates.

A special respiratory pigment is of common, though not universal occurrence, in the blood or cœlomic fluid of marine invertebrates: hæmoglobin in the case of most worms and a greenish substance chlorocruorin in some others; a yellow pigment, echinochrome in the case of sea-urchins and hæmocyanin in that of higher crustacea and of some molluscs. Hæmocyanin is colourless in the living animal, but acquires a bluish tinge upon exposure to the air. The respiratory pigment may be carried in special corpuscles (amœbocytes), as in the case of the sea-urchin, or may be simply dissolved in the blood plasma.

Respiration nearly always involves a mechanical process whereby a renewal of the respirable medium is ensured to the animal, the degree to which such a process is necessary being governed by the extent to which the organs of respiration are protected, by the sluggish or active habits of the animal, by the nature of its normal habitat, and so on. In a typical land vertebrate, owing to the enclosed situation of the respiratory organs, which is necessary in order to avoid desiccation, the active nature of respiration is very marked. The renewal of the air is effected by the rhythmical contraction and expansion of the respiratory organs themselves, aided by the movements of the chest wall. In insects the same object is attained by the opening and closing of the stigmata or entrances to the air-tubes, and by the compression of the air-tubes themselves. In aquatic animals, particularly in those forms in which the gills are 
protected, a circulation of the water over the respiratory tissue is only a degree less necessary and is obtained in various ways. The method in fishes hardly needs description. Water is taken in at the mouth and expelled through the gill-slits, or the water may enter underneath the gillcover and leave by the same opening. In crabs and lobsters, where the gills are very completely protected, a current of water is kept passing through the gill-chambers from behind forwards by the regular action of a specially modified appendage-the baler or scaphognathite.

Respiration in sea-cucumbers shows a very curious convergent resemblance to the same process in a land vertebrate. The respiratory organs in this group are mainly the "respiratory trees" (known in French as "poumons"), hollow, branched structures situated within the body cavity of the animal and communicating indirectly with the exterior by means of the cloaca. As a result of the rhythmical contraction of the cloaca, the lower portions of the trees are alternately filled and emptied, an exchange of gases taking place between the water, when the trees are full, and the blood contained in their walls.

In the so-called "current-feeders" the water which is caused to flow through the body by means of ciliary action serves to convey the food and, at the same time also, the oxygen necessary for respiration. The tentacular crownwhen this is present-and parapodial cirri of bristle-worms, notwithstanding their exposed character and the fact that the water surrounding them is in constant motion, are also ciliated, as are analogous outgrowths in other groups, e.g. Nudibranch molluses.

To the student who is thinking over the process of respiration in shore animals a word of caution is necessary. The tendency is to regard any delicate vascular outgrowths as respiratory. This is a common-sense view, but it is doubtful, however, whether it is in every case borne out by facts. The removal of the so-called gills of certain tubeworms, for instance, has been shown to have little adverse effects on these animals from the point of view of breathing. 
As a matter of fact, Puitter, whose views on nutrition we have discussed elsewhere, holds the belief that these frequent reduplications of the body surface among invertebrates are concerned rather with the absorption of food materials in solution from the sea-water, than with respiration. Apart altogether, however, from Pütter's views, we still have to take into account the fact that the so-called branchiæ are almost invariably covered with cilia which, in some cases at least, undoubtedly serve to drive food particles towards the mouth, e.g. the cephalic "gills" of tubicolous worms, the "gills" of bivalve molluscs.

A very comprehensive research into the question of respiration in Polychæts has been undertaken by Bounhiol (I902), and has provided data of much interest. With regard to the significance of the numerous extensions of the body surface so characteristic of this group, Bounhiol is of the opinion that in the great majority of cases the term "gill" is physiologically incorrect and should no longer be employed. True branchiæ occur only in the highest types of the Errantia (e.g. the Eunicidæ) and of the Sedentaria (Arenicolidæ and Terebellidæ).

The following analysis of the factors capable of influencing respiration in Polychæts is given by Bounhiol :

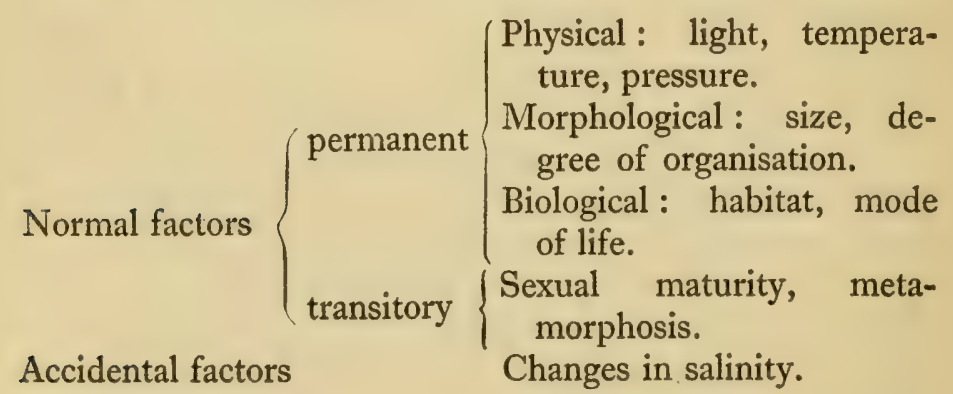

Our chief concern in this chapter is the effect upon respiration of the special conditions of the sea-shore. We wish to know, for instance, what are the special respiratory modifications which enable certain shore animals to carry 
on an active existence in both air and water; how those animals which are quite incapable of breathing atmospheric oxygen survive the periods of low tide; what is the effect on respiration of such characteristic shore habits as burrowing and living inside a tube; what is the influence of wave action and of low salinity upon this same all-important function? and so on. Some of these questions have been answered already in connection with the discussion of the ways in which shore animals meet the problems raised by the retreat of the tide; others are new and now claim our attention.

The Accommodation of Water-breathers to Breathing in Air.-How is it that certain animals are able to carry on their activities both in and out of water, and what are the most essential features which distinguish air- and waterbreathing? In spite of the apparently great difference in structure between a water-breathing organ and one adapted to breathing air, the physiology of respiration in the two cases is essentially similar. Thus, a point of great importance is that in both cases the oxygen is absorbed from the surrounding medium by a membrane which is kept moist and which, as Semper (op. cit.) points out, should be able to carry out its function quite equally well whether the oxygen is received from air or from water. In fact, says Semper, provided the osmotic power of the respiratory membrane remains the same, since the amount of oxygen taken up within a given period obviously depends on the proportion of oxygen contained in equal volumes of the air or the water, the respiratory surface may be in a position to take up more oxygen from the air than from the water in the same unit of time, because air has a larger admixture of free oxygen. From this it follows that, if there is no other hindrance to an alteration in the mode of life, an animal which has been used to breathing in water will more easily accustom itself to breathe in air than an animal living in the air, on the contrary, can accommodate itself to breathing in the water. One serious hindrance there is to the passage of an aquatic animal to air : the tendency of the gills, if these are exposed, 
to collapse or to become dried up and entangled with one another. We have seen, however, that in fishes, Gasteropod molluscs, and Crustaceans, the gills are quite effectively protected. Now, it is precisely these groups that have furnished truly amphibious forms, and we cannot doubt that it is the protection given to the respiratory organs that has rendered the partly terrestrial habits possible.

Certain fishes which, however, are not represented in Britain, have acquired the habit of leaving the water periodically and of disporting themselves in the air. Among these are two species of goby: Periophthalmus (see Fig. I4) and Boleophthalmus, which are said to skip along the waterline on the sea-shore where they hunt for molluscs (Onchidium) and insects (Semper, op. cit.). The gills in these forms do not fill the branchial cavity, which is larger than usual and apparently contains air as well as water. Several other fishes belonging to unrelated families have their gill-cavities extended a considerable distance upwards on each side of the head, the mucous membrane of the extension being sometimes folded in complicated fashion to form a "labyrinthine organ." Formerly it was thought that the function of these accessory organs was to hold a store of water upon which the animals might draw during their long excursions. It is now certain, however, that they contain nothing but air and are really capable of respiring atmospheric oxygen. Among the species which possess this modification is the well-known " climbing-perch" (Anabas scandens), which is popularly credited with the power of mounting palm trees by the aid of the spines on its scales and gill-covers, and is certainly capable of living out of water notwithstanding that the accounts of its climbing powers may be exaggerated. The amphibious habits of these fishes and the relatively trivial amount of modification that has been required to make them possible show that the two processes of air-breathing and water-breathing are not so dissimilar after all. This statement is further corroborated by the readiness with which fishes living in water which is insufficiently aerated will come to the surface to 
refresh themselves with a gulp of air. As a matter of fact, if the two fishes Boleophthalmus and Periophthalmus are prevented from reaching the surface in order to take in air they are drowned (Willey, I9II), a curious end for such typically aquatic forms as fish.

In more or less similar fashion, the different common species of Littorina when placed in an aquarium will voluntarily climb up the sides to some distance above the water-level. They also die if permanently cut off from access to air. Many other amphibious snails occur outside

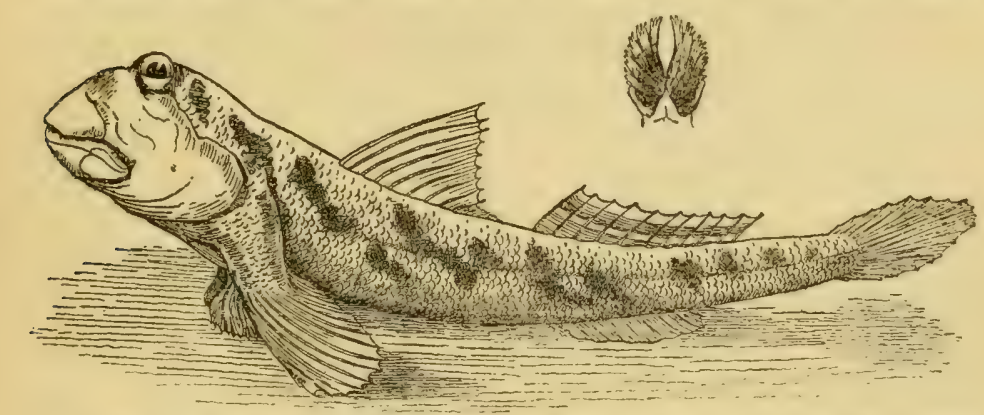

FIG. 14.--Periophthalmus, a tropical fish which moves about over mud flats at low tide by the aid of its pectoral fins. Note the modified pelvic fins acting as a sucker.

our area. One of the most remarkable of these is Ampullaria which has gill and lung cavities equally well developed and when living in water makes use of both in rapid alternation (see Semper, $o p$. cit.).

Certain species of crabs exhibit an almost exact analogy with Amphibians proper, spending most of their time on land, and only returning to the water for very short intervals or perhaps only at breeding time. They owe their partial conquest of the land largely to the protected situation of their respiratory organs which prevents their becoming dried up, and partly also to the gradual accommodation to sub-aerial conditions which shore life affords. The beginnings of air-breathing are already observable in the common crabs of our own sea-shore. But in order to see how far the process of emancipation from water-breathing may 
have proceeded in animals of truly aquatic origin it is necessary to study the many kinds of tropical land-crabs : Grapsus, Ocypoda, Gelasimus (Fiddler-crabs), Geocarcinus and Birgus. In practically all of these the largely terrestrial habits are accompanied by observable modification of the respiratory apparatus. In Ocypoda and Gelasimus the gill-chambers are larger than usual and their lining membrane is richly vascular. Air is said to enter the gill-chambers by an opening, protected by a brush of setæ, between the second and third pairs of walking legs on each side (Calman, rgII). The enlargement of the gill-chamber and the vascularisation of its wall are closely analogous to what is seen in the tropical fishes with similar amphibious habits. The modifications for air-breathing in the robber-crab (Birgus latro) have been studied by Semper ( $o p$. cit.), who found that the gill-cavity is divided into an upper and a lower half by a transverse fold. The lower half contains the gills which, though numerous, are reduced in size; the upper portion functions as a true lung and contains nothing but air; it also has its lining membrane produced into numerous arborescent tufts which are extremely vascular. A further striking feature is to be found in the arrangement of the blood-vessels, which is precisely that of a true lung : blood poor in oxygen entering the chamber from the body and the efferent vessels opening directly into the heart.

Members of the genus of hermit crabs Cœnobita, which is related to Birgus, in addition to the modification of the gill-chamber, have the soft skin of their abdomen richly vascularised, so as to be capable of effecting an exchange of gases, a specially active circulation being maintained in this region by a pair of contractile vesicles or accessory " hearts," situated at the base of the abdomen (Calman, op. cit.).

Cowles (1908) has made an exceedingly interesting study of the habits of Ocypoda arenaria, a land-crab which frequents the Atlantic shores of the more southern states of America. Although Ocypoda spends most of its time on land (in damp burrows), it is obliged to go down to the ocean from time to time in order to moisten its gills. On such occasions the 
crabs do not enter the water but take up their position close to the water-line and, with the appendages of one side firmly anchored in the sand, wait till an extra high wave washes over them; they then return immediately to the higher parts of the beach. Like other land-crabs Ocypoda breeds in the sea and it will also take to the water if hard pressed by an enemy.

Respiration in Relation to Structure and Habit.-Certain structural features of shore animals and certain of their habits also have had considerable influence on the function of respiration. Most molluscs, for instance, in consequence of the presence of a shell and the concealed nature of the branchiæ, require some special means of taking water into and expelling it from the branchial chamber. In most herbivorous Gasteropods (Littorina, Trochus) the water is carried to and from the branchial chamber by a simple extension of one of the mantle lobes, the incoming and outgoing streams being separated by a flap of tissue hanging from the lobe. In carnivorous molluscs, on the other hand, a more or less completely closed tube-the branchial siphon-has been developed from a fold of the mantlesurface for the express purpose of conducting water to the gills. The spent water does not return through the siphon, but by means of the cilia situated on the gills is driven towards the anus. Frequently, the siphon is protected along the whole of its length by a special prolongation of the shell called the canal, as in Murex; in the whelk and dog-whelk, however, the canal is simply a long notch in the mouth of the shell. In the group of the Zygobranchiata, which includes the key-hole limpet (Fissurella), common limpet and "ormer" (Haliotis), there may be one or more special apertures in the shell for the water to escape after it has passed over the gills (see Cooke, I 895).

A consideration of the siphons of bivalve molluscs is best deferred until we come to deal with the question of respiration in relation to the habit of burrowing.

Other shore animals, besides molluscs, in which the presence of a shell or, what comes to very much the same 
thing, a tube, affects the function of respiration, are the barnacles and tubicolous worms. Darwin (185I-4), for instance, gives an interesting description of the process of breathing in the former group. Each of the single pair of gills is formed from an inward plicated fold of the membranous sac in which the animal is enveloped. The water is being constantly pumped in and out of this sac by the movements of the opercular valves, which Darwin likens to the heaving of a man's chest. Further, the gills on each side are so closely attached to the point of one of the valves (the tergum), that each time the valve moves the whole gill is caused to open out as if moved by a lever.

Tubeworms, as we have already noticed, breathe, to some extent at least, by means of the terminal tentacles or "gills" which are left protruding from the open end of the tube. In addition, there are the parapodial cirri which are present in each segment and are sometimes very conspicuously developed (e.g. Nerine, Cirratulus). While the direct respiratory value of these is no doubt small, it should be taken into consideration that they are covered with cilia which ensure a plentiful circulation of water round the body itself. Indirectly, therefore, the cirri may have considerable respiratory value. In worms like Sabella, aeration of the body in the tube is obtained by the alternate protrusion and retraction of the "branchial crown " which is here supported by a skeleton. Other tubicolous forms obtain a more active circulation of water about their bodies by performing vigorous undulatory movements within their tubes. Burrowing worms exhibit analogous behaviour. According to Bohn (I9OI), the lug-worm, for instance, does not always frequent a U-shaped burrow, as is generally stated, but is often found occupying a vertical position (cf. Gamble and Ashworth's "Laminarian" form), head downwards, and then behaves exactly like a Pectinaria in its tube, causing the water, by means of dilating successive segments of the body, to flow either up (inverse current) or down (direct current). When the animal is submerged the direct current is the one employed (cf. Corystes, p. 213), 
the water then filtering through the acid fæces or through the sand held by the parapodial bristles, and losing in consequence any possible toxicity due to its being alkaline. At low water the current is inverse or nil.

Respiration in Relation to Burrowing.-The habit of burrowing is particularly useful on the sea-shore since it not only secures to an animal a quantity of food in a conveniently fine condition, but also provides a satisfactory response to several urgent problems such as the need of escaping observation by enemies, and of avoiding the consequences of wave action and of the retreat of the tide. It is therefore not surprising to find the soil of the tidal zone supporting not only a large permanent population, but also affording a sanctuary to other more active animals when this area is uncovered. The most characteristic burrowing forms are "worms" (including Nemerteans, Oligochæts, and Polychæts), crustaceans, and bivalve molluscs. Two particularly common burrowing Polychæts are the lugworm (Arenicola) and Cirratulus. The former has its respiratory surface augmented by a series of bushy gills which, in view of their delicate nature and exposed situation, one cannot but feel are ill suited to a burrowing animal. On the other hand, according to the observations of one of the writers, the respiratory arrangements in Cirratulus appear to be remarkably well adapted to a subterranean existence. The presence of this worm in its natural habitat is denoted by a group of delicate bright-red processes or cirri lying on the surface of the sand or gently waving in the water of a pool. These cirri, which are remarkably long and elastic, occur in paired clusters a short distance behind the anterior end and also in single pairs on each segment. When the worm burrows, the filaments are left protruding in the water at the surface and they almost certainly serve to keep the blood aerated while the owner is finding its food in the distinctly foul mud which it prefers.

The danger of asphyxiation in the rich mud of the seashore is by no means a remote one and, in fact, in the course of a hot summer may become acute. Thus, Bohn (op. cit.) 
has shown that in autumn certain species of worms and crustaceans may begin to suffer from a kind of poisoning due to the over-accumulation of toxic products in the sand. On the other hand, the same writer shows that water in which certain seaweeds have been living (red seaweeds and Lithothamnion in particular) tends to become very toxic to animal life on account of its excessive alkalinity, but filtering through sand rectifies this. In a sense, therefore, the sand offers a chemical as well as a physical protection to the animals which frequent it.

In bivalve molluscs, which are permanent burrowers in a stricter sense even than worms, the gills lie in a large cavity - the mantle chamber-which is placed in communication with the water above by means of two tubes or "siphons." Of these, one serves to conduct the water in, the other to lead it out again, after it has fulfilled its purpose. The siphons may be separate for practically the whole of their length or may be more or less completely united. The length of the siphons is, with few exceptions, an accurate index of the depth to which the animal burrows. The circulation of water through the mantle cavity is ensured by the cilia of the gills. Actually, this ciliary current serves, as in a number of other cases, the dual purpose of aerating the animal and conveying to it its food. The term "gill" is really a misnomer in this case, the so-called gills being nothing more or less than food-collecting organs; the true organ of respiration in bivalves is the mantle. Nevertheless, it is obvious that the siphons constitute an adaptation to subterranean breathing as much as to feeding.

Several of the larger Crustaceans spend a good deal of their time underground and show very distinct respiratory modifications in consequence. Both in the common shore crab and in the swimming crabs, the claws together with the marginal spines form a sieve through which the water of respiration is filtered free of sand. In Calappa and others which have no filtering spines there are crest-like expansions, divided into spines and notches, on the upper side of the claws themselves (Garstang, 1905). The greatest amount of 
specialisation, however, is seen in the "masked crab" (Corystes cassivelaumus), although this is not, strictly speaking, a shore species. The antennæ of Corystes, unlike those of the majority of crabs, are very long and are fringed with hairs arranged so as to interlock when the two antennæ are apposed, and to form a long tube. When the crab burrows, the tips of the antennæ are left protruding at the surface and, by a reversal of the normal respiratory current, a stream of water is kept passing down the tube into the front ends of the gill-chambers. At the entrance to each gillchamber is a hairy filter which rejects any particles of mud that may have entered the tube with the water (see Garstang, 1896, and Zimmermann, r912). The reversal of the normal respiratory current and the formation of an antennal tube, along with other slighter modifications, constitute a remarkable adaptation to the burrowing habit.

Respiration in Relation to the Turbidity of Inshore Waters.-Shore waters are always more or less turbid owing to the stirring-up by wave action of the sand and mud of the sea-bottom. In addition, a large amount of silt is continually being brought down by rivers. Such considerations naturally prompt us to inquire whether turbidity is a factor of any importance in the life of shore animals and, if so, what is the manner of its action? It so happens that there is not a little evidence, some of it of more than usual weight, to show that the presence of a quantity of solid particles in suspension does actually present an important problem to certain members of the shore fauna, and this is mainly because of their tendency to impede the proper functioning of the breathing organs. The problem, in fact, is closely analogous to that affecting burrowing forms which have to find some means of obtaining their water of respiration free of sand particles. Moreover, in both cases the most important adaptive modifications are observable among the higher Crustacea. Zimmermann (I9r.3) remarks " on a praiseworthy striving after cleanliness" on the part of the Galatheidæ, and instances numerous ways in which the members of this group (e.g. Galathea squamifera, Porcellana 
platycheles, and Munida rugosa), which live on flat shores, are able to guard against the choking of the branchial chamber and the clogging of the gills by mud in suspension.

What are undoubtedly the most careful and convincing researches on this subject have been contributed by Welldon (1899). They are indeed classic. Welldon's researches were primarily directed towards estimating quantitatively the effect of the continued selection of small variations in a particular direction, but incidentally they throw considerable light on the subject we have under consideration. By careful measurements extending over a period of six years Welldon and Thompson established that the mean frontal breadth of common shore crabs (Carcinus mœenas) living in Plymouth Sound was diminishing yearly at a rapid rate. Welldon formed the opinion that the change had been brought about by selective destruction of crabs due to changes in the physical conditions of the Sound, or more precisely, to a progressive increase in the turbidity of the waters of this area as a result of certain alterations effected by man. In particular, the construction of a huge breakwater has led to an increase in the quantity of fine mud (china clay from the adjoining land carried into estuaries on either side of Plymouth) on the shores and bottom of the Sound, since the mud can no longer be carried away by the scour of the tide or the waves of severe storms. By means of experiments conducted in the laboratory Welldon proved that the effect of this mud when in suspension is to cause the gills of some of the crabs to become choked, and the greater the frontal breadth of a crab the more readily will the choking occur. The gills of crabs which died during an experiment with fine clay or mud suspended in the water were covered with a fine white deposit which was not found in the gills of the survivors. The reason for the escape of crabs of narrow frontal breadth is because this character renders one part of the process of filtration of the water of respiration more efficient than in crabs in which the frontal breadth is greater.

These experiments of Welldon's are among the few which 
have been attempted to test the survival value of a particular character, and on that account we have more than the usual amount of justification when we speak of the narrow frontal breadth of shore crabs in Plymouth Sound as being an adaptive character-adaptive, that is, to the high degree of turbidity of the water which these animals are required to breathe.

Retrospect.-In spite of the fluctuating character of the tidal area the great majority of shore animals are typical waterbreathers. Many of them, in consequence, are obliged to become inactive at low-tide and to make shift with the small amount of oxygen present in the moisture retained on the surface of the gills. A small minority are truly amphibious in the sense that they can carry on their activities in two distinct media and have been actually found to breathe either air or water as circumstances require. Usually, this dual mode of breathing is accompanied by a certain amount of structural modification, but this is not always the case. The fact of the matter is that, physiologically, the difference between air- and water-breathing is not profound, and in one important feature the two processes are identical-the membrane through which the exchange of gases is effected has its surface bathed in moisture. There is a sense in which the most typical land animals may be said to breathe dissolved oxygen.

The chief hindrance to the passage of an aquatic animal from its original habitat to air is the tendency of the respiratory surfaces, if these are exposed, to become dried up. This provides us with a reason why the amphibious habit has proceeded furthest in forms such as crabs and snails (and to a lesser extent in fishes), for these have their respiratory organs effectively protected. It by no means follows, however, that the protection has been evolved for this particular purpose.

The habits of tube-building and of burrowing in the sea-floor are other typical shore activities which have influenced the function of respiration. Burrowing, in 
particular, has led to interesting arrangements whereby water may be drawn from the surface or filtered clear of sand. One of the best examples of these is provided by Corystes in which the antennæ. when apposed, form a long tube, down which, in consequence of the reversal of the normal respiratory current, water is drawn into the gillchambers. The habit of burrowing also involves interesting respiratory problems such as the effect of the accumulation in the sand of decaying substances and of the waste products of metabolism.

Wave action has here been seen to involve yet another source of danger to certain shore animals : that of asphyxiation in consequence of the agitation of the sand and mud of the sea-bottom. In Plymouth Sound, for instance, selective mortality among the members of the local fauna was caused, during a certain period, by an increased turbidity of the water due to physical changes introduced by man. A consequence of particular interest was that those crabs tended to survive which varied in the direction of greater efficiency in the methods of filtering the water required for respiration.

An extreme example of how turbidity of sea-water may affect marine animals was provided by a rain of ash from Vesuvius in April, 1906 (Lo Bianco, 1906-8). Here, also, the mortality caused by the matter in suspension, among the animals of Naples Bay, was selective, some forms suffering only slight inconvenience, while others, such as sea-urchins, were wiped out. The death of the sea-urchins was due to clogging of the madreporite, and other forms which succumbed in more or less analogous fashion to the mechanical effects of the ash were Amphioxus and various bivalve molluscs. The consequences of the catastrophe continued to be felt for many years. 


\section{CHAPTER XI}

The Nervous Organisation and Behaviour of Shore ANIMALS

SHORE animals are favourite subjects of experiment in connection with the study of "behaviour" and have furnished very interesting and important results. These results have been obtained not by psychologists in the usual sense of the term, but by biologists who, untrammelled by the methods of traditional psychology and free from considerations of " mind " and "consciousness," have confined themselves to a purely objective study of the reactions of the animal to its environment. In consequence of the adoption of this method of inquiry, the whole subject of animal behaviour is now on a better and very much sounder basis ; there isor should be at least-an end to anthropomorphism and the often fanciful interpretations of the older naturalists no longer have a place.

Our object, then, in this chapter is to illustrate the manner in which the special conditions of the tidal area have influenced behaviour, so far as critical observation and experiment have made this apparent. Since, however, the behaviour of an animal is essentially a function of its nervous system, we cannot do better than take as the foundation for our study a description of the nervous organisation and sense organs of the most important shore types. To this we will add an account of such experiments as tend to throw light upon the level reached by behaviour in the respective groups.

Nervous Organisation of Shore Forms.-The type of nervous organisation most familiar to us, viz. that of 
vertebrates, is composed of a number of comparatively simple structural units, the nerve-cells or neurones, having a typical arrangement. This includes (I) a sensory cell extending from the body surface to the grey matter of the spinal cord (with its body situated in the spinal ganglion), along which impulses pass in to the central nervous system; (2) a motor nerve-cell, with its body situated in the grey matter, connecting the spinal cord with a muscle; and (3) a connecting or internuncial nerve-cell joining up the sensory and motor nerve-cells within the central nervous system. This chain of related parts, consisting of receptor, adjustor, and effector elements, has been designated the neuro-muscular system (Parker, 1918), since the term "nervous system" does not usually include the muscles, or effectors, which are nevertheless an integral part of the behaviour organisation. According to Parker (op.cit.), this system probably did not originate as a nervous structure, but the first trace of it is to be seen in independent effectors such as the smooth muscle of the lowest multicellular animals. "This tissue, as seen in the oscular and pore sphincters of sponges, represents muscle unassociated with nerve and acting under direct stimulation from the environment. Such independent effectors are apparently open to only a limited range of stimuli, particularly to those of a physical type, and are relatively slow and sluggish in response." To this simple effector system was next added a receptive element in the shape of a sensory surface formed by modification of epithelial cells in the neighbourhood of the already differentiated muscle and particularly responsive to pressure changes, chemical changes, and changes in heat and light; the disturbances set up by any of the above stimuli being communicated to the muscles. In practically every case of this kind the processes of the receptive cells are applied not only to the muscle-cells, but branch to form a plexus or " primitive nerve net " in such a way that a stimulus affecting only a few of the sensory cells is conveyed to a considerably greater number of muscle-cells. A system of this kind is present in the tentacles of sea-anemones. More 
usually, however, in Coelenterates a third type of cell is intercalated among the branches of the nerve-net, adding to its complexity and bringing the nervous organisation a step nearer to the centralised system of higher animals. These cells have been called ganglion cells, a term which Parker thinks is inappropriate.

A nervous organisation such as that just described is characterised by its general diffuseness and lack of centralisation; points which bring it into sharp contrast with the highest type of nervous system, where a central nervous organ or adjustor is differentiated. According to Parker, this new adjustor element, which plays so important a part in correlating and controlling behaviour, has arisen from the nervenet which, as we have seen, forms an indirect connection between receptors and effectors. The nerve fibres constituting the plexus, originally situated in the outer layers of the animal, tend to become grouped into distinct tracts or bands of tissue, which gradually become separated from the ectoderm and sink into the deeper parts of the animal, giving rise to the ventral nerve-cord characteristic of the higher invertebrates, such as worms and crustaceans.

This brief outline of the evolution of the primitive nervous system, for which we are indebted to Parker, will serve as a basis for a more detailed discussion of the nervous organisation of the most important shore groups.

Sponges.-These, the most inert of all the multicellular animals, are devoid of any observable nervous elements whatever. They display, however, a diffuse contractility due to the presence of contractile cells or myocytes. The principal activity of sponges is that of maintaining a continual flow of water through the body by means of the action of the flagellate cells which occur in their interior. The only behaviour observable is when, at low tide or in other unfavourable circumstances, the sponge (e.g. Stylotella, or the British genus Pachymatisma) closes its oscula and contracts its flesh. When conditions are again favourable opening occurs as the result of the elasticity of the surrounding flesh. The muscle elements act as unco-ordinated 
independent effectors and their activity is due to direct stimulation from external sources. It is interesting to note, however, that an injury performed within a centimetre of the osculum will induce the latter to close, so that a method of transmitting an impulse is not entirely absent in sponges. Moreover, in some cases at least, the transmission of the stimulus occurs without visible motion and would therefore appear to be nerve-like (Parker, op. cit.).

Sea-Anemones. The body of an anemone is composed of two organised cell-layers and a third non-cellular layer or lamella placed between them which discharges the function of a skeleton. The outer and inner layers (ectoderm and endoderm) have, notwithstanding the different functions they discharge, very much the same structure.

In each the epithelial outer portion contains sensory cells whose deep ends are produced into a number of delicate fibres interlacing to form a middle nervous layer which includes, in addition, the so-called "ganglion" cells already mentioned. Beneath this is a third layer, consisting almost entirely of elongated muscle cells with their bases closely applied to, or even embedded in, the supporting lamella. The nervous organisation of the anemone thus includes, in addition to effector and receptor elements, the beginning of an adjustor element in the shape of a nervenet which, as we have already seen, permits a stimulus affecting only a small sensory area to be conveyed to a comparatively large system of effectors. It is only fair to point out, however, that doubts have recently been raised as to the importance of the nervous sub-layers in the ectoderm and endoderm in nervous conduction, and it is now considered that a more important part in the transmission of impulses is played by the lamella, which has been shown to contain a quantity of nervous elements and connections (Parker, op.cit.).

Generally speaking, the responses of Cœlentera are distinctly of a quick type, though slower than those of Arthropods, and this is due to the possession of sensory surfaces, since by means of these the muscles are called into action more quickly than by direct stimulation. 
Fleure and Walton (1907), from a study of Actiitia, Tealia and Anthea, conclude that the base of the animals and the tentacles are the parts most sensitive to mechanical stimuli. In Anthea and Actinia the mouth is the region specially sensitive to chemical stimuli, and the tentacles are insensitive except when the chemical stimulus is excessive. The behaviour of these forms would seem to be modifiable by experience. Thus, pieces of filter paper placed on some of the tentacles of an Actinia were carried to the mouth, but, after a few trials lasting over two to five days, similar offers were rejected by the tentacles.

According to Jennings (1905), changes in the internal metabolism, former stimuli that have affected the animal, previous reactions performed and other factors, combine to determine the action of a sea-anemone. There is also a marked tendency in some cases to repeat an action in the way it has been performed on previous occasions. These various factors give, according to this writer, a high degrec of complexity and adaptiveness to the behaviour of even these lowly animals.

A structure of particular interest in sea-anemones is the stinging cell or cnidoblast. These have been described already (p. I05), but we may refer here to the fact that each stinging cell possesses a special sensory process or cnidocil, stimulation of which provokes the liberation of the stinging thread. The fact that the bases of the stinging cells branch as do those of the ordinary sensory cells led observers to believe that the stinging cells were subject to nervous control in the same way as the muscles of these animals. Apparently, however, there is no experimental evidence in support of this view, and it must therefore be concluded that the nematocysts are only discharged under direct stimulation from the exterior (Parker, op. cit.).

Hydroids.-From an experimental study of Corymorpha, Parker (op. cit.) concludes that the nervous organisation of hydroids is very much like that of anemones, but represents a somervhat simplified condition; it is characterised by the same lack of any general nervous centre and the same 
general independence of parts from the standpoint of neuromuscular activity. Compared with the behaviour of anemones that of Corymorpha is distinctly less effective. For instance, the tentacles of an anemone when touched by a morsel of food turn in all directions till they have gradually entwined it. At the same time the tentacles secrete a sticky mass and liberate nematocysts with great freedom. Eventually, by the action of cilia and muscles, the food is delivered at the mouth. In Corymorpha, on the other hand, the tentacles respond by waving in only one direction-towards the mouth - and since the response remains unaltered whether food touches their oral or ab-oral surface, the food in the latter case is left behind. The proximal tentacles of Corymorpha secrete no mucus, and there are no cilia to help waft the food towards the mouth. 'The behaviour of Tubularia shows the same lack of correlation and, on the whole, the behaviour of hydroids would thus seem to be on a distinctly less effective level than that of Anthozoan polyps.

Echinoderms.-The nervous system of this group, as illustrated by the starfish, represents an interesting advance upon that of Cœlenterates. What we have referred to in this latter group as the primitive nerve-net is represented in Echinoderms by a plexus of nerve fibres and "ganglion" cells at the base of the ectoderm. This nervous layer, however, becomes distinctly thickened in certain places and causes the ectoderm to project as a ridge. One of these ridges runs down the middle of the under side of each arm and is known as the radial nerve cord. These ridges or radial nerve cords are united by a similar thickening of circular shape on the inner surface of the mouth, known as the nerve-ring. Translating this into the terms employed at the beginning of this section we may say that the nervous organisation of Echinoderms is at that stage where an adjustor element is becoming plainly differentiated.

The activities of Echinoderms show a high degree of co-ordination, but it is impossible to point to any obvious centre, such as the cerebral ganglion of worms and Arthropods, or the brain of higher types. The co-ordinator of the 
movements of the separate arms of the starfish, for instance, is evidently the nerve-ring. It is easy to demonstrate this experimentally. Thus, in spite of the absence of any brain, or of anything representing a head region, a starfish invariably moves in a determinate direction with one arm generally directed forwards. This is brought about by the tube feet of all five arms swinging in a direction parallel to that in which the animal is moving, and without reference to the long axis of the arm to which they belong. If, now, the connection of each of the radial nerves with the nerve-ring be severed, the tube feet of each arm will act perfectly independently and the animal will be pulled first one way and then another, according to which arm chances to exert the strongest effort.

A similar co-ordination of activities is particularly well seen when a starfish is placed upon its back. The tube feet are first extended in all directions and quite independently. When, however, a hold is obtained by some of the tube feet, the remainder at once exert their effort in the same direction, and the harmonious efforts of all the tube feet enable the animal to turn over.

The sense cells scattered through the ectoderm of starfish and sea-urchin render these animals sensitive over their whole surface. The sensory elements are, however, particularly numerous round the discs of the tube feet, and it is these which form the chief sense organs. Each tube foot also receives a branch of the radial nerve cord. The tip of the terminal tentacle of each arm is modified as an optical organ, consisting of a number of cup-shaped depressions of epithelium, lined by pigmented, rod-like sensory cells. The eyes of Asterias rubens and Solaster papposus are said to perceive distant illumination which is in contrast, either positively or negatively, to that of its immediate surroundings. There is, however, no evidence of imageforming or detection of movements on the part of the eyes (Plessner, r9r3). According to another worker (Mangold, I909), the use of the " eyes " in starfish is doubtful, their excision making no difference to the light reactions. This 
has been confirmed by Cowles (I9II). In all three groups, starfishes, sea-urchins, and brittle-stars, the light sense would appear to have its seat in the whole skin.

The activities of spines and pedicellariæ in the sea-urchin have already been alluded to (see pp. 88 et seq.). Though their behaviour is of a purely reflex character (a spine or pedicellaria removed from the test, along with a small portion of the underlying skin, will continue to respond to stimulation), yet these structures act together wonderfully harmoniously, so that the sea-urchin has been called a "republic of reflexes."

On the whole, it would appear that the behaviour of Echinoderms, notwithstanding its predominantly reflex character, is yet exceedingly varied and flexible and is, moreover, capable of being modified by experience. Thus starfishes, when pegged down several times in succession in the same position, showed a gradual reduction of the movements necessary for escape. Again, a short piece of rubber tubing, when passed several times over the arm of a brittle-star, was observed by Preyer to be removed in five different ways.

Bohn (1908), however, who has repeated Preyer's experiments, has been unable to obtain any confirmation of this whatsoever. The escape of the arm from the rubber tubing is said to be purely a matter of chance.

Annelids and Crustacea.-The plan of the nervous system is approximately the same in both these groups. Typically, it consists of a pair of ganglia in the head region (cerebral ganglia) united by a ring of nerve tissue to a similar pair of ganglia placed beneath the anterior end of the gullet (subœsophageal ganglia). The lower ganglia form the most anterior pair of a double chain of ganglia extending the whole length of the body and united by strands of nerve tissue. In the earthworm or in Nereis, which we may take as typical of Annelids, there is a pair of ganglia to each segment, and from each ganglion nerve fibres extend to the skin. In Crustacea such as the crab, successive ganglia tend to fuse, which means that the activities of these forms are more highly centralised 
than those of worms. The diffuse and superficial system of the forms hitherto studied has been replaced by a definitely centralised and more deeply situated band of tissue or nerve-cord. In certain worms, e.g. Sigalion, the nerve-cord still retains its connection with the ectoderm, and though it has become completely separated off in the earthworm, in Nereis the brain still retains its connection with the skin.

Contrasting the so-called "little brain" type of the higher invertebrates, which reaches its culminatıng point in insects, and the "big brain" type of vertebrates reaching its highest development in birds and mammals, Sir Ray Lankester notes that the former is distinguished by its wealth of ingrained capacities of instinctive behaviour and its comparative ineducability. The big-brain type, on the other hand, is relatively poor in ingrained capacities of instinctive behaviour, but has a remarkable capacity for learning.

Sense organs in marine worms (Polychæts) are frequently well developed. Thus Nereis has eyes, tentacles, palps and cirri all situated on the front of the head. The tentacles and cirri are tactile in function, the axis of each organ being traversed by a nerve whose fibres terminate in sensory cells. The palps are probably organs of chemical sense and combine the functions of taste and smell (Benham, 1896). Eyes are not necessarily confined to the first segment of the body but may occur elsewhere, the situation depending on the particular conditions of life. In some of the tubeworms eyes occur on the gill-filaments, their dark colour being in sharp contrast to the bright pink of the blood circulating in the filaments.

Another type of sense organ found in some Polychæts, c.g. the lug-worm Arenicola, is an otocyst, perhaps better called a statocyst. Though not common in worms, a similar organ is of considerable importance in Crustacea. These statocysts are equilibrating organs rather than organs of hearing and probably keep the animal informed as to its position in space. In Arenicola, a pair of statocysts is situated at the base of the prostomium. Von Buddenbrock 
(I9I3), who has studied these structures in the lug-worm Arenicola and other forms, including the bivalve Solen vagina, states that they have nothing to do with the perception of oscillations in the water, but effect an increase in the tonus of the longitudinal muscles on the side that is undermost and cause their contraction. There is also a musculosensory regulation which always tends to keep the tail parallel to the head, and these two factors co-operate to enable Solen to bore in the sand in a vertical, positively geotropic, fashion.

The tough cuticle which is so characteristic a feature of Crustacea would not seem to point to a high degree of sensitivity in these animals. As a matter of fact, however, many of the numerous setæ which are scattered all over the body and limbs of a typical Crustacean have a sensory function and render these animals more sensitive to stimuli of touch, at least, than might be expected. These setæ are hollow extensions of the integument, movably articulated at the base, and contain a prolongation of some of the cells of the skin, among which lie one or more nerve fibres. When feathered or provided with secondary barbs the setæ will react to movements or vibrations of the water. Some setæ of this type are thought to have an auditory function (Calman, I909).

The so-called " ear" of Crustacea, really a statocyst or equilibrating organ, is a small, usually open sac placed, in typical cases, upon the basal joint of the first pair of antennæ and having its inner surface lined with sensory cells of the kind described above, each of which contains a nerve fibril. Within the cavity of the sac are a number of tiny sand-grains, the contact of which with the sensory hairs results in impulses being transmitted along a nerve to the cerebral ganglia, from which messages are then sent out to the muscles.

The antennules themselves are thought to be responsive to changes of a chemical nature in the surrounding water. In the case of the fresh-water crayfish the setæ on the exopodites of the antennules have been definitely shown to 
have an olfactory function. If crabs and lobsters are observed in an aquarium, these antennules are often to be seen in rapid vibration, and this is especially the case when the animals have been moved from one place to another. The antennæ proper are obviously tactile in function.

The eyes of Crustacea are of the well-known compound type, thought, until quite recently, to give only "mosaic" vision. They are either stalked, as in crabs, shrimps, and lobsters, or sessile, as in Isopods and Amphipods.

The appearance in higher Crustacea of a perfected visual (image-forming) organ has meant a great addition to the number and variety of elements capable of affording sensations (colour, form, etc.), and of entering into combination with one another to bring about a particular reaction or series of reactions. The fact that such combinations are numerous, complex, and flexible (capable of being modified in a new environment), means that the behaviour tends to become less predictable and more "intelligent."

An important point made by Bohn is that among a number of sensations acting in conjunction to produce a particular reaction, one may gradually acquire predominance and eventually become so important as to be sufficient in itself to produce the reaction. There is thus a process of secondary simplification. But while this is an advantage in some cases, in others it may lead the animal astray. Thus, hermit crabs when seeking a Gasteropod shell tend to explore any round object, whether this possesses an aperture, i.e. is of use to their purpose, or not. 'That is to say, among the many variable features which distinguish shells the curved nature of the surface is the most essential and has so become the trigger which releases a whole series of reactions quite independently of any other features which may be present.

Molluses.-The details of the nervous organisation of this phylum vary considerably in the different groups. Generally speaking, a series of paired cords innervate the chief organs (foot, mouth, and viscera) and these are linked in the head region by circular commissures, and elsewhere 
by a series of transverse commissures. In view of the abundance of communication between cords and the massing of the ganglia in the head region, one seems safe in assuming that the nervous organisation of molluscs is both well co-ordinated and subject to a fair degree of control.

The sense organs of molluscs show many features of interest. Sensory cells occur scattered over the whole surface of the body, which is thus everywhere sensitive. These sensory cells are most numerous in the most exposed parts such as the head tentacles of snails, the epipodial tentacles of Trochus, Haliotis, etc., and the pallial tentacles of bivalves, which are thus essentially tactile organs (Pelseneer, Igo6).

Situated at the entrance to the mantle cavity in nearly all marine molluscs is an organ of smell or chemical sense called an osphradium, the function of which is, probably, to test the water before it passes over the gills. The osphradium has the form of a ridge or pit lined with epithelium and is said to be most highly specialised in the carnivorous Gasteropods, particularly the whelk (Buccinum undatum), in which species it is so large as to resemble a gill.

Otocysts occur in nearly all molluscs and have, broadly speaking, the same essential structure and functions as those of Crustacea, except that they are more often closed than open.

Visual organs in the molluscs show considerable diversity of structure. True cephalic eyes are characteristic of Gasteropods ; in nearly all bivalves, where the head region is hardly developed, they are replaced by analogous organs situated on the mantle. Eyes are absent from many marine forms which creep about wet sand, e.g. Bulla, Sigaretus, Scaphander, Philine. In certain species, the eyes, though present, are covered by a layer of skin, e.g. Doris and Natica. The cephalic eyes of Gasteropods vary greatly in the degree of their development. They are least developed in the limpet, where they are little more than pits in the skin lined by pigmented and sensory cells.

Pallial eyes show similar variation in their degree of 
complexity. In their simplest form they are merely groups of pigmented cells situated on those parts of the body which can be protruded from the shell, that is to say, on the siphons (Pelseneer, loc. cit.).

In some forms, a group of pigmented cells come into closer association, forming a compound or faceted eye, e.g. Arca and Pectunculus. In Pecten the pallial eyes are much more complex, and their structure is superficially not unlike that of the vertebrate eye. They appear as shining black beads at the edges of the mantle and are very beautiful. The supposedly close resemblance between the eye of Pecten and that of Vertebrates has provided material for a considerable amount of discussion. According to Dakin (IQI2), however, any hypothesis founded on such a conclusion must necessarily be unsound, since there is no real structural or developmental resemblance between the two. The only feature common to the two types of eye is an inverted retina and this is by no means rare in the animal kingdom. These pallial eyes are with one exception (the near relative of a marine form) entirely absent from freshwater bivalves and are most abundant in genera living between tide-marks, so that it has been suggested that they have arisen in response to the special needs of this area. Forms such as Solen, Mya, and Mactra, for instance, which live between tide-marks and are in the habit of protruding their siphons and sometimes part of their shells, are " manifestly very much at the mercy of their watchful enemies the gulls, and anything which would enable them to apprehend the approach of their enemies would be greatly to their advantage." Again, Pecten being a relatively active form and given to darting rapidly through the water, it is thought that the eyes may be of assistance to the animal in directing its movements so as to escape its enemies (Cooke, 1895).

REACTIONS OF SHORE ANIMALS TO THEIR ENVIRONMENT

The environmental factors which have had most effect upon the behaviour of shore animals are: (I) light, 
(2) moisture, (3) pressure or contact, and (4) gravity. These are obviously not peculiar to the sea-shore, but, owing to the transitional and fluctuating character of this area, they act and interact in a manner which is perfectly distinctive and hardly paralleled elsewhere.

Thus, to cite an example, the behaviour of a periwinkle at a particular moment with regard to light will depend upon the degree of hydration of its tissues, and in certain cases a complete reversal of the behaviour towards light may be brought about simply by placing the animal beneath a jet of water (Bohn, I905).

The Reaction of Shore Animals to Light.-The importance of light to the life of the organism is emphasised by Benjamin Moore (I909), who says that "since the very existence of a living organism, either directly or indirectly, is dependent upon the energy of light and the transformation of this into other types of energy, it is not surprising that reactions to light are among the most fundamental and most widely spread throughout the whole world of organised living creatures. Such reactions must have been developed in the very beginning of the dawn of life when the first living cells commenced to synthesise organic products from the inorganic materials of the environment by the use of the store of energy from the sunlight. Later on, organisms arose which were only dependent upon the light at second hand, since they were able to consume the synthesised organic products formed by other organisms converting the light energy directly, and so were only indirectly dependent upon the light for their existence. Even for this type of organism, utilising the light energy indirectly, reactions to light remained essential in the search for food and for other physiological functions, and also there would be an inheritance of relationships to light derived from the earlier ancestry with direct dependence upon light."

"At a later stage structures or organs arose specially adapted for light reactions, and in those living creatures possessing such organs there probably came a deterioration of the sensitiveness to light of the remaining cells of the 
body. But in spite of all such decline in direct sensitiveness to light there must have remained some trace of this old primeval relationship to light."

Many reactions to light almost certainly come under the head of tropisms. That is to say they are obligatory responses under the direct compulsion of an external stimulus : as when a moth flies into the flame of a candle.

The key to this type of behaviour lies in the symmetrical structure of the animal, symmetrical not only morphologically, but physiologically as well, " inasmuch as under normal conditions the chemical constitution and the velocity of chemical reactions are the same for symmetrical elements of the body," e.g. the sense organs (Loeb, I9I8). When a sense organ of one side is stimulated and not the corresponding one of the other, as when light falls upon one of the eyes, the physiological symmetry of the brain is disturbed, and this disturbance being communicated to the muscles of the more illumined side they are thrown into a state of increased tension. The effect of this is to cause the animal to turn head and body until both eyes are equally illuminated, when, the physiological symmetry being restored, the animal proceeds in a straight line towards the source of light. The term tropism is best retained for the bending or growth movements of sedentary organisms in response to external stimuli, while we can apply the term taxis to the method of orientation displayed by freely-moving organisms. Thus we may speak of the heliotropism or phototropism of hydroids and tube-worms, and the phototaxis of a Littorina or larval barnacle. This makes a convenient method of distinguishing between the responses of sedentary and motile organisms.

An important feature of tropisms is that they may be modified or even completely reversed by changes in the external medium, or in the internal physiological condition of the animal. Again, an animal may be positively phototaxic at one stage of its existence and negatively so at another. The responses vary with the nature of the habitat: thus, Bohn (1908) finds that starfishes (Asterias rubens) from 


\section{THE BIOLOGY OF THE SEA-SHORE}

rocky shores of the English Channel behave differently as regards light from those which live in sandy parts of the Arcachon basin. The former move away from the light into the shade ; the latter, since there are no shadows on a flat shore, remain stationary in phototropic positions with the tips of the arms turned inwards in such a way as to protect them from the injurious influence of the direct solar rays.

Similarly with periwinkles, the sign of the phototaxis may be reversed by the presence of moisture. Thus, when the rocks where Littorinas occur are reached by the waves, the animals, being negatively phototaxic, are guided by the darkness to the deepest crannies where, of course, they find the greatest degree of shelter. At ebb-tide, when the water leaves the rocks, the animals leave their crevices and proceed towards the light among the wet algæ where they find their nourishment.

As we have already mentioned, a periwinkle which moves away from the light can be made positively phototaxic by the simple process of placing it under a jet of water (Bohn, op. cit.).

Bohn's numerous experiments with Littorinas would seem to leave very little that is unpredictable in the behaviour of these molluscs. Thus, among other points, they are said to be attracted and repelled by stones and rocks, the extent of the influence of these objects being dependent upon their size and degree of illumination.

Sedentary animals react to light much in the same way as plants do. Since they are incapable of moving their position they respond by growing or bending towards the source of illumination. When, for instance, the Polychæt Spirographis spallanzani, with the tough but flexible tube in which it lives, is placed in an aquarium which receives light from one side only, it is not long before the anterior end of the whole tube is raised by the worm until the axis of symmetry of the gills faces in the direction of the rays of light. The animal retains this orientation as long as the direction of the light rays remains unaltered. If, now, the 
aquarium is turned round through $180^{\circ}$ so that the light enters its opposite end, the worm during the next day or two bends its tube in such a way that the axis of symmetry of its circle of gills is again in the direction of the rays of light. A similar response to light is shown by the hydroid Eudendrium. If, when the colony is brought into the aquarium, the old polyps are cut off, the new polyps which are regenerated will bend towards the light in the same way as the tube-worm (Loeb, op. cit.).

One must not fall into the error of assuming that all reactions to light are of the nature of tropisms. There is a forced character about a tropism which it is not difficult to test by experimental means.

One important type of response which cannot be interpreted in this way is that consequent on a brusque change in the intensity of a stimulus : as when a tube-worm retracts its tentacles under the influence of a sudden shadow. In the case of non-sedentary forms this reaction usually takes the form of an abrupt stoppage followed by a turning movement of $180^{\circ}$, after which the animal continues its progress in a direction directly opposite to the one previously followed. This is what happens (in varying degree) when a positively phototaxic animal reaches the limit of a shadow, or when an animal climbing up a slope encounters an abrupt change of gradient. The term applied to this type of reaction is "differential sensitivity." It has been much studied by Bohn (IgI I), who regards it as of great importance. When acting in combination with tropisms, it gives an aspect of considerable complexity to the behaviour. For instance, an adult brittle-star does not move directly towards the area of shadow which it ultimately reaches, but the path it follows after the initial impulse is spent is frequently a tortuous one, and is governed by the attraction of the darkened area, acting in conjunction with the oscillations caused by variations in the degree of illumination of the surfaces the animal encounters. Actually, the movements of the animal are governed by a combination of three factors : (I) the initial impulse resulting from the state immediately preceding the 


\section{4

behaviour in question ; (2) the impulse towards or away from the light (tropism) ; and (3) the turning or oscillatory impulse (differential sensitivity).

Keeble and Gamble (1904) have made a profound research into the effects of light on littoral Crustacea ; in particular Macromysis, Hippolyte, and Palcomon.

Instead of becoming inured, these animals remain highly susceptible to the light conditions of their environment; thus, light affects the amount of pigment in the chromatophores, and its distribution in these structures, giving rise to changes of colour ; light affects the irritability of the organism, forms like Hippolyte and Palcemon after remaining quiet all day being seized at night by a strange restlessness ; light influences the orientation and movements of various Crustacea, forcing them to assume particular attitudes and to move in a particular direction, and so on.

The question of colour change is of particular interest. The changes of tint so often observed are brought about by the expansion and contraction of masses of pigment contained in irregularly shaped cells with numerous branched processes-the chromatophores (in Mysids the chromatophores are multicellular structures, in Palcamon they are multinuclear). On appropriate stimulation the pigment flows out into the branches in such a way that what was a mere pin-point of pigment becomes spread out over a wide surface, producing a change in coloration. More than one kind of pigment may be present in a chromatophore ; red, yellow, and blue pigments may occur together. The movements of the pigment may be either of the nature of a direct response to the light, or they may be modified by the action of the eye and nervous system. The direct response is a reaction to light intensity and is of an ephemeral nature, of no value for protection. The indirect response is determined by background and is independent of variations of intensity. In contrast to the direct responses it is slow and lasting.

Reactions to Moisture.--The moisture conditions of the shore are continually varying between the two extremes 
represented by high and low spring tides. Within much narrower limits (owing to moisture-conserving arrangements, etc.) the amount of water in the tissues of shore animals also varies, and since we know that water is of fundamental importance to vital processes, it is only to be expected that its presence in varying quantity should have considerable effect on behaviour. We have already had evidence of this in the completely different phototaxic responses of Littorinas before the tide reaches them and when it has just left them.

Anna Drzewina (1908) has noticed that shore crabs (Carcinus mœnas) living under stones at the water's edge show a very definite response to the moisture arising from the sea, which may be regarded as a kind of hydrotaxis.

A shore crab placed on the ground 50, 100, or 200 metres from the water's edge invariably tends to make a direct line towards the sea, in spite of any obstacles it may encounter, and practically regardless of wind, shadows, and degree of slope. After rain, however, when moisture is rising from the ground as well as from the sea, this behaviour is no longer manifested. It is particularly evident among those crabs which live on a shore where the sea retreats a long way and where desiccation may be severe.

In other habitats crabs do not behave in this way. For instance, those which live under stones near low-tide mark, and are in no danger of drought, exhibit this response either very slightly or not at all. The danger in this case is that of being carried away by the waves. At a certain point of the French coast (Gatteville lighthouse) the seaweed-clad rocks project far into the sea and are pounded by the waves. Numbers of crabs are found clinging to the weeds, and no sooner are they detached than they return to their original position. When placed upon a sandy beach, instead of proceeding towards the sea, they make for rocks covered with Fucus, if these are near, or towards any large expanse of similar colour, in this case being guided, apparently, by their powers of vision (Bohn, op. cit.).

Reactions to Pressure or Contact.-Certain animals 


\section{THE BIOLOGY OF THE SEA-SHORE}

show a tendency to bring their bodies completely into contact with solid objects, and this is particularly marked in many shore creatures. One of the commonest shore Polychæts, Cirratulus tentaculatus, always occurs beneath flat stones embedded in sandy mud, as much of the body as possible being kept in contact with the under side of the stone. When transferred to a dish of sea-water where there are no stones, the worm roams about restlessly. If a flat stone is now introduced into the dish the animal will be found, in a very short time, firmly ensconced beneath it and looking distinctly more comfortable (Flattely, I9I6). Maxwell (quoted by Loeb, op. cit.) placed a number of specimens of Nereis in a porcelain dish devoid of sand, but containing glass tubes of varying sizes to correspond with the different sizes of the worms. After twenty-four hours every tube was inhabited by a worm which had made it its permanent abode, not stirring even when exposed to sunlight although this caused its death. This attraction or repulsion by solid surfaces is known as stereotropism or stereotaxis and is a phenomenon of great importance.

Negative stereotaxis is seen, according to Loeb, in the larvæ of the barnacle at a certain stage and of other Crustaceans.

Different parts of the same organism may show different responses. It is in this way that Loeb accounts for the righting reactions of starfishes, etc., their ventral surface being positively phototropic, and their dorsal surface negatively so. That this phenomenon is quite distinct from geotropism is demonstrated by Loeb's observation that starfish will cling to solid surfaces with their tube feet, even if by doing so their dorsal surface is turned towards the ground.

Similarly, the stolons of hydroids will cling to solid bodies, while their polyps bend and grow away at right angles. The regenerating polyp of Tubularia mesembryanthemum, the stem of which is in contact with the glass side of an aquarium, will grow out at right angles to the vertical wall (Loeb, op. cit.). 
This stereotropism or stereotaxis is essentially an orientation phenomenon and has its roots in the necessity for establishing a balance of contact among the nerve endings at the surface of the skin. It supplements the other two modes of orientation, viz. by means of light and gravitation. Stereotropic phenomena are nowhere of more importance than on the shore and one is led to speculate as to how far shore conditions, with the influence of wave-shock and the necessity for keeping a firm hold on the substratum, may not have been instrumental in fostering this reaction. In other words, bearing in mind Willey's remark on the apparently fundamental nature of this reaction, is it too much to ask whether this particular lesson may not have been learnt on the shore?

Reactions to Gravity.--The upward growth of the plant shoot and the growth of the root in a diametrically opposite direction constitute the most obvious features of plant behaviour. In normal conditions this behaviour of root and stem remains unvaried and persists no matter in what way the plant may be oriented. The root is said to be positively geotropic, the shoot negatively geotropic. Behaviour of an exactly similar kind has now been demonstrated by Loeb and also by Miss Stevens for the hydroid Antenmularia antennina. This is perhaps not surprising, when we consider the plant-like form of hydroids. The phenomenon, however, according to Loeb, is not confined to sedentary animals, but the burrowing and climbing movements of worms and molluscs are of the same nature. Loeb justifies the application of the term " tropism " to the vertical movements of some animals by assuming that gravitation acts by influencing the distribution of certain chemical substances in the organism. When a plant or an animal is turned on its side or inverted the distribution of these substances is altered, and the physiological symmetry of the animal is destroyed. If a specimen of Cerianthus (a sea-anemone) is placed head downwards in a test tube filled with sea-water the tentacular portion will gradually turn upwards, and the base will turn downwards until eventually the normal orientation is reached 


\section{THE BIOLOGY OF THE SEA-SHORE}

(Loeb, 1905). That contact stimuli are not responsible for this phenomenon has been demonstrated by the following experiment. A Cerianthus is placed upon a piece of wire netting resting on the sides of a glass vessel in the aquarium. The animal gradually forces the base through one of the meshes until it is in a vertical position with the tentacles upwards. If the piece of wire is now turned completely over, the animal does not pull itself out again, but the foot near the tip turns vertically downwards until it reaches the wire net when it is again pushed through as far as possible. By reversing the wire net twice in this way a Cerianthus has been made to push its foot through the meshes three times (Loeb, op. cit.).

Gravity is of fundamental importance in controlling the orientation of the organism in space, and it is supplemented, as we have seen, by light and by contact stimuli acting on the nerve endings of the skin (stereotropic phenomena). A great number of animals possess some form of organ which has the special function of securing equilibrium, viz. the statocysts of worms, crustaceans, and molluscs, and the ear (semicircular canals) of vertebrates. The stimuli leading to the maintenance of equilibrium are produced, in invertebrates, by the contact of small particles with the sensory cells lining the statocyst. The classical proof of this was afforded by Kreidl. It is well known that, when a crustacean moults, the lining of the statocyst is shed, it being simply inturned cuticle. At the same time the sand-grains are also got rid of, and must consequently be renewed by the animal itself. Kreidl placed specimens of Palcomon during the moult among a quantity of fine particles of iron, and these particles, in default of anything more suitable, were eventually transferred by the prawns to their statocysts. By the use of a magnet Kreidl was then able to overcome the force of gravitation and any inhibitory effect of vision, and to orient the animal as he chose.

Animals which are naturally devoid of otoliths, nevertheless show geotropic phenomena. In addition to the case of hydroids, and of the anemone Cerianthus already quoted, 
we may cite that of the sea-cucumber Cucumaria cucumis. When placed upon a vertical plate of glass or slate, the animal creeps upward until it reaches the highest level, where it remains. It is sufficient now to turn the glass through $180^{\circ}$ round an horizontal axis to induce the animal to move upwards once more, and this behaviour continues indefinitely as long as the glass is rotated. It has been shown that this behaviour takes place independently of any influences of light and oxygen (Loeb, op. cit.).

Rhythmic Behaviour on the Shore.-The rhythmic nature of many biological phenomena has long been observed, and in analysing behaviour the effect of these periodicities must not be ignored (see Flattely, 1920). They play a particularly important part on the shore. The majority of shore animals are, as Bohn points out, subjected to a double periodic influence, the rhythmic ebb and flow of the sea and the alternation of day and night, to which they are constantly reacting. This is well seen in the case of Convoluta, a tiny ciliated flat-worm which occurs on flat sandy shores, such as those of Normandy and Brittany.

The much discussed form, Convoluta roscoffensis, is green in colour owing to the presence of unicellular green plants living with it symbiotically. It occurs in immense colonies which appear, at low tide, as great patches of green scum about halfway down the shore. As the tide laps the edges of the colony the green patches disappear, the worms retreating below the surface and remaining there till the next ebb-tide. Twice during the twenty-four hours the zone occupied by the colonies is submerged and the animals live in darkness underground, and twice the zone is uncovered and the animals rise to the surface. The burrowing reaction is due to the necessity of avoiding extermination by waveshock, the upward movement is determined by the presence of the algal cells and their light requirements. The worms thus show up-and-down movements synchronous with those of the tides, but in an inverse direction (see Keeble, I9I0).

This constant reaction to the tidal rhythm has had a 


\section{0 THE BIOLOGY OF THE SEA-SHORE}

profound effect upon the functions of the organism, the movements persisting even when the external stimuli have been suppressed. When Convolutas taken directly from their normal habitat are placed in moist sand in a tube, the up-and-down movements continue to take place at the periods corresponding to those of the animals' emergence and submergence on the shore. Not only this, but the variations of the tide are closely followed by the Convolutas in the aquarium, the movements being more sluggish during neaps and more rapid at springs (Bohn, 1910). A similar phenomenon can be observed in periwinkles which have been exposed to the tidal rhythm.

Inert periwinkles, even in a dry environment, can be reactivated by shaking; but, according to Bohn (1905), if a collection of these molluscs has been taken from the shore and isolated for a certain time in the laboratory, it is easily demonstrated that, at periods of low tide, one has to shake much longer to produce the reactivation than when the tide is out; that is to say, the periods of inertia in the laboratory correspond to the periods of desiccation on the shore.

The impress of the external rhythm on the organism is, of course, not permanent but gradually weakens with the passage of time.

Certain of the colour changes of shore Crustacea to which reference has already been made, have been shown to be of a rhythmic character. The colour of the Æsop prawn (Hippolyte varians) is dependent on three pigments, and during the day varies greatly according to the nature of the background, intensity of illumination, and certain other influences. At nightfall, however, the colour of Hippolyte, whatever it may happen to be at the moment, changes to a transparent azure blue, the place of this blue colour being taken at daybreak by the prawn's diurnal tint or tints (Keeble and Gamble, loc. cit.). The animal thus exhibits rhythmic colour change corresponding to the transition from light to darkness and vice versâ. 
SOME CHARACTERISTIC ACTIVITIES OF SHORE FORMS FROM THE STANDPOINT OF BEHAVIOUR

Certain characteristic activities of shore forms to which we have referred already in other connections deserve further study from the standpoint of behaviour. They are: the construction of tubes by Polychæts, and similar activities; the occupation of molluscan shells by hermit crabs ; and the masking of spider crabs.

Tube-building in Polychæts.-Many marine worms are adapted to living in tubes of their own construction. Most frequently, the tubes are formed of particles of sand, mud, or similar material collected by the tentacles and cemented in position by a substance secreted by the body. The accuracy with which these particles are fitted and the symmetrical and finished appearance of the tubes are often extraordinarily fine. What is equally wonderful is that out of a heterogeneous mass of material at the disposal of the worm only fragments of one particular kind are selected and employed. What interpretation is to be placed upon the behaviour is, in the absence of careful experiments, not apparent. The tendency is, perhaps, without sufficient evidence, to postulate intelligence. Thus, a case of what is described as "apparent intelligence" has been observed in Terebella conchilega (Watson, 1916). One of these worms, with the combined effort of several tentacles, was observed to be lifting to the edge of its tube a piece of gravel too large to enter the opening. It appeared to the observer that the stone was too large, and that when placed on the edge of the tube it must necessarily fall off, as the cement supplied by the animal's lips would be too weak to hold it in position. However, the stone in due time reached the edge of the tube, held by several tentacles; the worm then emerged to receive it and with its lips grasped as much of the stone as they would cover, and then rested it upon the edge of the tube. The observer then expected to see it fall, but it was kept in place by the tentacles which were now passed around it. A supply of small grains of sand 


\section{THE BIOLOGY OF THE SEA-SHORE}

having been emptied into the lips by other tentacles the head was extruded and the sand-grains deposited, mixed with cement, outside and just underneath the stone. A fresh lot of sand-grains was then brought up in the same way and deposited beneath the stone on the other side. The tentacles then released their hold, the stone having been " scientifically supported and securely fixed in position with all the skill of a professional builder." The danger of attributing the term "intelligent" to these complex and very remarkable activities is seen when we reflect that workmanship of an equally wonderful kind is displayed by such lowly forms as the Foraminifera in the construction of their shells. These pick out their materials in exactly the same way as do the tube-worms and put them together in a manner which is even more remarkable. Thus, from an enormously varied mass of material Technitella thompsoni picks out only the plates of an Echinoderm, and specimens of Crithonina pisum, which are exposed to being bored by parasitic worms, will sometimes protect themselves with a "chevaux-defrise" of sponge spicules. Heron-Allen (I9I5), who has brought to light a number of very striking examples of this kind, sees in them illustrations of " purposive intelligence." In criticising this interpretation, Lankester (Igr6) remarks that he finds no great difficulty in conceiving of a mechanism in the protoplasm of the Protozoa which selects and rejects building material, and determines the shape of the structures built, comparable with that mechanism which is assumed to exist in the nervous system of insects and other animals which " automatically" go through wonderfully elaborate series of complicated actions. Darwin and others have attributed the building up of these inherited mechanisms to the age-long action of Natural Selection and the survival of those individuals possessing qualities or tricks of life-saving value. Lankester, therefore, disagrees with Heron Allen's opinion that the architectural and selective phenomena exhibited by Foraminifera have no relation to adaptation and tropisms. On the contrary, they are not only closely related to such phenomena, but are of the same nature, 
These activities of Foraminifera and tube-worms are " instinctive " in the sense that they are displayed independently of experience and in equal measure by all the members of a particular group, but the use of this term leads us no nearer an understanding of the mechanism underlying them.

The nest of the stickleback as a piece of workmanship is of a considerably lower order than that represented by the shell, let us say, of the Foraminiferan Marsipella spiralis (in which the spicules are twisted into a left-handed spiral, so increasing the strength of the shell) or the tube of Amphictene (see p. 103), but the behaviour of the stickleback may well be on a higher level notwithstanding. For the form of the Polychæt tube follows closely that of the body, and direct stimuli of contact, pressure, and so on, are possibly of importance in determining the placing together of the grains. The nest-building of the stickleback, on the other hand, like that of birds, involves a much more diverse series of operations : active search for the proper weeds, removing them when found, weaving them together and securing them with threads of mucus and so on.

Occupation of Gasteropod Shells by Hermit Crabs.-Not only does the hermit crab require to gain admittance into a univalve shell when it first becomes adult, but as it increases in size, larger shelters have to be looked for. The question therefore arises as to what extent hermit crabs may be said to "recognise" the shells likely to prove suitable for them, and by what means this recognition is accomplished?

According to Bohn (1910), a hermit crab in the task of finding a suitable shell is aided, not by its powers of vision, but by an extraordinarily well-developed tactile sense. No sooner does one of the crab's limbs chance to come in contact with a shell than the crab at once applies its body to it with the head downwards and, getting a support for the chelæ on the lower part of the shell, causes the latter to rotate so as to bring the orifice into a convenient position. The animal then sounds the orifice with its chelæ and eventually 


\section{THE BIOLOGY OF THE SEA-SHORE}

turns round and inserts its abdomen. The whole sequence of movements is, according to this writer, invariable, and its unintelligent nature is proved by the way in which hermit crabs will explore a small wooden ball or practically any convex surface exactly as they do Gastropod shells.

The experiments of Drzewina (quoted by Bohn, op. cit.) shed further light on the behaviour of these forms. Hermit crabs deprived of their protection were placed in the presence of Trochus shells the mouths of which had been completely closed with plaster. For a considerable time the crabs endeavoured to obtain an entry, but without success. Gradually, however, they became indifferent towards the shells and a week or so after the beginning of the experiment took no further notice on chancing to come into contact with them, but simply climbed over them or pushed them to one side. When, now, shells of another kind and shape were placed in the aquarium with their openings also plastered up, the crabs, on encountering them, at once set about exploring them actively and systematically, turning them round and continually endeavouring to introduce their forceps into the orifice and pulling away pieces of plaster. From these experiments Drzewina concludes that the behaviour of hermit crabs is modifiable by previous experience, and further that hermit crabs are able, by means of their tactile sensitivity, to discriminate between different forms. In fairness, it must be pointed out that the results of Drzewina's experiments tend to show that the behaviour of hermit crabs is less mechanical than Bohn would, perhaps, lead us to believe. While our own attitude towards these problems is admittedly a sceptical one, we are anxious to avoid doing injustice to facts.

Masking of Spider Crabs.-The habit which spidercrabs have of planting out their backs with pieces of weed, hydroid, and so on, has already been referred to from the point of view of its significance in the shore struggle. The habit seems to be most highly perfected in species of Dromia, which make use of the Laminarian seaweed among which they live. Pieces of the weed are cut off with the forceps 


\section{BEHAVIOUR OF SHORE ANIMALS}

and placed upon the back by means of the modified last pair of thoracic legs. If the piece of weed is too big and sticks out over the edges of the carapace the crab removes it, cuts a piece off and replaces it. This behaviour, in spite of its apparently intelligent appearance, is said to be of a more or less automatic nature (a statement which those who have witnessed the performance will have difficulty in believing) and to continue unaffected even when the eyes are removed or the brain destroyed (Bohn, op. cit.). Equally interesting is the way in which a crab covered with algæ of a particular colour tends to make for the environment which is most in harmony with it, a fact brought out by Aurivilius and later by Mienckewiecz. The nearest we can get to an explanation of these activities at present is to say, with Bohn, that the masking habit of crabs is a complex of activities in which, in addition to differential sensitivity, associative phenomena play a part (see p. 227). 


\section{CHAPTER XII}

\section{The Reproduction and Growth of Shore Animals}

To a certain extent the eggs and larvæ of shore animals are exposed to the same dangers as those which beset the adults. There is this difference, however, to be borne in mind, that inasmuch as the larvæ of most shore animals, and often the eggs themselves, are pelagic organisms, they become for a period exempt from the influence of factors normally associated with shore life. Reproduction on the shore thus involves the double problem as to how the young animal is to be launched, and how, later on, if the larva is pelagic, it can obtain a footing in an environment similar to that of its parents? Speaking generally, the chief risks which beset the eggs and larvæ of shore animals may be enumerated as follows: (a) stranding on the shore or being swept out to sea (eggs and larvæ); (b) desiccation at low tide (eggs); $(c)$ varying character of the environment: tides, fluctuating temperature, etc. $;(d)$ predaceous animals (eggs and larvæ); (e) failure to obtain a foothold (larvæ).

Adhesive Spawn-Protective Coverings.-So far as the eggs are concerned, the danger of stranding is frequently avoided by the firm way in which they are attached to rocks, weeds, stones, empty molluscan shells, etc. Frequently, the spawn is deposited in flat, adhesive masses surrounded by gelatinous material (e.g. Nudibranchs). Or the embryos may be surrounded by a stout, horny capsule which is attached by a stalk (viz. many Gasteropods). The ova of many Polychæt worms (e.g. Phyllodoce) are enclosed in globular gelatinous envelopes which are moored by a long strand of mucus (see Fig. I8). 
Shore Forms with Pelagic Larvæ.-A question which can hardly fail to exercise the minds of those studying the reproduction of shore animals is, how does it come about that while, apparently, pelagic larvæ are continually being driven and dispersed over vast areas, the adult forms are invariably restricted to constant and definite portions of the shore? According to Lo Bianco (1909), the answer to this question lies in the way in which the reactions of the larvæ towards the light are related to the periodic circulation of coastal water and in particular to those coastwise currents which, owing to the wealth of pelagic forms they contain, are known as zoo-currents.

During the day, the larvæ of such typically shore forms as Sycon, Balanus, Echinus, Ascidea, Amphioxus, etc., owing to their strong positive phototropism, occupy the surface layers of the sea ("phaoplanktonic"); whereas at night, owing to the absence of light stimulus, they may be found occupying a zone extending from the surface to a depth of several metres ("knephoplanktonic"). Now, as is well known, owing to the unequal heating of land and sea by the sun, the general direction of the wind during the day is on-shore (sea-breeze), while at night it is in the opposite direction (land-breeze). Consequently, during the day, the larvæ which occur at the surface are driven towards the coast where they are caught in the littoral currents already referred to. On completing their metamorphosis the young animals drop to the bottom and, being still positively phototropic, are guided to their final habitat in the tidal area. The difference in the degree of sensitiveness to light determines why, for instance, a form like Arbacia pustulosa finds its final habitat among the rocks in a few feet of water, while Echinus microtuberculatus is led towards the deeper water and its typical habitat among the "meadows" of Posidonia.

Generally speaking, larval forms which are negatively phototropic undergo their development in the middle waters or knephoplanktonic zone, while positively phototropic forms develop in the surface waters or phaoplanktonic zone.

It is thus evident that the survival of shore forms with 
248 THE BIOLOGY OF THE SEA-SHORE

pelagic larvæ is not so fortuitous a matter as one might suppose. The risks, it is true, in spite of adaptive phenomena are still formidable, but against this we may place the fecundity of such forms and the fact that the larvæ are usually hatched at the season of calms.

Places selected for Spawning.-The risk of desiccation is countered, in the case of eggs fixed to the substratum within the tidal area, by the fact that such eggs are usually surrounded by a protective gelatinous envelope or, in the case of embryos, by a horny capsule. Fronds of algæ are favourite places for the deposit of such spawn, the weed lending its moisture and protecting the eggs from evaporation. Forms in which fertilisation is external (e.g. most Annelids) may liberate their reproductive products in shore pools at low tide. Where the spawn is deposited on the substratum the place selected is almost invariably some sheltered cranny or nook formed at the junction of rocks, by a fault in the rock itself or by an overhanging ledge. Often the spawn is so abundant as to suggest the term " nursery" for such nooks.

Abundant use is made of the protection for the ova and developing young offered by the empty shells of molluscs, the empty cups of barnacles, etc. Empty barnacle shells frequently contain numerous tiny Littorinas. The larvæ of Mytilus edulis may invade the empty air vesicles of Ascophyllum, occasioning a protective reaction of the plant (Tobler, 1909). The roots of Laminaria afford similar shelter for tiny mussels and numerous other young forms.

Adjustment of Life Cycle.-In view of the many vicissitudes of shore life and the variable character of this environment generally, it is not surprising to find on the shore numerous adjustments of the individual life cycle. For instance, Lo Bianco (I III) finds that the species in the Gulf of Naples which live continuously exposed to wave-shock spawn almost invariably at the season of calms (or during the warmest months of the year), or otherwise the larvæ would not survive. The small minority which form an exception to this rule, spawning in winter and spring 
(Asterina, Murex, Blennius, etc.), fix their eggs securely to the rocks and protect them by a capsule. The shallow and stagnant waters of harbours, which are subject to intense putrefaction and excessive heating, especially in summer, are populated by species which mostly reproduce in winter and spring; such commensal and parasitic species as live in an unvarying medium lay their eggs at every season. Certain Hydroids (Pennaria, Corydendrium) shed their polyps and enter into a state of latent life when the autumn storms come on, giving off new branches and developing fresh polyps in the following May. Lo Bianco interprets this as a protection against wave action, but Issel (1918) thinks other factors: temperature, density, food, are concerned as well.

Of the several species of Littorina which are found on the shore L. littorea, which occurs nearest to low-water mark, deposits its ova in small capsules, shaped like a soldier's tin hat. They are not attached. The embryo is freed as an early veliger. But the larvæ of L. obtusata, which occurs at about half-tide mark, are freed as second stage veligers, while $L$. rudis and $L$. neritoides, the latter of which lives actually above high-water mark, are viviparous (Tattersall, I909). The importance of this is clear. As one proceeds up the shore the periods of drought become longer and the risks to a free-swimming larva considerably greater. Consequently, there is a tendency to abbreviate the free-swimming stage and even to cut it out altogether. Again, the Nudibranch Cenia, which frequents brackish estuaries and even possesses to a limited extent the habit of leaving the water, has an abnormal development which takes place within the eggs (Eliot, I9ro).

An analogous case is that of the viviparous blenny (Zoarces viviparus) whose habits are in marked contrast to those of other shore-frequenting fish. Instead of depositing demersal eggs in spring or summer, like most shore fishes, this species of blenny produces well-developed living young in winter (Aflalo, 1904). According to M'Intosh (I9OI), an adult female may produce from 40 to 70 living young capable 


\section{$25^{\circ}$ THE BIOLOGY OF THE SEA-SHORE}

of at once taking shelter under stones, shells, etc., and of fending for themselves.

As has been already noted, shore Crustacea retire to deeper water to spawn, probably because the temperature becomes more stable with increasing depth.

The tidal rhythm has in several cases had a profound effect on the timing of the life-cycle. This is well seen in Convoluta roscoffensis, the tiny ciliated Planarian worm containing green symbiotic algæ which we have mentioned as living in large colonies on the sandy shores of Normandy and Brittany, just at the level reached by high water at the slackest of neap tides. We have already seen (p. 239) that with the onset of the tide the patches disappear as the animals retreat beneath the surface till the next ebb-tide. Twice each day, for a period of six hours, the animals live underground, and twice they rise to the surface and remain there for a similar period. These vertical movements are imposed on the animal, the burrowing reaction being due to wave-shock and the upward movement to the influence of light in relation to the symbiotic algæ. Now, it so happens that at Roscoff in the summer the low water of spring tides falls at midday and midnight, and consequently when the Convoluta zone is uncovered for the second time, the animals in the absence of light are not obliged to come to the surface. It is precisely at this period, when the worms are able to remain below the sand for the longest possible time, viz. eighteen hours at a stretch, that egg-laying, as observed at Roscoff, reaches its maximum (Keeble, I910).

Perhaps a still more striking example of a similar phenomenon is afforded by the "Grunion" (Leuresthenes temuis), a small smelt about $5 \frac{3}{4}$ to $6 \frac{1}{2}$ inches long occurring on the sandy shores of California. On moonlight nights during the big tides of March, April, May, and June- - on the 2nd, 3 rd,

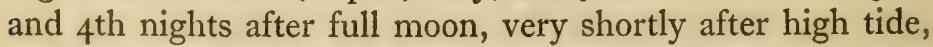
to be exact-the Grunion comes in with the sweep of the water and, as the waves break, lies for a moment, squirms and drops back into the wash of the next wave. Crowds of 
people assemble to pick up these fish by moonlight, bonfire, and flashlight, using various methods : hand, wire screens, seines, etc. During the run thousands of fish may be visible at one time; their purpose is spawning. Male and female burrow together at the wave margin and pair. The eggs are laid in small masses or "pods" $3 \frac{1}{2}$ inches below the surface at a point far above the limit of an average tide. They are even preyed upon by an Histerid beetle! The ova, which are protected by capsules, are very resistant to desiccation. Ten days after the commencement of spawning and one day before the first of the next high tides, the eggs are washed out of the sand, hatch immediately, and the larvæ are free to escape into the surf. Though errors of adaptation may occur, the whole procedure is evidently wonderfully synchronised and adjusted so as to allow the fish to lay their eggs on what is little less than "terra firma." The "runs " of fish begin at about the turn of the tide and continue for about an hour ; the eggs are thus laid as the water-line has reached its highest limit and in a region which is out of reach of the succeeding tides. Eggs laid an hour too early would get washed out again. Tides accompanying the dark of the moon are always very much higher than those of the full moon, and therefore uncover all the eggs laid at the previous spring tide. If spawning took place at the new moon, the eggs would have to wait a month before hatching out, with correspondingly greater risks from enemies and desiccation, etc. Eggs, however, though on the point of hatching, are capable of lying quiescent without harm for an additional fortnight if circumstances make it necessary (Thompson and Thompson, 1919).

As a final illustration of periodicity on the sea-shore we have the remarkable facts elucidated by Lloyd-Williams (1905) with regard to the alga Dictyota. In this seaweed the successive crops of sex cells are initiated, matured and discharged within the space of a fortnight, and the course of their development is governed by the time and height of the tides. Consequently, a knowledge of the tides at any given spot will enable one to predict almost the precise 
moment in the fortnight at which the sex cells will be set free.

Care of Eggs by Parents.-The eggs of shore species are not always deposited at haphazard, but are frequently, after extrusion, the object of special attention on the part of the parents. This phenomenon, though not confined to the shore, is yet very characteristic of it. Obviously, the danger from which the eggs are protected by this habit lies in the attacks of predaceous animals rather than in physical factors. As regards the latter, as we have seen, the method of telescoping the life-history is more likely to secure survival. In most of the familiar species of Crustacea, the eggs, until the time of hatching, remain attached to the female after extrusion, either stored in sacs at the side of the body (Copepods), or attached by a sticky secretion to the numerous hairs on the abdominal swimmerets (Decapoda, Amphipoda, Isopoda). In this position they are kept constantly aerated by the paddlelike movements of these appendages. A similar habit is found in the Pycnogonida, but here, curiously enough, it is the male animal that carries the eggs, the latter being transferred from the female after extrusion to a pair of special appendages (ovigerous legs) present in the male. It is, however, among shore fishes that the clearest cases of parental care are found, and here, too, it is almost always the male which assumes charge of the ova.

In many shore fishes the eggs remain in the care of one or both of the parents during the period between deposition and hatching. In some cases the female dies after spawning, and thus the male becomes parental. There is no reason to read human nature into the conduct of the fish on such occasions. On the other hand, that the presence of the parent in the vicinity of the eggs is not merely fortuitous is proved by the persistence with which the fish remains at its post, even under conditions of considerable discomfort. M'Intosh (I886) has described the behaviour of a male "lumpsucker" (Cyclopterus) which was observed at St. Andrews, about the middle of May, lying in a broad runlet 
with its head close to a mass of ova placed on the seaward edge of a stone, close to low-water mark. The stream of water at low tide was not sufficient to float the fish, which accordingly had to lie on its side for a considerable period twice daily, under a warm sun, with the upper portion of its gill region out of water. The animal, however, was oriented in such a way that the current of the runlet flowed directly into its mouth, and thus, notwithstanding a slight acceleration of the action of heart and gill-apparatus, sufficient aeration was obtained. In this position the fish was observed at low tide for a period of five or six weeks. When, on one occasion, it was removed a couple of yards from the eggs and placed upon a stone it wriggled actively into the water, at once rushed to the ova and assumed its former position with the snout almost touching the eggs. The same ensued when the fish was placed in the runlet at a somewhat greater distance. M'Intosh states that the solicitude of the males for the ova which they have under charge was further illustrated by the occurrence early in May of a heavy sea, which swept masses of ova from their positions all along the rocks. As soon as the water became calm again " numerous anxious males, like 'pilgrims,' were seen by the laboratory attendant (who had been familiar with the sites) seeking for their lost charges. Many of these masses of eggs were found on the beach, so that the statement is probable."

Not infrequently the shore collector will find a mass of eggs, about the size of a walnut, closely invested by the body of the male butterfish or gunnel (Centronotus gunnellus) (see Fig. 15). Storrow (1915) has observed the behaviour of one of these fishes, which was found beneath a stone in an inch and a half of water with another gunnel close by. When the ova were moved three inches the fish followed and again coiled round them and, although touched, refused to move. Eventually it had to be pushed into deeper water. Meanwhile, the second fish coiled round the eggs and did so again even after they were removed two feet. The eggs were on the point of hatching. Elmhirst (1915) 


\section{THE BIOLOGY OF THE SEA-SHORE}

has watched the spawning of Cottus bubalis in tanks at the Millport Biological Station. At the end of January a female was seen to deposit her eggs on a stone. They were then fertilised by the male who never went more than a few inches away for five or six weeks. During this time no other male was tolerated in the neighbourhood of the stone. Later on, a second female spawned on the same stone and the eggs

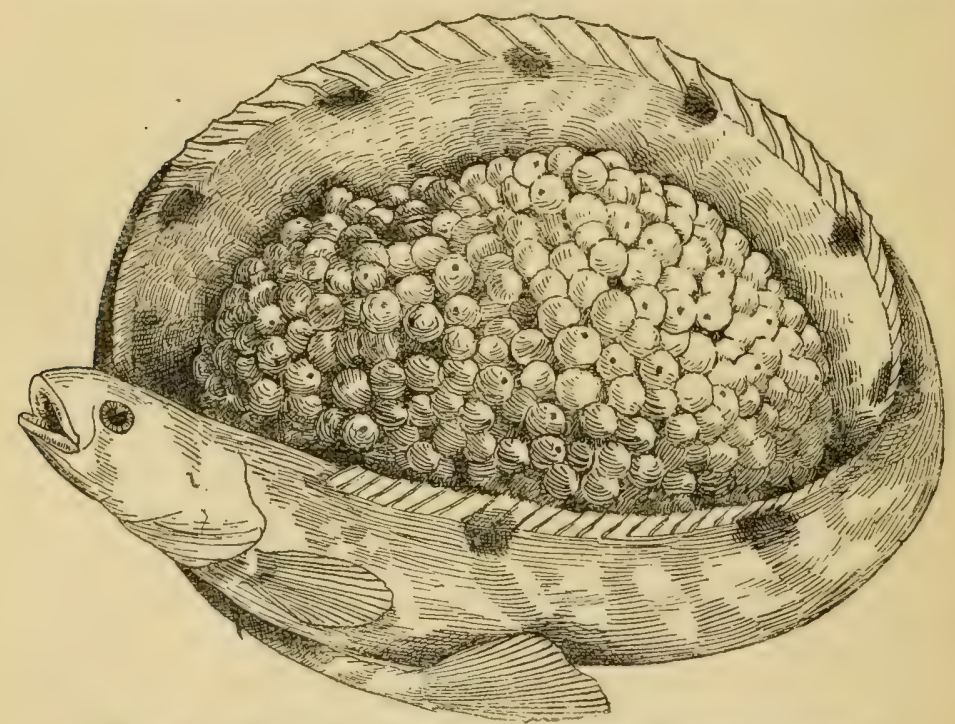

FIG. 15.-Butterfish (Centronotus gunnellus) protecting eggs.

were fertilised. The male was brilliantly coloured and swam about excitedly during fertilisation, several times darting at the female and half engulfing her head in his mouth. Still later a third female laid her eggs on the same stone. All three died a few days after spawning.

In connection with the care of the ova as practised by members of the genus Cottus a case of an interesting kind has been recorded by Meek (I915), in which an immature female of one species ( $G$. bubalis), in a tank, assumed guard over the eggs deposited by a female of a related species ( $C$. scorpius). Apart from this, and from the nest-building forms which we are now about to discuss, other records of 
parental care on the part of shore fishes are on the same lines. In all there is the evidence of some powerful stimulus operating on the parent to keep it in touch with the eggs.

As to how far the presence of the parent is operative in warding off enemies it is not always easy to pronounce. Probably in most cases the habit is concerned rather with the necessity for keeping the eggs aerated than with active protection. The male lumpsucker, for instance, has been observed to keep up a continual motion of the pectoral fins and so maintain a steady flow of water about the eggs, which are laid in such large masses that, without this attention, the central ones might, in still water, easily be asphyxiated. Against this, however, we may place the case of the stickleback which shows itself very active in defence of the eggs, and will boldly attack any intruder however much stronger than itself.

Nest-building.-The habit of nest-building found in the fresh-water stickleback and its marine relative the fifteenspined form as well as in other less familiar shore fishes, evidently represents an elaboration of the habits described above. According to Couch (1877), the nests of the fifteenspined stickleback are placed in sheltered situations where there is ample circulation of pure water without violent wave action. The nests may occur hanging in rock pools and not infrequently between tide-marks where the moisture of the materials is apparently sufficient to protect the grains of spawn from drought. While sometimes making use of the materials found growing on the spot selected, the fish has also been observed to collect some of the softer kinds of green or red seaweeds and to join them together with so much of the coralline tufts growing on the rocks as will afford firmness to the structure and constitute a pear-shaped mass five or six inches long, about the size of a man's fist. The whole structure is held together by a network of threads formed of mucus secreted by the fish, and there is evidence of considerable skill in the way in which these threads are interwoven through the weeds (see Fig. I6). After the ova, 


\section{THE BIOLOGY OF THE SEA-SHORE}

which are of a bright amber colour, are deposited, the male

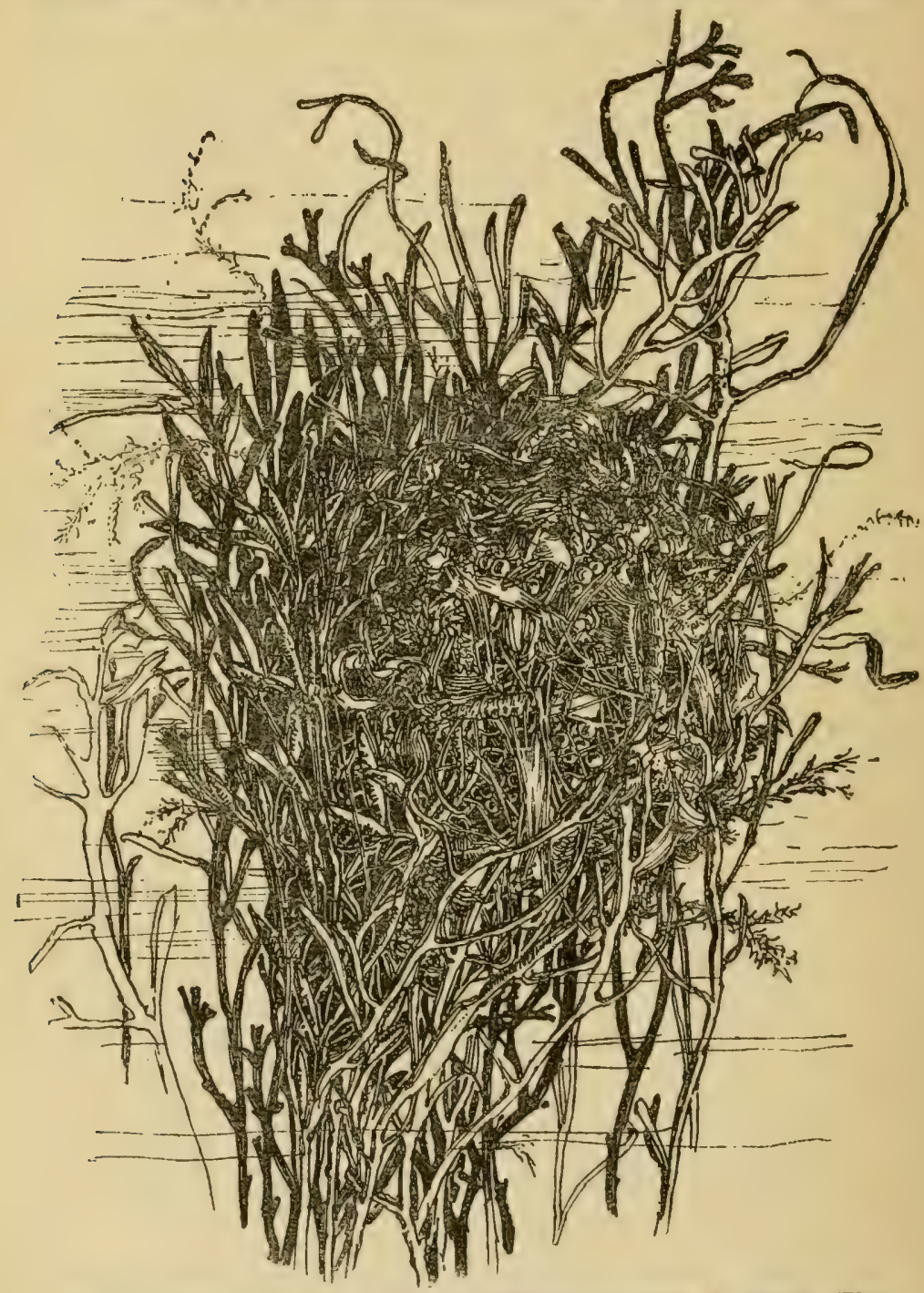

Fig. 16.-Nest of Fifteen-spined Stickleback (from A. Meek, The Migrations of Fish).

remains in attendance on the nest for a period of four to five weeks until the young are able to fend for themselves. 
Any damage to the nest is at once repaired. If compelled to retreat by the falling tide the fish returns as soon as the way is open.

Another interesting nesting form is the so-called "kelpfish" (Heterotrichus rostrata), occurring among the great kelp beds of the shores of S. Carolina, the nest of which has been described by Holder (1907). The fish usually resembles very closely the seaweed on which it lives, except during the breeding season, when the colour of the male becomes much more vivid. A female, in captivity, was seen to examine a bunch of seaweed, pushing her way through it, and passing many times round it, depositing as she went a pure white viscid cord, which clung to the branches and on which were many small white eggs. Then, while the female rested, her mate mounted guard. The whole nest took two hours to complete and formed a globular white mass about the size of a hen's egg.

We will now go on to consider the breeding habits of some of the commoner shore species, beginning with sponges and taking each of the more familiar groups in turn. Before doing so, however, it is necessary to emphasise the many gaps in our knowledge of the reproductive habits of even the commonest shore species. Notwithstanding, for instance, the multitude of Polychæts occurring on the shore, it is only in very few cases that the spawn of these forms, even when quite conspicuous, has been identified with certainty. Again, it is only recently (1920) that Tattersall has cleared up a long-standing mistake with regard to the spawning of the common periwinkle (Littorina littorea), showing that the eggs of this species have long been confounded with those of L. obtusata. Orton has obtained valuable data on the growth rate of a number of marine invertebrates by means of immersing various objects in the sea and subsequently observing and collecting the various kinds of animals growing on them, but it is evident that this is an aspect of shore life which should well repay further study. 
BREEDING AND GROWTH OF SOME COMMON SHORE FORMS

Porifera.-Sponges reproduce both sexually by means of ova and spermatozoa and asexually by one of three methods, viz. budding, gemmulation, and formation of asexual larvæ. In the former case the genital products are found in all stages in the middle gelatinous layer or mesogloea. According to Dendy, in Halichondria panicea the eggs are fertilised in the inhalant canals whither they migrate by amœboid movements and where they become suspended by means of a peduncle. The free-swimming larvæ: minute, oval, ciliated bodies, escape by the osculum. An asexual bud is simply a portion of the parent wall containing the usual three tissue layers which, originating as a small projection, eventually becomes pinched off, floats away, and after fixation gives rise to a new individual. In the simplest sponges the bud is merely one of the Ascon tubes which becomes pinched off and so liberated. In Leucosolenia botryoides the free, distal end of the bud, instead of becoming the osculum as might be expected, forms the base of the young sponge, the osculum being formed where the bud is constricted from the parent.

In Oscarella lobularis the buds are transparent floating bladders, their vesicular nature being regarded as adaptive, as it lessens their specific gravity and enables them to float to a distance from the parent.

Gemmulation is familiar from the well-known case of Spongilla where it is a means of ensuring survival in variable fresh-water conditions, gemmules, like spores, being remarkable for their powers of resistance to adverse surroundings. Gemmules very similar to those of Spongilla are known in a few marine sponges, especially in Suberites and in Ficulina.

In the Hexactinellida, which are deep-sea forms and consequently do not concern us here, the place of sexually produced larvæ is taken by bodies of similar origin to gemmules, but of structure practically identical with that of the larva developed from the fertilised egg. The occurrence of these asexual larvæ may be associated with the difficulties of life in the depths (see Sollas, 1909). 


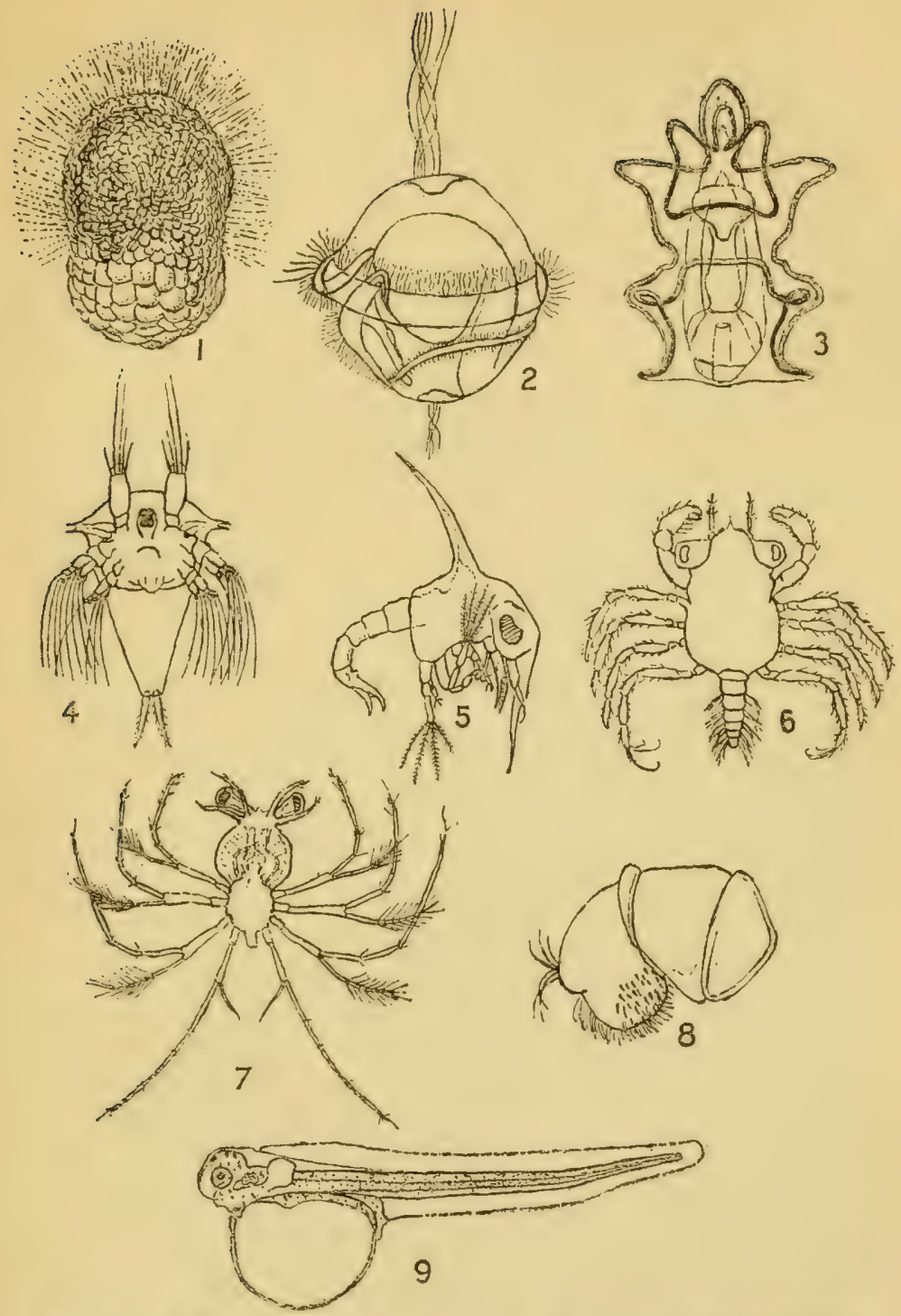

FrG. 17.-Larvæ of common shore animals. I, Blastula stage of Leucosolenia (after Minchin); 2, Trochophore of Polychæt worm (after McBride); 3, Bipinnaria larva of starfish (Asterias rubens); 4, Nauplius larva of barnacle : 5, 6, Zoœa and megalopa stage of common shore crab (after Williamson); 7, Phyllosoma larva (glass-crab) of spiny crayfish; 8 , Veliger of periwinkle, Littorina littorea (after Tattersall); 9, Young flounder. 
At Plymouth, Sycon coronatum, Grantia compressa, and Leucosolenia sp. were found to be annual by Orton (I9I4). This has been confirmed by Dendy for $G$. compressa. According to Orton, there are two breeding seasons at Plymouth, summer and late autumn, and there is evidence that the same individuals may breed twice : once in late summer and again in the summer following, after which they die down. Growth continues through the winter and temperature appears to be the main factor in reproduction.

With regard to the growth rate, an exceptionally fine specimen of Sycon coronatum attained a length of more than $28 \mathrm{cms}$. with an average width of about $2 \cdot 2 \mathrm{cms}$. during a period extending from July to the following May. Between June and the following January a colony of Halichondria panicea grew, on a flat surface, to cover an area of about 45 sq. cms., the thickness of the sponge being about the normal.

Hydrozoa.-The marine members of this class normally occur in two forms : as a fixed asexual colony, the hydrosome or hydroid, and a free-swimming sexual stage, the medusome or medusoid. The actively-swimming medusoid forms an efficient means of distributing the sex-cells, the dangers to which such delicate organisms are exposed being reduced by their liberation during the warm months of the year only, at the season of calms. Hydroid and medusoid are not always equally predominant in the life-history. In several shore forms, e.g. the common Tubularia indivisa, the eggs are produced on the parent stock within structures known as sporosacs, which correspond to the medusoids but are sessile. The eggs ripen within the sporosacs and eventually the young are liberated as free-swimming embryos. The sporosacs may be pendent and naked as in the species above named, clustered at the bases of the tentacles, e.g. Clava squamata, or contained in a special cup or gonotheca, e.g.some Campanularians. Hickson (1906) gives the following table to illustrate the relative importance of the different stages in some common forms. The habitat in each case has been added by ourselves. In these formulæ the fertilised ovum is represented by $\mathrm{O}$, a conspicuous medusome stage by $\mathrm{M}$, 
a conspicuous hydrosome stage by $\mathrm{H}$, an inconspicuous or degenerate hydrosome stage by $\mathrm{h}$, and an inconspicuous or degenerate medusome stage by $\mathrm{m}$.

I. O-H-O- (Hydra) Fresh-water.

2. $\mathrm{O}-\mathrm{H}-\mathrm{m}-\mathrm{O}$ (Sertularia) $\}$ Littoral.

4. $\mathrm{O}-\mathrm{h}-\mathrm{M}-\mathrm{O}$ (Liriope)

5. O-M-M (Geryonia) $\}$ Deep-sea.

From the above table it would appear that, on the whole, the disappearance of the medusoid stage is associated with littoral or fresh-water conditions, and that of the hydroid stage with conditions of life in the deep sea. Plausible enough as this explanation seems it cannot be accepted without qualification, since of two closely related forms like Obelia geniculata and Campanularia flexuosa living under apparently quite similar conditions, one bears sporosacs and the other true medusoids (Newbigin, rgro). The fact of the matter is that the feature of the shore as essentially a transitional area is reflected in the varied means by which shore animals secure survival.

With regard to the growth rate of Hydrozoa, Orton (op. cit.) finds that many species of Cœlentera give off medusæ when not more than a month old. A Tubularian (probably Tubularia larynx) was found to give off actinula larvæ at an age of six weeks, and in one experiment this form had moderately developed gonophores in twenty-six days. As these actinulæ have been found to settle and to grow into polyps within a few days it follows that this species may pass through its life-cycle in six weeks and, if conditions are favourable, a week or fortnight sooner. A raft moored at sea for six weeks was found to be covered with a growth of Obelia geniculata. In Plumularia and Gonothyrae the lifecycle may be completed in three months and probably more quickly still if conditions are favourable. Hence there is little doubt that these hydroids pass through several generations in a year. Most of the Coelenterate species investigated by Orton appear to have a maximum rate of growth in the months of August and September. 
Anthozoa.-Though a good many anemones may reproduce asexually by a process of fission, e.g. Metridium (Actino$l o b a)$, the sexual method is more common. In some anemones a curious form of asexual reproduction occurs known as "pedal laceration." In the common British Metridium, for instance, a favourite aquarium species, "the pedal disc sometimes spreads on the glass or rock upon which the animal rests, in the form of a thin membrane or film of an irregular circular shape, nearly twice the diameter of the column. As the anemone glides along, the film remains behind and breaks up into a number of hemispherical droplets, which in a few days develop tentacles, a mouth, mesenteries, and other organs of a complete independent anemone. A similar method of reproduction has been observed in several species of Sagartia." (Hickson, op. cit.)

As in the case of most sessile animals, anemones are hermaphrodite forms and fertilisation may take place either externally (Actinoloba marginata, $A$. dianthus, Sagartia sps. Actinia cari, Anemonia sulcata, Calliactis parasitica) or internally (Bunodes sps. Cereactis aurantiaca, Sagartia troglodytes, Bunodactis gemmacea, etc.). Where fertilisation takes place in the water the early larvæ are oval or pear-shaped and covered with cilia. Their further development depends on their finding a suitable place for fixation within a comparatively short time. Where fertilisation takes place internally the embryos are sometimes retained within the body cavity of the parent to an advanced stage, the length of time depending upon the risks to which the young are likely to be exposed. Thus, in Arctic species, the embryos are retained within the body until several cycles of tentacles are developed or even the full complement. The common British species, Actinia equina, also liberates what are practically young adults, though the incubation period is said not to be so prolonged as in the same species in the tropics.

The gonads of British species usually ripen in spring or summer; but aquarium specimens, if regularly fed, will reproduce all the year round.

Anemones are an unusually long-lived group, at least 
so far as can be judged from aquarium specimens. Dalyell kept a specimen of Actinia mesembryanthemum for sixty-six years and specimens are still living which are known to be almost as old. Orton (op. cit.) found that a specimen of Sagartia viduata attained full size at a maximum age of fourteen to fifteen months.

Echinoderms.-The forms whose habits are of most interest to us are the two starfishes Asterias muilleri and Cribrella sanguinolenta. Both these forms, which occur under stones in pools between tide-marks, carry their eggs in pouches over the mouth, and hatch them there. Larval starfishes are plentiful in summer and autumn. The commonest form, Asterias rubens, spawns in November at St. Andrews, and may then be found grasping the ova in the same curious stool-like position which is adopted when devouring molluscs (M'Intosh, 1874, and see Plate XI).

Annelida.-With few exceptions Polychrta are unisexual and oviparous. The common Nereis diversicolor has frequently been stated to be hermaphrodite, but $\mathrm{M}$ 'Intosh (1907) considers there is no foundation either for this statement or for another which is frequently made about this species, namely, that it is viviparous. Masses of clayey mud, for instance, brought from the habitat of this worm at St. Andrews showed many free ova.

In the majority of cases the eggs are pelagic, but in others they are demersal and surrounded by a layer of protective jelly which is said to serve as food for the young larvæ, e.g. Aricia, Ophelia, Phyllodoce (Benham, 1896). In some Polynoids the eggs undergo part of their development attached to the body of the parent beneath the scales or, in the case of certain Syllids, attached to the ventral cirri. This tendency towards a greater provision for the offspring is most pronounced in Autolytus (Sacconereis), where the eggs develop within a ventrally-placed brood sac formed by the hardening of a secretion. The young are liberated at an advanced stage, being provided with head appendages and three pairs of parapodia. As many as 300 embryos were counted in a brood sac of Autolytus ebiensis (Benham, loc. cit.). The eggs 


\section{THE BIOLOGY OF THE SEA-SHORE}

of tubicolous worms are frequently attached to the tube, either inside or outside-a distinct advantage. According to Leschke (1903), the eggs of Terebella zostericola and of Terebellides strœemi are laid in a mucous mass attached to seaweed or to the mouth of the tube. In Spirorbis the modified gill-filament which acts as an operculum to the tube is grooved on one side and serves as a brood pouch (cf. p. 62).

It is well known that several species of Nereis undergo very considerable modification at the breeding season. The changes affect mainly the parapodia, which become flattened and oar-like, and their chætæ and to a certain extent other organs as well. These changes are evidently related to the pelagic habits which the worm (now called a Heteronereis) adopts at this period, and ensure a wider distribution of the sex cells than is possible to a bottom-living form. It is only the posterior segments, containing the gonads, that become modified; the anterior segments remain unchanged.

A similar change takes place in Syllids; moreover, some of the members of this family are further remarkable owing to the fact that the hinder genital region of the body becomes separated off, on maturity, from the anterior non-sexual region (Benham, $o p$. cit.). The original worm thus becomes separated into a sexual and a non-sexual portion (schizogamy) the former of which grows a head and the latter regenerates a tail and again becomes sexual. In the simplest form of this phenomenon, the growth of the new head and tail takes place after the fission has occurred, but in some cases the regeneration of the new portions may take place before the separation, so that the original animal now consists of two complete worms. Further, a narrow neck of proliferating tissue may make its appearance in front and, becoming very active, may bud off a number of new worms, all of which become sexual. In this way, a chain of as many as sixteen worms may be formed, e.g. Autolytus (Benham, loc. cit.). The worms formed from a particular parent "stock" are all of the same sex as that stock. Moreover, the difference between male and female worms is so great as to cause 
considerable difficulty to those working out the different life-histories.

Among Polychæts the forms known as "Palolo worms," which live in crevices of rock or of coral reef, are remarkable for their habit of swarming at the period of reproduction. The first of these worms to attract attention was the Pacific species Eunice viridis, but others with the same habit are the Atlantic Palolo (Eunice fucata) and the Japanese form (Nereis japonica). These forms agree in showing at the time of swarming two distinct body regions, one of which contains the reproductive elements. In each species the swarming takes place every year with the utmost regularity in the same month or months, at the same particular phase of the moon. During the swarming the sexual portion breaks off and carries away the sex products. So extraordinarily numerous are the worms constituting the swarms that to a Japanese observer they appeared to cover the whole surface " as with a sheet" (Akira Izuka, 1908 ; and for the breeding habits of the Atlantic Palolo, see Mayer, 1908).

Several species of Polychæts deposit ova surrounded by a mass of jelly. Such cocoons, which are demersal, are frequently encountered in rock pools between tide-marks, and yet considerable doubt still exists as to the precise species to which they belong. The eggs of Phyllodoce are green in colour and are enveloped in a spherical mass of gelatinous material secreted by the skin of the worm. M'Intosh (I908) has observed them in May, and further states that the ripe male is distinguished by the pale yellow hue of the body. Ashworth (1904) states with regard to the lug-worm that " in spite of the abundance in innumerable places of the adult worm, and of much searching by many workers, the egg masses of Arenicola have never been found on the coast of Europe." Various writers, however, have brought forward a considerable amount of circumstantial evidence as to the relation of certain globular masses of green spawn to Arenicola. Hornell (I89r) has found large, green, pear-shaped egg-masses associated with the 
sandy coils of Arenicola on the 2nd March, the stalk of the cocoon passing 2 or 3 inches into the sand. $M^{\prime}$ Intosh (1915) states that numerous pale green gelatinous masses about the size of a gooseberry were found by fishermen digging for lug-worms on the 3 rd of May; they usually had a strand of mucus at one end. Williamson (I9I6) has kept a number of Arenicola in captivity and has obtained several green capsules which, however, appeared somewhat smaller than those usually found on the beach. The spawn, with one or two trailing strands of mucus, was found adhering to the sides of the box, which seemed to indicate that the worms were swimming about during oviposition.

The cocoons of Scoloplos armiger have been found by Hornell (op. cit.) in close proximity to the adult worm, on a sandy beach at Egremont (2nd March), and by Cunningham and Ramage (1888) in the estuary of the Forth (February). According to the first-named writer, they are small, gelatinous, pear-shaped and brownish in colour, smaller than the green masses of Arenicola, and are anchored amongst the bare ripple-furrows of the sand, the cylindrical stalk descending two or three inches into the sand. Cunningham and Ramage describe them as gelatinous and transparent with opaque white eggs and embryos. Garstang gives February as the breeding season for this species at Plymouth.

Oviposition in Ophelia radiata has been observed by Cosmovici (quoted by $\mathrm{M}^{\circ}$ Intosh, 1915); $O$. limacina is not uncommon near low-water mark on British shores, and no doubt the spawning habits of the two species are not very dissimilar. The animals first envelop themselves in a mass of sticky mucus within which the eggs are deposited. The animal next withdraws, leaving a rounded mass with a long tubular process. In Spio the spawn forms a flattened tubular mass, 10-16 mm. in length, with a delicate envelope. The eggs are in one layer or in several layers, each layer with about a dozen longitudinal rows. Their colour is from yellowish white to slightly orange.

Orton (op. cit.) has obtained a good deal of material with regard to the growth rate of various Annelids, especially 


\section{REPRODUCTION AND GROWTH}

of the sedentary Polychæts: Pomatoceros triqueter and Hydroides norvegica attain nearly full size in about four months and are then sexually mature; Polymnia, Daschyone, and many others have attained a good size in considerably less than a year; Serpula vernicularis was found to be sexually mature at not more than ten months old; Sabella pavonina formed a tube $12^{\circ} 6 \mathrm{cms}$. long in less than thirty-one weeks, and at this age contained well-developed but not quite mature ova.

Crustacea.-Perhaps the most characteristic feature of the breeding of shore Crustacea is the long period of incubation, during which the eggs are carried about by the female. In the Copepods, the commonest shore representatives of which belong to the Cyclopidæ and Harpactidæ, the eggs are carried in sacs, usually paired and placed at the sides of the abdomen. These sacs are easily seen if females of the above-mentioned families are collected from among the algæ of shore pools and examined under the microscope. The habit of carrying the eggs about is no doubt an adaptation to shore conditions, and is also seen in fresh-water species of Copepods.

In the higher Crustacea (i.e. Decapoda) the eggs are usually attached by a sticky material to the swimmerets of the female, but in the Stomatopoda they are carried by the female in a temporary chamber formed by the apposition of the large maxillipeds.

The sexes are separate, except in sessile and parasitic forms, which follow the usual rule in such cases and are hermaphrodite. The chief types of larvæ are the Nauplius and Cypris, characteristic of the Entomostraca, and usually associated in the same life-history; and the Zoœa and Megalopa, confined to the Malacostraca, also consecutive stages of a single life-history. The larval stage, however, may be considerably abbreviated, when the young animal, which differs from the adult only in points of detail, is known as a Mysis (e.g. lobster). As a curious modification of the Mysis we have the Phyllosoma larva of the spiny crayfish (see Fig. 17). 


\section{THE BIOLOGY OF THE SEA-SHORE}

Cirripedes.-As hinted already, both the sedentary rock barnacles and the parasitic Sacculina are hermaphrodite species. The young barnacle is hatched as a Nauplius, passes after a short period into a Cypris stage and eventually fixes itself head downwards by means of a cementing substance secreted by the first antennæ. According to Orton (op. cit.), Balamus balanoides attains to full size in a year and gives off large numbers of nauplii at this age, but there does not seem to be more than one breeding season, namely, in the late winter months.

Sacculina, the adult of which is little more than a bag of gonads, is also hatched as a typical Nauplius except for the absence of an alimentary canal. It passes into a Cypris stage, the larva after a period of free existence grappling on to a hair on the crab's body by means of hooks on its antennæ. The commonest species in this country is $S$. carcini parasitic on C. moenas; S. neglecta on Inachus mauritanicus is frequent in the Mediterranean (Naples).

Decapoda.-A considerable amount of knowledge has been amassed with regard to the development of species of Decapoda of economic value (Herrick, I895, Williamson, 1904, Pearson, 1908, etc.). We are only able to notice here the very broadest features; details can be sought in the literature above mentioned.

According to Pearson (1908), fertilisation of Cancer pagurus takes place in the inshore waters during late summer and autumn and is effected immediately after the female has cast. The spermatozoa remain in the openings of the oviducts or spermathecæe and the eggs are fertilised during extrusion. The one supply of sperms is probably sufficient for two or even three successive batches of eggs.

The larvæ of the Galatheidæ, which include the familiar "hermit lobster" (Galathea), and the porcelain crabs (Porcellana platycheles and P. longicornis), are distinguished by the enormous length of the spines upon the carapace, regarded by some as an adaptive feature which renders their ingestion by enemies a matter of difficulty.

Hermit crabs pass through a zoœa stage and a stage 
equivalent to a megalopa. The former differs from that of the Galatheidæ in the absence of the long spines.

Among the Brachyura generally the following larval stages may be distinguished: Protozoœa, Zoœa (4 kinds), Megalopa (Pearson, loc. cit.). The general appearance of Zowa and Megalopa can be seen from the illustrations (Plates III and XIV). The Protozoœa differs from the later zoœa only in the absence of the spines on the carapace.

The larva of the lobster (Homarus vulgaris) is a Mysis, that is to say, it is very much like the adult except that the thoracic limbs are biramous. After five or six months of a free-swimming existence during which it moults 4-5 times, the animal, now exactly like the parent except for $\operatorname{size}\left(\frac{1}{2} \mathrm{inch}\right)$, sinks to the bottom. The breeding season of the lobster extends over July and August. A female lobster begins to lay when she is a! out eight inches in length, the number of eggs produced increasing up to about 180,000 at eighteen inches, after which there is a gradual decrease.

Like that of the lobster, the metamorphosis of prawns and shrimps is greatly abbreviated, the larva hatching out at a late zoœa stage (almost a Mysis). According to Monaghan (IgI4), the time of maximum spawning of the shrimp (Crangon vulgaris) for the Lancashire coast is about April roth.

The larva of the spiny crayfish (Palinurus), which takes the place of the lobster on Mediterranean coasts, is known as a Phyllosoma and is characterised by its leaf-like body and flattened appendages. It may be regarded as a greatly modified Mysis stage. Lovett (IgOr) remarks that while the spiny lobster Palinurus quadricornis carries enormous numbers of ova of very small size in proportion to the parent, Callianassa subterranea produces ova which, though large, are few in number. As, however, the latter species is greatly protected by living underneath the sand such disparity is accounted for.

Amphipoda and Isopoda.-Sex-union in this group, particularly the former, may be readily observed, the male carrying the smaller female beneath him by means of the anterior thoracic legs for a considerable period (several days). 
The number of eggs laid at one time is not large and they are carried about by the female in the brood pouch. According to Hewitt (1907), the ova of Ligia oceanica are large, oval in shape, and contain a large amount of yolk.

Growth of Crustacea.-Orton (op. cit.) has made use of an ingenious method for determining the growthrate of some Crustacean forms. A wire basket of small mesh is lowered in the sea and is entered by such young animals as are small enough to pass through the narrow mesh. Some of these remain and, feeding on the natural growth which accumulates on the basket, increase in size and so are trapped. From an experiment of this kind Orton concludes, for instance, that the prawn (Palcmon serratus) becomes mature and carries eggs within a year, and that the common shore crab, Carcimus monas, also attains maturity within a similar period.

The fact that many Crustacea are in process of transition from an aquatic to a terrestrial life lends particular interest to their reproductive habits. These show an interesting analogy with the habits of Amphibia, inasmuch as while the adult animal may be essentially terrestrial a return must be made to the original habitat for breeding purposes.

Crabs of the genus Geocarcinus, which live in sheltered situations several miles from the sea, are said to make their way in spring in immense numbers to the sea-shore where breeding and spawning take place (Smith and Welldon, I909). A return migration occurs when this is completed. The young pass through the normal larval stages in the sea and then migrate inland. A similar return to the sea for breeding purposes is also necessary in the case of the robber crab (Birgus latro).

Other genera whose members are in process of gaining a place on the land are Ocypoda and Gelasimus.

Molluscs.-The sexes may be either separate as in most Pelecypods, Mytilus, Cardium, etc., and nearly all Prosobranchiata, e.g. Patella, Acmea, Fissurella, Haliotis, Trochus, Neritina, Natica, Littorina, Rissoa, Hydrobia, Nassa, etc., or united as in Opisthobranchiata and Pulmonata, e.g. Bulla, 


\section{PLATE XIV}

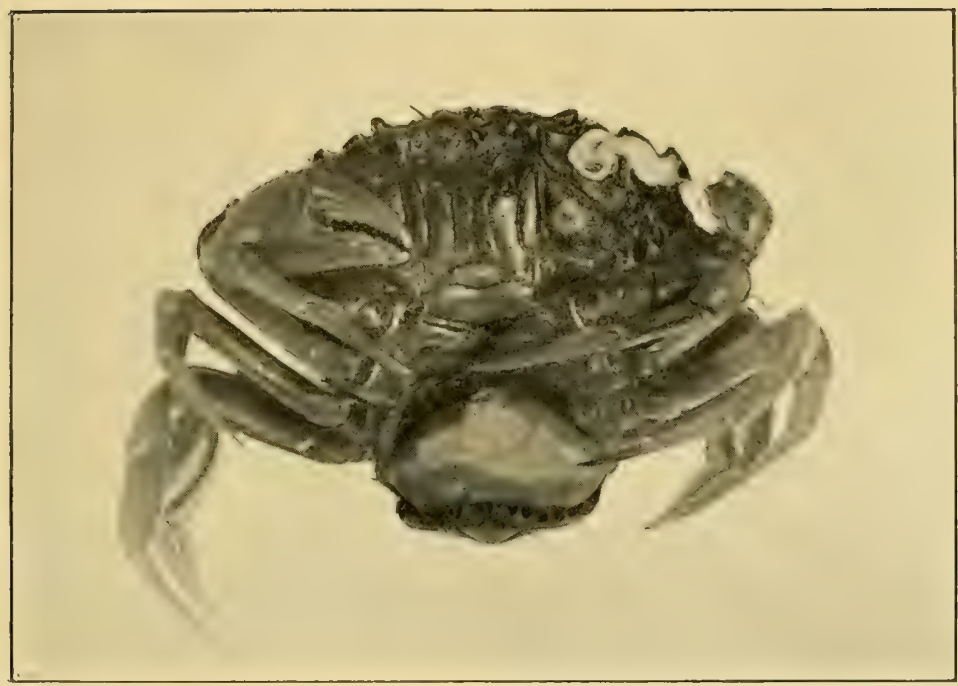

I.-Common Shore Crab Parasitised by Sacculina.

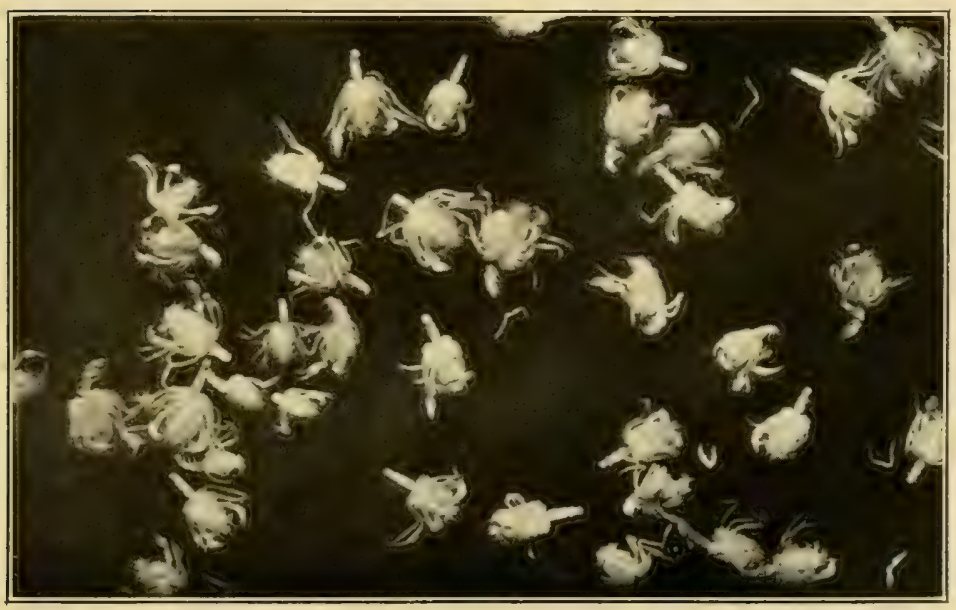

II.-Megalopa Larve of Shore Crab. 

Acera, Philine, Aplysia, and Nudibranchs generally. In the great majority of shore molluscs the young are hatched as free-swimming larvæ, but a small number of forms are viviparous (e.g. L. rudis and $L$. neritoides).

Gasteropods.-The tendency to abbreviate the larval period in Littorinas in relation to the position occupied on the shore has already been noticed. The life-history of three common species of Littorina has been worked out by Tattersall (op. cit.), from whose paper the following details are taken. The eggs of Littorina littorea are pink in colour and are enclosed, usually singly or in pairs, in small transparent capsules shaped like a soldier's "tin" hat, with the eggs lying in the crown (see Fig. 18). The diameter of the capsules varies from $6 \mathrm{~mm}$. to $9 \mathrm{~mm}$., that of the eggs themselves from ${ }^{1} 15 \mathrm{~mm}$. to $16 \mathrm{~mm}$. Instead of adhering in masses which are attached to weeds, etc., as in Nudibranchs, for example, the capsules are separate and are laid freely on the sea-shore, where they have been found in numbers by Tattersall among the fine shore deposit at low-water. The larva hatches as an early veliger and the pelagic life is prolonged. The total number of eggs a single female may deposit is estimated roughly at about 5000. Oviposition may proceed intermittently for a month or more, the original act of copulation sufficing for the whole of the eggs laid.

As contrasted with that of $L$. littorea the life-history of $L$. obtusata presents the following characteristics: (I) the egg capsules are aggregated in masses and attached to weeds ; (2) the early veliger stage is suppressed and the egg hatches as a fully formed veliger larva ; (3) the free-swimming larval life is much abbreviated. As already pointed out, Littorina neritoides is viviparous.

The Trochidæ deposit their eggs on the under side of stones and on seaweed; each ovum is contained in a separate capsule and the capsules may be either all glued together into an irregular mass of varying size or be deposited separately. According to Robert (Igor), agglomerated spawn is formed by $T r$. granulatus, Tr. striatus, Tr. conuloides, Tr. exasperatus, while $\operatorname{Tr}$. magus, $T r$. cinerarius, $T r$. crassus lay their eggs singly. 
Carnivorous Gasteropods deposit their eggs in stout, leathery capsules which often fuse in various ways so as to give a characteristic appearance to the spawn of particular species. Each capsule contains a varying number of ova, and there is competition among the embryos within the capsule, the stronger eating the weaker, so that only a very small percentage survive. A similar struggle, it will be remembered, takes place within the cocoon of the earthworm. The egg-capsules of Purpura are among the most familiar objects of a rocky shore. In appearance they are like small cereal grains, somewhat pinkish in colour, and they are laid in groups attached by short stalks to the rock surface. A single Purpura has been observed to produce 245 capsules (Cooke, 1895). Equally well known are the egg cases of the common whelk or "buckie" (Buccimum undatum). The specimens of these so often found lying on the shore at or above high-tide mark are, of course, no longer living. The capsules of Fulgur (Busycon) resemble rolls of coins attached at equal distances to a long string (nearly 3 feet) ; Murex deposits clusters of from 15 to 150 triangular capsules, each with a short stalk, and there are said to be about 20 ova in each capsule. Allied species may have very different forms of spawn. Thus the egg capsules of Nassa reticulata, which are fastened in rows to the leaves of Zostera, are shaped like flattened pouches with a short stalk, while those of $N$. incrassata are solitary and shaped like rounded oilflasks (Cooke, loc. cit.).

The manner of formation of the egg capsules of carnivorous sea-snails has been described by Cunningham (1899), who saw that the spawn was formed and deposited by the foot. The sole-gland is thus really the nidamental gland, and the ova are probably transferred to its cavity before closure and deposition of the capsule.

The eggs of Natica are laid in a coiled sheet held together by copious mucus in which numerous sand-grains are entangled, the spawn thus resembling a thick sheet of sand-paper (see Fig. I8).

Nudibranchs.-The spawning of littoral species of 


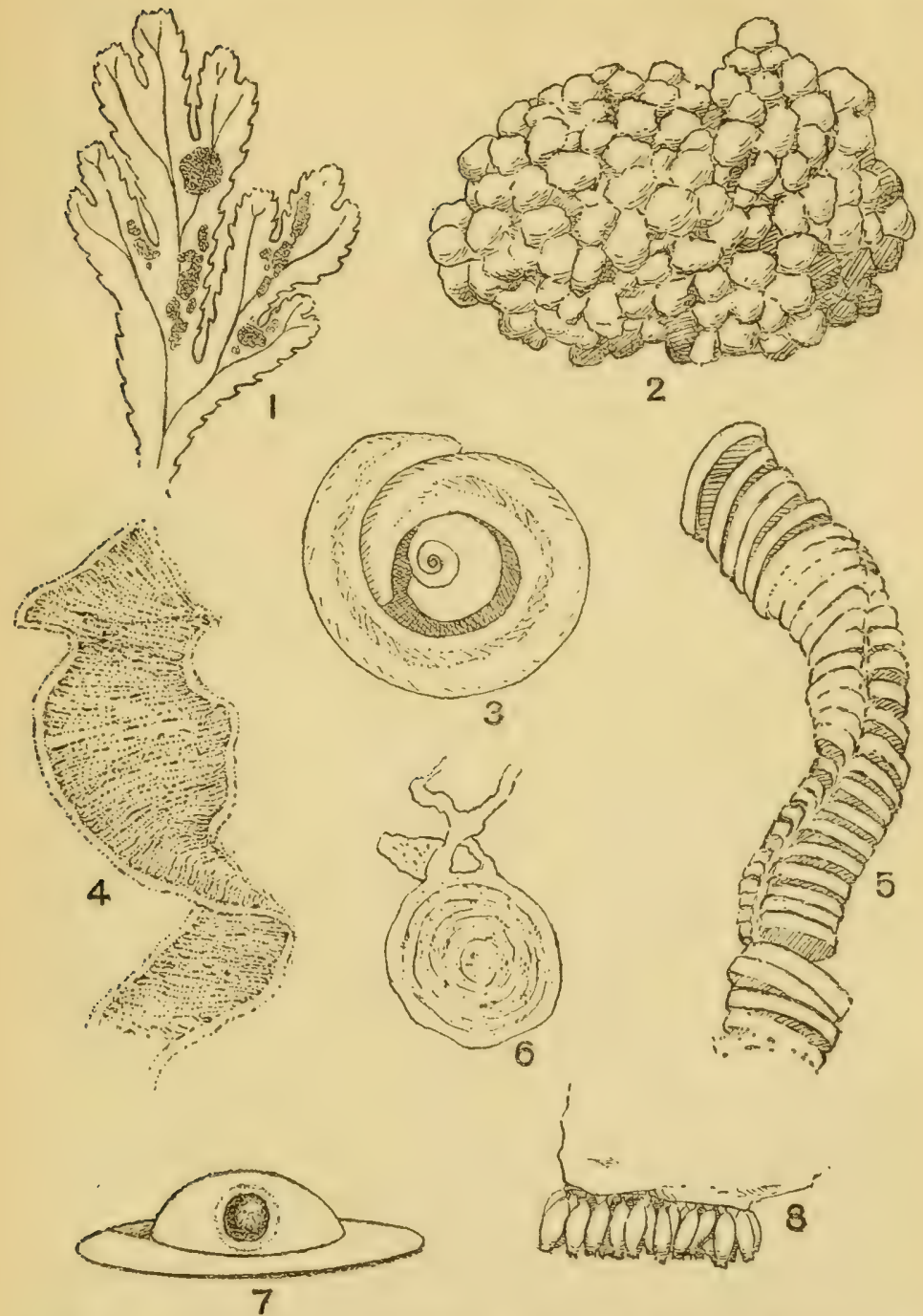

Fig. 18.--Spawn of shore animals. I, Spawn of Littorina obtusata on Fucus serratus; 2, Egg-cases of whelk (Buccinum undatum); 3, Spawn of Natica; 4, Egg-ribbon of Dorid; 5, Egg-cases of Fulgur; 6, Spawn of Polychæt ; 7, Egg and capsule of Littorina littorea (after Tattersall); 8, Egg capsules of Purpura lapillus. 
Nudibranchs has been extensively studied by Eliot (op. cit.), from whose valuable monograph most of the following details are taken.

No elaborate precautions are taken by this family of molluscs to conceal their eggs, a circumstance which is probably amply compensated by their enormous fecundity, as noted earlier in this chapter. Sometimes the strings or ribbons containing the eggs are left in conspicuous positions ; sometimes they are placed in surroundings where they are not noticeable or in sheltered nooks such as the under side of rocky ledges. But in all cases the eggs are enclosed in some sort of case.

The simplest form of egg-case is a rounded capsule such as that laid by the Limapontiidæ; Galvina exigua hangs oval masses of bright white on seaweed; Tergipes despectus deposits its eggs in kidney-shaped capsules.

Many small Æolids, e.g. Amphorina aurantiaca and A. olivacea, deposit spawn in a single imperfect coil, roughly crescentic in shape, and the spawn of some Polycerids, e.g. Polycera quadrilineata and Ancula cristata, is much the same. Other genera, however, both of E⿰olids and Dorids, produce more complicated patterns. The spawn may be a simple string, or a ribbon with eggs collected along one margin, which may also be described as a string attached to its support by a membrane along its entire length. In arrangement, the string or ribbon may be hung in an irregular festoon on seaweed or arranged on a flat surface, sometimes in the shape of a cup with the margin turned outwards (Acanthodoris pilosa), or more frequently in a spiral of varying completeness and complexity; Lamellidoris bilamellata lays a short spiral of one or at most two coils. The eggs of Archidoris tuberculata, perhaps the commonest shore Nudibranch, are laid in a large triple coil, according to Eliot, some I 5 inches long. Colgan (I9I4) states that four coils taken at Bullock and Dalkey Island in April, 1914, were, when opened out, $32,28 \frac{1}{2}$, and 17 inches long respectively, the breadth being from $\frac{3}{4}$ inch to $1 \frac{1}{3}$ inches. The number of ova in the largest was calculated at 645,000 . Darwin (Voyage of 
the Beagle, ch. ix., footnote) calculated 600,000 eggs for a ribbon 20 inches long of a Falkland Island Dorid.

The spawn of Jorunna johnstoni is in a spiral of four coils with gracefully scalloped margins while that of Lamellidoris inconspicua and $L$. depressa is a simple but extensive spiral of 7 to ro whorls.

In many Æolids (Coryphella, Facelina, EEolidia, also Antiopella) the spawn is not only arranged in a spiral, but the ribbon itself is zigzagged in its spiral course ; Cumanotus suspends a single cork-screw shaped coil by a long thread.

The forms of Nudibranch spawn are so distinctive that recognition is easy. 'Those of members of the same genera and families have generally speaking the same pattern (cf. carnivorous Gasteropods). Kindred species may, however, show very different degrees of elaboration in their work ( $e . g$. Lamellidoris bilamellata and L. depressa).

Dorids with wide mantle margins are best adapted to produce broad, flat ribbons because the egg-jelly is compressed between foot and mantle and the undulations of the edges of the ribbon, when they exist, are the counterpart of the undulations of the mantle margin. On the other hand, as we have seen, small animals, without any mantle, such as the Limapontiidæe, merely deposit short capsules.

The egg-ribbon may be said to be composed of three parts, as follows :-

(I) General envelope enclosing all the eggs.

(2) One or more envelopes enclosing groups of eggs in strings or patterns.

(3) Attachment jelly, which fixes the whole structure to its support.

Bolot, quoted by Eliot (loc. cit.), has given an interesting account of the method of extrusion of the egg-ribbon in Dorids. "The ribbon as it issues is soft and adhesive but soon hardens in water. The Dorid attaches one end to a suitable spot and then begins to move slowly, thus aiding the exit of the ribbon by pulling against the fixed point. But the emergence of the ribbon is also due to an 


\section{THE BIOLOGY OF THE SEA-SHORE}

intrinsic movement caused by a pulsating vesicle situated at the opening of the oviduct, which partly surrounds the ribbon and throbs rhythmically as it slowly pays the latter out (according to Trinchese and Hecht, the number of pulsations is from 24 to 56 per minute). In Doris tuberculata the rate of spawning is a little more than $\frac{1}{2}$ inch per hour. (A specimen at Plymouth laid 15 inches in 24 hours.) The ribbon passes backwards on the right side of the animal between the mantle and the foot and thus receives a curve along the whole of its length, the concave side facing outwards. The edge which lies nearest to the foot is attached to the rock, and the curl of the spiral is counter-clockwise (occasionally clockwise)."

While the spawn of British species is nearly always white (at most tinged with rose or yellow), that of tropical Dorids is deposited in very beautiful red or violet spirals which look like flowers.

Eliot puts the duration of life of these molluscs at about a year. The young are hatched as veligers in spring or summer (England) and can reach their full size, as animals from 2 to 3 inches long, in less than twelve months. In the experiment made by Orton already referred to, a raft moored at sea for six weeks was found to be covered with a growth of Obelia geniculata on which adult Nudibranchs, chiefly Galvina picta, were feeding. Masses of spawn belonging to this species were found and from these freeswimming veligers were given off. Orton concludes that these Nudibranchs had peopled the raft as veligers, rushed through their development at the expense of the hydroids, and were giving off veligers again to populate hydroids elsewhere within a period of not less than six weeks and two days :

The spawning habits of several species of shore bivalves have been extensively studied and are of considerable commercial importance, but from our particular point of view they show no features of outstanding interest beyond the fact that they are all enormously fecund. The common Oyster (Ostraa edulis) produces from 600,000 to I, 800,000 
eggs, while a large American Oyster has been computed to contain more than 100,000,000 ova (Woodward, I9I3). There is, however, a point in connection with the growth of forms such as the oyster, mussel, and cockle which deserves notice. As the animal increases in size, the shell, of course, is enlarged pari passu by the addition of successive areas of lime secreted by the edge of the mantle. From an examination of these "growth" lines and from the general appearance of the shell a considerable amount of information can be gained as to the age of the molluscs and the suitability or not of the conditions in which the animal has been growing. Mussels which, owing to unsuitable conditions of temperature, food, or salinity, remain small and stunted in size will, when transplanted to suitable areas, grow to marketable size in a very short time.

Fishes.-Shore fishes are not particularly fecund but the comparatively small number of ova produced is perhaps compensated by the care which is bestowed on them by the parents. Notwithstanding parental care, however, the mortality among eggs and young is very great. M'Intosh (I9OI), in fact, considers that no group of marine fishes is better fitted for demonstrating the great losses which ensue between the period of the deposition of the ova and the adult condition than the littoral fishes, such as the Shanny, Cottus, Gunnel, and even Viviparous Blenny. To take the Shanny, for instance : notwithstanding the fact that the adult females deposit a considerable number of eggs in small rocky caverns, and that the young while still more or less pelagic abound in the rock pools in August and September, yet frequently only a single adult is encountered in a shore pool. This decrease in numbers $\mathrm{M}$ 'Intosh attributes not so much to the fish becoming spread out in the ocean or to their taking advantage of new sites among the rocks, as to the onslaught of predatory neighbours.

A similar disproportion is observable between the numbers of young (eggs or larvæ) and of adults of most shore fishes. The demersal eggs of the short spined Cottus (Cottus scorpius) are said by M'Intosh (loc. cit.) to be a 
favourite food of many fishes and of certain birds, so that destruction begins early in the life-history. Nor, according to the same writer, do the gaudy coloration and protective spines of the larvæ prevent a serious reduction in their numbers, so that the contrast between the crowds of young and the comparatively few adults is noteworthy.

The spawning season for shore fishes extends from early spring to summer. It is not possible to give accurate descriptions of the ova of the different species without entering into details as to their size and microscopic appearance, etc., which are beyond the scope of this work. We shall therefore content ourselves with noting such features as are likely to interest the general reader.

The eggs of the bullhead or "father lasher" (Cottus scorpius) form large masses of dark red or pinkish colour attached to the rocks, stones, or Laminaria between tidemarks.

Of all shore frequenting fishes the lumpsucker (Cyclopterus lumpus) would seem to be the most fecund. Day (I880-1884) quotes the statement of Johnston that the spawn of a single female will fill a large basin, and gives Bloch's figures of 207,000 eggs for a $6 \frac{1}{2} \mathrm{lb}$. fish. The eggs, as already noticed, are looked after by the male, who keeps a current of water circulating through the mass by means of his pectoral fins. Cunningham (I888) has taken masses of Cyclopterus spawn from rocks near low-water mark at St. Andrews during January and February. The colour of the eggs varies from red to pale yellow or nearly white. The young Cyclopterus are very common among the algæ on any rocky shore and are easily recognised by their tadpolelike appearance and modified pelvic fins.

A favourite spot for the deposition of spawn is an old bivalve shell: that of Lepadogaster bimaculatus, another form with pelvic fins modified as a sucker, is described by Cunningham (loc. cit.) as being invariably found adhering to the inner surface of the shells of Pecten opercularis, where it is guarded by at least one of the parents. Another writer, Hefford (I910), has taken a spent female of $L$. bimaculatus 
in a Lutraria valve within which a batch of eggs had been deposited but had disappeared, leaving traces of their former presence in the shape of oval impressions. Occupying the same shell was the Nudibranch Calma glaucoides (which had first spawned) and the observer thinks it almost certain that the fish eggs had been devoured by the Nudibranch, which has been recorded as commonly associated with goby and blenny eggs and varying in colour so as to resemble the eggs which it apparently preys upon.

Of the several species of goby frequenting our coasts, the rock-goby, Gobius paganellus, is the one most frequently encountered, being usually abundant among rock pools and under stones between tide-marks. Breeding takes place in spring, and the ova, regularly fusiform in shape with pointed apex, are most commonly laid on the under side of an overhanging rock or stone and there guarded by the mate until they hatch; any suitable shelter, however, such as a shell or old tin, probably serves for breeding purposes (Holt and Byrne, Ig0I).

Another species, Gobius ruthensparri, is frequent among beds of Laminaria and Zostera. The breeding season extends from April to August, during which period there is a constant succession of broods. The eggs are pear-shaped with a somewhat pointed apex, and seem to be laid upon any sheltered and fairly smooth surface, e.g. inside the "bulbs" of Laminaria bulbosa (Holt and Byrne, loc. cit.).

Other gobies with more or less similar breeding habits are found frequenting estuaries, e.g. the black goby ( $G$. niger) and the common or freckled goby ( $G$. mimutus). A notable feature in the breeding of these gobies, apart from the care of the ova by the male, is the fighting between rival males, which in the case of the last-named species at least is said to be so furious as not infrequently to result in the death of the weaker fish, though perhaps as much from exhaustion as from wounds (Holt and Byrne, loc. cit.).

The eggs of the gunnel have already been noticed; those of its relative the Shanny (Blennius pholis) are ovoid in shape with flattened under side (Hefford, $o p$. cit.), and are attached 


\section{0}

\section{THE BIOLOGY OF THE SEA-SHORE}

to stones, where they are accompanied by one of the parents, or, according to Day, to the upper surface of small caverns in the rock. The frequent occurrence of the Nudibranch Calma glaucoides in the neighbourhood of the eggs of goby and shanny has already been remarked.

The Five-bearded Rockling, Motella mustela, is exceptional among shore fishes, inasmuch as its eggs are pelagic. This is all the more surprising since the adults are typically tidal forms and seldom, according to M'Intosh (IgOI, loc. cit.), extend far seaward. Though the eggs are numerous, the adults only occur sparingly among rock pools, so that it is difficult to say which of the two methods, the deposit of a restricted number of demersal eggs which are carefully watched, or the random liberation of large numbers of pelagic eggs, is the more advantageous to the species. Certainly the former method is much the more common in the littoral area.

Retrospect.-The main facts which emerge from the foregoing survey are as follows :

(a) The spawn of shore forms is frequently attached and protected by some form of horny or gelatinous investment.

(b) There is a tendency to modify chapters of the normal life-history in response to special needs. For instance, the larval period of a form living near high-tide mark may be much condensed as compared with that of an allied species living in the Laminarian zone. Cases in point are those of Littorina neritoides and L. littorea. On the other hand, circumstances may sometimes result in the larval stages being prolonged.

(c) The period of reproductive activity is frequently adjusted to the seasons or may even coincide with a particular phase of the moon (e.g. Convoluta), the result being to allow the larvæ the optimum chance of survival.

(d) Cases of parental care are not uncommon and make economised reproduction possible, in contrast to the great fecundity required in those cases in which the eggs are liberated at random. From a habit such as that of the 


\section{REPRODUCTION AND GROWTH 28I}

parent butterfish it is then but a short step to the building of a nest as in the case of the fifteen-spined stickleback.

(e) The survival of shore forms with pelagic larvæ is not entirely fortuitous, but sensitiveness to light acting in conjunction with the movements of the surface waters tends to lead a larva towards the environment suitable to its adult existence. 


\section{CHAPTER XIII}

\section{Some Economic Aspects of Shore Life}

THE animals and plants inhabiting the tidal area have from the earliest times been utilised by mankind, the shore offering to coastal people sources of food supply denied to those dwelling inland. This is amply proved by the mounds or "kitchen middens" which occur almost universally wherever these food supplies have been unusually abundant. While shore species are still utilised in great variety by peoples of all grades of civilisation these represent a subsidiary rather than a primary source of natural wealth, which is no doubt destined to be exploited in more intense fashion than at present. It is interesting to notice, for example, that the economic difficulties occasioned by the recent war at once caused attention to be directed to the life of the seaboard as a source of food for man and beast, chemical manure, material for war industry, etc. We are considering here the actual products of the tidal zone, to the exclusion of flotsam and jetsam (except where composed of forms living in the tidal area), however interesting or valuable (ambergris for example).

\section{SHORE ANIMALS UTILISED BY MAN}

The commercial products of the tidal zone, so far as animals are concerned, consist primarily of shell fish, such as the Oyster, Mussel, Cockle, and Periwinkle. Now and again certain others are eaten, but are seldom marketed. Further we have Crustacea (Crab, Shrimp, and Prawn), and fish taken by nets, etc., within the tidal limits, during 
such periods as the rising and falling tides enable these animals to visit and utilise the region.

Shore Fishes.-The use of shrimp, seine and other nets is supplemented in some districts by the use of permanent weirs, baulks, and stake nets. The coast of $\mathrm{N}$. Wales from the Menai Straits to Colwyn Bay affords several examples of these permanent fish weirs, which entrap a variety of species, at times including large numbers of mackerel. In one tide 7000 mackerel were taken in a baulk at Birkdale (Rept. of Superintendent of Lancs. and Western Sca Fisheries, for Quarter ending 3oth September, 1915).

Any one visiting the enormous tidal areas of Morecambe Bay can hardly fail to be impressed by the variety and extent of stake nets, stream nets, baulks, etc., some fixed, others temporary, which occur mile after mile. Most of these are designed to capture fish which do not belong permanently to the actual tidal zone but visit it for feeding purposes, and hence must exercise a very marked influence upon its permanent fauna. The flat-fish: Plaice, Flounder, and Dab, etc., are undoubtedly those of chief commercial importance: their larval stages are partly inshore, and even when older they continue to be largely inshore feeders, especially during the summer months. The commercial round-fish can be regarded as chiefly summer visitors, when they are taken by net or line in large numbers (Mackerel, Mullet, Gar, etc.). Particularly are many fish attracted by the larvæ and young forms of the shell-fish beds of the inshore waters and tidal zone. Nevertheless, these commercial fish are not shore dwellers in the strict sense, as are the various Wrasses, and the numerous species of Blennies, Gobies, and Rocklings, that breed within the tidal zone. We may summarise the relation of coastal fishes to the tidal zone somewhat as follows :-

I. Species that pass through tidal waters during migration:

(a) To spawn in the sea-Eels.

The larvæ ascend, and thus these fish normally traverse the tidal zone twice during their life-history. Sticklebacks may migrate to shallow coastal waters to breed. 


\section{THE BIOLOGY OF THE SEA-SHORE}

(b) To spawn in fresh water; larvæ descend.

I. Lamprey : supposed not to return alive.

2. Sturgeon : has been known to spawn in the brackish water area of the Delaware in cold seasons.

3. Salmonidæ: salmon, sea trout, white trout.

II. Species particularly affecting shore life but not spawning within tide-marks :

I. Conger. 2. Various Cyprodontidæ. 3. Mullet (Mugil spp.). 4. Codling (Gadus spp.). 5. Rocklings (Onus spp.). 6. Sand Eels (Ammodytes spp.). 7. Flat-fish (Pleuronectidæ), Plaice, Dab, Flounder, Topknot. 8. Skate, etc. 9. Bass. I0. Dragonet (G. lyra). II. Weevers (various); also many others on different shores.

III. Shore-spawning species :

1. Fifteen-spined stickleback (Spinachia spinachia). 2. Pipe Fish. 3. Atherina spp. 4. Wrasse (various). 5. Gobies (various). 6. Cottus scorpius. 7. Agonus cataphractus. 8. Cyclopterus humpus. 9. Bullheads. 10. Butterfish (Centronotus). II. Sucker Fish (Lepadogaster). Note the absence of edible forms.

The edible Crab is also a migrant, moving into deeper waters during rough winter weather, although young forms that can hide and protect themselves effectively may be found within tide-marks at almost all times.

Shore Molluses.-The Mussel and Oyster find their optimum natural conditions just below low-water mark (whence they are obtained by rake or dredge) and above it have to be catered for in special spots or by artificial aid, in "layings" for fattening, etc. Only the beds that can be hand picked can be regarded as coming strictly within our province, but these include many extensive mussel-beds and practically all the cockle-beds that are utilised; also the winkle grounds. The taking of all these is regulated by Bye-laws which aim at conserving the beds from depletion by protecting the young forms, and the adults during spawning periods.

Some idea of the commercial value of the mussel may be gathered $f_{\llcorner} \circ \mathrm{m}$ the following figures. Before the war, 50 
boats and roo men (with boats or carts) were at work on the Morecambe beds. The average amount sent away from Morecambe during the winter months was 300 tons per month, the bulk being sent for bait for long lines. The total present yield of these beds is probably 3000 tons per annum, of which only about 200 tons are utilised for human consumption.

A quart of bait mussels will average about 60 mussels, and a bag of 65 quarts will consequently suffice to bait 3900 hooks; there are 16 bags to a ton (Report of Superintendent, Lancs. and Western Sea Fisheries District, Dec. I9I8).

Below are the weight in cwts. and value of different kinds of shell-fish landed in the Lancs. and Western Sea Fisheries District during the first quarter of 1914, with corresponding figures for $\mathrm{I} 9 \mathrm{I} 3$ :-

\begin{tabular}{|c|c|c|c|c|c|}
\hline Fish & & $\begin{array}{l}\text { I913 } \\
\text { cwts. }\end{array}$ & $\begin{array}{l}\text { I9I4 } \\
\text { cwts. }\end{array}$ & $\begin{array}{l}\text { I913 } \\
\text { value }\end{array}$ & $\begin{array}{l}1914 \\
\text { value }\end{array}$ \\
\hline Cockles & .. & 23,399 & 25,917 & $£ 2,809$ & $f 3, \mathrm{I} \times 6$ \\
\hline Mussels . & . & 33,437 & 28,907 & 3,399 & 2,932 \\
\hline Winkles . & .. & $55^{2}$ & 782 & 179 & $23 I$ \\
\hline
\end{tabular}

The value of shell-fish landed at all ports in the Lancs. and Western district during $1917-18$ is given as follows :-

\begin{tabular}{llrrr} 
& & & \multicolumn{1}{c}{1917} & \multicolumn{1}{c}{1918} \\
Cockles & $\ldots$ & $\ldots$ & $£ 11,582$ & $£ 6,166$ \\
Mussels & $\ldots$ & $\ldots$ & 9,754 & $2 \mathrm{I}, 031$ \\
Periwinkles & $\ldots$ & $\ldots$ & 444 & $\mathrm{I}, 292$
\end{tabular}

It is obvious even from this table that these fisheries fluctuate enormously, and the reason is mainly economic. If local industries absorb all spare labour at remunerative rates, only a more or less fixed and normally professional class of fishers will follow the work of gathering shell-fish. A local dearth of employment or a strike will quickly cause a considerable number, including women and children, to turn their attention to such work as a stop-gap, the products 
going either to distant markets, or being utilised locally. Again, should the demand from the big inland markets cause prices to rise above normal, a number of gatherers are temporarily attracted and there is increased local production. These factors can be seen in operation over and over again, in almost any locality offering a large supply of shore products. During the war there was a great reduction in the value gathered, owing to more remunerative employment being available for the few who remained. The few who did continue the work, however, obtained greatly increased prices. The following data (see Annual Report of Sea Fisheries for 1914, Pt. I., Appendix A) refer to 19r4.

At Boston (Lincs.) 59 boats were licensed for mussels, and 30,000 cwts. valued at $f_{2} 250$ taken from the beds in the Wash, etc. In addition $9600 \mathrm{cwts}$. were transplanted to more favourable places. Of cockles 94,000 cwts. were obtained. The value of the oysters marketed from the Colne averaged for the three seasons previous to the war between $f_{1} 3,000$ and $f_{14}, 000$. From Tollesbury and Mersea, $3,160,975$ oysters value $\oint_{0} 12,035$ were marketed in $1913-14$, the stock on the ground being estimated on August 3 rst, 1914 , at $3,618,780$ : also $18,000,000$ of " half ware."

Mussels may sometimes be found to occur on the seashore in such dense crowded masses as almost to obscure the rocks. Such beds are frequently termed "scars " or "skears" (a Lancashire term which is useful to denote beds of this type), and the shell-fish inhabiting them may grow fairly well, but without attaining marketable condition, or may remain stunted, thick-shelled, and coated with the Cirripede Balanus. The shells of these mussels, through being constantly wetted and dried, become rough and unsightly ; the chitinous outer shell-layer (the periostracum) being lost and the prismatic layer thus rendered visible gives the shells a blue colour (Wright, I917), whereas the rapidly grown shells are either smooth black, or variegated (" pitch pine" mussels). The causes of lack of growth are over-crowding, and insufficiency and irregularity of food supply (Diatoms, Protozoa, detritus, etc.). If such mussels are removed to 
more suitable areas where they may either remain submerged in brackish water (the "bed" system) or attached to artificial supports of brushwood, etc. (the "fascine" or "bouchot" system of the French and other coasts), where food is especially abundant, they make such rapid increase in flesh as to render transplantation a profitable commercial transaction.

Periwinkles (Littorina littorea) often occur in great numbers on boulder-strewn shores, estuarine areas that are gravelly, etc., and also among mussels, where they can obtain firm foothold and some shelter from storms. The winkle is a vegetarian and browses upon algæ and their young growth. Piel, near Barrow-in-Furness, is one of the centres of the industry on the west coast of England, and some figures and details have been published by Scott (1917). The molluscs are collected by hand, the bulk between October and May; the average annual quantity sent to the inland towns of Lancashire, and to London, from 1906 to I9I4, was about 48 tons, valued at $£ 240$ per annum. A bag of winkles contains 136 pints and weighs $\mathrm{I}_{4}^{1}$ civts.; there are about 125 winkles in a pint, so that the average bag contains some 17,000 . In the twelve years $1906-17$, over 500 tons have been despatched from Piel Station alone, the value to the fishermen being at least $f_{2} 2680$. In certain cases such shell-fish as Solen (the Razor Shell), Mya arenaria (the clam), Scrobicularia piperita and Vemus gallina (both known as " Hens "), Patella vulgata (the limpet), Buccinun undatum (whelk), Haliotis tuberculata (the "ormer" of the Channel Islands), and others, may be made use of as food, but seldom in any commercial sense.

We may allude here to the extraction of dye from molluscs. The forms used by the ancients were species of Murex and Purpura. Other forms yielding coloured secretions having the properties of dyes are the Sea-hare (Aplysia) and Ianthina. This industry, begun by the Minoans of Crete, has now lost all commercial importance.

Shore Crustacea.-On sandy and muddy coasts the shrimping industry is of some importance. In some places, 
c.g. the Lancashire and Essex coasts, it may support a fleet of cutters which employ a trawl or a more or less similar net. This method of shrimping is, however, not so much our concern as the employment at low tide of the push-net or the use of a horse and cart to pull the trawl, methods which are worked from terra firma and so bring shrimping under the head of a shore industry. The term "shrimping " includes, of course, the taking of prawns, which latter name includes a variety of species. The true prawn is Leander serratus and is distinguished by its long serrated rostrum. Another species which appears on the market is Pandalus montagui, known on the Lancashire coast as the "Fleetwood prawn" or shank or pink shrimp. It is said to prefer a more stony or rocky substratum than the shrimp (Jenkins, 1920). Like $L$. serratus it has a long serrated rostrum, but differs from it in the characters of the first two pairs of walking legs; Leander squilla, with a much shorter and straighter rostrum than the true prawn, and $L$. adspersus (L. fabricii) are said to be sold on some parts of the English coast as "Cup shrimps" (Calman, I9II).

Echinoderms.-The body-wall of certain species of large Holothurians or sea-cucumbers when dried and prepared is eaten by the Chinese, who esteem it a great delicacy. This product is known on the market as " trepang" or "bêche-de-mer," and forms the basis of a valuable industry. In the quest of this dainty the Chinaman has penetrated from Japan in the north to Australia in the south, and is continually pioneering the trade and introducing proper methods of curing. One of the bulletins of the Madras Fisheries Department (Hornell, I9I7) deals with the future prospects of this industry in India.

The gonads of another Echinoderm, Echinus esculentus, are eaten in Italy and elsewhere and are regularly marketed in Naples. One of us has derived amusement from watching a number of children fishing up sea-urchins from the harbour at Anzio, cracking the shell and devouring the contents "senz' altro."

Bait.-Certain shore-dwelling species acquire an economic 
importance by reason of their use as bait by fishermen. Foremost among these is the Lug-worm (Arenicola marina), whose "casts" are so marked a feature of tidal mud flats, or of sands with an underlying layer containing vegetable detritus. From these situations they are dug in quantity and used as bait for the capture of flat fish, whiting, cod, haddock, etc. In some estuarine and similar sheltered areas this worm occurs in immense numbers, varying with the amount of food available (see Plate VI). Davison (189I) at Holy Island found their numbers to vary from 8.2 to 42 per sq. yd. in 19 measured areas. At Musselburgh, Firth of Forth, in January, 12 to 15 casts occurred per sq. yd. and many of the worms were 13 inches in length. From these sands about rooo were dug daily (Ashworth, 1904).

Aberdeen is an area unfavourable to lug-worms, and they are (or were) imported from the Moray Firth, and sent 100 miles by rail prior to use. They weigh, on average, half an ounce each, which is equivalent to 400 worms per stone of $\mathrm{I}_{4} \mathrm{lbs}$. The cost was given by Ashworth at Ios. per stone, and the railway charges at Is. $2 d$. per stone; this transport was only possible in cool weather.

M'Intosh states that a single worm may bait from four to six hooks, but that breaking up the worm causes the fingers to suffer from friction and the worm's secretions : the fingers are dipped in a solution of alum to avoid this.

In Guernsey, Nereis cultrifera is used as bait for whiting, conger, etc. Mussels are of importance as a bait, as are also the sand eels (Ammodytes spp.); of lesser value are "soft" specimens of the green shore crab (Carcinus moenas), limpets, cockles, and others.

Adverse Factors.-Certain animals and birds may at times exercise a distinctly adverse influence upon the shore forms that are of economic value.

Shore-haunting sea-gulls are chiefly scavengers, but on occasions have been accused of destroying cockles. Scott (Igr6), however, considers that it is difficult to say whether undisturbed cockles can be reached by them. Fishermen state that they have seen gulls "tread" cockles 
to the surface with their feet ; but this may be an exaggeration. Cockle-gatherers riddle out their catch, taking the large shells and leaving the smaller on the surface "practically presented to the gulls" (see Fig. 19).

The heron frequently fishes in tidal waters, and Dr. F. Ward (1912) estimates that $I_{2}^{1} \frac{1}{2}$ bs. of fish are consumed per day for each young heron, while the adults take $3 \mathrm{lbs}$. A heronry of 50 nests would thus require $500 \mathrm{lbs}$. of fish

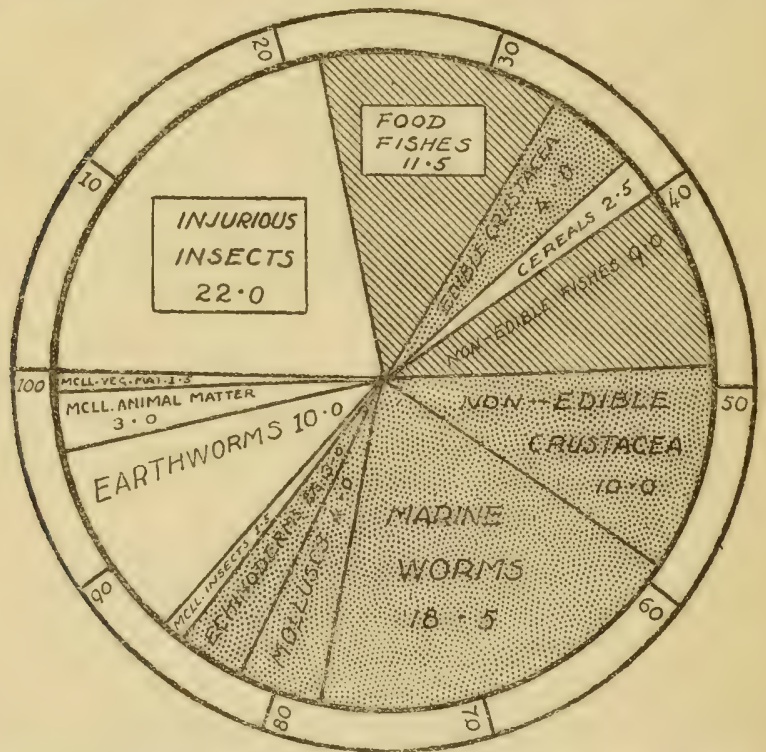

FIG. 19.-Food of black-headed gull (adapted from Collinge).

daily. Two broods may be raised and the heronry occupied from April to August, giving a consumption of 45 tons of fish per nesting season. On muddy flats, eels are the chief food, but where trout and salmon-parr are accessible, these are used.

Kellogg (I9I0) states that many New England farmers living near the shore made it a practice to fatten their hogs on clams, up to a quarter of a century ago. According to this writer, "there are many places on the New England coast where the low tide exposes hundreds of acres of 
continuous flats, and most of these at one time bore enormous beds of clams. It seems incredible that digging alone could have destroyed them, and yet without question this is almost the sole cause of the nearly complete destruction that has occurred on almost all of these immense beds. There is no such thing as an inexhaustible supply of organisms useful to man." Kellogg finally refers to the depredations and reckless misuse of these natural resources by man. In winter, Mya arenaria is marketed alive inland, and at a temperature near the freezing point will keep alive for weeks. Near the shore it is eaten in summer, baked, steamed and in " chowders," and immense numbers are cooked, canned, and shipped away. Recently, also, "clam-juice," the mucus drained from the bodies of "shucked" clams, has been canned or bottled and widely used as a broth, especially for invalids.

PLANTS OF ECONOMIC VALUE LIVING WITHIN THE TIDAL ZONE

Zostera.-Mankind finds various uses also for a number of the plants that grow within the tidal area. These plants are all algæ with the exception of one form, which deserves notice. This is the sea-grass or Zostera, which grows in immense quantities between tide-marks in sheltered bays or inlets where the water is shallow and the bottom muddy (e.g. the Beaulieu estuary which opens into the Solent), and harbours an interesting fauna (see Herdman, 1919). The two commonest species are Z. marina and $Z$. nana; the place of which is taken on Mediterranean coasts by Posidonia. They are utilised mainly for their fibre, which may serve as litter, for stuffing mattresses and furniture, as a packing material, and for the manufacture of paper (Gloess, 1919). The fibre is disassociated from the organic matter by appropriate methods, bleached and dried. According to Gloess, Zostera fibre is distinguished by its elasticity, uninflammability, keeping qualities and absence of smell, features which render it particularly valuable for the purposes above named. Both Gloess (loc. cit.) and 
Sauvageau (1920) mention the formation of a company "La Parisette" for the manufacture of a packing material from Z. marina. In spite, however, of the excellent quality of the product, the venture failed owing, thinks Gloess, to difficulties of transport due to the factory not being situated on the spot.

Zostera frequently forms a portion of the plant jetsam utilised by the agriculturists of the coast as manure. Though containing the same fertilising elements as algæ the proportions of these are somewhat smaller, and this, added to the fact that decomposition is very slow, renders the Zostera less valuable for this purpose.

Red Seaweeds.-The economic value of red algæ lies chiefly in the gelatinous matter or gelose contained in the cell wall. The most important species is Chondrus crispus, the use of which is ancient and practically world-wide; Chondrus crispus, or Carrageen moss, is one of the commonest algæ of our shores and occurs in the zone extending from the low tide of neaps to that of springs. After being picked the weed is spread on the shore, bleached and dried in the sun, a certain amount of moisture being essential to the bleaching process (Sauvageau, op. cit.). When boiled in water the weed partially dissolves and, on cooling, forms a jelly which serves a number of uses. Along with other red seaweeds it is employed in the preparation of various dishes, especially jellies; as a thickening for textiles; as a vegetable glue; and during the war it fulfilled a useful purpose as a substitute for gelatine of animal origin. According to Sauvageau, Chondrus crispus as it occurs in commerce is almost invariably mixed with Gigartina mamillosa, which it sometimes resembles very closely, the two species being collected indiscriminately.

Prof. R. W. Phillips, of Bangor University, informs us that $C$. crispus was formerly used on the Anglesey coast as a food for calves. According to Cotton, the same species is prescribed in certain parts of Ireland for the treatment of chest complaints.

A species of alga familiar to most inhabitants of the 
Scottish seaboard is Rhodymenia palmata or " dulse." It may be cooked and eaten as a vegetable, but in the majority of cases it is merely dried in the sun, rolled up and chewed like tobacco ; or the preliminary treatment may be dispensed with altogether and the weed employed in the fresh state. Sauvageau quotes Johnston and Croall to the effect that the presence of epiphytes or forms such as Idothea and small molluscs (e.g. Rissoa and Mytilus) is considered an advantage by some !

Another kind of red seaweed used in this country is Porphyra, either P. laciniata or P. vulgaris, known in England as "laver," the Irish appellation being "sloke." The distribution of this seaweed is, however, more local. At Clare Island, according to Cotton, the weed is gathered in spring and eaten either cooked or pickled. At Llwyngwril, near Aberdovey, and on the South Pembrokeshire coast, previous to the war, a fair quantity of laver was picked and forwarded regularly to Cardiff for the preparation of a special bread used by persons suffering from diabetes,

Another species which in virtue of its peppery flavour is sometimes employed as a condiment in Scotland is Laurencia pinnatifida, where it is known as Pepper-dulse.

Both dulse and laver may be seen on sale in the smaller shops of the coastal towns of south-west Britain, and the former is regularly exposed for sale on the Aberdeen fishstalls.

It is in Japan, however, that seaweeds are put to the greatest number of uses, being employed as food, as plaster and glue, as starch, and as manure for the rice-fields(Davidson, I906). The best known product is "kanten" or seaweed isinglass, familiar in this country as agar-agar, where it finds its chief application as a culture medium for bacteria. In addition, agar-agar is used in numerous ways for edible purposes, particularly for preparing jellies; for clarifying wines; for sizing textiles and silks, and in the manufacture of paper. Under the name agar-agar is included a series of products, possessing similar properties, derived from several different species of red seaweed, chiefly species of Gelidium. 


\section{THE BIOLOGY OF THE SEA-SHORE}

The advantage which this product offers as a culture medium for bacteria is that it remains solid at a considerably higher temperature than does gelatin of animal origin. It is also quite free from impurities.

Brown Seaweeds.-So far as this country is concerned, the value of brown seaweeds lies in their manurial qualities, although they are employed in all kinds of ways by the Japanese, notably in the preparation of Kombu (from species of Laminaria) which is much esteemed as an article of food.

The use of seaweeds as manure is almost world-wide. They are either cut direct from the rocks, or the masses cast ashore after gales are collected and carried to the adjacent fields, or carted inland as far as is convenient. The species thus utilised are the various Fucoids : F. spiralis, $F$. vesiculosus, F. serratus, and Ascophyllum nodosum, together with Laminaria digitata and $L$. cloustoni, while at times the non-algal Zostera and others are employed.

Seaweeds as manure contain about as much nitrogen as farmyard manure (but in a form rather less available as plant food), about half as much phosphates, and considerably more potash, besides supplying a large amount of organic matter. The following analyses are taken from the Ministry of Agriculture leaflet No. 254 :

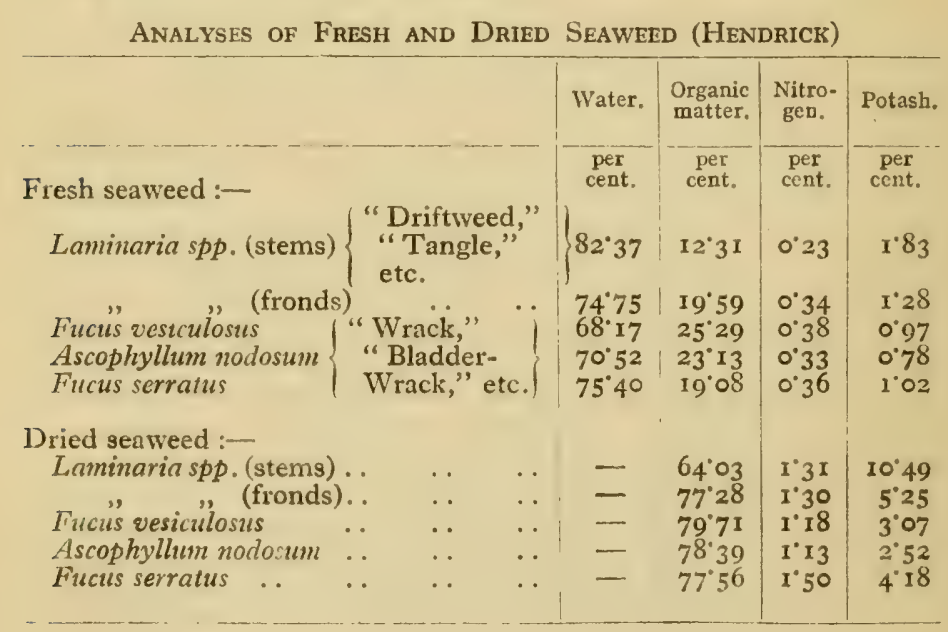


The utilisation of seaweed as manure carries several advantages. It conserves moisture and has a special value in improving the mechanical condition of the soil, an effect which is due to the changes of form following upon variations in the moisture content, algæ being markedly hygroscopic. Moreover, no weed seeds, fungus spores or larvæ of injurious insects are introduced by its use, as is frequently the case with farmyard manure. Seaweed is used as a dressing for potatoes, mangold, turnips, and cabbage, and sometimes as a top dressing for young "seeds." Ten to fifteen tons per acre are given to lucerne, or to sainfoin, in autumn (Isle of Thanet) and raked off in spring; $25-30$ tons per acre are used for the potato crop in Ayrshire.

Pethybridge (1915) describes how in certain favourable localities artificial beds of stone are laid on the coasts of Achill Sound, Co. Mayo, the Donegal Coast and Mill Bay, Co. Down, to obtain an extra source of algæ for manurial purposes. Rectangular beds are formed of more or less regular lines of stone, and these belong to those farmers whose land fringes the coast. The algæ are cut once in two or three years, and are sometimes sold. If the stones sink, they may have to be raised by means of spade and crow-bar. The weed is cut with a hook. Some of the beds are stated to be from one to one and a half miles from high-water mark. One bed in 19r3 sold for $£ 40$, the area cut being $3^{8}$ sq. perches (Irish). The average price per load in that year was 15 . to $16 s$., and in 1914 only $8 s$.

Yendo (I9I4) describes similar methods for the coast of Japan, a difference being that the crevices between the stones are filled in. By so doing a richer vegetation is obtained, since more or less flat reefs are the richest for sea-weed. Yendo further states that the cultivation of marine algæ in Japan yields an annual value of a million pounds sterling, of which about one-third is exported to China. In many cases women and children do the work on the farms and the sea-weed cultivation, the men being fishers. Davidson $(o p$. cit.) stated that no less than fifty-one 


\section{THE BIOLOGY OF THE SEA-SHORE}

species were collected and employed by the Japanese for various purposes.

The chief drawback to a more extended use of seaweeds as manure lies in their bulk and in the difficulty and cost of transport. Instead, therefore, of being employed as a complete manure the algæ are frequently burnt for the sake of their ash, which contains a high percentage of potash. The ash obtained from algæ is usually known as "kelp," though the same term is sometimes applied to denote the living algæ which are utilised for obtaining potash. Until a few years ago, however, even the kelp was only of comparatively local value, as on the open market it was incapable of competing with potassic fertilisers of other origin. The Americans had already begun to turn their attention to the giant kelp-beds of their Pacific coasts as a source of potash when the loss of German supplies due to the war gave a new impetus to this industry. Large factories sprang into existence on the shores of the Pacific and rendered important service in connection with war needs. The species exploited are chiefly Laminarians of great size, known as giant kelps, which form immense beds a short distance from the coast. As the majority of these are provided with floating organs (pneumatocysts) which support the fronds at the surface, mechanical means of harvesting become possible and result in a considerable reduction of the working expenses. Although the financial success of these concerns under peace conditions is not yet assured, already thousands of tons of algæ are removed from the Pacific for the extraction of potash and other products (Sauvageau, op. cit.).

The extraction of iodine from seaweeds is still practised on a small scale in different parts of the world, but this substance is now generally obtained more economically as a byproduct of the nitre industry. Iodine was formerly obtained from various seaweeds on the Scottish coasts, but the industry has declined for the reason just stated (Cameron, I9I6).

The exploitation of littoral algæ on a commercial scale opens the question as to how far the supply of algæ is inexhaustible and as to what effects their removal may have on 
the shore fauna in general and on fishes in particular. This is a question which is discussed at length by Sauvageau, who disagrees with Gloess's statement that Laminaria when cut quickly grows anew. According to the former writer, the Laminaria of the French coasts, when the stipe is severed, no matter at what point, never continue to grow whether from the stipe or from the "roots." Though the reproductive zone is situated at the junction of stipe and frond, growth by cell division only begins at a point of the frond well above the base, and though theoretically it might be possible to sever the weed so as to make sure of its growing anew, in practice this is not feasible. The chief points to be considered in connection with this question are the situation of the conceptacles, the length of life of the particular species, and the season of reproduction. Delage (I9I3) is of the opinion that an increased use of Laminaria for industrial purposes might prove a serious menace to the inshore fisheries, not because of the shelter these afford to the fishes themselves, but on account of the large invertebrate population which lives among them and on which the fish feed.

As an example of the many miscellaneous uses which have been made of algæ we may mention the way in which their highly hygroscopic qualities were utilised by the Germans in the construction of a delayed-action bomb. These bombs, which were employed in the late war, exploded after lying for a time in a pool of water or in any damp place. The explosion was produced by the swelling of a portion of the stipe of $L$. cloustoni breaking a glass bulb and so bringing sulphuric acid into contact with chlorate of potassium. In other grenades, a needle, pushed by the expanding Laminaria, came into contact with a capsule of fulminate of mercury (Sauvageau, op. cit.).

Injurious Algæ. - A curious instance of the adverse effects of an alga upon a commercial enterprise may be given. The spread of the species Ciolpomenia simuosa has been mentioned elsewhere (see Ch. III, p. 54), and Mangin (1907) describes its effects upon some oyster-beds on the French shores at 
Quiberon, Cherbourg, and other places. These algæ are spherical or ovoid, solid when young, later hollow and filled with water. They may attain the size of a hen's egg, or even that of a fist. These plants become attached when young to the oysters, and gradually increase in size. When they have attained a certain size and are left uncovered by the retreat of the tide, they split from the pressure of the water they contain, and this, on trickling out, is replaced in part by air. The rising tide imprisons this air, and the alga swells, rises, and carries up the oyster to which it is attached. 'The whole is now drifted away by currents, and in this manner, no less than 400,000 oysters have been (according to Fabre-Domergue) removed from oyster-beds. The same author states that this evil is to some extent mitigated by the drawing of faggots of thorn bush over the beds, thus breaking the "balloons."

Effects of Sewage, etc.-'The system by which the sewage of towns and effluents of works, etc., is got rid of by being led on to, or allowed to escape within, the tidal area has in many instances led to serious results by infecting valuable beds of mussels, cockles, and oysters with disease-causing bacteria.

Bacteriological and epidemiological evidence from many sources has produced irrefutable evidence of the fact that shell-fish, owing to their peculiar methods of feeding, are capable, if infected by sewage bacteria, such as $B$. typhosus, of transmitting such bacilli to human beings who may consume them. This has led to much discussion and experiment, and to the condemning of shell-fish from infected sources by many Medical Officers for Health, and considerable interruption of the usual trade has resulted. Naturally, methods are being sought to eliminate this danger and to place these frequently valuable fisheries on a safe and sound basis. The Ministry of Agriculture and Fisheries have for some years past carried out experiments at Conway, the object being to cleanse mussels of dangerous bacteria associated with sewage pollution, so as to render them " pure in a bacteriological sense." As regards cockles, these also 


\section{PLATE XV}

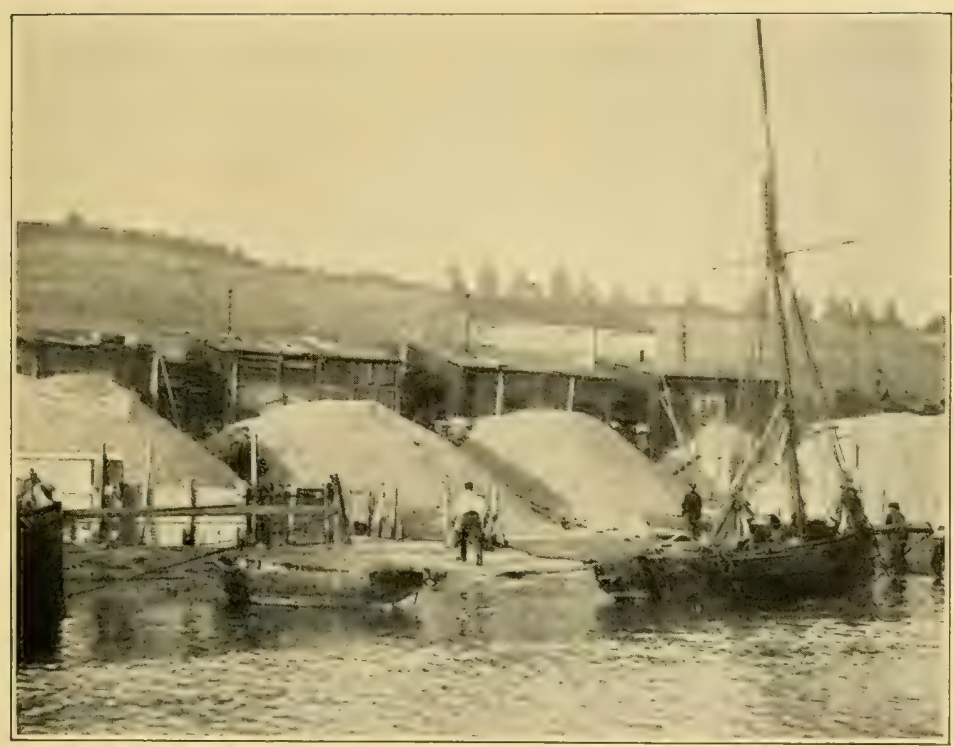

[Photo by Padgett, Leigh-on-Sea.

I.-The Cockle Industry at Leigh-on-Sea: Landing the Cockles. Notice the shells, which are later to be crushed and employed on the land.

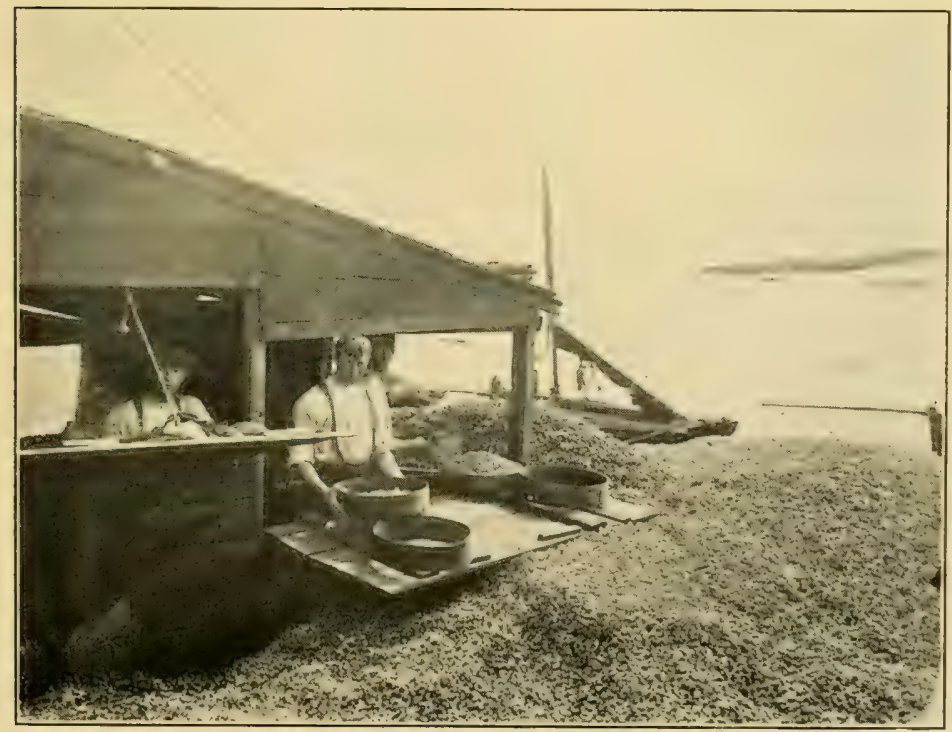

[Photo by Padgett, Leigh-on-Sea.

II.-Cooking Cockles at Leigh-on-Sea.

Treatment in autoclaves sterilizes the cockles and at the same time removes them from their shells. The soft parts are then prepared for the London market. 

may become polluted, but frequently the situation of the chief beds is sufficiently remote from sources of pollution to ensure their escape. In some places cockles are cooked after gathering, and marketed in this condition, thus avoiding much danger, besides eliminating the chief bulk and much expense in transit. Such methods are employed at Leighon-Sea where sterilisers are used (see Plate XV).

The release of refuse from works has produced in certain instances curious results among the shore fauna and flora. Farran (I9r4) investigated the effects produced by the establishment of a whaling station in Blacksod Bay, Co. Mayo. He found that defilement of the shore, with destruction of animal and vegetable life, took place only when the valuable parts of whales were treated, and the refuse allowed to accumulate in large quantities on the shore. In the case of a station with installation sufficient to deal promptly with the whole of the whale, such a result did not occur. In the instance investigated, only a residue, consisting mainly of water and some organic matter in solution, was allowed to escape. Any changes observed on the shore extended at most for 200 yards on either side, the most noticeable result being the greatly increased growth of Ulva lactuca, which formed a dense band along and below extreme low-water mark. Within this area, the roots of Laminaria at low water yielded a much smaller supply of worms than usual. Above low-water mark the shore was as usual except just below and at the sides of the station, where there was a notable increase in Enteromorpha and decrease of Fucoids, and the animal life they shelter.

We ourselves investigated an instance on the shores of Milford Haven, in 1913 , in which the effluent from a fishmanure and oil-works flowed across a tidal reef (Walton, 1913). A drain pipe from these works opened within the tidal zone and the rocks thereabouts were oily and there was a strong fishy odour. The fauna of the vicinity was somewhat curiously affected. Immediately around the outlet the rocks were barren; a little further away alga began to appear, and gradually increased in amount. Then 
occurred Littorina littorea (large), L. obtusata (small), Patella and Carcinus. Some stone work then intervened and on the reef and in the pools immediately beyond the rocks were still decidedly oily, and the fauna was rich. Over forty species of invertebrates were collected within a few yards and in some cases the specimens were of very large size and peculiarly coloured as compared with those of unaffected rocks near by.

It has also been shown by several workers that the green alga Ulva latissima grows more rapidly in polluted than in pure water (see Chap. II, p. 45).

Injurious Animals.-Some other invertebrates may be a source of loss on shell-fish beds, as for instance Cliona-the boring sponge. The mollusc Crepidula fornicata may increase on oyster-beds to such an extent as to enter into serious competition with the oysters by reducing their food supply; while mussel-beds may be ravaged by hordes of star-fish (Asterias rubens), or dog whelks (Purpura lapillus), both of which feed upon the shell-fish.

The Sea-shore in relation to Human Culture.-The foregoing pages will have served to convey some idea of the economic value of the sea-shore at the present day. The importance of this area to human affairs cannot be correctly gauged, however, by the figures we have given, as to minds accustomed to modern industrial undertakings these will always appear small. It is not too much to say that without the food supply, represented chiefly by molluscs, offered by the shore the development of early civilisations would have been much retarded. Quite apart from food, however, the rôle played by shells in human life has been very great. In many parts of the world littoral shells were, and are still, employed as a medium of exchange. One of the commonest forms put to this purpose is the money-cowrie (Cypraea moneta), still current in West Africa. Among the coastal tribes of North-West America the elephant-tusk shell (Dentalium indianorum) was the standard of value until under the Hudson Bay Company it was superseded by blankets. The "wampum" of the eastern coast of North America consisted of strings of beads formed from the shells of 


\section{SOME ECONOMIC ASPECTS OF SHORE LIFE 301}

Venus mercenaria, the beads derived from the purple-coloured parts of the shell being the more valuable. Another form of wampum was made from the shells of Busycon carica and $B$. perversum. Other shells employed for the same purpose in California were Olivella hiplicata, Saxidomus arata, Pachydesma crassatelloides and Haliotis (Cooke, I9I3). Other practical uses of shells are as sinkers for fishing nets and as material for the manufacture of fishhooks, weapons, etc.

No less important than the practical is the æsthetic and imaginative aspect of shells gathered from the sea-shore (see Wilfrid Jackson, 1917. Also essay on "The Cult of Shells," in Thomson's Secrets of Animal Life). From the very earliest times shells have been employed for ornament, notably cowries and top-shells. Their beauty early stimulated man's æsthetic sense and stirred his sense of wonder and so shells acquired a symbolic and later, a religious significance. At the present day the chankshell (Turbinella rapa) has a special religious significance for the Hindu, and the very rare left-handed form is said to be regarded with extraordinary veneration (Hornell, 1915). 



\section{APPENDIX I}

NOTES ON SOME OF THE COMMONEST SHORE ALGÆ

THE drawings of seaweeds (Figs. 20 and $2 \mathrm{I}$ ) inserted in this appendix are intended as a rough-and-ready guide for the benefit of the beginner and represent the species to which reference has been most frequently made in the text. The notes below refer to the most obvious features by which they may be identified. For the distribution of Fucoids reference should be made to Plate VIII.

Fig. 20. No. I. Pelvetia canaliculata. Distinguished by its narrow fronds, usually without distinct mid-rib. The margins of the frond are thickened and incurved so as to give a channelled appearance to one side of the frond. Hence the name of " Channelled-wrack." Receptacles (or specialised region bearing the reproductive organs) terminal, oblong or lanceolate, either in pairs or deeply-forked, their surface tubercular. Air-vessels absent. Colour : a pale yellowisholive. Habitat : extreme high-tide mark.

No. 2. Halidrys siliquosa. Easily distinguished by the character of the receptacles which roughly resemble the "pods" of a typical cruciferous plant. No air-vessels. Colour : greenish-olive to olive-brown. Habitat : in deep pools between tide-marks, never exposed to the air. When occurring in shallow pools is usually stunted.

No. 3. Fucus vesiculosus ("Bladder-wrack"). Frond flat, with a stout mid-rib and entire margin. Air-vessels elliptical, mostly in opposite pairs along the frond. Receptacles terminal, roundish ovate, oblong or lanceolate. Colour : deep olive-green. Habitat : typically at about half-tide mark in situations where it is left exposed to the air.

No. 4. Laminaria digitata ("Tangle-weed"). Easily recognised by its large size, long cylindrical stem expanding 
into flat, strap-like fronds, and much-branched "holdfast." Colour: brownish-olive. Habitat: the seaward
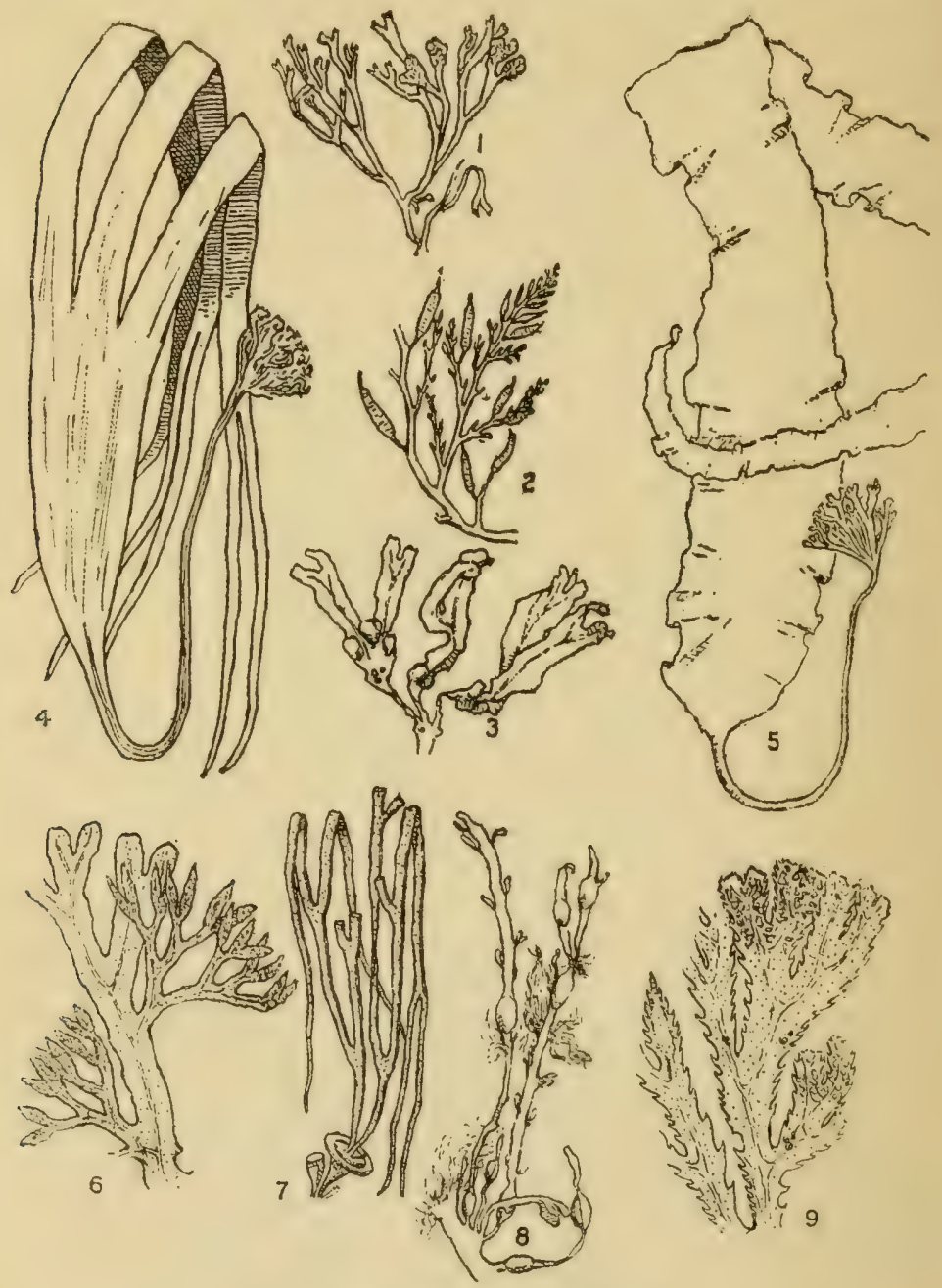

FIG. 20.-Common shore algæ.

1. Pelvetia canaliculata. 2. Halidrys siliquosa. 3. Fucus vesiculosus. 4. Laminaria digitata. 5. L. saccharina. 6. Fucus ceranoides. 7. Hi. manthalia lorea. 8. Ascophyllum nodosum with Polysiphonia. 9. Fucus serrahts. 
margin of the tidal zone where it is is only exposed at spring tides. Also in deep pools higher up the shore.

No. 5. Laminaria saccharina ("Oar-weed"). Distinguished from No. 4 by its simple frond with crisped edges. Colour and habitat as in L. digitata.

No. 6. Fucus ceranoides. Frond with mid-rib. Distinguished by the tapering shape of the receptacles, which are either in pairs or forked. Air-vessels usually absent. Colour : brownish-olive. Habitat: between tide-marks wherever there is fresh-water influence.

No. 7. Himanthalia lorea. The identification of this species is rendered easy by the characteristic cup-shaped region of attachment (the thallus proper), and long fertile fronds. Colour: dark olive. Habitat: between tidemarks in positions exposed to air. Very common on some rocky shores, absent from others.

No. 8. Ascophyllum nodosum (Fucus nodosus). Frond linear, frequently enormously long (see Plate IX), without mid-rib (or, one might equally well say, consisting entirely of mid-rib). Air-vessels very large, occurring singly at intervals along the middle of the frond. Receptacles ovate, borne on short lateral stalks. Frequently bears tufts of the epiphytic Polysiphonia fastigiata. Colour: olive-green. Habitat : about half-way between tide-marks, particularly on boulders. The common name is " Knotted-wrack."

No. 9. Fucus serratus ("Notched-wrack "). Frond with broad mid-rib and strongly serrated margins. No airvessels. Reproductive organs, or conceptacles, distributed over the whole of the distal portions of the fronds. Colour : olive-green. Habitat : the lower part of the shore, immediately above the Laminarian Zone ; also in deep pools.

Fig. 21. No. I. Cladophora rupestris. A conspicuous dark-green alga occurring in thick, bushy tufts, in pools from high to low tide mark.

No. 2. Enteromorpha intestinalis. Frond unbranched, inflated, arising from a very slender base and gradually dilating to a rounded extremity. Colour: dark green. Habitat : between tide-marks, either exposed near highwater mark or in pools. Another common species is E. compressa.

No. 3. Corallina officinalis. A common red seaweed 

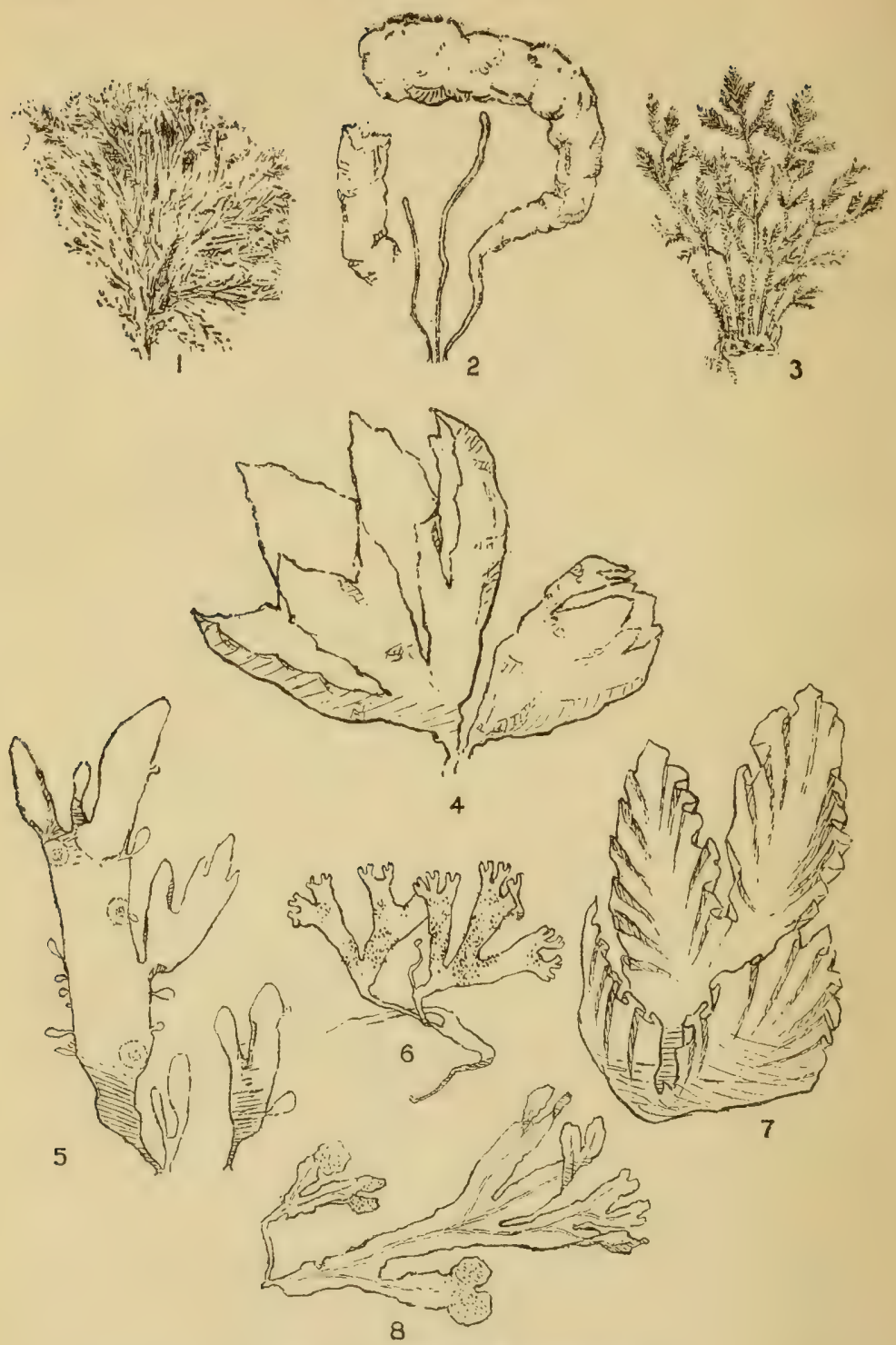

FIG. 21.-Common shore algæ.

1. Cladophora (greon). 2. Enteromorpha intestinalis (green). 3. Corallina (red). 4. Ulva lactuca (green). 5. Rhodymenia palmata (red). 6. Chondrus crispus (red). 7. Porpliyra laciniata (red). 8. Fucus platycarpus (brown). 
of bushy growth characterised by being strongly impregnated with lime. Colour: dull purple, often fading to pure white. Habitat : in pools, commonest towards low-tide mark. Never exposed.

No. 4. Ulva lactuca ("Sea-lettuce"). Fronds practically sessile and, when floated by water, inflated or cup-like, with margins more or less cleft. Colour : yellowish-green. Habitat : in pools above half-tide level. Another common species is $U$. latissima, which is of a deeper green and has a somewhat different frond.

No. 5. Rhodymenia palmata. A common red seaweed with flat, irregularly-branched, somewhat leathery fronds ; well known to all coastal inhabitants, in Scotland at least, as "Dulse." A very variable form. Habitat : everywhere between tide-marks where not too exposed except, say, the upper third of the shore.

No. 6. Chondrus crispus (" Carrageen Moss "). Another common red seaweed, also of variable form. Stem elongate (one or two inches), cylindrical at base but passing into a flattened, dichotomously-branched frond. Habitat: the lower third of the sea-shore, exposed and in pools. Colour : dark reddish-brown fading to yellowish-green.

No. 7. Porphyra laciniata ("Laver "). Frond broad and membranous, irregularly cleft and with crisped margins. Very common on some shores between tide-marks where exposed to air, appearing at low-tide as filmy sheets coating the rock or other weeds. Colour: variable, from pale purplish-brown to dark purple.

No. 8. Fucus platycarpus. Resembles $F$. vesiculosus, but is distinguished therefrom by the absence of air-vessels and also by its habitat which is higher up the shore, immediately below Pelvetia canaliculata (see Plate VIII). A further difference between the two species is that in $F$. platycarpus, male and female elements are produced in the same conceptacle, while in $F$. vesiculosus they arise from different conceptacles. 


\section{APPENDIX II}

\section{SHORE INSECTS}

THE following short account is intended to supplement the somewhat scanty references to insects in our survey of the life of the sea-shore.

Among the features which have enabled these typically air-breathing creatures to extend their activities to the seashore, we may note that they are not readily wetted, the chitinous body-covering and the frequent presence of hairs alike preventing this. In addition, the tough chitin delays almost indefinitely the passage of the toxic salts from the water to the tissues (endosmosis). The surface-film of water will not pass into small openings, such as the mouth or spiracles, and in any case the spiracles are guarded by hairs. Furthermore, sea-shore insects are mostly small (see Miall, I895). A striking point is the frequent reduction, or total suppression, of wings, as seen for example in the small Hemipteron Aëpophilus and the beetle Aëpus marimus. This is generally supposed to be advantageous in preventing the animals from being blown away from their narrow environment. Generally speaking, however, the adaptive features seen in marine insects are few as compared with those which secure the survival of the fresh-water members of the same group. One thinks of the many remarkable arrangements for locomotion ("pond-skaters," "waterboatmen "), for respiration, and for securing the survival of eggs and young, which are so frequently met with in fresh-water insects. Probably the chief obstacle offered to insect life in the sea is the constant agitation of the water. The fact that shore insects so rarely swim may be almost certainly attributed to this cause. We must not forget, however, that Hemipterous insects belonging to the genus 
Halobates show a degree of adaptation to a marine existence which is extraordinary, being found gliding over the calm seas of the tropics hundreds of miles from land or clinging to any flotsam from which they can obtain food. Their eggs have been picked up attached to the floating feather of a sea-bird (see White, 1883, and Carpenter, 1895).

From the ecological point of view, insects form an important part of the jetsam associations referred to in Chapter III. In fact, it is the shore jetsam, with its mixed plant and animal constituents, which has been the chief factor in attracting these forms to the sea-shore. Probably, also, the warmth of the decaying weed is a condition which favours the development of the eggs and larvæ, particularly those of flies and beetles; moreover, the larvæ will have no difficulty in finding a plentiful supply of decaying plant or animal food.

One of the most abundant and, at the same time, the most typical of sea-shore insects is the Collembolan Anurida maritima, a small, blue-black, wingless form, from two to three millimetres in length. It is found on or under stones, crawling on weeds or walking over the surface-film of pools between tide-marks, but never above high-tide mark nor in the Laminarian Zone. A supply of air is retained by its thick coating of hairs sufficient to last it for four or five days under water. The orangeyellow eggs are deposited deep in crevices (Imms, I906). A related insect with similar appearance and habits is Lipura.

Quite a number of small species of Collembola (springtails) and Thysanura (bristle-tails) frequent the sea-shore in addition to the preceding. The spring-tails have been studied by Davenport (1903), among others, and he describes their reactions to contact, moisture, gravity, and air-currents. Some species go into the sand when the tide rises and come to the surface again to take air when the tide falls. They will run up surfaces in the face of the wind, leaping when the top is reached and so being blown back to the startingpoint. A common bristle-tail on British shores is Machilis maritima, which is to be found creeping over the surfaces of rocks or resting on and under stones close to high-tide mark. 
Beetles are especially common on the sea-shore, and Keys (I9I8) in enumerating the species found on the South Devon and Cornwall coasts has classified them as follows: (a) Maritime species: those covered by the sea for a considerable time during the ebb and flow of the tide; 8 species. (b) Sub-maritime species : dwellers at high-tide mark or thereabouts and subject to occasional wettings; inhabitants of brackish pools and wet places in salt marshes ; 54 species. $(c)$ Coast species which are, as a rule, safe from the reach of high tide but are peculiar to coast plants or live under stones, on wooden piles, and in fresh-water oozes on the cliffs ; 89 species.

Many shore beetles belong to the predaceous Carabidæ and, in addition to feeding on animal refuse, may prey upon sand-hoppers. They may burrow in the sand at low tide or lie motionless under stones and in this way are able to resist short immersion. Several are wingless and in one case at least, that of Aëpus marinus, there is very marked specialisation for an amphibious existence. In addition to being wingless and to having its body covered with hairs, Aëpus is provided with a large pair of air-sacs in its abdomen which supply the respiratory needs of the animal when submerged. At low water Aëpus may be seen running about on stones, sponges, and weeds, and is thought to prey upon the Gasteropods Rissoa and Lascea (Miall, op. cit.).

The sea-shore flies (Diptera) are hardly less numerous than the beetles. "Flesh-flies" (Sarcophaginæ) are prominent and the "black-fly" (Cœlopa frigida), which is not unlike a house-fly in appearance, is also common; while in addition to the adult flies, numbers of their maggots may be seen feeding among the jetsam. Both larva and pupa can withstand short immersion. Miall (op. cit.) mentions the larvæ of the fly Arctora cestuum as feeding upon stranded bladder-wrack (Fucus vesiculosus). The adult flies, which occur in summer at the water's edge, are larger than Ccelopa and of a lighter grey in colour, while the larvæ are covered with short hairs. Other prominent flies which frequent the water's edge belong to the Dolichopodidæ and are readily distinguished by their brilliant, metallic coloration. Midges are numerous above rock 
pools and their larvæ are truly marine, feeding on green seaweed, and breathing dissolved oxygen by means of gill filaments or over their whole surface (Carpenter, 1899). A list of British seaside Diptera has been compiled by Col. Yerbury (1919).

Besides insects, several other kinds of tracheate Arthropods may be found between tide-marks. The most inconspicuous, but, at the same time, the commonest of these, are mites (see p. 65). In addition, a number of Myriapods have been described by Plateau (I890) and Sylvestri (I903). The latter author distinguishes between $(a)$ accidental, $(b)$ indifferent and $(c)$ genuine halophilous forms. According to Plateau, Geophilus maritimus and G. submarimus are able to exist in sea-water for periods of twelve to seventy hours. Altogether, Plateau, in 1890 , enumerated 40 genera and 80 species of tracheate Arthropods known to inhabit the sea-shore, but the list has almost certainly been greatly augmented since then. 


\section{APPENDIX III}

\section{ILLUSTRATION OF A METHOD OF SURVEYING A TYPICAL PIECE OF SEA-SHORE}

THE accompanying plan, sections, and photographs of a small inter-tidal area have been prepared mainly with the object of illustrating a method of survey which might be used in order to bring out, in a manner that is clear and easily grasped, some of the main ecological features of any given shore, or portion of shore. In a lesser measure it may serve as a sort of commentary on some of the facts connected with the distribution of tidal plants and animals which are discussed in Chapter III.

The method is one that has been employed by the writers for teaching purposes and found to answer well. Each student is given a specially prepared plan of the area under consideration (similar to Fig. 22, but on about twice the scale) and told to mark down the distribution of certain species while indicating their precise mode of occurrence, e.g. on stones, under stones, in sand, in mud, etc., by appropriate symbols. The advantage of such a method is that it serves to give focus to the work of the student and to counteract the tendency, on his part, to adopt somewhat aimless methods of collecting.

Our present illustration of the method, as applied to a fair-sized portion of the shore of Balloch Bay, is nothing more than an outline. It could, however, be elaborated without difficulty. In particular, any fraction of the same shore might be selected for closer treatment and the survey be so made to comprise almost any desired amount of detail.

Balloch Bay is situated on the east side of Gt. Cumbrae Island, Firth of Clyde, and thus faces towards the mainland, 


\section{PLATE XVI}

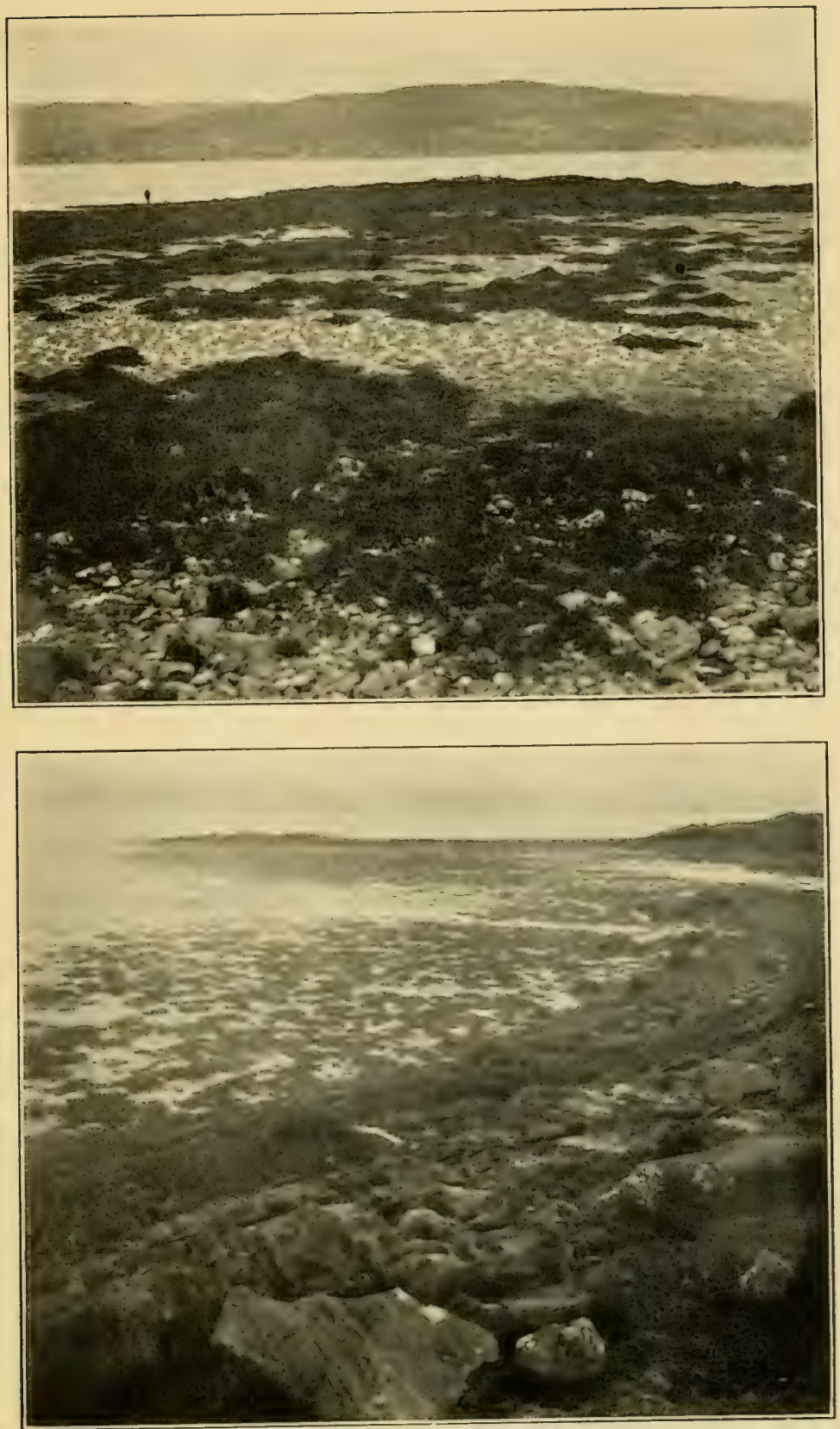

Shore of Balloch Bay. I. at Low-tide and II. at Half-tide. 

from which it is separated by a narrow channel. The portion selected for study is, roughly, about 2-3 acres in extent and is, for the most part, covered with mediumsized boulders. In places, however, these are interrupted, leaving patches of sandy mud. Running parallel with, and close to, low-tide mark for a distance of about 50 yards, is a narrow reef, the top of which just remains uncovered at high water of ordinary spring tides. At the southern boundary of the area a low cliff or bluff makes an abrupt salient in the coast-line. Generally speaking, then, the shore is one of mixed physical character and is consequently well adapted to showing the chief species of plants and animals associated with each of the three types: (I) solid rock, (2) boulders, (3) sandy mud.

The character of the area can be further made out from the accompanying illustrations. Plate XVI shows the general appearance of the area at low tide and at half-tide ; Fig. 22 is a plan; Fig. 23 shows two sections, mutually at right angles, taken along the paths indicated by the two dotted lines in the chart. The direction of the upper section is due north and south, that of the lower one due east and west, proceeding from low-tide to high-tide mark in each case.

On the upper section are indicated the names of some of the commonest animals at points corresponding as closely as possible to those in which they were found. Five "positions" are recognised: (I) on weeds, (2) on the upper surface of boulders, (3) on the under surface of boulders, (4) under stones resting on the substratum, (5) in the substratum. It by no means follows, of course, that an animal indicated in any one of these positions does not occur elsewhere. Some animals, indeed, will be so restricted, but others may be found in as many as four out of the five positions, or possibly even in all five. Generally speaking, however, the mode of occurrence we have indicated for a particular species may be regarded as being the most typical for that species. The species named form about one-half of those found in the course of a fewhours' collecting.

An important point to be noted in connection with these sections is their trend, relative to the advancing waterline. The upper section runs for the most part parallel 
to the line of low-tide mark; consequently, a well-marked zoning of species is not apparent, except towards the foot of the cliff on the right. Thus, there is little difference in the composition of the fauna of the portions numbered 4,5 , and 6 , respectively, which were really more or less arbitrarily chosen. Zone 3 marks a different physical type, sand here taking the place of boulders. On the other hand, in the lower, west-to-east, section, this being taken at right angles to the line of the advancing tide, zoning is much more pronounced. The succession of brown seaweeds here should be compared with that illustrated on Plate VIII. An ecological feature which deserves attention is that the zoning on the two sides of the reef, close to low-tide mark, repeats exactly that found on the other portion of the shore. This is an example of the vertical zoning, as distinct from the linear zoning, to which allusion was made on p. 12. With regard to the fauna, that of zones $I-3$ in the lower profile is practically the same as that of $\mathrm{I}-2$ in the upper one; similarly, that of zones $4-5$ in the lower corresponds approximately to that of zone 3 in the upper. The two profiles intersect at a point equivalent to the middle of zone 3 in the upper section and the beginning of zone 6 in the lower, consequently the list of species is the same in the two cases.

The student who attempts to carry out for himself a survey of this type will obtain valuable assistance from the paper describing a method for the study of the ecology of the sea-shore by Prof. L. A. L. King and Dr. G. S. Russell (Proc. Roy. Soc. Edin. XVIII, I909). 




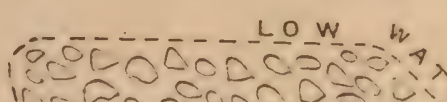

iñ

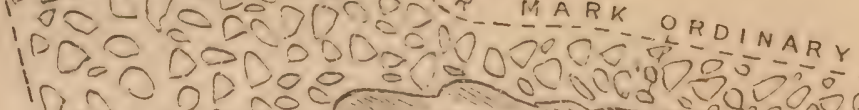

IV

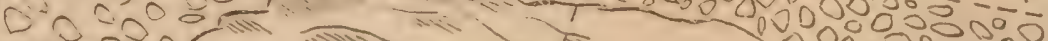

CHART OF PORTION

$\mathrm{OF}$

BALLOCH BAY

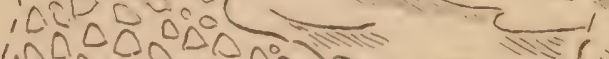

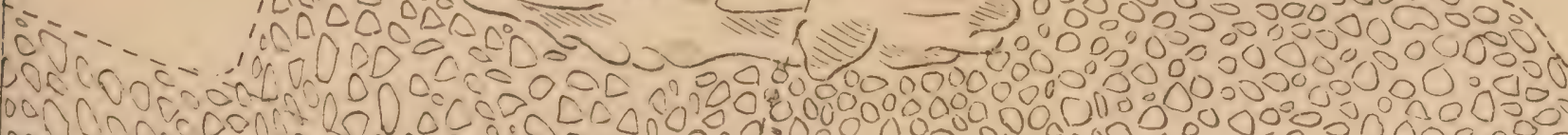

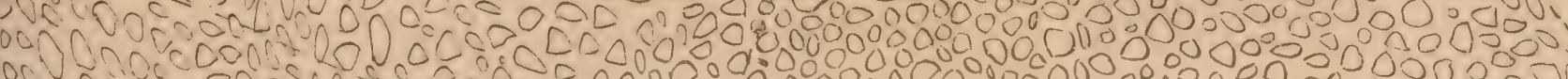

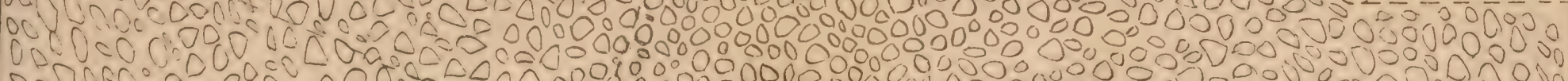

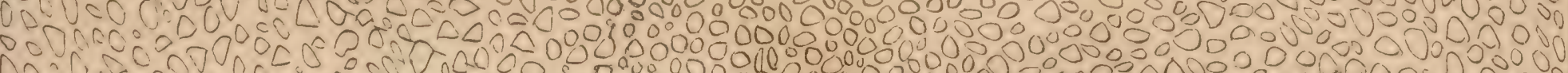

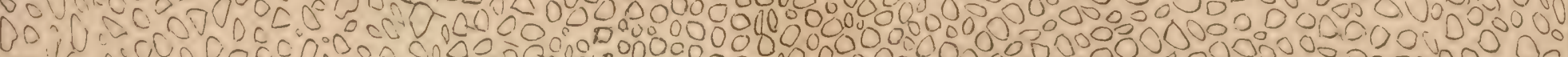

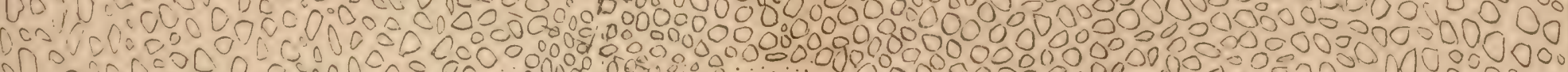

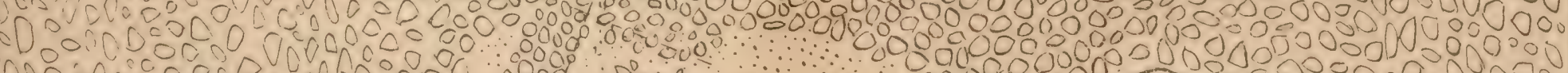

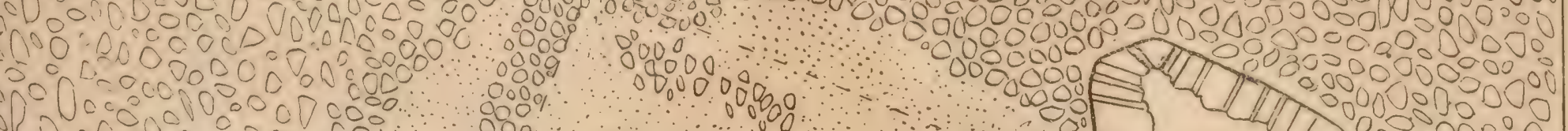
i)

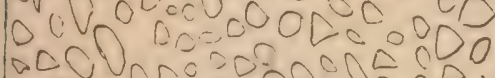

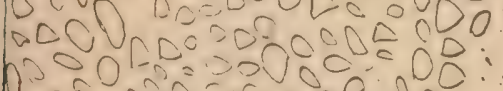

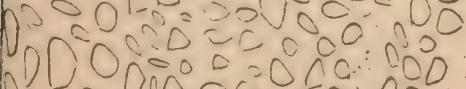

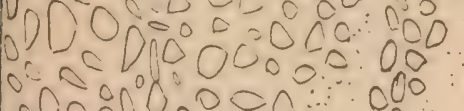

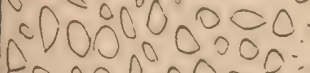

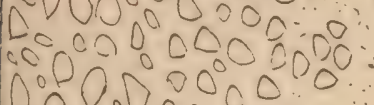
1000 on o o c o 000,0000000

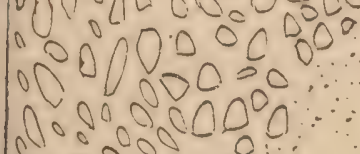
0
00000000 009 009 009

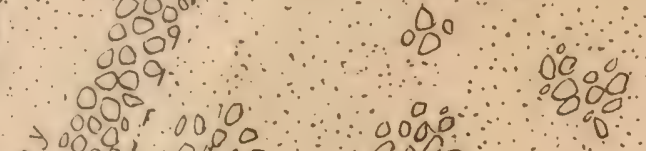

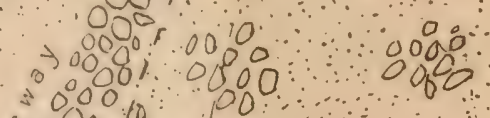
$\therefore 00010$ ऽ $000,0.00$

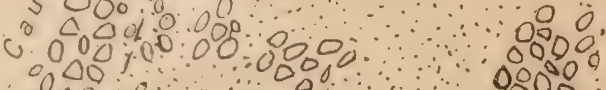
0000700, Doca 0001. doocit. 0000.1 : $00000 \quad \therefore \quad \because 000000$

RDINARY SPRI

Bouldars covered with Fucus Sandy Mud_........ Rocky Reef _._._._ IIIII 150

Scale of feet (approximate)

Fig. 22,-Shore of Mixed Physical Type (portion of Balloch Bay). 



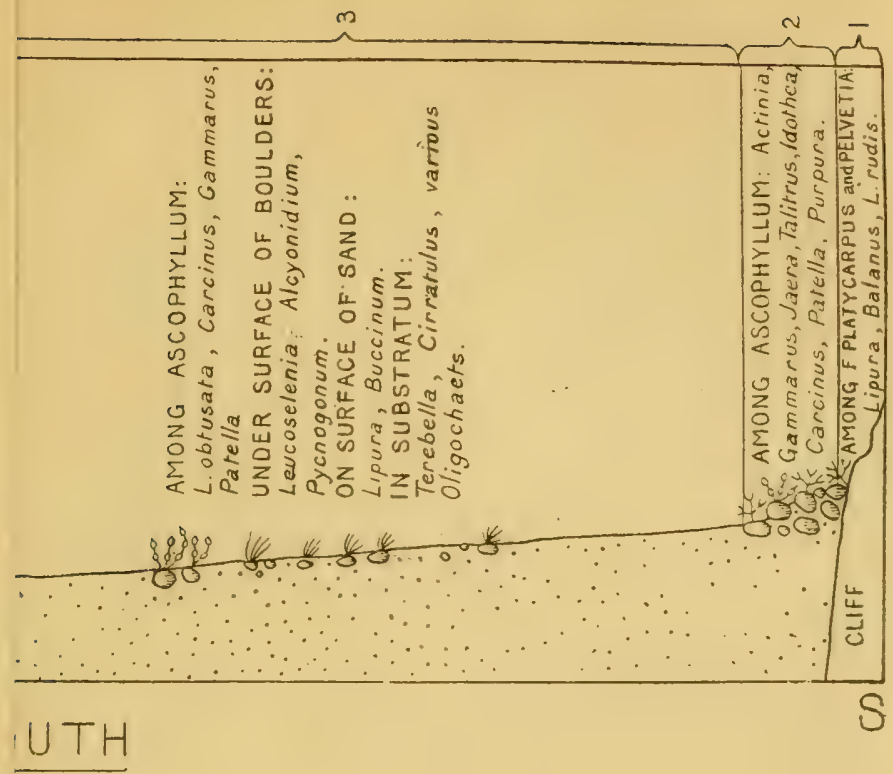

CALE.

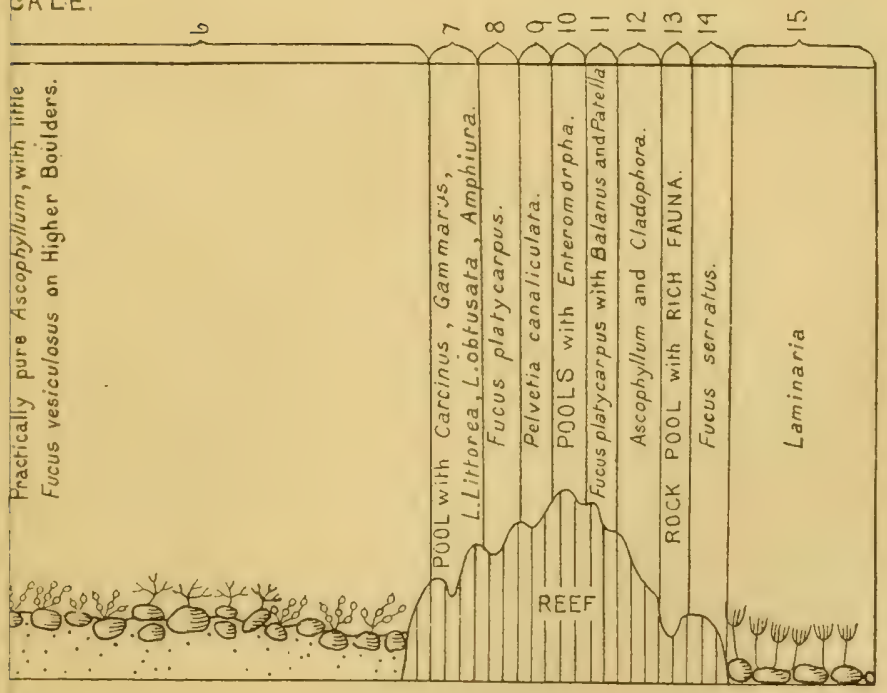

EAST.

INDICATEd By DOtTED LiNeS IN Fig. 22.

Plate XVI, and for further explanation see Appendix III. 



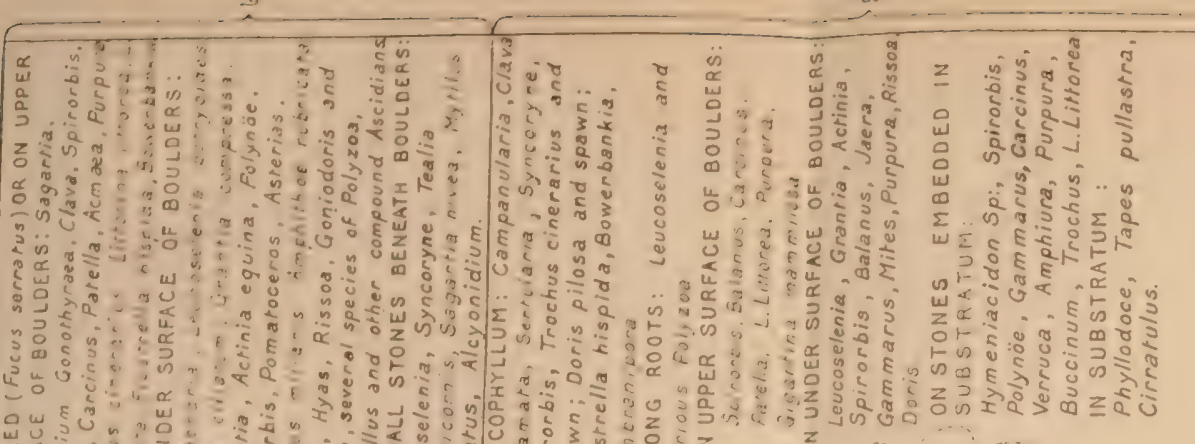

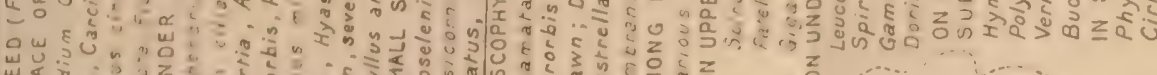

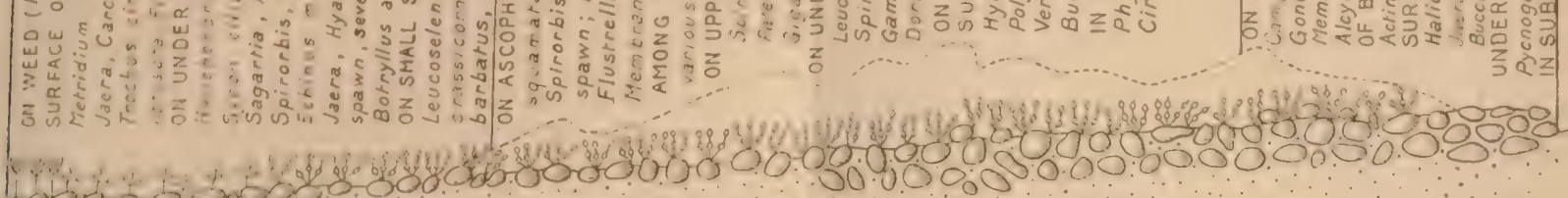

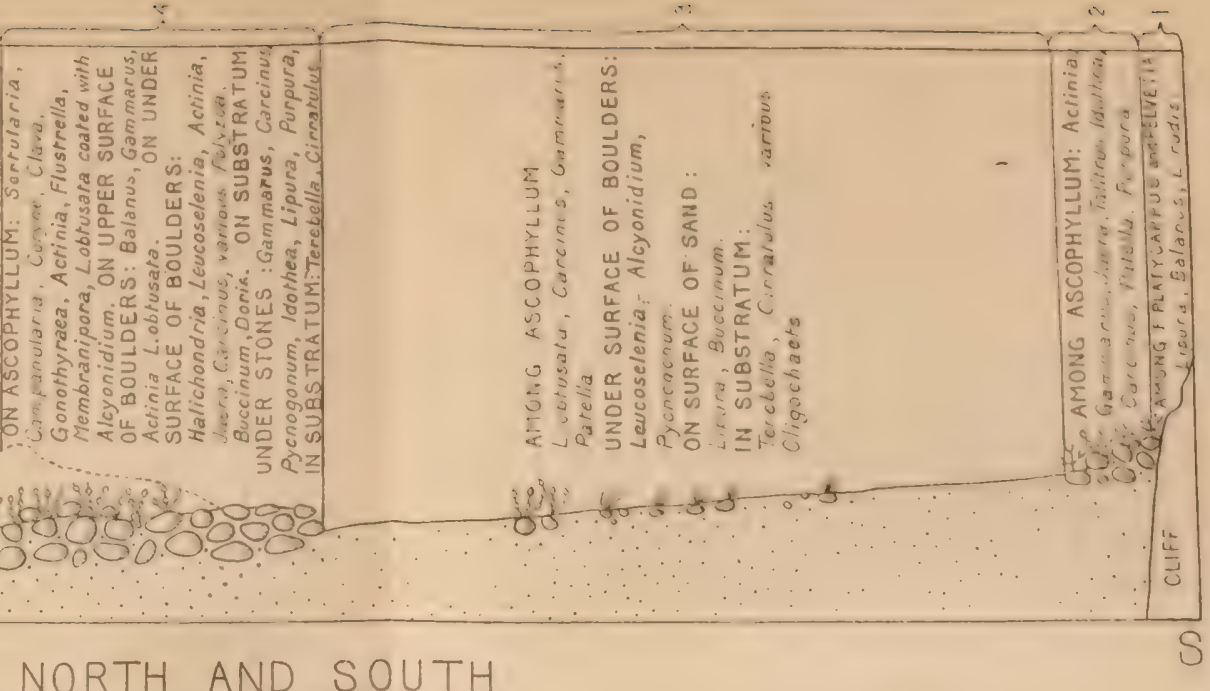

N

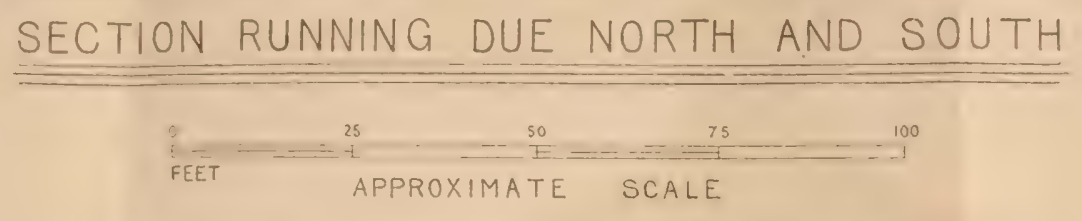

VERTICAL SCALE EQUaLs abOUT TWICE THE LINEAR SCALE.

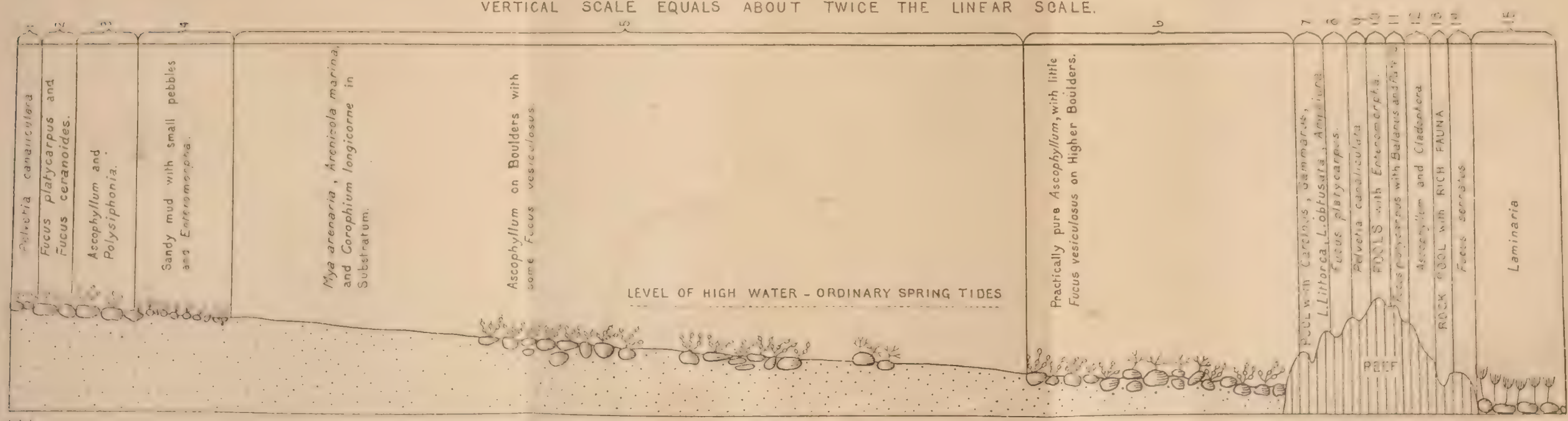

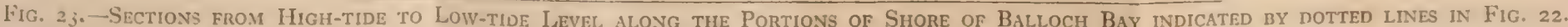
Showing distribution and mode of occurrence of the commonest shore species. Scale approximateiy twico that of plan. Of. views on I'late XVI, and for further explanation see Appendix IIS, 



\section{BIBLIOGRAPHY}

Adams, C. C. Guide to the Study of Animal Ecology. New

York, r9r3.

Aflalo, F. G. British Salt-water Fishes. London, 1904.

Akira IzUKa. Ann. Zool. Japon., VI. 1908.

Alcock, A. W. A Naturalist in Indian Seas. London, 1902. Allingham, W. Manual of Marine Meteorology. London, 1917.

Allen, E. J. Journ. Mar. Biol. Assoc., XI (N.S.), 3. Dec., I9I7. ANNANDAle, Nelson. Records Indian Museum, I. 1907.

Ashcroft, R. L. Rept. Lancs. Sea Fisheries Lab. for I899.

Ashworth, J. H. Liverp. Mar. Biol. Cttee. Memoir, Arenicola.

London, I904.

Baker, S. M. The New Phytologist, VIII, I909, and IX, I9ro. Barrows, A. L. Univ. California Publ. in Zool., XVIII, 2. I917. BATE, C. S. and WeSTWOOD, J. O. A History of the British Sessile-eyed Crustacea, I. London, 1863.

Bateson, W. Journ. Mar. Biol. Assoc., I (N.S.). 1889.

BAUER, V. Internat. Revue Hydrobiol. et Hydrographie, Bd. VI,

Heft. I-3. Leipzig, I9I3.

BEECHER, C. E. Studies in Evolution. London, Igor.

Benham, W. B. Camb. Nat. Hist., II. London, I896.

BoHn, G. C. R. Acad. Sci., CXXXIII. rgor.

- Bull. de 1'Inst. Gén. Psychol. $8^{\mathrm{e}}$ Année, No. I. Janr.Févr., I908.

C. R. Acad. Sci, CXLVIII. Igog.

La Naissance de l'Intelligence. Paris, I9Io.

La Nouvelle Psychologie Animale. Paris I9II.

Borradaile, L. A. Manual of Zoology. London, I918. Bounhiol, J. Ann. Sci. Nat. Zool. Sér. 7, XVI. I893.

BRandt, K. Mitth. der Deutschen Seefischereivereins, Nr. 6. 1887.

Braun, M. Animal Parasites of Man. London, 1905.

Brunelli, G. Atti. Rend. R. Accad. Lincei Roma. 1910. 
Calman, W. T. A Treatise on Zoology (edited by Sir Ray Lankester), Part VII (Crustacea). London, I909.

- The Life of Crustacea. London, I9II.

- Marine Boring Animals. Brit. Museum Publ. London, I9I9.

Cameron, A. T. Contrib. to Canadian Biology. igi6.

CarazzI, D. Mitth. Zool. Stat. Neapel., XII. 1896.

- Rassegna delle Scienze Biologische, N. 3-4. I920.

CAReY, A. E., and Oliver, F. W. Tidal Lands. London, I9I8.

CARPenter, G. H. Natural Science, VII. 1895.

CHuRCH, A. H. Thalassiophyta and the Sub-aerial Transmigration. Oxford, I9I9.

Clark, H. L. Zool. Anzeig., XLII. I9I3.

Colgan, N. Ann. Mag. Nat. Hist., Ser. 8, III. April, Igog.

- The Irish Naturalist. July, Igro.

Cooke, A. H. Camb. Nat. Hist., III. London, I895.

Cotron, A. D. Roy. Commiss. Sewage Disposal, Rep. 7, App. IV. I9II.

_ Clare Island Survey, Sect. I, Part 15. Proc. Roy. Irish Acad., r912.

Couch, J. A History of the Fishes of the British Islands, Vol. I. London, 1877 .

Cowles, R. P. Habits, Reactions, and Associations in Ocypoda arenaria. Papers from the Tortugas Lab. of the Carnegie Inst., Washington, II. I908.

Johns Hopkins Circ. No. 2. IgIr.

Crossland, C. Proc. Zool. Soc. London, I9r r.

Cúenot, L. Les Moyens de défense dans la sêrie animale. Paris (Edition undated).

Cunningham, J. T. Trans. Roy. Soc. Edin., XXXIII. 1888.

- and Ramage, G. A. Trans. Roy. Soc. Edin., XXXIII. I888.

Dakin, W. J. Liverp. Mar. Biol. Cttee. Memoir, Pecten. I909.

— Nature. March 28, I912.

- Pearls. Camb. Manual, No. 75. Cambridge, r9r3.

Darwin, C. A Monograph of the Sub-class Cirripedia, 2 Vols. London, $185 \mathrm{I}-54$.

Davenport, C. B. The Animal Ecology of Cold Spring Sandspit. Chicago Decennial Publ. X, Ser. I. 1903.

- Collembola of Cold Spring Beach. Cold Spring Harbour, Monograph II. I903.

Davidson, C. J. Bull. Imp. Inst. IV. 1906.

Davis, B. M. Biol. Survey of the Waters of Woods Hole and Vicinity, Sect. II, Botanical. Washington, Igr3. 
Davis, J. R. Ainsworth. Nature. March 28, 1895.

- and Fleure, H. J. Liverp. Mar. Biol. Cttee. Memoir, Patella. London, 1903.

Davison, C. Geol. Mag., VIII. Dec., I891.

DAY, F. The Fishes of Gt. Britain and Ireland, 2 Vols. London, I $880-84$.

Delage, J. Arch. Zool. expér (2). 1884.

- La Question du Goémon du fond. Bull. de l'Inst. Océanographique, No. 267. Monaco, 1913.

- et Hérouard, E. Traitê de Zoologie Concrète, III. Paris, 1903.

Dolfus, R. C. R. Acad. des Sci., CLVIII. I9I4.

DrEw, G. A. Biol. Bull., XII. I907.

Drew, G. H. Journ. Mar. Biol. Ássoc., IX (N.S.). I9I3.

Drzewina, A. C. R. Soc. Biol., LXIV. Paris, I908.

DUerden, J. E. Proc. Zool. Soc. 1905.

EIsIG, H. Fauna und Flora des Golfes von Neapel. Monograph 28. 1906.

Eliot, Sir Charles. The British Nudibranchiate Mollusca. Roy. Soc. London, I9io.

Elmhirst, R. The Zoologist. Feb., I9Io.

- The Glasgow Naturalist, VII. I9I5.

Evans, W. Proc. Roy. Phys. Soc. Edin., XVII. Igog.

Fantham, H. B., Stephens, J. W. W., and Theobald, F. W. Animal Parasites of Man. London, 1916.

FARRAN, G. P. Fisheries Ireland Sci. Invest., III. IgI4.

Field, A. J. Trans. Amer. Fisheries Soc. 1913.

Flattely, F. W. Journ. Mar. Biol. Assoc., XI (N.S.), No. I. 1916.

- Science Progress, No. 55. Jan., 1920.

Science Progress, No. 62. Oct., I92I.

Fleure, H. J., and Walton, C. L. Zool. Anzeig., Bd. XXXI, Nr. 7. 1907.

Florentin, R. Ann. Sci. Nat. Zool., Sér. 8, IX-X. 1899.

Fowler, G. H., and others. The Science of the Sea, Challenger Soc. London, 1912.

Fox, C. J. J. Conseil Perm. Internat, pour l'explor. de la mer. Publ. de circonstance No. 4r. Copenhagen, 1907.

FrÉDÉRICQ, L. La Lutte pour l'existence chez les animaux marins. Paris, 1889.

Gamble, F. W. Trans. Liverp. Biol. Soc, VII. 1892-93. Animal Life. London, I908. 
Garstang, W. Trans. Norfolk and Norwich Nat. Hist. Soc., VIII, Part I. 1905.

- Journ. Mar. Biol. Assoc., IV (N.S.). r896.

Gemmill, J. F. Proc. Roy. Soc. B., Vol. 85. 1912.

Gloess, P. Les plantes marines. Leur utilisation. Bull. de l'Inst. Océanographique, No. 350. Monaco, I9I9.

Harmer, S. F. Camb. Nat. Hist., II. London, I 896.

Hedley, C. Journ. and Proc. Roy. Soc. N.S. Wales, Pt.I. I9I5. HefFord, A. E. Journ. Mar. Biol. Assoc., IX (N.S.), No. I. I9IO.

Henderson, L. J. The Fitness of the Environment. New York, I9I3.

Herdman, W. A. Fauna of Liverpool Bay, Rept. II. I889.

—- Quart. Journ. Micros. Sci., XXXI (N.S.). 1890.

- Fauna of Liverpool Bay, Rept. III. I892.

- Rept. Lancs. Sea Fisheries Invest. for 1892.

- Rept. Lancs. Sea Fisheries Invest. for 1893 .

- 2rst Ann. Rept. Liverp. Mar. Biol. Cttee. (Port Erin Mar. Biol. Sta.). 1907.

- Journ. Linn. Soc. Zool., XXXIV. Jan., I919.

- Journ. Linn. Soc. Zool, XXXIV. March, I920.

_ and ClubB, J. A. Fauna of Liverpool Bay, Rept. III. 1892.

Heron-Allen, E. Ex. Reports Royal Institution. May 2I, 1915.

Hickson, S. J. Camb. Nat. Hist., I. London, Igo6.

Holder, C. H. Amer. Nat., XLI. 1907.

Holt, E. W. L., and Byrne, L.W. Rept. Sea and Inland Fisheries of Ireland. Igor.

Hornell, J. Proc. Liverp. Biol. Soc., V. I89I.

— Fauna of Liverpool Bay, Rept. III. I892.

Bull. No. 7. Madras Fisheries Dept. I915.

Hornyold, H. A. G. Biol. Centralbl., XXXIX. 1910.

Hunt, A. R. Journ. Linn. Soc., XVIII. 1885.

HuRST, C. H. Natural Science, II, No. I6. June, 1893 .

Imms, A. D. Liverp. Mar. Biol. Cttee. Memoir XIII, Anurida. I906.

IsseL, R. Biologia Marina. Milan, r918.

JACkson, H. G. Liverp. Mar. Biol. Cttee. Memoir XXI, Eupagurus. 19r3.

JACKson, W. Shells as Evidence of the Migrations of Early Culture. Univ, of Manchester. I9I7. 
Jameson, H. Lyster, and Nicol, W. Proc. Zool. Soc. London, I913.

JeHu, T. G. Scot. Geog. Mag. Jan., I9I8.

Jenkins, J. T. The Sea Fisheries. London, 1920.

Jennings, H. S. Proc. Acad. Nat. Sci. Philadelphia, LVII. 1905.

Univ. California Publ. in Zool., IV, No. 2. 1907.

Johnson, D. S., and York, H. H. Cold Spring Harbour, Monograph 206. I9I 5 .

Johnson, D. W. Shore Processes and Shore-line Development. New York, rgrg.

Johnstone, J. Conditions of Life in the Sea. Cambridge, I908.

Keeble, F., and Gamble, F. W. Phil. Trans, Roy. Soc. B., Vol. 196. 1904.

- Quart. Journ. Micros. Sci., XLVII (N.S.). I904; idem L, 1907.

- Plant Animals. Camb. Univ. Press. Igro.

Kellog, J. L. Shell Fish Industries. New York, 1910;

Kesteven, H. L. Proc. Linn. Soc. N.S. Wales, 32. 1903.

Keys, J. H. Journ. Mar. Biol. Assoc., XI (N.S.), No. 4. I9I8. KING, H. D. Archiv. für Entwickluugsmechanik, Bd. 7. 1898. KIng, L. A. L. Proc. Roy. Phys. Soc. Edin., XIX. I9I3.

- and Russell, G. S. Proc. Roy. Soc. Edin., XVII. I909.

Knowles, M. C. Sci. Proc. Roy. Dub. Soc., XIV. I9I3.

LAise, P. Physical Geography. Cambridge, I9r5.

LANKeSter, Sir E. Ray. Journ. Roy. Micros. Soc. April, igr6.

Lebour, M. V. Parasitology, IV, No. 4. I9r2.

— Journ. Mar. Biol. Assoc., XI, No. I. Igr6.

- Journ. Mar. Biol. Assoc., XII, No. I. I9I9.

Lloyd-WilliaMs, J. Ann. of Bot, XIX. I905.

Lo Bianco, S. Mitth. a. d. Zool. Stat. Neapel., Bd. XVIII. 1906-8.

Mitth. a. d. Zool. Stat. Neapel., Bd. XIX. rgog.

Mitth. a. d. Zool. Stat. Neapel., Bd. XX. IgII.

LoEB, J. Comp. Physiol. of the Brain and General Psychol. London, I905.

- Forced Movements, Tropisms and Animal Conduct.

Monographs Exp. Biol. Philadelphia and London, I918.

Loppens, K. Ann. de Biol. lac., Tome I. 1906.

LOVETT, E. The Essex Naturalist, XI-XII. I899-I90I.

Ludwig, H. Bronn's Thier-Reich, Bd. II, Abth. I. I889-92.

LUlı, R. S. Organic Evolution. New York, I9I7. 
Macfarlane, J. M. The Causes and Course of Organic Evolution. New York, r918.

McClendron, J. F. Biol. Bull., X. Jan., I906.

Carnegie Inst. Washington, Year Book No. 7. 1908.

M'Intosh, W. C. Ann. Mag. Nat. Hist., Ser. 4, XIV. 1874.

— Ann. Mag. Nat. Hist., Ser. 5, No. 104. Aug., 1886.

- 6th Ann. Rept. Scot. Fishery Bd. I888.

- Ann. Mag. Nat. Hist., Ser. 6, XIII. 1894.

- I4th Ann. Rept. Scot. Fishery Bd. 1896.

- Ann. Mag. Nat. Hist., Ser. 7, VIII. Igor.

- Ann. Nat. Hist., XX. 1907.

- British Marine Annelids. Roy. Soc., III, Part I. I9I 5.

Mangin, L. C. R. Soc. Biol. Paris, XII. 1907.

MANGOLd, E. Zeitschr. f. allgemein. Physiol., IX. I909.

Martin, C. H. Biol. Centralbl., XXXIV. I9I4.

Mayer, A. G. C. R. Acad. des Sci., CXLVII. Ig08.

- Papers from the Tortugas Lab. Carnegie Inst., Washington, VI, I83. I9I4.

Mayne, C. 32nd Ann. Rept. Liverp. Mar. Biol. Soc. Dec., 1918.

Meer, A. Rept. Dove Marine Lab. I9I5.

Miall, L. C. Natural History of Aquatic Insects. London, 1895 .

Mrchel, Aug. C. R. Acad. des Sci., CLII. I9II.

Mitzururi, J. K. Annot. Zool. Japon., IV. 1902.

MOore, Benjamin. Biochem. Journ., IV. 1909.

— Trans. Biol. Soc. Liverp. I9I5.

- Edie, and Whitley. Biochem. Journ., VI. I9I2.

_, Rept. for ${ }^{1913} 3$ on the Lancs. Sea Fisheries Lab., No. XXII. I9I4.

Morgan, T. H. Regeneration. Columbia Univ. Biol., Ser. 7. New York and London, rgor.

Morgulis, S. Proc. Amer. Acad. Arts and Sci., XLIV. I909. Mortensen, T. H. Papers from Pacific Expedn. Pub. fra Univ. Zool. Mus. Kobenhavn, Nr. I. I9I4-I6.

- and Rosenvinge, K. L. Overs. k. Dansk. Vidensk. Selsk. Forh. I910.

Needham, J. G., and Lloyd, J. T. The Life of Inland Waters. New York, I9I6.

Newbigin, M. The Study of the Sea-shore. London, I9Io.

Orton, J. H. Journ. Mar. Biol. Assoc., IX (N.S.), No. 3, 1912 ; idem X (N.S.), No. I, 19r3.

- Journ. Mar. Biol. Assoc., X (N.S.). I9r3-15. 
Orton, J. H. Journ. Mar. Biol. Assoc., X (N.S.), No. 2. June, I9I4.

Nature. Dec. 23, 1920.

Osborn, H. F. The Origin and Evolution of Life. London, I918.

Parker. G. H. The Elementary Nervous System. Monographs on Exp. Biol. Philadelphia and London, 1918.

Paul, J. H. Proc. Roy. Soc. Edin., XXXV. I9I4.

- Proc. Roy. Soc. Edin., XXXV, Part III, No. 23. Edinburgh, I9I5.

Pearse, A. S. Bull. Wisconsin Nat. Hist. Soc., XI (N.S.). June, r9r3.

Bull. Wisconsin Nat. Hist. Soc., XII (N.S.). June, I9I4.

—- Proc. U.S. Nat. Mus., XI. I9I5.

Pearson, J. Liverp. Mar. Biol. Cttee. Memoir XVI, Cancer. 1908.

Pelseneer, P. A Treatise on Zoology (Edited by Sir E. Ray Lankester), Part V. London, I906.

Ann. de la Soc. Zool. et Malac. de Belge, XLIII. I9I4.

Perez, C. Proc. Verb. Soc. Sci. Bordeaux, I903.

Petersen, C. G. J., and Jensen, P. Boysen. Valuation of the

Sea. Rept. Dan. Biol. Sta., XX. Copenhagen, rgrr.

Pethybridge, G. H. Journ. Bd. Agric., Ireland, XX. I9I5.

Pıéron, H. C. R. Soc. Biol. May, rgo\%.

— Arch. Zool. exp. Ser. 5, I. I909.

Plateau, F. Journ de l'Anat. et Phys., 26. 1890.

Plessner, H. Zool. Jahrb., XXIII. I9I3.

PotTs, F. A. Quart. Journ. Micros. Sci., L. I906.

Proc. Camb. Phil. Soc., XVII. I9I4.

Poulton, E. B. The Colours of Animals. Internat. Sci. Ser. London, I890.

Prouho, H. C. R. Acad. des. Sci,, CXI. Paris, 1890.

PütTER, A. Zeitschr. f. allgemein. Physiol., Bd. VII, Heft. 2-3. 1907.

__ Abhandil. GeselI, der Wissensch, Göttingen, Bd. VI. I908.

Quatrefages, A. de. Ann. des Sci. Nat., 2 Sér. Zool., Tome I7. 1842 .

Roap, H. E. Journ. Physiol., XXXIX. I9ro.

Robert, A. Bull. Soc. Zool., France, Tome XXXIII. 1908.

Russell, G. S. Proc. Zool. Soc. London, 1907. 
Sauvageau, C. L'Utilisation des Algues Marines. Paris, I920. Schiemenz, P. Journ. Mar. Biol. Assoc. IV (N.S.). 1895-97. — Mitth. Zool. Sta. Neapel., Bd. X. I89I.

Scotт, A. Liverp. Mar. Biol. Cttce. Memoir VI. I90r.

— Rept. for I909, Lancs. Sea Fisheries Lab., No. XVIII. r910.

_- Rept. for I915, Lancs. Sea Fisheries Lab., No. XXIV. I9I6. - Rept for I9I7, Lancs. Sea Fisheries Lab., No. XXVI. I9I8.

Semon, R. Mitth. Zool. Sta. Neapel., Bd. VII. 1887.

SEMPER, K. Animal Life, 5th ed. London, I899.

Shelford, V. E. Journ. Ecology, III, No. I. March, I9I5.

- Puget Sound Mar. St. Publ. I, No. I4. IgI6.

Shipley, A. E. Camb. Nat. Hist., II. London, I896.

Simroth, H. Die Entstehung der Landtiere. Leipzig, r89r.

Skinner, S. A. Minnesota Botanical Studies, III. 1903.

Smallwood, M. The Beach Flea. Cold Spring Harbour

Monographs, I. I903.

Smith, G. Fauna and Flora des Golfes von Neapel. Monograph XXIX. Rhizocephala. I906.

- Quart. Journ. Micros. Sci., LIX. I9I3.

Sollas, W. J. Sci. Trans. Roy. Dub. Soc., III, Ser. 2, No. 5. I 884 .

Sollas, I. B. J. Camb. Nat. Hist., Vol. I. London, Igo6.

Sorby, H. C. The Essex Naturalist, XII. I90I.

Southern, R. Proc. Roy. Irish Acad., XXXI. I9I5.

Stafford, J. Contrib. to Canadian Biol. I90I.

Stead, D. G. Proc. Linn. Soc. N.S. Wales. Igrz.

Stebiring, T. R. R. A History of Crustacea. Internat. Sci. Ser. London, 1893 .

Stockard, C. R. Carnegie Inst., Washington, Year-book No. 7. 1908.

Storrow, B. Rept. Dove Mar. Lab. for 1915.

Sumner, F. B. Biol. Survey of the Waters of Woods Hole and

Vicinity, Part I (Zoological). Washington, I9I3.

Sylvestri, F. Ann. Mus. Zool. Univ. Napoli, No. 12. 1903.

TAIT, J. Journ. Mar. Biol. Assoc., IX (N.S.). I9I0-I3.

Tattersall, W. M. The Athenæum. Feb. I3, I909.

- Dept. of Agric. and Tech. Instr. Fisheries Sci. Invest., I. 1920.

Taylor, J. W. Monograph of the Land and Fresh-water

Molluscs of the British Isles, 3 Vols. Leeds, I894-r9r4.

'Thompson, D'Arcy W. Camb. Nat. Hist., Vol. IV. Igog.

- Growth and Form. Cambridge, I9r7. 
Thompson, W. F., and Thompson, J. B. State of California

Fish and Game Comm. Fish. Bull. 3. July, r919.

Thomson, J. A. Outlines of Zoology, 6th ed. London, I9I9.

Tobler, F. Pringsheim's Jarhb. wiss. Bot., XLVI. IgOg.

Vlìs, F. C. R. Acad. des Sci., CXLIV. 1906.

C. R. Acad. des Sci., CXLV. 1907.

VON BUDDENBRock, W. Zool. Jahrb., XXXIII. I9I3.

Von Uexkul.l, J. Zeitschr. für Biol., XXXVII. I899.

Walton, C. L. Journ. Mar. Biol. Assoc., X (N.S.), No. I. I9I3. - Shell Fisheries of Milford Haven. Univ. Coll., Aberystwyth, I9I3.

Rept. for 1919, Lancs. Sea Fisheries Lab., No. XXVIII. 1920.

WARD, F. Country Life. Dec. 7, I9I2.

Ward, H. B., and Whipple, C. H. Fresh-water Biology. New York, I9I8.

WARMing, E. Lehrbuch der ökologischen Pflanzengeographie. Berlin, I896.

Warren, E. Ann. Natal Museum, II. Ig09.

Watson, A. T. Journ. Roy. Micros. Soc. June, Igr6.

Welldon, W. F. R. Rept. of 68th Meeting of the British Association at Bristol, I898. Presidential Address to the

Zool. Sect. London, I899.

WesenBerg Lund, K. Internat. Revue Hydrog. et Hydrobiol.,

Bd. I. 1908.

White, F. B. Rept. on the Pelagic Hemiptera. Challenger Zool., VII. I883.

Whitelegge, T. Journ. and Proc. Roy. Soc. N.S. Wales, XXIII. I889.

Willcox, M. A. Science, XXII (N.S.), No. 55I. July, 1905.

Willey, A. Convergence in Evolution. London, I9II.

Williamson, H. C. I8th Ann. Rept. Scot. Fishery Bd. 1900. - 25th Ann. Rept. Scott Fishery Bd. 1907.

- Journ. Econ. Zool. Igr6.

Woodward, B. B. Proc. Malac. Soc., VII, No. 5. 1907. The Life of the Mollusca. London, I913.

Wright, F. S. Ann. Applied Biol., IV, No. 3. I9I7.

Yendo, K. Econ. Proc. Roy, Dub. Soc., II. I9I4.

Yerbury, Col. J. W. Journ. Mar. Biol. Assoc., XII (N.S.), No. I. I9I9.

Zimmermann, K. Journ. Mar. Biol. Assoc., IX (N.S.). 1912.

- Journ. Mar. Biol, Assoc., X (N.S.). 1913. 



\section{INDEXES}

I. INDEX OF NAMES

II. GENERAL INDEX 



\section{INDEX OF NAMES}

Acanthodoris pilosa, spawn, 274

Acera, spp., habitat, 57

reproduction, $27 \mathrm{I}$

Actinia, spp., protective coloration, 95

behaviour, 221

reproduction, $262-3$

Actinoloba, spp., locomotion, I60-I reproduction, 262

Acmcea, reproduction, 270

Adamsia, spp., commensal, 135, sqq.

Acolids, parasitised, 146

locomotion, 173

spawning, 274-5

Aepophilus, adaptations, 308

Aipus marinus, adaptations, 308, 310

Alcyonium digitatum, habitat, 49

Alcyonium, feeding, 194

Alga, associations (zones), 4I, sqq. as food of shore animals, I 89 economic use, 292, $s q q$ injurious spp., $297-8$

Ammodytes, burrowing, 73 bait, 289

Amphictenidæ, tubes, IO3, 243

Amphioxus, larvæ, 247

Amphipoda, care of eggs, 252 reproduction, 269

Amphorina, spp., spawn, 274

Ampullaria, respiration, 207

Anabas scandens, respiration, 206

Ancistrum, spp., commensal, I39.

Ancula cristata, power of adhesion, 69

spawn, 274

Anemonia sulcata, reproduction, 262

Annelida (Polychreta), tubes, IO2

locomotion, I64-5

nervous system, 224, sqq. reproduction, 263 , sqq.

Anomia, commensal, 135

Antennularia antennina, reaction to gravity, 237

Anthea, behaviour, 22 I
Antholoba reticulata, commensal, I37

Anthozoa, locomotion, 159-60

feeding, 190

reproduction, 262

Antiopella, autotomy, 129

spawn, 275

Anurida maritima, description, 309

Aphrodite aculeata, bristles of, 102

Aplysia, reproduction, 27 I

dye-yield, 287

Aporrhais pes-pelicani, adaptation,

$$
73-4
$$

Arbacia pustulosa, habitat, 247

Arca, eye, 229

Arenicola, habitat, 52

resistance to desiccation, 64

feeding, 192

respiration, 210-I

nervous system, 225

reproduction, $265^{-6}$

spawn, 273

bait, 289

Aricia, reproduction, 263

Artemia salina, salinity conditions, 83

Arthropoda (tracheate), 3 I I

Ascidians, spp., commensalism, I35 feeding, 196 larvæ, 247

Ascophyllum, effect on waves, 66 galls, 86, I36, 149, I 50 economic aspect, 294 description, 305

Asterias, spp., burrowing, 73

in combat, 107

autotomy and regeneration, 124

locomotion, 156

feeding, 190

sight-sense, 223

reaction to light, $23 \mathrm{I}$

reproduction, 259,263

damage by, 300

Asterina, spawn, 249 
Astropecten, locomotion, 157

Australium rugosum, defensive adaptation, I I I

Autolytus, self-division, 126 reproduction, 263

Balanus, spp., habitat, 49,56 invader, 55

resistance to desiccation, 62

power of adhesion, 68

temperature range, 78

salinity conditions, $8 \mathrm{I}$

larvæ, 247

reproduction, 259,268

Birgus latro, form and habit, 104 respiration, 208

breeding, 270

Blennitus, spp., temperature range, 79

locomotion, 159

feeding, 197

spawn, 249

spawning, 277,279

Boleophthalmus, respiration, 206-7

Bonellia, invader, 54

Bopyrus, parasite, I 35

Botryllus, adaptive form, 70

Brachyura, autotomy and regeneration, I I9, sqq.

larval stages, 260

Buccinum, burrowing, 73

salinity conditions, 8 I

host, 147

locomotion, 162

feeding, 195

sense organs, 228

spawn, 272-3

economic aspect, 287

Bucephalus haimeanus, parasite of cockle, 147

Bulla, burrowing, 73

reproduction, 270

Bunodactis gemmacea, reproduction, 262

Bunodeopsis, commensal, I37

Bunodes, spp., reproduction, 262

Busycon, spp., reproduction, 272 uses of, 301

Calappa, respiration, 212

Caligus, parasite, 146

Calliactis parasitica, reproduction, 262

Callianassa subterranea, reproduction, 269

Calliostoma zizyphinus, habitat, 5o
Calma glaucoides, protective resemblance, 97

spawn, 279

Campanularia flexuosa, reproduction, 261

Cancer irroratus, locomotion, 154

Cancer pagurus, temperature range, 79

death-feigning, 94

migrations, $x 74$

feeding, 193

respiration, $207,212-3$

nervous system, 224

reproduction, 259,268

Carabidæ, of shore, 3 IO

Carcinus borealis, as host, 134

Carcinus mœenas, habitat, 49

salinity conditions, 80

death-feigning, 94

weapons, 109

host of Sacculina, 142

migrations, 174

feeding, $x 93$

respiration, 207, 212-214

nervous system, 224

reaction to moisture, 235

growth, 270

bait, 289

in polluted water, 300

Cardium, spp., habitat, 52

adaptive form, 73-4

temperature range, 78

salinity conditions, 81

host, $146-7$

locomotion, $\mathrm{x} 72$

fish-food, 198

reproduction, 270

economic aspect, $284, s q q$.

prey of gulls, 289

Carteria subcordiformis, salinity conditions, 82

Centronotus gunnellus, temperature range, 79

care of eggs, 253-4

spawning, 277

Cenia, spawning, 249

Cercariæ of periwinkle and whelk, 147

Cereactis aurantiaca, reproduction, 262

Cerianthus, reaction to gravity, 237

Chelura terebrans, borer, 170

Chondrus crispus, economic aspect, 292

description, 307

Chromodorids, coloration, 99 
Cirratulus, spp., habitat, 49 avoidance of desiccation, 65 feeding, 192 respiration, 210-I reaction to contact, 236

Cirripedia, respiration, 210 reproduction, 259,268

Cladophora rupestris, description, 305

Clava squamata, reproduction, 260

Cliona celata, borer, I68 damage by, 300

Colentera, protective resemblance, 95

nervous system, 220 reproduction, $26 \mathrm{I}$

Coelop a frigida, description, 3 10

Coenobita, spp., respiration, 208

Collembola, locomotion, I 7 I description, 309

Colpomenia sinuata, invader, 54 damage by, 297

Conus, defensive adaptation, II 3

Convoluta, symbiotic, 150 saprozoic, 180

Convoluta paradoxa, power of adhesion, 69

Convoluta roscoffensis, reaction to tidal rhythm, 239-40

life-cycle, 250

Copepoda, salinity conditions, 82-3 parasitic, I $45-6$

care of eggs, 252 reproduction, 267

Corallina officinalis, description, 305

Coronula, power of adhesion, 68

Corophium longicorne, burrowing, I 67

Corymorpha, behaviour, 22I-2

Coryphella, spawn, 275

Corystes cassivelaunus, respiration, 213,216

Cottus, spp., care of eggs, 254 spawning, 277-8

Cradactis, locomotion, 160

Crangon vulgaris, feeding, 193 spawning, 269 economic aspect, 288

Crepidula, spp., epizoic, 9r, I34 damage by, 300

Cribrella sanguinolenta, reproduction, 263

Crisia eburnea, epizoic, 87

Grithonina pisum, shell construction, 242

Crustacea, encrustation, $86,9 \circ$ masking, 9I

protective resemblance, 95
Crustacea, armour, 100

locomotion, $166-7$

respiration, 206, 212-3

nervous system, 224, sqq.

eyes, 227

reactions to contact, 236

reproduction, $250,252,267$

growth, 270

Cucumaria, reaction to gravity, 239 respiration, 203

Cumanotus, spawn, 275

Cyanea arctica, temperature range, 77

Cyclopidæ, reproduction, 267

Cyclopterus lumpus, prey, $5^{8}$ suckers, 69 care of eggs, 252, 255 spawn, 278

Cylista undata, habitat, 52

Cypraa, defensive adaptation, I I 3

Cypraa moneta, as money, 300

Cypris larvæ, 267-8

Daschyone, growth, 267

Decapoda, care of eggs, 252 reproduction, $267,268-9$

Dendrocœlum lactea, locomotion, 162

Dentalium indianorum, uses of, 300

Diadema, temperature range, 76

Dictyota, life-cycle, 25 I

Diptera, of shore, 310-1 I

Discodoris fragilis, autotomy, I29

Distomum hepaticum, parasitic, 147

Dolichopodidx, of shore, 3 ro

Dorids, parasitised, 146 locomotion, 164 feeding, 194 spawn, 273, sqq.

Doris flammea, protective resemblance, 97

Dorocidaris papillata, autotomy, 127

Doto coronata, autotomy, 129

locomotion, I73

Dromia, spp., masking, 91, 244-5

Echinoderma, protective armour, roI weapons, 107

autotomy and regeneration, I 24, sqq.

locomotion, $15^{6-7}$

feeding, 190

nervous system, 222-3

larvæ, 247

reproduction, 263

economic aspect, 288

Echinostomum sccundum, parasite of whelk, 147 
Echinus esculentus, habitat, 57 pedicellariæ, 88-9 parasitised, 149 food, 288

Echinus microtuberculatus, habitat, Echinus miliaris, parasitised, I33

Elysia, locomotion, I64

Ensis directus, burrowing, 167

Enteromorpha, spp., salinity test, 79 sheltering Copepoda, 83 description, 305

Entomostraca, larval forms, 267

Eudendrium, tropism, 233

Eulalia viridis, habitat, 67 protective coloration, 95

Eunice, spp., reproduction, 265

Eupagurus, spp., armour, $103-4$ invader, III commensal, 136 shell selection, 134, 243-4

Facelina, spawn, 275

Ficulina, reproduction, 258

Fissurella, temperature range, 76 respiration, 209 reproduction, 270

Flustra, adaptive form, 70

Foraminifera, shell construction, 242-3

Fucus, spp., economic aspect, 294 serratus, description, 305 platycarpus, description, 307 vesiculosus, description, $3 \circ 3$

Fulgur, spawn, 272-3

Galathea, spp., masking, 91 autotomy and regeneration, 123

locomotion, 154, 167

respiration, 213 reproduction, 268

Galvina, spp., autotomy, I29 spawn, 274 growth, 276

Gamasus, resistance to drowning, 65

Gammarus, spp., habitat, 49, 56, 6 I adaptive form, 70 locomotion, 155

Gasteropoda, power of adhesion, 67 protective resemblance, $97-8$ spines, function of, 113 locomotion, I59, I62-3

feeding, 194

eyes, 228

spawn, 246

reproduction, $27 \mathrm{I}, s q q$.
Gasterosteus, spp., nest-building, 255-6

Gasterostomum, spp., parasitic, I47

Gelasimus pugilator, locomotion, 166 respiration, 208 development, 270

Gelidium, spp., economic aspect, 293

Geocarcinus, spp., breeding, 270 respiration, 208

Geophilus, spp., 3 II

Geryonia, reproduction, 26 I

Gibbula cineraria, parasitised, 146

Gibbula, spp., habitat, 49,50

Gigartina mamillosa, economic aspect, 292

Gobius, spp., habitat, 5 I suckers of, 69 temperature range, 79

locomotion, 159

feeding, 197 spawning, 279

Gonothyrce, reproduction, 26r

Grantia compressa, reproduction, 260

Grapsus, spp., autotomy, 123

locomotion, I55

respiration, 208

Gymnophallus margarita, parasitic, 147

Halichondria panicea, habitat, 49 adaptive form, 70 reproduction, 258,260

Halidrys siliquosa, description, 303

Flaliotis, salinity conditions, $8 \mathrm{I}$ respiration, 209

sense organs, 228

reproduction, 270

economic aspect, 287

Halobates, spp., adaptation, 309

Halolalaps; see Gamasus.

Halosydna gelatinosa, autotomy, I29

Hapalocarcinus, spp., commensal, I 36

Harpacticus, salinity conditions, 82-3 reproduction, 267

Helcion pellucidum, habitat, 49

Hermaa, spp., protective resemblance, 97

Heteronereis, 264

Heterotrichus rostrata, nest-building, 257

Hexactinellida, reproduction, 258

Hildenbrandtia, epizoic, 134

Himanthalia and Convoluta, 50 description, 305

Hippolyte varians, reaction to light, 234,240 


\section{INDEX OF NAMES}

Holothurioidea, self-evisceration, I 27 Homarus vulgaris, temperature range, 79

weapons, 109

autotomy, I I 8-19

migrations, 175

feeding, 193

mysis stage, 269

Hyas, masking, $9 \mathrm{I}$

Hydra, reproduction, $26 \mathrm{I}$

Hydractinia echinata, commensal, 135

Hydrobia, resistance to desiccation, 63

reproduction, 270

Hydroides norvegica, growth, 267

Hydrozoa, nervous system, 22 I reproduction, $260-1$

Hymeniacidon caruncula, habitat, 49

Hymenocera, protective resemblance, 96

Hypophorella, epizoic, 86

Ianthina, dye-yield, 287

Icthyonema grayi, parasitic, I49

Idotea, habitat, 57

Inachus, masking, 9I-2, I33

Isopoda, spp., care of eggs, 252 reproduction, 269

Forunna, protective resemblance, 97 spawn, 275

Kellia, habitat, 49

Lacuna, spp., habitat, 49

Lafoea dispolians, epizoic, 87

Lagis koreni, tube, 103

Lagisca extenuata, autotomy, 129

Lamellidoris, spp., protective resemblance, 97 spawn, 274-5

Laminaria, spp, 47

fauna of, $49,50,86$

economic aspect, 294, 297

description, 303, 305

Lanice conchilega, habitat, 49

Lascea rubra, resistance to desiccation, 63

Laurencia pinnatifida, as food, 293

Leander, spp., autotomy, I I 8 migrations, 175

feeding, I 93

economic aspect, 288

Lepadogaster bimaculatus, spawn, 278

Lepeophtheirus pectoralis, parasitic, 146
Lepralia foliacea, affording shelter, 86

Leptoplana tremellaris, locomotion, I $6 \mathrm{I}-2, \mathrm{I} 64$

Leucosolenia botryoides, reproduction, 258-9

Leuresthenes tenuis, life-cycle, 250

Lichomolgus agilis, parasite, 146

Ligia, spp., habitat, 49

adaptation, 70

locomotion, 155

gills, 201

spawn, 270

Limapontia nigra, locomotion, 173

Limnoria lignorum, borer, 170

Limulus polyphemus, temperature range, 77

Linckia multifora, autotomy and regeneration, 124,126

Lineus, spp., habitat, 49

feeding, I9I

Liparis, suckers, 69

Lipura, description, 309

Liriope, reproduction, $26 \mathrm{r}$

Lithothamnion, adaptive form, 70

Littorina, spp., habitat, 49, 50, 57

invader, 55

resistance to desiccation, 63

protective resemblance, $97-8$

parasitised, I 47

locomotion, 163

respiration, 207,209

reaction to light, 232

reaction to tidal rhythm, 240

reproduction, $249,257,259$, 27o, sqq.

economic aspect, $284, s q q$.

in polluted water, 300

Machilis maritima, habitat, 309

Macoma balthica, habitat, 52

Macromysis, reaction to light, 234

Mactra, eye, 229

Malacostraca, larval forms, 267

Marsipella spiralis, shell construction, 243

Megalopa stage, 267, 269

Meleraphe, habitat, 5 I

Melia tessellata, commensalism, I37

Melibe, feeding, 194

Melobesia, adaptive form, 70

Membranipora, salinity conditions, $8 \mathrm{I}$ adaptive form, 70

Metridium marginatum, locomotion, I $59-60$

reproduction, 262 
Modiolaria, commensal, 135 locomotion, 173

Molgula, habitat, 57

Mollusca, armour, 100 adductor muscles, 109-т0 nervous system, 227-8 reproduction, 270

Monodonta crassa, habitat, 49-5 I

Monstrilla helgolandica, parasitic, 134

Motella mustela, spawning, 280

Munida rugosa, respiration, 214

Murex, defensive adaptation, I I I respiration, 209

spawn, 249

dye-yield, 287

$M y a$, spp., habitat, 57

as prey, $5^{8}$

eye, 229

economic aspect, 287,291

Myriapoda, 3 II

Mysis stage, 267, 269

Mysis vulgaris, habitat, 56

Mytilus edulis, habitat, 49, 56-7 salinity conditions, $8 \mathrm{r}$

epizoic, 134

commensal, $x 36$

parasitised, $\mathrm{x} 44, s q q$.

locomotion, 158, I 76

larvæ, 248

reproduction, 270

economic aspect, 284, sqq.

bait, 289

Myxicola, tube, I02

Nassa, spp., burrowing, 73

defensive adaptation, I IO, I 12

feeding, 195

reproduction, 270,272

Natica, spp., burrowing, 73 feeding, 195

reproduction, 270, 272-3

Nauplius stage, $267-8$

Nebalia bipes, habitat, 49

Nematoda, parasites, I 4 I-2, I 49

Nemertea, feeding, I9I

Nereilepas fucata, commensal, I35, I 36

Nereis, spp., habitat, 49

resistance to desiccation, 64

feeding, 192

nervous system, 224-5

reaction to contact, 236

reproduction, $263,264-5$ bait, 289

Neritina, spp., death-feigning, 94 reproduction, 270
Nicomachia, tube, 102

Nudibranchiata, spp., protective resemblance, 96

locomotion, 164, 172

spawn, 246, 274

reproduction, 271, sqq., 279

Obelia, reproduction, $26 \mathrm{I}$

Octopus, temperature range, 76

commensal, 135

feeding, 193

Ocypoda arenaria, respiration, 208-9 development, 270

Odostomia rissoides, parasitic, $\mathbf{I} 33$

Olivella biplicata, uses of, 301

Onus mustela, feeding, 196

Ophelia, spp., reproduction, 263 , 266

Ophioactis virens, autotomy, 125

Ophiocoma, spp., autotomy and regeneration, 125

Ophioderma, autotomy, 125

Ophioglypha, 57, autotomy, 125

Ophiomyxa, autotomy, 125

Orchestia, habitat, 49 locomotion, $\mathbf{I}$ I

Oscarella, adaptive form, 70 reproduction, $25^{8}$

Ostrcea edulis, salinity conditions, 8 I spawning, 276 economic aspect, $284, s q q$.

Pachydesma crassatelloides, uses of, 301

Pachymatisma, contractility, 219

Palcemon, growth, 270 reaction to light, 234

Palinurus, spp., reproduction, 269

Paludestrina stagnalis, habitat, $5^{\mathbf{I}}$ resistance to desiccation, 63

Pandalus montagui, economic aspect, 288

Parthenope, spp., protective resemblance, 95

Patella, spp., habitat, 49 power of adhesion, 67 adaptive form, 70-I salinity conditions, $8 \mathrm{I}$ migration, $176-7$ reproduction, 270 economic aspect, 287 in polluted water, 300

Pecten, spp., habitat, 49 salinity conditions, 81 defensive adaptation, III locomotion, 165 eye, 229 
Pectinaria, feeding, 192 respiration, 2 IO

Pectunculus, eye, 229

Peltogaster paguri, parasitic, I35, I43

Pelvetia, description, 303

Periophthalmus, respiration, 206-7

Phallusia mentula, habitat, 49

Philine, burrowing, 73 reproduction, $27 \mathrm{I}$

Pholas dactylus, borer, 168

Phyllodoce, spawn, 246 reproduction, 263,265

Phyllosoma larvæ, 267, 269

Pinnotheres pisum, parasitic, $144-5$

Planaria dioica, power of adhesion, 69

Pleurobranchus, parasitised, I49

Pleurociona, power of adhesion, 68

Pleuronectes, spp., parasitised, 146 feeding, 197

reproduction, 259

economic aspect, 283

Plotosus anguillaris, coloration, 99

Plumularia, reproduction, 26I

Podocerophis, commensal, 135

Poduridæ, locomotion, I 7 I

Polycera quadrilineata, spawn, 274

Polychæta (see also Annelida), resistance to desiccation, 62 , 64

habitat, 49, 50, 52, 67, 168

bristles, IOI-2

respiration, 204, 211

nervous system, 225

tube-construction, 64, 24I

spawn, 246

reproduction and growth, $257,259,263, s q q$.

Polycirrus aurantiacus, coloration, 98-9

Polydora, borers, 168

Polymnia, growth, 267

Pomatoceros, commensal, 135 reproduction, 267

Porcellana, spp., adaptive form, 70 death-feigning, 94 protective resemblance, 96 commensal, I35 respiration, 213 reproduction, 268

Porifera, spicules, IOI contractility, 219 reproduction, 258

Porphyra, spp., as food, 293 description, 307

Portunus, spp., burrowing, 73 locomotion, 164-5
Proctonotus, autotomy, 129

Protozoca larva, 269

Psammobia tellinella, adaptive form, 73-4

Purpura, spp., habitat, 49 adaptive form, $7 \mathrm{I}$ salinity conditions, $8 \mathrm{r}$ feeding, 195 spawn, 272-3 dye-yield, 287 damage by, 300

Pycnogonida, locomotion, I 55-6 care of eggs, 252

Pylodieles miersii, tube, 104

Rhodymenia palmata, economic aspect, 293

description, 307

Rissoa, spp., habitat, 57

locomotion, $172-3$

reproduction, 270

Rostanga coccinea, protective resemblance, 97

Rostellaria, spp., locomotion, 172

Runcina hancocki, protective resemblance, $96-7$ locomotion, 173

Sabella, feeding, 192 respiration, 210 growth, 267

Sabellaria, grottos of, 67, I03 feeding, 192

Sacconereis, reproduction, 263

Sacculina, spp., parasitic, $142-4$ reproduction, 268

Sagartia, spp., commensal, 135,137 reproduction, 262-3

Sarcophaginæ, of shore, 3 I0

Saxicava rugosa, habitat, 49 borer, 67,168

Saxidomus arata, uses of, 301

Scalaria, defensive adaptation, II 2

Scoloplos armiger, reproduction, 266

Scomber, economic aspect, 283

Scrobicularia, habitat, 57 economic aspect, 287

Scyphidia littorince, commensal, ${ }_{3} 8$

Sepiola atlantica, host, I49

Serpula, feeding, 192 growth, 267

Serranus, commensal, I35

Sertularia, parasitised, 87 reproduction, $26 \mathrm{r}$

Sigalion, nervous system, 225

Skenea planorbis, locomotion, 173

Solaster papposus, sight-sense, 223 
Solen, spp., adaptive form, 74 parasitised, 148 locomotion, 167 nervous system, 226 eye, 229 economic aspect, 287

Spelotrema excellens, parasitic, 147

Spio, reproduction, 266

Spirographis spallanzani, tropism, 232

Spirorbis, habitat, 49

epizoic, 134

reproduction, 264

Spongelia fragilis, habitat, 49

Spongilla, temperature range, 77 reproduction, 258

Stenorhynchus, feeding, 193

Sthenelais boa, habitat, 49

Stomatopoda, reproduction, 267

Strombus luhuants, invader, 54

Strongylocentrus lividus, in combat, I07

Stylotella, contractility, 219

Suberites domuncula, commensal, I35, 136

nutrition, 186

reproduction, 258

Sycon, spp., habitat, 49 larvæ, 247 reproduction, 260

Syllidæ, self-division, 126 reproduction, 264

Synaptidæ, self-division, 128

Talitrus locusta, habitat, 49, 53 temperature range, 79 locomotion, 167,171

Talorchestia longicornis, locomotion, I 66

Tapes pullastra, adaptive form, 74

Tealia crassicornis, masking, 92 behaviour, 22 I

Technitella, shell construction, 242

Tectarius, habitat, 5 I

Tellina, spp., habitat, 52 salinity conditions, $8 \mathrm{I}$ fish-food, 198

Terebella, spp., tube, 102, 24 I reproduction, 264
Terebellides stromi, reproduction, 264

Terebripora, epizoic, 86

Teredo, spp., borers, 169-70 salinity conditions, 82

Tergipes despectus, autotomy, 129 spawn, 274

Tetrarhynchus, symbiotic, 149

Thysanura, of sea-shore, 309

Trematoda, parasitic, $146, s q q$.

Triticella, epizoic, 86

Triton, regeneration, I I 5

Tritonia plebeia, protective resemblance, 96 feeding, I94

Trochicola enterica, parasitic, 146

Trochon carinatus, defensive adaptation, I I I

Trochus, spp., host, 146 respiration, 209

sense organs, 228

reproduction, 270

spawn, $27 x$

Tubifex benedeni, habitat, 49

Tubularia, spp., behaviour, 222 reaction to contact, 236 reproduction, 260

Turbellaria, power of adhesion, 69 locomotion, I59, 16 I-2

Turbinella rapa, æsthetic aspect, $30 \mathrm{I}$ Typhis tetrapterus, defensive adaptation, III

Ulva, spp., growth conditions, 45 description, 307 in polluted water, 299,300

Venus, spp., adaptive form, 74 economic aspect, 287,3 or

Zebrida adamsii, mimicry, 100 Zenobiana prismatica, tube, 104 Zoarces viviparus, reproduction, 249

Zoochlorellæ, symbiotic, 150

Zoœa, larva, 267, 269

Zooxanthellæ, symbiotic, ${ }_{50}$

Zostera, spp., economic aspect, 29r, 294

Zygobranchiata, respiration, 209 


\section{GENERAL INDEX}

ADHESION, powers of, $67, s q q$.

Agar-agar, 293

Armour, protective, 100, sqq. borrowed, $103-4$

Associations, animal, 3, sqq., 48, sqq., I32, $s q q$.

of jetsam, 53, 309 plant, 5, 4I, sqq.

Attack, methods, 85, sqq.

Autotomy, II 7, sqq., $\mathrm{I}_{3} \mathrm{O}$

Avicularium, function, 87

BACTERIA, in sea-water, 187

Behaviour, 229, sqq.

Borers, rock, I 68 wood, 169

Burrowers, 72, sqq.

Carrageen moss, 292, 307

Castration, parasitic, $143-4$

Cnidoblast, 105, 22 I

Coloration, protective, $95, s q q$. warning, 98-9

Commensalism, 5, 93, $132,135, s q q$.

Currents, dispersal by, 53

DEATH-FEIGNING, 93-4

Defence, methods, $85, s q q$.

Desiccation, resistance by shore forms, 62 , sqq.

Drowning, resistance by shore forms,

Dulse, 293 65

Dye products, 287

Ecology defined, $\mathrm{I}, s q q$.

Ecological succession, 56

Economic aspects of shore life, 282, $s q q$.

Ectoparasitic forms, 140, I 55

Eggs, care of, 252

Endoparasitic forms, 140, 152

Epizoic forms, 86, sqq.

Evolution of life, 15, sqq.
Fauna, shore, zonal classifications, 8, sqq., 12, sqq., 35, sqq., $40,50, s q q$.

enumeration of, 47

GILLS, position and function of, 201 , $s q q ., 212$

Granny crab, 90

Gravity, reaction to, 237-8

Growth, 258, sqq

Habitat, terrestrial, 7 aerial, 7 aquatic, 8

Heron, 290

Hiding, 93

Homing sense, $176-7$

Hypnosis, 93-4

INSTINCTIVE behaviour, 241, sqq.

Insects of shore, $308, s q q$.

Iodine, 296

JETSAM associations, 53, 309

KANTEN, 293

Kelp, 296

LARVIE, pelagic, of shore forms, $247, s q q$.

Laver, 293, 307

Life, origin and evolution of, $x_{5}, s q q$.

Light, reactions to, $25,230, s q q$.

Manurial use of seaweeds, 294, $s q q$.

Masking, 91, 244

Migrations, 173

Mimicry, 100

Moisture, reaction to, 234

Movements (locomotion) animal, I $52, s q q$. 
Nematocyst, function, $105, s q q$.

Nervous system, development, 217 , $s q q$.

Nest-building, 255, sqq.

Nutrition of marine organisms, I79 plants, $180, s q q$. marine animals, $183, s q q$. shore organisms, 188 shore animals, I9o, sqq.

ОтосYST, function, 225,226

Palolo worms, 265

Parasitic chain, 144

Parasitism, 5, 132, sqq., 139, sqq.

Pearls, formation of, 148

Pedicellariæ, function, 88, 107, sqq., I9I, 224

Poison devices, animal, 105, sqq.

Physiography of sea-shore, 20, sqq.

Pools, as habitat, 61

Protective resemblance, 94, sqq.

RADULA (of gasteropods), function, I 94-5

Regeneration, power of, I I 5-6, I 2 I, 131

Reproduction, 246, $s q q$. adaptive phenomena, 248

Respiration of shore animals, 200, $s q q$.

Rhythmic behaviour, 239, sqq.

SALINITY, variation, effects, $79, s q q$.

Saprophytes, 180

Scavengers, sea, 189, 192

Sea-gulls, 289-90

Sea-water, composition of, $2 \mathrm{r}$, sqq. effect on, of vegetation, 24 of light, 25 of temperature, $25,75, s q q$. freezing of, 26 circulation of (British), $3 \mathbf{I}$
Sea-water, salinity, variation, $79, s q q$. nutritive elements in, $18 \mathrm{I}-2$, 186

oxygen-content, 200

pollution of, 298-9

Seaweeds; see Álgæ (Index of Names).

manurial use, 294, sqq.

Self-evisceration, $127-8$

Sewage, effects, 298-9

Siphons (of molluscs), function, 212

Sloke, 293

Spawning, 246, sqq.

Statocyst, function, 225

Struggle for existence, 53, sqq.

Surveying, shore, method of, 312 , $s q q$.

Symbiosis, 5, I32, sqq., 149-50

Temperature of sea-water, 25 variation, effects, $75, s q q$.

Tides, the, causation and effect, 27 ,

Trepang, 288

$$
s q q ., 60
$$

Tropisms, 23 I

Tubes, construction, $102-3,24 \mathrm{I}, s q q$.

VEGETATION (marine) and alkalinity, 24

as animal habitat, $6 \mathrm{I}$

Vibraculum, function, 87

WAMPUM, 300

Wave action, effect on shore, 32, sqq.

Wave-impact, effect on shore forms, $66, s q q$.

Weapons, animal, ro5, sqq.

ZoNEs of marine habitat, $8, s q q$.

particular classifications of, 12, sqq., 35, sqq., 40, 50, sqq. 



SMITHSONIAN INSTITUTION LIBAARIES 